\title{
TRANSFORMATION OF LEGISLATIVE INTENTIONS: A MULTI-LEVEL EXAMINATION OF THE INFLUENCE OF NEOLIBERALISM ON QUALITY POLICY ENACTMENT AND IMPLEMENTATION IN TEACHER PREPARATION
}

\author{
A Dissertation \\ Presented to
}

The Faculty of the Curry School of Education

University of Virginia

In Partial Fulfillment

of the Requirements for the Degree

Doctor of Philosophy

by

Afi Yaminah Wiggins

B.S., University of Montevallo

M.Ed., University of Montevallo

Ed.S., University of Alabama at Birmingham

Ph.D., University of Virginia

May 2014 
(c) Copyright Afi Yaminah Wiggins

All Rights Reserved

May 2014 


\section{ABSTRACT}

Advisor: Walter F. Heinecke, Ph.D.

This is a case of the influence of neoliberal ideologies on the transformation of teacher quality standards and the consequences for teacher education. It examines how neoliberal influences shaped the thinking and actions taken by policy makers at the federal, regional and state levels and how those processes shaped the definition and implementation of teacher quality standards within a college of education. The research presented is an examination of the conditions, processes, and consequences of the implementation of quality standards at a faith-based School of Education in the southern region of the United States analyzed through Hall's (1995) Transformation of Policy Intentions Framework and Baltodano's (2012) critical policy analysis framework. This study investigated how policy actors make sense of, interpret, and respond to federal, national accreditation, state, and university mandates to implement teacher quality standards in teacher preparation.

The findings show neoliberalism in action, and how policies transform from the intentions of senior managers across all levels of the policy enactment and implementation process to the actions of lower-level policy actors on the front line of policy implementation. The neoliberal characteristics evidenced from the findings include those identified by critical policy analysts (Baltodano, 2012; Giroux, 2002; Lorenz, 2012): 
- The eroding or elimination of the notion of education as a common good to be supplanted with the notion of education for the purpose of global economic competition;

- The development of new discourses, rewards, norms, institutional practices, and common-sense values;

- The state acquiring a new identity as the protector of capital, where its role is to enhance social and educational policies to protect the market;

- Active political intervention of schools, colleges and universities by national and state governments;

- Senior management control over policies and policy implementation actions;

- The standardization of efficient, formal input/output processes to measure quality;

- The use of predetermined standards and measurable indicators of performance to determine quality; and

- Defining quality in education by the product of education.

Neoliberal conditions provide a rationale for how and why quality policy enactment and implementation at the teacher preparation program level transforms as it does. 


\section{DEDICATION}

For my Daddy, I miss you. Your pride still emanates.

For my MoMA, the personification of excellence. I aim to be the woman you are.

And for my Grandma. 


\section{ACKNOWLEDGEMENTS}

I am grateful to the participants of this study. Without your open and honest dialogue and unrestricted access, this dissertation would not have been possible. To my doctoral dissertation advisor, Dr. Walt F. Heinecke, beginning with our first class together, Theoretical Perspectives in Education Policy, you taught me that analyzing policy matters through a critical analysis frame is the foundation of meaningful policy transformation. Thank you for your guidance. To Dr. Nancy Deutsch, my doctoral program advisor, I am so proud to call you my friend. Thank you for our talks. And thank you for affording me so many opportunities to hone my qualitative research skills. I appreciate the patience and encouragement of my other dissertation committee members: Dr. Heather Wathington and Dr. Sandi Cohen.

There are a few educators who sparked my interest in and appreciation for research statistics and evaluation. To Beverly Kimes, my high school Probability and Statistics teacher, you planted the first love-for-statistics seed, which has been flourishing ever since. To Dr. Gypsy Abbott, my former statistics professor, my love for program evaluation started with our work, and is the reason I chose this field for my doctorate. To Dr. Charles McLafferty, my former research professor and fellow Wahoo, your brilliant mind is the reason I chose to study at University of Virginia. 
I am also grateful to a few people who have offered unsurpassed support throughout this journey. To my dear friend, Elizabeth, thank you for all your wonderful words of encouragement, and for being my partner in all things film and politics. I always looked forward to our fun outings; my escapes from academia. To Lori and Paul, you two are the most selfless people I know. Thanks for your infinite hospitality. I am honored to know you and to be your friend. To Dr. Irv Richardson, your offer to be a reader and editor of my dissertation can never be repaid. Thank you greatly for your time and skills. Your editing saved me.

To my commiseration committee: Oren (Oh-Ren) and Natalie (Nat-diggs). There is not enough room to thank you for all the talks, lunches, dinners, emails, and texts. You both made my doctoral journey a little lighter. I am honored to call you my friends.

I am utmost grateful for the support and encouragement of my family. To my MoMA, I learned from you the values of hard work, integrity, diligence, and perseverance, all of which were used abundantly as I trudged through my doctoral program and dissertation. Thank you for laying a solid foundation. Grandma, you believed I was a Ph.D. from the day I was born. Your effusive pride, and constant reminders of how pleased my Daddy would be, pulled me out of many days of dissertation-writing darkness. To Maurice and Talib, my 
bookends. Your questions about what I have been doing in Virginia over this period of time confirmed that my brothers are always concerned about my wellbeing. Thank you for being my protectors. To Aunt Jean, thank you for being my first writing teacher. I wish you were here to witness my accomplishments.

Finally, to il mio inamorato, Marcus, you are my peace, my joy, my happiness, and my whole heart. Your benevolent, unselfish spirit is unmatched. Thank you for your endless support. There is no better partner. 


\section{TABLE OF CONTENTS}

\section{Page}

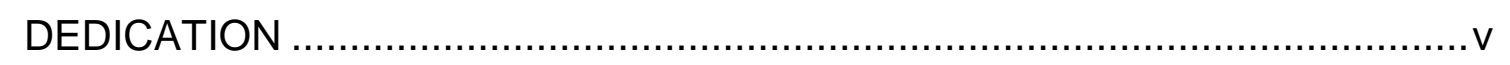

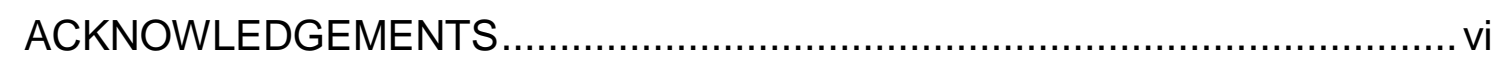

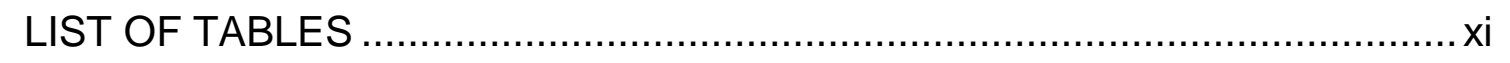

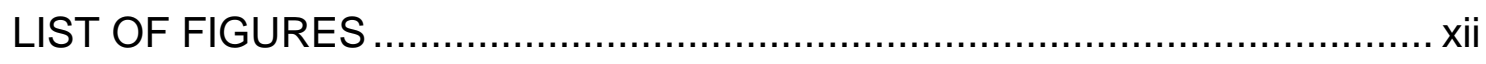

CHAPTER

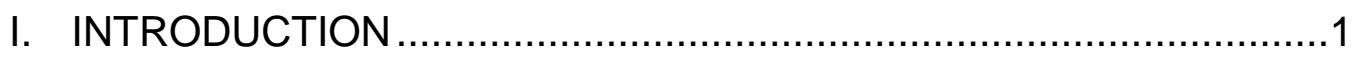

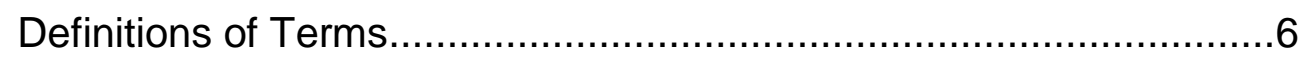

II. REVIEW OF THE LITERATURE ........................................10

Historical Context: The Evolution of Teacher Quality Policy............10

Neoliberal Ideology as the Foundation for Education Policy............25

Theoretical Framework ...................................................63

Guiding Research Questions............................................ 83

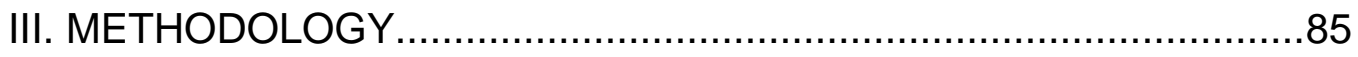

Research Design and Rationale .......................................... 85

Research Methodology.................................................... 88

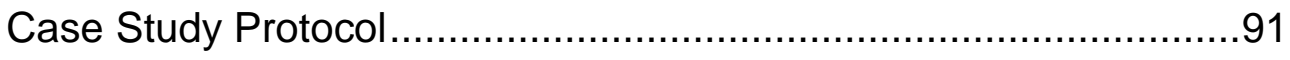

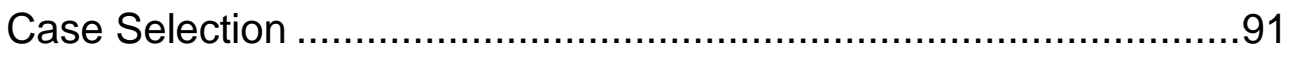

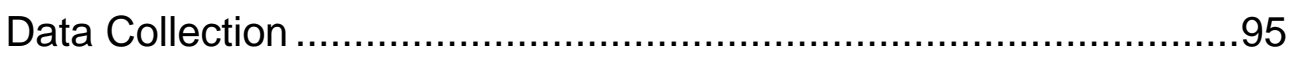




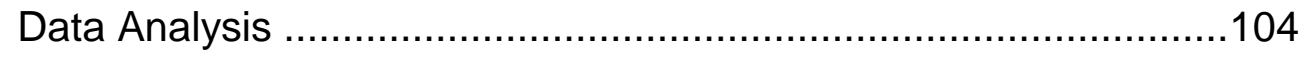

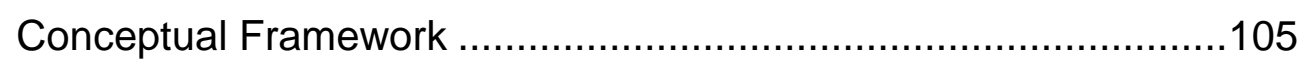

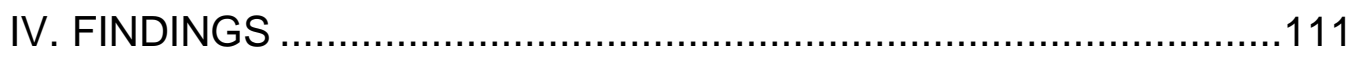

The Multi-Level Teacher Quality Policy Process ..........................111

The National Level................................................................114

Linkages: National and State Levels ........................................162

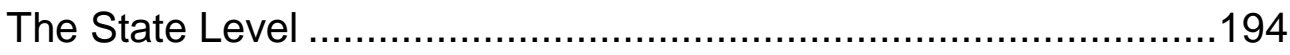

Linkages: NCATE, State, University, and Program ......................228

The University and University and Program Linkages ...................236

The Teacher Preparation Program Level ....................................244

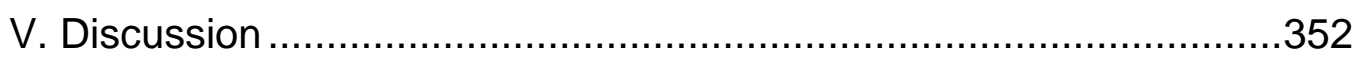

Summary of the Transformation of Legislative Intentions................355

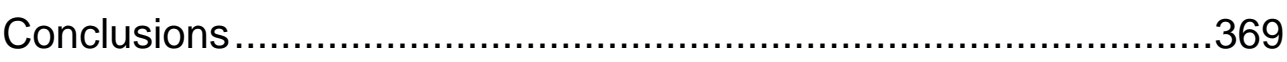

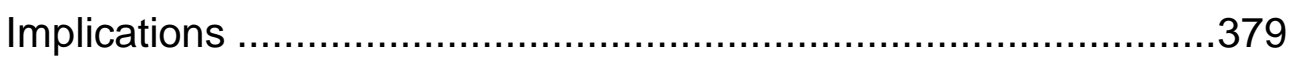

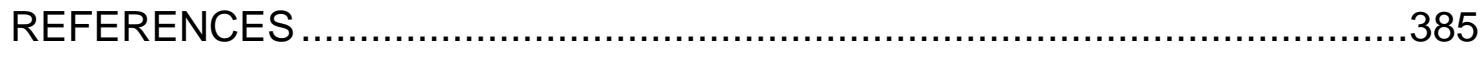

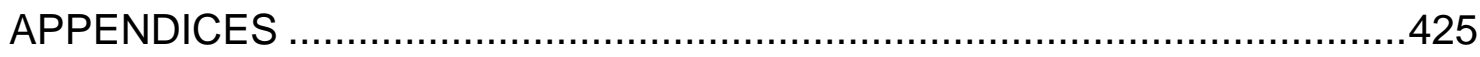




\section{LIST OF TABLES}

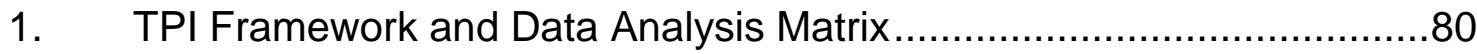

2. The National Level...............................................................114

3. Linkages: National and State Levels...........................................162

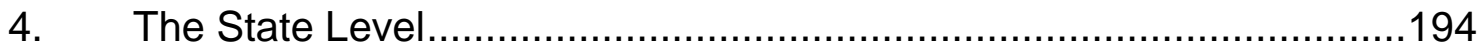

5. Linkages: NCATE, State, University, and Program ...........................228

6. The University and University and Program Linkages ......................236

7. The Teacher Preparation Program Level.......................................244

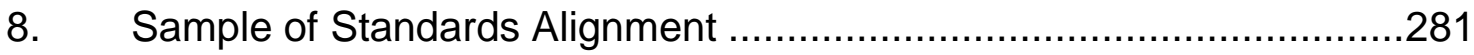

9. Sample Professional Growth Plan Documents Review .....................330 


\section{LIST OF FIGURES}

FIGURE $\quad$ Page

1. Teacher Quality Policy Power and Governance .................................55 


\section{CHAPTER I}

\section{INTRODUCTION}

The definition of teacher quality and the establishment of teacher quality policies and standards in the United States have evolved over hundreds of years of education and teacher training. Literature on definitions, standards, and measures of teacher quality is limited from the Colonial Period to the beginning of Twentieth Century. During this time period, aspects of teacher preparation and training serve as proxies for teacher quality definitions and standards. The end of the Twentieth Century marked the onset of a national focus on teacher quality with the Standards-Based Reform Movement. In the 1980s, the StandardsBased Reform Movement called for a set of research-based learning standards which would identify what all students across the nation should know and be able to do. At this time, the measurement of student achievement became based on state standards, and how well students performed on standardized tests in the context of such standards.

The components of Standards-Based Reform —-the development of standards and curricular frameworks, the alignment of state education policies, professional development for teachers, and others-established the foundation for the development of mechanisms for accountability across the nation's educational systems (Spillane, 2004; Hamilton, Stecher, Yuan, 2008; DarlingHammond, 2001). As accountability for student learning became a focal point of 
education reform, the quality of teaching rose to the surface as being equally important. The Standards-Base Reform Movement was preceded by a shift in the global and national ideological meaning of education. The notion of education for the common good was supplanted with the notion of education for the purpose of economic competition and advancement (Hursh \& Martina, 2003; Baltodano, 2012). This newly established purpose of education is aligned with characteristics of neoliberalism and focused on human capital (Giroux, 2002; Hursh \& Martina, 2003; Baltodano, 2012; Lorenz, 2012).

Neoliberalism is a socio-political ideology that combines traditional liberal ideals of social justice with a focus on economic growth (Giroux, 2002; Hursh \& Martina, 2003; Baltodano, 2012; Lorenz, 2012). Neoliberal political philosophy began influencing American social and political beliefs in the 1970s (Hursh \& Martina, 2003). The main tenets of neoliberalism include: a change in focus from the common good to individual responsibility; an overall reduction of government regulation or control, including the deregulation of markets; the reduction of public expenditures for social services, like education and healthcare; and, privatization of public goods and services (Giroux, 2002; Hursh \& Martina, 2003; Baltodano, 2012; Lorenz, 2012).

The neoliberal socio-political climate led to the political demand by policy makers for increased accountability in public education nationwide. The political desire for accountability in education led to a large body of empirical research and normative statements of practice about redefining and measuring teacher quality (Darling-Hammond, 1997b; O'Day \& Smith, 1993 as cited in Darling- 
Hammond, 2001). The empirical research, beginning in the mid-1980s, was used as the foundation for the establishment of a new wave of national and state legislation, policies and standards for teacher quality. National education organizations and boards, national teacher education accrediting agencies, educational policy organizations, and content-specific professional organizations used the research to support the establishment of newly-defined standards for teacher quality.

Today, as teacher quality standards are continually developed and revised by national- and state-level education policy actors, certain teacher inputs, established early in the history of teaching and teacher education remain important in determining teacher quality: teacher preparation, pedagogy, demonstration of teaching ability, teacher knowledge, teacher testing, and teacher certification. Other indicators of quality, like measuring teacher effectiveness using student achievement outcomes, developed more recently under conditions of neoliberalism. The main shift in how teacher quality is currently conceptualized, under neoliberal conditions, relates to how the aforementioned teacher inputs are used as indicators in systems of performance accountability where teacher inputs are linked to student outputs to determine teacher quality and effectiveness. Current debates about defining and measuring teacher quality have devolved into a narrow discussion about whether student achievement should be the sole indicator of teacher quality or one of several other observable factors related to teacher quality (Darling-Hammond \& Youngs, 2002; Darling-Hammond, Holtzman, Gatlin, \& Heilig, 2005; Clotfelter, 
Ladd, \& Vigdor, 2006; Hanushek, Kain, O’Brien, \& Rivkin, 2005; Boyd, Grossman, Lankford, Loeb, \& Wyckoff, 2008; Harris \& Sass, 2008; DarlingHammond, Wei, Andree, Richardson, \& Orphanos, 2009).

There are an abundance of teacher quality definitions, policies and standards derived from a variety of sources, for example: No Child Left Behind Act (2001); Obama's Elementary and Secondary Education Act (ESEA) reauthorization; professional studies standards, like National Council for Teachers of Mathematics (NCTM); Interstate Teacher Assessment and Support Consortium (InTASC); National Council for the Accreditation of Teacher Education (NCATE); and State- specific, like Alabama Quality Teaching Standards (AQTS). Yet, little research exists on how and why policy actors, who are involved in formulation and implementation across multiple sites, actually understand, interpret, and act on such policies and standards under current socio-political conditions. Further, the preponderance of the research literature on teacher quality standards is limited to issues of policy formulation. Additionally, much of the literature on educational policy is clouded by traditional assumptions of policy formulation, enactment, implementation, and evaluation as discrete stages rather than an interconnected process of interpretation, reinterpretation, action, and reaction by actors operating at various levels of the policy system (Yin, 1982; Hall \& McGinty, 1997; Hall, 1995). Examinations into the conditions, processes, and consequences of the implementation of quality standards and policies at schools, colleges, and departments of teacher education (SCDTEs) are even more limited. The limited policy implementation 
research that exists is framed using stage theory; a traditional theoretical framework that artificially separates policy formulation from policy implementation and does not capture the real-world complexity of policy enactment and implementation processes across multiple levels.

Any causal claims linking the quality of the teaching force with the existence of formal standards of teacher quality fall short without a clear understanding of how policy actors across and within national, state, and local government and education agencies make sense of, interpret, negotiate, and act on teacher quality policies and standards; and how decisions and actions at different levels of the policy process affect understanding and implementation at other levels. There is a need for researchers to penetrate deeper into the black box of teacher quality policy processes to make valid causal connections between teacher quality policy intent, implementation, and outcomes by shedding light on how context, culture, power, and interactions influence understandings, decisions, and actions of various policy actors across multiple implementation sites. Such policy processes ultimately influence what teacher quality policy becomes in action.

This is a case of the influence of neoliberal ideologies on the transformation of teacher quality standards and the consequences for teacher education. It examines how neoliberal influences shaped the thinking and actions taken by policy makers at the federal, regional and state levels and how those processes shaped the definition and implementation of teacher quality standards within a college of education. The research presented is an 
examination of the conditions, processes, and consequences of the implementation of quality standards at a faith-based School of Education in the southern region of the United States of America analyzed through the Transformation of Policy Intentions Framework (Hall, 1995) and Baltodano's Baltodano's (2012) critical policy analysis framework. This study investigated how policy actors at the faith-based School of Education make sense of, interpret, and respond to federal, national accreditation, state, and university mandates to implement teacher quality standards in teacher preparation. Through an in-depth interpretive qualitative implementation and critical policy analysis case study, the translation of standards policy into educational practice is brought into clear relief.

\section{Definitions of Terms}

The following is a presentation of the key terminology and acronyms used throughout this dissertation.

Covert authoritarianism is a leadership style where a leader exhibits outward dispositions of democratic leadership, but uses power and authority to appoint others to execute authoritative control. As such the covert authoritarian appears as a democratic leader who openly involves others in decision making.

Neoliberalism is a socio-political ideology that combines traditional liberal ideals of social justice with a focus on economic growth (Giroux, 2002; Hursh \& Martina, 2003; Baltodano, 2012; Lorenz, 2012). The main tenets of neoliberalism include: a change in focus from the common good to individual responsibility; an overall reduction of government regulation or control, including the deregulation 
of markets; the reduction of public expenditures for social services, like education and healthcare; and, privatization of public goods and services (Giroux, 2002;

Hursh \& Martina, 2003; Baltodano, 2012; Lorenz, 2012).

Symbolic implementation is implementation actions that signal meaningful or instrumental implementation (Smith, Miller-Khan, Heinecke, \& Jarvis, 2004). Such actions yield no meaningful information that can be used to determine impact.

Symbolic accountability technical checks of implementation documentation without any meaningful or instrumental investigation of implementation processes.

\section{List of Acronyms}

AACTE - American Association of Colleges of Teacher Education

AEA - Alabama Education Association

AESC - Alabama Education Study Commission

ALACTE - Alabama Association of Colleges of Teacher Education

ALBOE - Alabama State Board of Education

ALSDE - Alabama State Department of Education

AMSTI - Alabama Math, Science, and Technology Initiative

APTT - Alabama Prospective Teachers Test 
ARI - Alabama Reading Initiative

AYP - Annual Yearly Progress

CAEP - Council for Accreditation of Educator Preparation

CCSSO - Council of Chief State School Officers

ECEP - Elementary and Collaborative Education Program

ESEA - Elementary and Secondary Schools Act

GCTQ - Governor's Commission on Teacher Quality

GPA - grade point average

HEA - Higher Education Act

HOUSSE - High Objective Uniform State Standards of Evaluation

INTASC - Interstate New Teacher Assessment and Support Consortium

InTASC - Interstate Teacher Assessment and Support Consortium

LEA - local education agency

NASDTEC - National Association for State Directors of Teacher Education

NBPTS - National Board of Professional Teaching Standards

NCATE - National Council for the Accreditation of Teacher Education

NCATE BOE - Board of Examiners 
NCLB - No Child Left Behind

NCTAF - National Commission on Teaching for America's Future

NEA - National Education Association

PATs - Performance Assessment Templates

PEI - Planning Effective Instruction

PEU - professional education unit

PLC - professional learning community

PLP - professional learning plan

RTTT - Race to the Top

SEA - state education agency

USDE - United States Department of Education

UTR - Urban Teacher Residency

TEAC - Teacher Education Accreditation Council

TFA - Teach for America 


\title{
CHAPTER II
}

\author{
REVIEW OF THE LITERATURE \\ Historical Context: The Evolution of Teacher Quality Policy
}

\section{The Colonial Period}

The term teacher quality as we define it today was not a concept early in the history of teaching and teacher education. Teaching ability was defined in simplistic, subjective terms determined by local school boards. Readiness to teach consisted of prospective teachers having adequate standards of morality and being able to read, write, and spell (Ornstein \& Levine, 2008). Basic reading, writing, and spelling skills were measured by the level of elementary education a prospective teacher reached. A high school or college diploma was not a requirement for becoming a teacher. As long as a teacher knew more than the students she would teach, she was considered qualified for the profession (Ornstein \& Levine, 2008). A prospective teacher would seek approval to teach from a minister, religious board, or school board in the school community. Once approval was granted, the teacher was considered by the profession as being of quality (Ornstein \& Levine, 2008; Ravitch, 2003).

The quality of teaching was determined at the local level as well. Members of local boards would establish education objectives associated with the needs of their local schools (Markley, 2004). Teachers would be observed by 
school committees, ministers, and other lead education personnel and criticized and advised on their teaching methods (Barr, Burton, \& Brueckner, 1938). Teacher observations were conducted for the purposes of "job continuation and pay increases" (Markley, 2004, p. 1). Observing and evaluating teachers for the purpose of improving instruction did not occur until the 1920s (Barr, Burton, \& Brueckner, 1938). It was not until the late 1880s and the professionalization of teaching, through the establishment of teacher preparation academies, that teacher quality became conceptualized as we understand it today.

\section{The Common School Movement}

Horace Mann and Henry Barnard were education reformers who established a statewide system of free, accessible elementary education financed by public funds in the States of Massachusetts and Connecticut, respectively (Kaestle, 1983). This period in education is referred to as the Common School Movement. Through the establishment of the common school, education went from being private to being accessible to the masses (Kaestle, 1983). The Common School Movement brought about many changes to definitions, standards and indicators of teacher quality. In the early 1800 s, teachers were seen as integral to improving schools; and teacher training and quality became imperative (Kauchak \& Levine, 2007). The mid-1800s marked the beginning of the professionalization of teaching (Darling-Hammond \& Berry, 1988). Formal teacher preparation and state control over teacher quality began, during this time, with the creation and establishment of state normal schools ${ }^{1}$

\footnotetext{
${ }^{1}$ The first state-supported Normal School was established in Lexington, Massachusetts in July 1839. Prior to this time normal schools were private institutions (Harper, 1970).
} 
(Ornstein \& Levine, 2008; Kauchak \& Levine, 2007; Levine, 2006; Harper, 1970). Normal schools were 2-year institutions formed exclusively for the purpose of training and improving the quality of teachers (Harper, 1970). Normal schools were not colleges; they were secondary schools which prepared teachers for teaching in the elementary or common school ${ }^{2}$ (Levine, 2006). Standards for admission to early normal schools were similar to standards for teaching before the 1820s. As long as a prospective teacher had an elementary-level education and a desire to teach, she could enroll in a normal school (Levine, 2006).

The course of study at early normal schools spanned, at most, one year. Prospective teachers took courses in the history and philosophy of education, teaching methods of subjects taught in common schools (e.g., arithmetic, grammar, spelling, algebra, music, drawing, etc.), and were required to demonstrate their ability to teach through practice teaching (Kauchak \& Levine, 2007; Levine, 2006; Harper, 1970). In the late 1880s-1890s, pedagogy, the science and art of teaching, became a pertinent aspect of teacher training programs at normal schools (Levine, 2006; Harper, 1970).

Today's teacher preparation programs reflect teacher preparation practices in normal schools; except that during the early Normal School Period, teacher certification was not required (Ornstein \& Levine, 2008). Prospective teachers were only expected to have completed a state teacher preparation program to be considered qualified to teach. The later Normal School Period

\footnotetext{
${ }^{2}$ The Common School is a term coined by Horace Mann, known as the Father or American Education. Common schools were established in the $19^{\text {th }}$ Century for the purpose of providing a free, public education to all children (Kauchak \& Levine, 2007).
} 
introduced teacher testing and teacher education certification as measures of teacher quality. State teacher certification was granted after prospective teachers passed a locally-administered test of reading, writing, math, American history, spelling, and grammar (Angrist \& Guryan, 2005; Ravitch, 2003). Beginning in the 1940s, teacher certification tests evolved from local examinations to national standardized certification tests, like the National Teacher Examination (NTE) ${ }^{3}$, now known as Praxis II $^{4}$. In addition to teacher testing, the late-1800s brought about the use of student test scores to reward or sanction teachers (Darling-Hammond, 2004). The responsibility for teacher quality, certification, and licensing was solely under the control of each state. With the professionalism of teaching, professional training, content knowledge, knowledge of basic skills, pedagogy, teacher certification, teaching methods, and student achievement became indicators of teacher quality.

\footnotetext{
${ }^{3}$ The National Teaching Examination (NTE) was developed by Educational Testing Service (ETS), and first administered as a teacher test in 1940. NTE was intended as "supplementary measures of academic and cultural attainment which are based on the performance of a nationwide group of teaching candidates" (Crissy, 1942). The NTE consists of a set of required, common exams and one or more optional exams. The common exams assess knowledge attainment of the following topics: (1) Reasoning, (2) English Comprehension, (3) English Expression, (4) General Culture, consisting of Current Social Problems, History, Literature, Science, Fine Arts, and Mathematics, (5) Professional Information, consisting of Education and Social Policy, Child Development and Educational Psychology, Guidance, and Individual and Group Analysis, and General Principles and Methods of Teaching, (6) Contemporary Affairs. The optional exams assess mastery of a particular subject area the candidate will teach. Each candidate will take one of the following optional exams: Education in the Elementary School, English, Social Studies, Math, Biological Sciences, Physical Sciences, French, German, Spanish, and Latin (Pilley, 1941; Crissy 1942).

${ }^{4}$ In 1998, the NTE became known as Praxis II (Angrist \& Guryan, 2005). The Praxis measures teacher candidates' knowledge and skills. The Praxis Series includes two exams: Praxis I and Praxis II. Praxis I Pre-Professional Skills Test (PPST) measures basic skills in reading writing, and mathematics. Praxis I is often USDE as a pre-qualification measure for entry to a teacher education program. Praxis II measures subject-specific content knowledge acquisition, and general and subject-specific teaching skills. Praxis II is a teacher licensure and certification test taken at the culmination of a teacher education program (http://www.ets.org/praxis/about).
} 


\section{The Progressive Period}

The first inklings of formal, national standards for teacher quality and preparation appeared during the late-1880s to early-1900s (Harper, 1970). In 1908, administrators at the then Department of Normal Schools of the National Education Association (NEA $)^{5}$ established a set of policies for teacher training institutions. The seven-statement policy resolution called for normal schools to raise admission standards to require enrollees to have a high school diploma; prepare teachers for elementary and secondary education; extend the length of their preparation programs to two and four years for elementary and secondary teachers, respectively; establish educational research agendas; and broaden their curriculum to include all demands of the public schools (Levine, 2006; Harper, 1970). The resolution also included a specific policy statement on teacher quality. The policy statement read that as normal schools are an agent of the state, there should be established standards and ideals of teaching (Harper, 1970). The policy resolution was in response to a meeting of normal school presidents, which resulted in the establishment of standards for "professional courses, practice teaching, academic work, and general administration" of normal schools (Harper, 1970).

During the period between 1900 and 1930, normal schools transitioned into state teachers colleges (Kauchak \& Levine, 2007; Levine, 2006; Harper, 1970). The primary reason for this transition was due to the growth in the

\footnotetext{
${ }^{5}$ The National Education Association (NEA) is the largest professional education organization and labor union in the United States (http://www.NEA.org).
} 
number of students attending the American high school (Kauchak \& Levine, 2007; Harper, 1970). The need for teachers to be trained in high school curricula resulted in the expansion of the common school to include preparation for teaching high school grades (Kauchak \& Levine, 2007; Levine, 2006; Harper, 1970). By 1930, teachers colleges and university teacher education schools were the only institutions preparing prospective teachers. Standardized teacher education curricula consisted of four years of curriculum and pedagogical training in liberal arts, including one year of student teaching, where prospective teachers were required to demonstrate content knowledge and teaching ability (Levine, 2006; Harper, 1970). Measures of teacher quality for pre-service teachers continued to be associated with teacher training, content knowledge, pedagogy, and certification.

The supervision and evaluation of teachers for the purpose of improving quality emerged during the Progressive Period (Nolan \& Hoover, 2008; Glanz, 1998; Nutt, 1920). The quality of in-service teaching was determined by evidence collected during teacher observations. Between 1910 and 1930, it became common practice for principals to make classroom visits to teachers and take notes on their methods of instructional delivery (Spears, 1953). Observations were followed by a conference where teachers were commended on areas in which they taught well, asked about their perception of the effectiveness of the methods they employed, and then criticized on weak methods (Spears, 1953). The teacher was then handed ready-made procedures 
for how to improve their methods of teaching (Barr, Burton, \& \& Brueckner, 1938).

Later in the Nineteenth Century, evaluation checklists replaced anecdotal evidence as measures of teacher quality (Nolan \& Hoover, 2008). Labor unions, like NEA, became part of the movement to transform anecdotal evaluations of teacher quality to rating systems, by establishing evaluative criteria for the dismissal and advancement of in-service teachers (Markley, 2004). Evaluation checklists were seen as tools that would improve proficiency and efficiency in determining the quality of teaching (Nolan \& Hoover, 2008; Glanz, 1998; Spears, 1953). Principals would use checklists to rate teachers on physical arrangements of the classroom and student and teacher interactions and behaviors (Spears, 1953). If the conditions of the checklists were met, the teacher was determined to be of adequate quality.

Mid-Nineteenth Century - Twentieth Century (1920 - 2000)

In the Mid-Nineteenth Century, teacher quality became conceptualized differently due to a socio-political cultural and economic shift in national ideology. This shift led to the intense development of empirically-based research on teacher quality and effectiveness, and the establishment of professional education organizations and teacher education school accrediting bodies. Professional education organizations, like The National Association of State Directors of Teacher Education and Certification (NASDTEC) and American Association of Colleges for Teacher Education (AACTE), began forming to promote the advancement of teacher quality through teacher preparation. As the 
professional organizations were establishing national standards of teacher quality, educational researchers were commissioned by private and government agencies to conduct research on teacher quality and effectiveness. The Coleman Report (1966), Equality of Achievement in Education, is known as the first report of its kind to present research measuring the impact of school attributes, including teachers, on students. It is considered one of the most influential reports in the history of American education, and has led to an influx of research and attention on teacher quality which still continues today. Research on the influence of teacher inputs on student outputs became the basis for changes in standards and measures of teacher quality for teacher training and development.

Teacher Quality and the Establishment of Professional Education Organizations

Some of today's most influential national professional education and teacher education school accrediting bodies were established between 1920 and 1960. The organizations were established for the purpose of focusing attention on improving the quality of America's teachers. The National Association of State Directors of Teacher Education and Certification (NASDTEC) was established in 1922 to improve teacher quality through teacher preparation programs, professional development ${ }^{6}$, and teacher certification (NASDTEC, 2009; Daniels \& Swartz, 1994). American Association of Colleges for Teacher Education (AACTE) was incorporated in 1948 as an accrediting body for teacher education schools. Since the inception of AACTE (2010), administrators there

\footnotetext{
${ }^{6}$ Professional development is defined as college courses, workshops, and seminars (Garet, Birman, Porter, Yoon, \& Desimone, 2001).
} 
have worked to establish "a knowledge base for teaching, professional standards, and accountability systems." AACTE's (2010) current mission is to promote "high-quality, evidence-based preparation and continuing education for all school personnel."

In 1954, National Council for the Accreditation of Teacher Education (NCATE) was founded as an independent teacher education accrediting body, replacing AACTE (NCATE, 2010a; AACTE, 2010). AACTE, however, maintains governorship over NCATE. NCATE (2010) "is the teaching profession's mechanism to help to establish high quality teachers" and other education support personnel. NCATE's core mission is accountability, improvement, and providing leadership to reform teacher education, preparation, and training (NCATE, 2008). Through teacher education accreditation criteria, NCATE identifies what a quality teacher should know and be able to do. Specifically, Standard 1: Candidate Knowledge, Skills, and Dispositions indicates a teacher candidate must "know and demonstrate the content knowledge, pedagogical content knowledge and skills, pedagogical and professional knowledge and skills, and professional dispositions necessary to help all students learn" (NCATE, 2008, p. 12). NCATE (2008) also indicates teacher candidates must meet teacher quality standards established by the state, professional organizations, and teacher education programs. Some states, like the State of Alabama, partner with accreditation agencies to establish an evaluation and approval process for teacher education programs. 
NCATE administrators collaborate with colleagues from specialized professional associations (SPAs) to incorporate content-specific criteria into program review and accreditation standards. SPAs are organizations such as National Association for the Education of Young Children (NAEYC), Association for Childhood Education International (ACEI), Teachers of English to Speakers of Other Languages (TESOL), National Association of Gifted Children/Council for Exceptional Children, International Reading Association (IRA), National Science Teachers Association (NSTA), and National Councils for the Teaching of English, Foreign Language, Mathematics, and Social Studies. The standards set by SPAs have historically utilized cutting-edge research on teaching and learning to develop up-to-date standards of quality for teaching related to specific subject areas and types of learners. As professional organizations were establishing standards, prominent educational researchers were establishing links between teacher quality, student outcomes, and school and teacher attributes.

A competing accreditation organization would come later. The Teacher Education Accreditation Council (TEAC) was founded in 1997 (2010). Both NCATE and TEAC combined in 2013 to establish a broader teacher education accreditation organization, Council for the Accreditation of Education Preparation (CAEP). CAEP will serve as the national-level accrediting body for public and private traditional and private non-traditional schools, colleges, and institutions of teacher education. 


\section{Process-Product Research ${ }^{7}$}

In the 1960s, James Coleman and colleagues conducted research using aggregated measures of school inputs (i.e., facilities, teacher characteristics, and student population characteristics) to investigate the impact of schools on student achievement. The most important finding related to teacher quality was that "teacher characteristics explained more variance in student achievement than any other school resource" (Coleman et al., 1966 as cited in Borman \& Kimball, 2005, p. 2). Although The Coleman Report was criticized for utilizing a weak research design that did not examine individual teachers (Gallagher, 2002) and school effects (Dreeben, 2000), the findings led to a wealth of research on the impact of teacher attributes on student achievement.

Following The Coleman Report, educational researchers began in earnest to objectively investigate what teacher quality looks like, link teacher quality to student achievement, and discover ways to improve teacher quality (Dunkin \& Biddle, 1974; Hanushek, 1971). This type of research was known as processproduct research. Donald Medley's work, which identified five indicators of teacher effectiveness, also sparked the intense development of process-product research. According to Medley (1979, as cited in Brophy \& Good, 1986, p. 5), an effective teacher is a:

(1) possessor of desirable personal traits, (2) user of effective methods,

(3) creator of a good classroom atmosphere, (4) master of a repertoire of competencies, and (5) professional decision-maker who has not only

\footnotetext{
${ }^{7}$ Process-product research is "the search for relations between classroom processes (teaching) and products (what students learn)" (Gage \& Needels, 1989).
} 
mastered needed competencies but learned when to apply them and how to orchestrate them.

Findings from The Coleman Report and results of process-product research allowed researchers to identify teacher personal attributes, teacher pedagogy, classroom environment and management, and teacher's productive interactions with students during instructional delivery as indicators of teacher quality (Brophy \& Good, 1986). An even more profound impact of The Coleman Report is that it served as a precursor to federal control over teacher quality. Federal and (More) State Control of Teacher Quality

During the 1980s, states began exerting more control over teacher quality by establishing teaching standards boards and charging its members with setting standards for teacher preparation, licensure and re-certification (DarlingHammond \& Berry, 1988). Additionally, with the establishment of the U.S. Department of Education ${ }^{8}$, legislators and administrators in the federal government-through the writing of initiatives-began garnering some control over teacher preparation and quality. During this time, teacher quality continued to be linked to student achievement and was expanded to include continued learning through professional development. Seminal research linked teacher quality to teacher preparation and development (Denning, 1983; Gardner, 1983; Goldberg \& Harvey, 1983).

\footnotetext{
${ }^{8}$ In 1867, under President Andrew Johnson, the Department of Education was established. In 1979, under President Jimmy Carter, the U.S. Department of Education was established as a cabinet-level organization.
} 
Researchers also found connections between teachers' IQ and student achievement (Soar, Medley, \& Coker, 1983), and scores on teacher certification tests and student achievement (Haney \& Madaus, 1987). Although primary control over teacher quality remained with each state, federal legislation and national standards were used as foundations by which states' formulated teacher quality standards. As the quality of the American educational system became publicly perceived as being in jeopardy, the context was set for more intense federal control over teacher quality.

\section{A Nation at Risk}

After the launch of Sputnik in 1957, there was widespread public perception that the American educational system was at risk of losing its globallycompetitive edge. As a result, legislators and administrators in the federal government began focusing direct attention on the quality of education and teachers (Gardner, 1983). In the 1980s, under the leadership of President Ronald Reagan, Secretary of Education Terrel Bell established the National Commission on Excellence in Education (NCEE). A report, A Nation at Risk: the Imperative for Educational Reform (NCE, 1983), was produced by this commission. The report focused on improving the quality of instruction in $\mathrm{K}-12$ schools. One of the five recommendations for improving America's educational system was focused on teacher preparation and professional development ${ }^{9}$.

Three main problems relating to teacher quality were defined by A Nation at Risk: (1) there were not enough "academically able students" attracted to

\footnotetext{
${ }^{9}$ The five areas of recommendations from $A$ Nation at Risk are: content, standards and expectations, time, teaching, and leadership and fiscal support (Denning, 1983).
} 
teaching (Gardner, 1983); (2) teacher preparation was too heavily focused on methods of teaching rather than content; and (3) teachers of mathematics, science, and English are not qualified to teach these subjects (NCEE, 1983). Recommendations for Teaching consisted of seven parts:

(1) Persons preparing to teach should be required to meet high educational standards, to demonstrate an aptitude for teaching, and to demonstrate competence in an academic discipline, (2) salaries for teachers should be performance-based, and promotion, tenure, and retention should be tied to effective evaluation systems, (3) school boards should adopt 11-month contracts for teachers to provide time for professional development, (4) there should be established a career ladder which distinguishes beginning, experienced, and master teachers, (5) qualified individuals in high-needs areas like math, science, and English should be allowed to immediately begin teaching in these fields, without a teacher education degree (6) incentives to attract outstanding students to the teaching profession should be instituted, and (7) Master teachers should be involved in designing teacher preparation programs, and should supervise pre-service and beginning teachers. (NCEE, 1983)

All seven recommendations provided the framework for how teacher quality is currently defined, measured, rewarded, and sanctioned.

Prior to the 1980 s, teacher quality was solely the responsibility of states. A Nation at Risk (NCEE, 1983) marked the beginning of the most influential reform movement in teacher quality. Through this national policy statement, the 
policy actors in the federal government defined the essential problem with United States' global competitiveness as failure in K-12 public education, attributed in large part, to the lack of quality in the teaching force. Socio-political and economic ideology on the national level influenced policy actors to think that in order for the United States to remain globally competitive, reforms in public education needed immediate action. For this to occur, policy actors believed teacher preparation programs and in-service teacher professional development needed to increase its focus on teacher content knowledge. According to this thinking by national-level policy actors, college-educated people without education degrees, but substantial knowledge in high-needs areas like math, science, and language arts, needed to be fast-tracked into classrooms across the U.S.

This federal stance, enacted by policy actors at the time, led to the establishment of professional standards boards (e. g., National Board of Professional Teaching Standards), the development of teacher quality standards by national education policy organizations (e.g., Council of Chief State School Officers), the establishment of private, non-profit, corporate-funding based alternative-route teacher education programs, like Teach for America, and the development of alternative-route teacher certification programs in traditional schools of education. Essentially, the real reform that was taking place was the transformation of the American educational system to meet the needs of globalization and corporate competitiveness (Hursh, 2001). 
Neoliberal Ideology as the Foundation for Education Policy

A discussion about President Reagan's national education reform agenda would be remiss without an explanation of the cultural, socio-political, and economic ideology in which it is grounded. The ideology that began to permeate much of national political and economic thought in the 1970s is referred to as neoliberalism (Hursh \& Martina, 2003). The rise of neoliberalism is attributed to a global shift, led by elite policy actors—after World War II—away from a government-interventionist approach to regulating capitalism to an unregulated, free market economy centered on principles of individual choice, efficiency, and economic growth (Kotz, 2002; Hursh \& Martina, 2003).

Neoliberal ideology promotes the "deregulation of business," the reduction or elimination of social welfare programs, and-most influential to current policies in education-the "privatization of public activities and assets," like K-12 public education, universities, and schools of education (Kotz, 2002, p. 2; Baltodano, 2012). Although proponents of neoliberalism promote the benefits of reduced government, neoliberalism in practice,

involves the active intervention of the state on the side of capital, first to destroy existing institutional arrangements, and then to create a new infrastructure to facilitate capital accumulation through intensified exploitation of labor and privatization of social infrastructure and institutions. (Lipman, 2009, p. 5-6)

Common neoliberal political thought is that public education is a hindrance to "freedom of the market" (Torres and Schugurensky, 2002 as cited in 
Baltodano, 2012). Many actions of policy actors in the federal government and national education policy organizations at the time of the Reagan Administration aligned closely with neoliberal ideology. Such actions laid the foundation for Standards-Based Reform. Consequentially, this reform movement effectively changed the function and purpose of public education and teacher preparation to be grounded in the needs global and national markets rather than its traditional purpose of creating a democratized, civil, thinking citizenry.

Shifting the purpose of public education to a focus on building the economy led to the increased influence of corporations becoming the decision makers about what counts as knowledge in the teacher quality debate. Therefore, education curriculum and standards of quality had to be shifted to reflect new definitions of content knowledge. Subsequently, so that quality could be defined, there became a need to separate people who acquired this new knowledge at higher levels than those who did not. An intense federal-level focus beginning with A Nation at Risk (NCEE, 1983) and continuing with the federal accountability oversight of Goals 2000: Educate America Act (1993), No Child Left Behind Act (NCLB) (2001), and the NCLB Waiver would serve to achieve this end.

\section{Characteristics of Neoliberalism in Teacher Quality}

There are specific characteristics critical policy analysts have identified as indicators of neoliberalism in practice. All such characteristics are evident at one or more levels of the teacher quality enactment and implementation processes 
investigated in this study. General neoliberal characteristics are delineated by Brown (2003) and Luke (2005), as cited in Baltodano (2012, p. 493):

- The development of "new discourses, institutional practices, rewards, norms, and new common-sense values."

- "Active political intervention and manipulation of all the social institutions" from P-12 schools, universities, schools of education.

- The state acquiring a new identity as the "protector of capital," in which "its role is reduced to the enhancement of monetary, fiscal, social, and educational polices to nourish and protect the market."

- The elimination of the "notion of education as a "common and public good in the public interest."”

Girouz (2002) and Lorenz (2012) identify neoliberal characteristics specific to education organizations.

- Organizational life governed by a corporate culture of "senior management control." (Giroux, 2002, p. 429)

- The standardization of efficient, formal structures and input/output processes which can be quantified and controlled by management. (Lorenz, 2012)

- The "use of predetermined standards to measure output" and the "introduction of measurable indicators of performance." (Lorenz, 2012, p. 608) 
- The definition of the "product of education as qualification" expressed in terms of course credits and the accumulation of diplomas. "The quality of the education is then defined as the quantitative efficiency with which the qualifications are produced." (Lorenz, 2012, p. 621)

A Nation at Risk and Neoliberal Policy Practices in Education

Around the time of A Nation at Risk (NCEE, 1983), global economic competitiveness became the mantra of neoliberal policy actors. Previous economic policies, which focused on social welfare, were now seen as hindrances to global economic success (Hursh, 2001a; Hursh, 2001b). Policies which promoted economic growth and corporate profitability were seen by influential policy actors as essential for America to remain globally competitive (Hursh, 2001a; Hursh, 2001b). Up to this point, the purpose of public education was defined as a means to provide all U.S. citizens with free, quality learning and social opportunities for the purpose of developing a more informed citizenry.

With the implementation of neoliberal policies by influential policy actors in the 1980s, the purpose of public education became focused on the extent to which education inputs yield economically productive individuals; i.e., those who could contribute to a market-based global economy and enable America to compete at high levels within the global economy (Hursh \& Martina, 2003). Consequentially, the federal and state roles in public education have taken on new meaning, as policy actors develop laws and policies that center on this redefined purpose of public education. 
Although it is not clear whether the crisis in public education preceded the solutions (Berliner and Biddle, 1995), policy makers used the A Nation at Risk (NCEE, 1983) movement as an opportunity to both define the problem and solutions to public education. According to neoliberal policy actors, the quality of the teaching force was in peril, and the solution was federal regulation on teacher preparation and development, and new systems for evaluating, rewarding, and sanctioning teachers. In this new landscape, policy actors in organizations like National Board of Professional Teaching Standards (NBPTS), the Council of Chief State School Officers (CCSSO), and accreditation organizations, like the National Council for the Accreditation of Teacher Education (NCATE), became very powerful players in setting a national agenda for teacher education reform. They began developing policies and guidelines for curriculum and pedagogical practices in teacher preparation (Hursh, 2005, as cited in Baltodano, 2012), thus granting them significant control over defining what inputs count as teacher knowledge and ability.

In this process, the acquisition of knowledge became associated with levels of achievement on standardized tests. The importance of pedagogy began to diminish as teacher quality became heavily associated with content knowledge, which gave rise to policies promoting public alternative-route teacher certification and private alternative-route teacher education programs heavily focused on content over pedagogy. Consequentially, the new policy actors operating under assumptions of neoliberal ideology created the link between student outcomes and teacher inputs became a major indicator in determining 
whether schools of education were effectively preparing teachers. This led policy actors to create education reform policies through federal legislation that ineluctably linked high levels of teacher quality to high standardized test scores, as seen with No Child Left Behind.

The intentional focus on proof of knowledge through standardized testing for both teachers and students, the subsequent rise in public and private alternative-route teacher education programs, the content-focused transformation of teacher preparation, the magnitude of the impact of program accreditation, the nationwide establishment of charter schools, and the systematic dismantling of teachers unions may be attributed, in significant part, to the actions of neoliberal policy actors in power positions across the country. Indeed, the actions of neoliberal policy actors in the federal government, and national professional education and accreditation organizations began to significantly influence policies and actions in teacher preparation in the late 1990s, and broadly redefined teacher quality as we know it today.

\section{National Board of Professional Teaching Standards (NBPTS)}

In 1986, three years after A Nation at Risk report (NCEE, 1983), National Board of Professional Teaching Standards (NBPTS) ${ }^{10}$ was founded by policy makers, teachers union leaders, business leaders, and educators to "advance the quality of teaching and learning" (NBPTS, 2002) in the United States. In 1989, National Board administrators issued a policy statement, What Teachers

\footnotetext{
${ }^{10}$ NBPTS is "an independent, nonprofit, nonpartisan, and nongovernmental organization formed in 1987 to "advance the quality of teaching and learning by developing professional standards for accomplished teaching, creating a voluntary system to certify teachers who meet those standards and integrating certified teachers into educational reform efforts" (http://www.nbpts.org/about us).
} 
Should Know and Be Able to Do, which outlined five core principles for high quality teachers. The five NBPTS (2010) core principles remain in effect today and include, a commitment to teaching and learning, subject-matter knowledge and knowledge of how to teach subject-matter, a responsibility for "managing and monitoring student learning," reflection on teaching practices, and involvement in learning communities. According to Darling-Hammond (2001, p. 765) National Board standards "provide the working principles and reasoning processes used by accomplished teachers." Although it is a voluntary certification, unlike state teacher licensure, National Board certification is considered the highest level of teacher education certification a teacher can obtain. As well, NBPTS are considered the highest quality standards for the teaching profession, and have formulated the basis for other national teacher quality standards, like those established by Interstate New Teacher Assessment and Support Consortium (INTASC) (1992).

Council of Chief State School Officers (CCSSO)

The Holmes Group (1990) was an organization comprised of representatives from roughly 100 research institutions across the U.S. The representatives were committed to redesigning teacher preparation programs into professional development schools. The report resulting from the work conducted by The Holmes Group, titled Tomorrow's Schools: Principles for the Design of Professional Development Schools (1990), emphasized the need to improve teaching processes and the quality of teaching. This report led to further research on teacher quality and effectiveness. Policy makers in professional 
education organizations, like NBPTS and CCSSO, continued to establish standards of teacher quality. Around the time of the Holmes Group report and the establishment of NBPTS, the Council of Chief State School Officers $(\mathrm{CCSSO}){ }^{11}$ commissioned the Interstate New Teacher Assessment and Support Consortium (INTASC) to establish model standards for beginning teachers. INTASC (1992) standards were performance-based and built on the work of National Board; teacher licensing standards in states like California, Minnesota, New York, and Texas; and performance-oriented teacher education programs like the one at Alverno College in Wisconsin (Darling-Hammond, 2001). The standards identified ten principles of effective teaching with accompanying measurable knowledge, skills, and dispositions.

INTASC (1992) standards for teacher quality were based on teacher's content knowledge and pedagogical skills; ability to teach students of varying developmental and cultural backgrounds; ability to utilize a variety of instructional strategies; use of effective communication in instructional delivery; understanding and implementation of appropriate assessment strategies; ability to reflect and improve on teaching practices; and ability to foster relationships with colleagues, parents, and educational agencies. INTASC standards, along with standards established by NCATE and NBPTS administrators were touted as "the most powerful tools...for reaching and rejuvenating the soul" of the teaching profession (Darling-Hammond, 1996, p. 196). When the 1992 INTASC standards were

\footnotetext{
${ }^{11}$ CCSSO is a non-partisan, non-profit organization of public officials who head departments of elementary and secondary education in the U.S.CCSSO provides leadership, advocacy and technical assistance on major educational issues. (http://www.ccsso.org).
} 
released, they were adopted or adapted by over 30 states (Youngs, Wiggins, Salazar, Diez, \& Paliokas, 2011; Darling-Hammond, 2001). Approximately eighteen of those states subsequently developed performance-based measures of teacher quality based on the standards (Curran, Abrahams, \& Clarke, 2001).

In 2009, CCSSO convened a group of education experts and practitioners to revise the 1992 INTASC standards to reflect current advances in teacher education and development, student learning and development, teacher and student assessment, technology, cultural competence, and globalization (Youngs, et al., 2011). The original INTASC standards were designed for beginning teachers only (Youngs, et al., 2011). The 2011 InTASC standards are "intended as professional practice standards...that will look different at different developmental stages of the teacher's career" (CCSSO, 2011). The updated InTASC standards still reflect teacher knowledge, skills, and dispositions across four major categories: The Learner and Learning, Content Knowledge, Instructional Practice, and Professional Responsibility.

Findings from influential research between 1990 and 2000 allowed researchers to link teacher quality to the following attributes: content knowledge based on content area courses (Goldhaber \& Brewer, 1997; Monk \& King, 1994), professional development (Wiley \&Yoon; 1995), associations between teacher certification test scores and student achievement (Ferguson \& Ladd, 1996; Erhenberg \& Brewer, 1994), and pedagogy in mathematics and science (Stigler, Gonzales, Kawanaka, Knoll, \& Serrano, 1999; Monk, 1994). Charlotte Danielson's (1996) research linked teacher quality with teachers' knowledge of 
teaching and ability to teach. Danielson (1996) identified four standards-based, measureable domains of teacher quality: planning and preparation, classroom environment, instruction, and professional responsibilities. Danielson's (1996) teacher quality indicators were compatible with 1992 INTASC standards. As a result of the Charlotte Danielson Framework and INTASC, standards and measures of teacher quality began to evolve from being content-based to being performance-based. States began developing performance-based measures of teacher quality related to both frameworks, and federal legislation continued to focus on teacher quality.

Goals 2000: Educate America Act

Enhancing teacher quality, through preparation and professional development, remained part of the focus of federal legislation to improve education in America during Presidents George H. W. Bush and Bill Clinton times in office in the1990s. In March 1994, President Bill Clinton signed legislation, Goals 2000: Educate America Act (1993), to codify eight national education goals $^{12}$. Goals 2000 (1993) marked the beginning of outcomes-based education reform. Outcome-based education is a method which considers education resources, such as teachers, as inputs, and measures of student performance on standardized tests as outcomes.

\footnotetext{
${ }^{12}$ The Eight Education Goals of Goals 2000: Educate America Act included goals for school readiness, raising the graduation rate, students having to demonstrate subject-are competency in grades 4, 8, and 12, access to professional development for teachers, U.S. students being world leaders in mathematics and science, literacy for all American adults, drug- and violence-free schools, and partnerships to increase parental involvement.
} 
Three of the eight components of the Goals 2000 Act (1993) were directly aligned with neoliberal ideology and intentions to reform America's educational system to focus on national economic growth and global competitiveness. Goal three addressed structuring all schools to increase academic achievement for all students so they may be prepared for "responsible citizenship, further learning, and productive employment in our nation's economy [emphasis added]" (Goals 2000, 1993, p. 7). Goal five stresses a desire for the United States "to be first in the world in mathematics and science achievement [emphasis added]" (Goals 2000,1993, p. 8). One objective of this goal is to see a "50 percent increase" in the "number of teachers with a substantive background in math and science" (Goals 2000, 1993, p. 8). Goal six indicates providing all American adults with the "knowledge and skills necessary to compete in a global economy" (Goals 2000,1993, p. 8). According to the legislation, this shall be done by involving "every American business...in strengthening the connection between education and work" and "substantially" increasing college attendance and completion (Goals 2000, 1993, p. 8).

Goal four urged state and local school districts to focus on high-quality teacher preparation and teacher learning through professional development. The goal reads, "By 2000, the Nation's teaching force will have access to programs for the continued improvement of their professional skills and the opportunity to acquire knowledge and skills needed to instruct and prepare all American students for the next century" (Goals 2000, 1993, p. 7). Goal four was a clear indication that state education reform must include provisions for recruiting 
quality teachers from quality teacher education programs, retaining quality teachers, and developing all teachers through professional development. Iterations of this goal are seen in standards established by members of future federal administrations. Following Goals 2000 (1993), federal education personnel continued to commission studies to identify indicators of teacher quality.

National Commission on Teaching and America's Future (NCTAF)

In 1996, $\mathrm{NCTAF}^{13}$ was established as a leading policy commission setting an agenda on improving America's schools through enhancing teacher quality. NCTAF's policy work was developed into a report, What Matters Most: Teaching for America's Future (1996) which established a "blueprint" for the recruitment, preparation, and support of quality teachers to improve America's schools (Darling-Hammond, 1996, p. 193; Weiss \& Weiss, 1998). The NCTAF (1996) report asserted that public schools employed unqualified teachers because of "poorly enforced standards for teacher training and licensing" (Ballou \& Purdursky, 2000, p. 2). NCTAF (1996) recommended National Board standards be used as the foundation for developing evaluations of teacher quality (Weiss \& Weiss, 1998); teacher licensure be based on demonstrated performance through content knowledge, knowledge of teaching, and teaching skill; and NBPTS be used as the benchmark of accomplished teaching (Darling-Hammond, 1996).

Around the time of What Matters Most (NCTAF, 1996) report, research surfaced about whether teacher certification and testing served as sufficient

\footnotetext{
${ }^{13}$ NCTAF is a "nonpartisan, nonprofit, advocacy group dedicated to improving teaching quality nationwide" (http://www.nctaf.org/faqs/index.htm).
} 
screening mechanisms for teacher quality (Angrist \& Guryan, 2005; DarlingHammond \& Youngs, 2002; Goe, 2008; Goldhaber \& Brewer, 2000; DarlingHammond, 2000; Fetler, 1999; Sanders \& Rivers, 1996; Monk, 1994; Ferguson, 1991). Research on the use of teacher certification as a teacher quality indicator was important at the time, and even now, since most states use teacher certification testing as an indicator that a teacher is qualified to teach.

In a study conducted in 900 school districts in Texas, researchers found that teacher licensing exam scores, level of education, and experience were important indicators of teacher quality (Ferguson, 1991). Researchers conducting a meta-analysis of production function studies found that education, ability, and experiences were significantly associated with student achievement gains (Greenwald, Hedges, \& Lane, 1996, as cited in Ballou \& Purdursky, 2000). In his study of characteristics of high school mathematics teachers, Fetler (1999) also found that teacher preparation and teaching experience are functions of teacher quality. Researchers of a large-scale study conducted in Houston, Texas, which compared the effects of traditionally certified teachers to Teach for America (TFA) teachers on student achievement, found that "certified teachers consistently produce stronger student achievement gains than do uncertified teachers" (Darling-Hammond, Holtzman, Gatlin, Heilig, 2005, p. 2).

Other research disputed the significant influence of teacher certification and testing on teacher quality. Ballou and Purdursky (2000) and Finn (1999) argued that teacher quality is more of a function of general academic ability than teacher training. Although Goldhaber and Brewer (2000) found that students of 
teachers of mathematics who hold certification achieve at higher levels than students of math teachers who are not certified, they also found that students of math and science teachers who hold emergency certification achieve at similar levels as students of teachers with traditional certification. Therefore, they concluded, traditional teacher education certification is not a sufficient measure of teacher quality (Goldhaber \& Brewer, 2000). Research conducted by Angrist and Guryan (2005) supported the findings of Goldhaber and Brewer.

Researchers countering the Houston, Texas TFA study found that TFA teachers effect significantly greater achievement in mathematics than certified teachers (Decker, Mayer, \& Glazerman, 2004).

Current research on the impact of teacher training on teacher quality suggests high-quality pre-service preparation leads to high-quality teachers, and accompanying increases in student achievement (Boyd et al., 2008; NCATE, 2006; Darling-Hammond et al., 2005; Darling-Hammond \& Youngs, 2002; Darling-Hammond, Berry, \& Thorenson, 2001). Although mixed findings have resulted from research on teacher preparation and certification, the most current research, as presented here, suggests teacher certification and preparation do matter when determining teacher quality. Contemporary standards of teacher quality are associated with teacher preparation and certification, teacher knowledge, teacher effectiveness, and student achievement outcomes. Section 207 of Title II of the Higher Education Opportunity Act

Research conducted in the late-1990s connecting teacher quality to aspects of teacher preparation and training may have established the rationale 
for the 1998 enactment of Section 207 of Title II of the Higher Education Opportunity Act (HEOA) (2007). Indeed, this legislation set the stage for federal control over defining and policing teacher quality in teacher preparation institutions. Section 207 of Title II of the Higher Education Opportunity Act (2007) is one of the first Congressional mechanisms granting the federal government oversight in determining the quality of teacher education and preparation in the United States (USDE, 2006). Under President Bill Clinton, Congress passed a law which required that the United States Department of Education (USDE), via states, collect data on the performance of teacher preparation programs, including state assessments, standards, and other regulations for teacher certification and licensure.

The law required teacher preparation institutions to annually submit data on indicators, such as teacher certification test pass rates, student teaching placements and supervision, and program accreditation, to the state so that states could prepare and provide annual reports cards to the Secretary of Education. At the time it was enacted, the law also required then Secretary of Education, Richard Riley - and education secretaries thereafter-to use the state report cards to submit to Congress reports on the quality of teacher preparation in the U.S. Although Section 208 of the same act indicated the state function is to assess the eligibility of each public teacher preparation institution, the USDE held a very important power position. Teacher preparation institutions not approved by states would be ineligible to receive federal funding for professional 
development and could not accept or enroll any student who received federal aid (USDE, 2006). 


\section{Twenty-First Century (2000 - Present Day)}

To guide the development of high-level standards and measures, prominent educational researchers are building a cutting-edge body of research on what matters most in quality teaching. Researchers are also establishing valid and reliable standardized measures of teacher quality. Twenty-First Century definitions and measures of teacher quality are based on teacher qualifications, teacher attitudes and dispositions, professional development, effectiveness of instructional practice, and student achievement outcomes. Although the U.S. Department of Education (USDE) garnered control over teacher quality about 30 years ago, the turn of the century brought about a different meaning of federal control.

Beginning in the late 1990s, Goals 2000 (1993) federal legislation mandated all states be held accountable for the quality in teacher preparation and training. Beginning in 2001 with No Child Left Behind legislation, the federal government garnered even more control over the quality of teachers in states when Congress passed legislation holding states accountable for training, preparing, retaining, and equitably distributing highly qualified teachers across all American schools. The network of policy actors at professional education organizations, professional standards boards, and teacher education accreditation agencies continue to be powerful leaders in identifying problems with teacher quality, and establishing empirical- and normative practice-based standards of teacher quality. Policy actors in states are required to implement some form of teacher quality standards and policies in the context of federal regulations. 
No Child Left Behind Act (2001)

President George W. Bush's federal legislation, No Child Left Behind Act (NCLB) (2001) brought about the next major change in the concept of teacher quality since A Nation at Risk (NCEE, 1983) and Goals 2000 (1993). Today's standards, policies, and measures of teacher quality are developed in the context of NCLB (2001) "highly qualified" teacher mandates. According to NCLB (2001), a teacher is considered highly qualified if she has earned a bachelor's degree from an accredited higher education institution, obtained full state certification through traditional or alternative routes, and demonstrated subject-matter expertise in the subject she teaches. New teachers must demonstrate subjectmatter expertise by passing a state-certified certification test which assesses basic skills knowledge, subject-area knowledge, and teaching skill. Experienced teachers must demonstrate subject-matter knowledge by either fulfilling the requirements of new teachers or meeting their state's High Objective Uniform State Standard of Evaluation (HOUSSE) requirements (Learning Point Associates, 2007; NCLB, 2001).

HOUSSE requirements vary from state to state, but must include the following provisions:

Cover grade-appropriate, academic subject-matter knowledge, and teaching skills; Align with challenging state academic content and student academic achievement standards...; Provide objective, coherent information about the teachers' attainment of core content knowledge in the academic subjects taught by the teacher; Allow uniform application to 
all teachers in the same academic subject and the same grade level throughout the state; Take into considerations but not be based primarily on the time the teacher has been teaching in the academic subject; and Permit the public to view the requirements upon request. (Learning Point Associates, 2007; NCLB, 2001)

HOUSSE allows veteran teachers to demonstrate content knowledge through a combination of experience, college coursework, an academic major in the subject they teach, professional development, and other federally-approved state measures (Smith, Desimone, \& Ueno, 2005, p. 76).

NCLB is the first federal legislation credited with strengthening accountability for teacher quality. To hold states accountable for hiring and retaining highly qualified teachers, NCLB (2001) requires schools to notify parents at the beginning of the year that they may request information about the qualifications of their child's teacher(s). Schools must also notify parents if their child has been placed in the classroom of a teacher who is not highly qualified. Additionally, states and districts must "develop plans to attain established, measureable goals that demonstrate progress in increasing the number of highly qualified teachers teaching core subjects (Learning Point Associates, 2007). Finally, states must report to the federal government statistics on teachers who are or are not highly qualified, assess the extent to which non-highly qualified teachers teach low-income or minority students (Learning Point Associates, 2007; NCLB, 2001). 
Title I, Part A of NCLB (2001) requires states to "ensure that 100 percent of all teachers teaching in core subject areas ${ }^{14} \ldots$ be highly qualified" (Learning Point Associates, 2007). NCLB did not radically change national-level indicators of teacher quality. As noted, teacher quality indicators were still associated with teacher preparation and demonstration of knowledge acquisition through certification tests, just as they were with previous administrations. The radical change is attributed to the strictness of the accountability component of NCLB. It was not until NCLB legislation that officials in states were held accountable for training, recruiting, equally distributing, and retaining "highly qualified" teachers, as the term is defined under federal law.

After the NCLB federal mandates on teacher quality were set, personnel at state departments of education (SDEs) were required to specify standards and regulations to ensure the state meets the federal government requirements of teacher quality. Although state personnel have control over developing their own standards for teacher quality, state policies must be in compliance with federal law. Rather than establishing a separate definition, state legislators mostly use NCLB's (2001) "highly qualified teacher" definition as their own. For example, legislators from the Alabama State Department of Education (ALSDE) define a highly qualified elementary teacher as one whom: "holds at least a valid Class B Professional Educator Certificate and has passed an Alabama-approved state subject-specific test in elementary education" (ALSDE, 2006). ALSDE's (2006)

\footnotetext{
${ }^{14}$ NCLB (2001) core subject areas are English language arts, mathematics, science, foreign languages, civics and government, economics, arts, history, and geography (Learning Point Associates, 2007).
} 
definition of teacher quality is written to be in compliance with NCLB's (2001) highly qualified teacher statute.

Legislators from Virginia and officials from the Virginia State Department of Education (VDOE) define a highly qualified teacher as one whom: "holds full state certification in the area being taught; has earned a minimum of a bachelor's degree; and has demonstrated subject-matter mastery (rigorous testing for new teachers or HOUSSE for veteran teachers)" (VDOE, 2010). VDOE's (2010) definition of teacher quality is the same as NCLB's (2001). The VDOE (2010) legislators also indicate the VDOE is committed to the recruitment and retention of highly qualified teachers by providing "high quality mentoring" and "high quality professional development". It can be deduced from VDOE legislative statements of federal compliance that teacher preparation, teacher knowledge, teacher certification (through passing a teacher test), and teacher learning through professional development are indicators of teacher quality in Virginia.

Research on teacher quality at the time of NCLB was focused on teacher qualifications, teacher effectiveness, and student outputs. Content knowledge (Darling-Hammond, 2000), professional development (Smith, Desimone, \& Ueno, 2005; Wenglinsky, 2002; Garet, Birman, Porter, Yoon, \& Desimone, 2001; Cohen \& Hill, 2000), and pedagogical skill (Hill, Rowan, \& Ball, 2005; Goldhaber \& Brewer, 2000) continued to be found as pertinent links to student achievement. Years of teaching experience (Smith, Desimone, \& Ueno, 2005; DarlingHammond, 2000; Rivkin, Hanushek, \& Kain, 2000), instructional practices (Frome, Lasater, \& Cooney, 2005; Wenglinsky, 2000) and teacher effectiveness 
(Clotfelter, Ladd, \& Vigdor, 2006; Goldhaber \& Anthony, 2005) were additional factors found as valuable indicators of the quality of teachers. As research continues to identify indicators of teacher quality, federal and state governments continue to establish legislation for teacher quality based on the empirical evidence.

Race to the Top (RTTT)

In 2009, President Barack Obama authorized a federal competitive grant program, Race to the Top (RTTT) (2009), as a funding mechanism to assist states in developing "innovative" accountability and evaluation systems for teaching and learning. RTTT (2009) served to further federal provisions for teacher quality in a way NCLB (2001), arguably, did not, by awarding muchneeded funds to states "that are leading the way in comprehensive, coherent, statewide education reform" in four key areas ${ }^{15}$, including "recruiting, developing, rewarding, and retaining effective teachers and principals, especially where they are needed the most" (Race to the Top, 2009). In order to receive funding through RTTT (2009), states must design teaching and learning accountability systems that are aligned with indicators identified by the USDE.

The RTTT (2009) grant program required states who receive funding to provide "high quality" pathways for teachers, use performance-based measures

\footnotetext{
${ }^{15}$ RTTT (2009) four key areas are: (1) Adopting standards and assessments that prepare students to succeed in college and the workplace; (2) Building data systems that measure student growth and success, and inform teachers and principals how to improve instruction; (3) Recruiting, developing, rewarding, and retaining effective teachers and principals, especially where they are needed most; and (4) Turning around their lowest-performing schools. (http://www2.ed.gov/programs/racetothetop/executive-summary.pdf)
} 
to improve teacher quality, ensure equitable distribution of effective teachers across diverse school systems, improve the effectiveness of teacher education programs, and improve teacher quality by providing effective support and professional development. In addition to the teacher quality systems aspect of the RTTT (2009) grant program, states are required to design student learning accountability systems which prepare all students to succeed in college and career, and to compete in a global economy.

Forty-six states and the District of Columbia applied for RTTT (2009) funding, indicating either widespread agreement with USDE interests or a dire need for funding to support state educational systems. Through Race to the Top (2009), key policy actors in the United States Department of Education (USDE) have decided that accountability and evaluation of quality in teacher preparation lacks rigor. They have suggested what such rigor would look like and what they expect of states transitioning to this new system of accountability and evaluation. As evidenced by the most up-to-date federal legislation and research, standards, policies, and measures of teacher quality continue to be linked to inputs (teacher qualifications and attributes), processes (instructional practices), and outcomes (teacher effectiveness as measured by student achievement) (Goe, 2008). Twenty-First Century Teacher Quality Attributes: Inputs, Processes, and Outcomes

Teacher Inputs. Teacher qualifications are indicated by teacher education preparation (Boyd et al., 2008; Darling-Hammond et al., 2005), level of degree (Clotfelter, Ladd, \& Vigdor, 2006; Hanushek, Kain, O’Brien, \& Rivkin, 2005), teacher education certification (Kane, Rockoff, \& Staiger, 2006; Hill, Rowan, \& 
Ball, 2005), teacher coursework and academic major/minor (Harris \& Sass, 2008), subject matter content knowledge as determined by teacher tests (Harris \& Sass, 2008; Clotfelter, Ladd, \& Vigdor, 2006), teaching experience (Harris \& Sass, 2008; Boyd et al., 2008; Darling-Hammond et al., 2005; Hanushek, Kain, O'Brien, \& Rivkin, 2005), and content-based, time-intensive professional development (Darling-Hammond, Wei, Andree, Richardson, Orphanos, 2009; Harris \& Sass, 2008).

Other teacher input indicators are attitudes and dispositions. Indicators of teacher attitudes include expectations of students (Frome, Lasater, \& Cooney; 2005; Danielson, 1996), teacher efficacy (Goddard, Hoy, \& Hoy, 2000), and teacher collaboration (InTASC, 2011; NBPTS, 2010; Leana \& Pil, 2006). Indicators of teacher dispositions include reflection, professional conduct, respect for diversity, compassion for students, education advocacy, fairness, and integrity (InTASC, 2011; NCATE, 2010a; Danielson, 1996).

Teacher Processes. The quality of instructional practice is included as a pertinent indicator of teacher quality in the Twenty-First Century. This aspect of teacher quality is defined by what happens in the classroom, planning, assessment; and includes pedagogical strategies like questioning of students, interactions with students, classroom management, and other performancebased measures of instructional practice (InTASC, 2011; Harris \& Sass, 2008; Leana \& Pil, 2006; Frome, Lancaster, \& Cooney, 2005; Hill, Rowan, \& Ball, 2005; Wenglinsky, 2000, 2002). Some measures of the effectiveness of instructional practice include teacher ratings on standards-based teacher observation 
instruments. Some researchers have found that ratings from teacher observations are good indicators of teacher quality and effectiveness (Gallagher, 2004; Milanowski, 2004; Hotzapple, 2003; La Paro, Pianta, \& Stuhlman, 2004). Further, in research on the use of subjective principal assessments in determining teacher quality, researchers found that principal assessments predict student achievement significantly better than teaching experience and education (Jacob \& Lefgren, 2005).

Teacher Outcomes. Teacher outcomes based on student achievement are not a new indicator of teacher quality. Today, a greater focus on the use of student achievement to determine teacher quality is one favored option in this era of accountability. Current research, much of which was reviewed previously in this document, indicates teacher quality in fact makes a difference in student achievement. Other seminal research in this area concludes using student achievement outputs, rather than teacher inputs are the most reasonable way to determine the quality of a teacher (Hanushek, 2003). Current debates center on whether student achievement should be a sole indicator of teacher quality or one of many other factors. Conclusions from value-added modeling (VAM) ${ }^{16}$ research, which indicates value-added scores are highly associated with student achievement, are used to support claims that teacher quality is, and should be, solely determined by student achievement (Rivkin, Hanushek, \& Kain, 2005;

\footnotetext{
${ }^{16}$ Value-added assessment is "any method of analyzing student test data to ascertain students' growth in learning by comparing students' current level of learning to their own past learning" (http://www.effwa.org/pdfs/Value-Added.pdf).
} 
Koedel \& Betts, 2005; Sanders \& Rivers, 1996; Sanders \& Horn, 1994;

Hanushek, 1992; Murnane \& Phillips, 1981).

Opponents of the use of student achievement measures as the sole determinant of teacher quality present two general arguments: (1) there are reliability and validity issues with VAM, and (2) there are many critical teacher input factors which more effectively determine teacher quality beyond that of student achievement. Factors such as teacher preparation and certification; teacher education, based on level of degree; content knowledge; pedagogy; teacher test scores; academic major/minor; National Board of Professional Teaching Standards (NBPTS) ${ }^{17}$ certification attainment; professional development; and teacher attitudes and dispositions have been thoroughly researched and linked to teacher quality (Goe, 2008). As such, Goe (2008) argues teacher quality should be defined by a two-pronged approach: (1) initial, pre-service qualifications tied to the subject and grade to be taught, and (2) linking teacher effectiveness to student learning. Education administrators in the federal government, state departments of education, and professional boards and organizations have heeded the research and adopted an approach to standards setting and teacher evaluation which uses student achievement as one of a variety of factors in determining the quality of teachers (Duncan, 1999; USDE, 2011a). However, student achievement test scores appear to weigh most heavily.

\footnotetext{
${ }^{17}$ NBPTS is a board comprised of teacher educations who establish advanced standards and assessments for teachers. NBPTS certification is the highest teacher education certification awarded in the United States.
} 
Current standards—created by various education agencies, like CCSSO Interstate Teacher Assessment and Support Consortium (InTASC) (2011) and NBPTS —reflect the most up-to-date research identifying teacher inputs, processes, and outcomes as pertinent factors of teacher quality. Teacher quality standards, then, provide the framework for teacher preparation and professional development programs. Schools, colleges, and departments, of teacher education are mandated by federal and state law to apply a state-approved set of quality standards to their programs so that their graduates will be considered highly qualified. Teacher education program review processes conducted by states and national and regional teacher education accreditation agencies are charged with the responsibility to ensure quality standards are being implemented in a way that will yield high quality teacher education graduates.

\section{Power and Governance}

As evidenced in this review of literature, teacher quality standards and policy are set by federal and state departments of education, and a variety of educational organizations. However, the power to enforce such policies in schools, colleges, and departments of teacher education (SCDTEs) lies within a few organizations: the U.S. Department of Education, state departments of education, and teacher education accreditation bodies. In 2001, drafters of NCLB legislation established criteria for defining a "highly qualified teacher." To avoid federal scrutiny and subsequent sanctions-like not receiving muchneeded federal funding for public education—-personnel from state departments of education adopted the federal definition of teacher quality, which included 
three criteria: (1) a teacher must hold at least bachelor's degree, (2) a teacher must obtain full state certification, and (3) a teacher must demonstrate subject matter competency in the core academic subject they teach (NCLB, 2001).

States also developed or adopted federally-compliant state standards of teacher quality. In establishing teacher quality standards, states consult or adopt standards developed by teacher education accreditation agencies, national education policy organizations, or other states. After standards and policies of teacher quality are developed or adopted, state departments of education are authorized, under the purview of the U.S. Department of Education, to ensure the implementation of such standards in schools, colleges, and departments of teacher education (SCDTEs) and in local school districts.

State departments of education (SDEs) set requirements for initial and continuing licensure and certification. SDEs control what counts as sufficient content, pedagogical, and dispositional knowledge and skills for pre-service and in-service teachers. SDEs control and define the attributes that contribute to professionalism (e.g., participation in professional organizations, knowledge of education laws and ethics, etc.). States also determine requirements for teacher education program admissions, retention, and graduation by setting criteria for: grade point averages (GPA); the number of courses, hours, and types of content; the length of observation and field experiences; appropriate dispositions, interests, and aptitudes for teaching; and passing scores for admissions and exit exams. 
Accreditation in higher education is another powerful force governing decisions about teacher quality standards in SCDTEs. Accreditation is recognized by the U.S. Department of Education and the public as an important factor in determining the quality of public universities and colleges, and the departments thereof. In the age of neoliberalism, accreditation has a major impact on public perceptions of quality. Some states partner with accreditation agencies in evaluating the credibility and effectiveness of teacher education schools and programs. In these states, the state review and national accreditation process is conducted at the same time. The first step in the accreditation process for SCDTEs is to show proof that their college or university is accredited by a higher education accrediting body, like the Southern Association of Colleges and Schools (SACS).

SACS is a regional accrediting body in eleven southern U. S. states: Alabama, Florida, Georgia, Kentucky, Louisiana, Mississippi, North Carolina, South Carolina, Texas, and Virginia; and Latin America for higher education institutions that award associate, baccalaureate, master's or doctoral degrees. To gain or maintain accreditation, "institutions must comply with the standards contained in the Principles of Accreditation: Foundations for Quality Enhancement and with the policies and procedures of the Commission on Colleges" (SACS, 2012). Once SACS institutional accreditation is established, SCDTEs may request accreditation or re-accreditation through a teacher 
education accrediting body, like NCATE or Teacher Education Accreditation Council (TEAC) ${ }^{18}$, currently CAEP.

NCATE is the accrediting body used by most traditional teacher education institutions in the United States. NCATE partners with many national-level education organizations, all of which are powerful forces in determining reform initiatives, and defining and establishing quality standards for education and teachers: the National Education Association (NEA), the American Federation of Teachers $(\mathrm{AFT})^{19}$, specialized professional associations (SPAs) (i.e., NCTM, NCTE, IRA, TESOL), and the Council of Chief State School Officers (CCSSO). Additionally, NCATE utilizes policy and research from INTASC and NBPTS in establishing quality standards for what pre-service teachers should know and be able to do. NCATE Standard 1 identifies a set of knowledge, skills, and dispositions required of prospective teachers who graduate from an NCATEaccredited teacher education programs.

There are criticisms of NCATE concerning which of the NCATE partner entities have definitive control over determining NCATE standards and policies. Additional criticism centers on the cumbersomeness and complexity of the NCATE accreditation process (Kraft, 2001). Deans at some schools of education

\footnotetext{
18 "The Teacher Education Accreditation Council (TEAC), founded in 1997, is a nonprofit organization dedicated to improving academic degree programs for professional educators, those who will teach and lead in schools, pre-K through grade 12. TEAC's goal is to support the preparation of competent, caring, and qualified professional educators" (http://www.teac.org/).

${ }^{19}$ The American Federation of Teachers (AFT), an affiliate of the AFL-CIO, was founded in 1916. AFT is a lobbying organization which represents the following professions: "pre-K through 12thgrade teachers; paraprofessionals and other school-related personnel; higher education faculty and professional staff; federal, state and local government employees; and nurses and other healthcare professionals. In addition, the AFT represents approximately 80,000 early childhood educators and nearly 250,000 retiree members" (http://www.aft.org/about/).
} 
have questioned the quality of national accreditation and have withdrawn from the NCATE process, "opting to establish state-level accreditation instead" (Kraft, 2001, p. 7). NCATE.org currently lists all 50 U.S. states as NCATE-partnership states, indicating that at least one school within each state partners with NCATE in evaluating the effectiveness of their teacher education program. Beginning January 2013, NCATE and TEAC joined forces to form one teacher education accreditation agency, the Council for the Accreditation of Education Preparation (CAEP).

Figure 1

Teacher Quality Policy Power and Governance

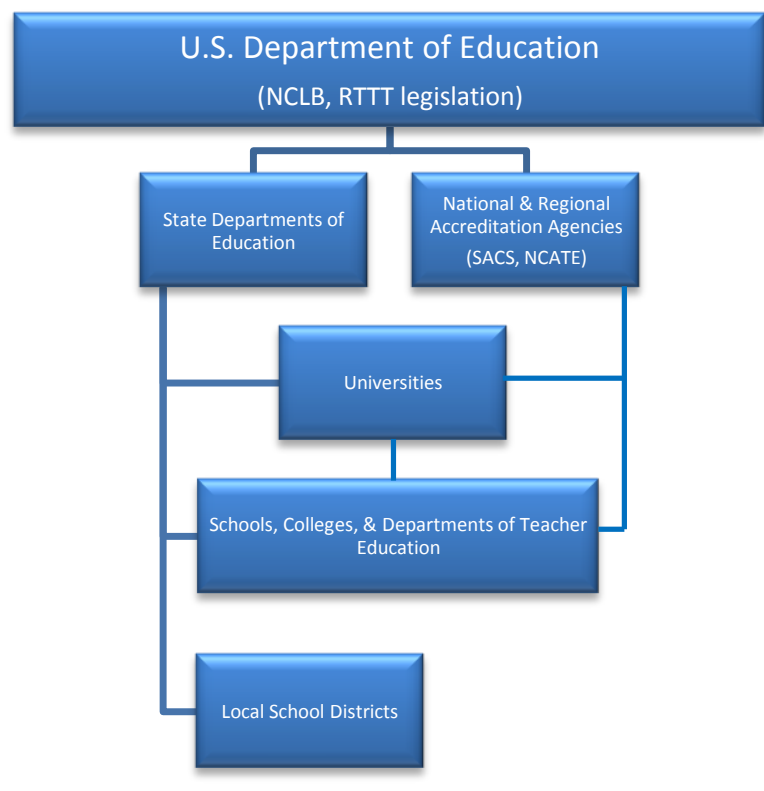

Implementation of Teacher Quality Standards Review \& Evaluation: A State Example

The Alabama State Department of Education (ALSDE) adopted a set of standards named, Alabama Quality Teaching Standards (AQTS) (Morton, 2007). Alabama Quality Teacher Standards were first established in 1978, but have 
been repealed and revised many times since then. The most recent iteration of AQTS is the March 2007 version. Recent AQTS were revised to meet current federal (i.e., NCLB) and state law and reflect up-to-date research-based standards for teaching (Morton, 2007). The AQTS include teacher education program requirements, what counts as content and pedagogical knowledge, and professionalism requirements. Teachers in the state are required to align their practices and professional learning with these standards. SCDTEs in the state are required to implement AQTS (2007) and two additional sets of standards into their teacher education programs: NCATE accreditation standards (or other national accrediting standards approved by the Alabama State Board of Education), and program standards established by specialized professional association (SPA) guidelines.

The process for regulating the implementation of teacher quality standards in SCDTEs in the State of Alabama was established by the Alabama State Board of Education (ASBE). Personnel at the Alabama Department of Education partner with NCATE personnel to ensure standards are being met. This process is referred to as the NCATE/State Partnership Protocol for First/Continuing/Probation Reviews of Professional Education Units in the State of Alabama (ALSDE, 1988). The protocol for ensuring standards are implemented involves several steps. The state superintendent of education appoints two teams whose members will review and evaluate all compliance documents: a subject area specialists (SAS) team and a state on-site review team. 
An NCATE Board of Examiners (BOE) team serves as the third compliance review team. The SAS team is comprised of specialized professional association (SPA) program review readers who reside in the State of Alabama. The state on-site review team is comprised of state-appointed professionals who have participated in NCATE-sponsored BOE training. There are two co-chairs on the on-site review team: one NCATE member and one state on-site team member. A state consultant serves on the NCATE team to advise the team of state requirements. NCATE invites non-voting observers from the National Education Association (NEA) and the American Federation of Teachers (AFT) to serve on the on-site team.

Before the on-site review is conducted, SCDTEs must first submit a program self-study or annual report, which is documentation of compliance with standards and regulations, to the SAS team. The self-study includes documentation of "how each standard is met for College and University Requirements, each program, and the Professional Studies standards [i.e., INTASC] that are common to all programs" (ALSDE, 1988, p. 10). Documentation of program admissions criteria; efforts to enhance field and clinical experiences; enrollment, retention, and graduation statistics; and faculty credentials is also included in the annual report. Similar documents are submitted to the NCATE Board of Examiners (BOE). In addition, the Professional Education Unit (PEU) must submit an institutional report (IR) to NCATE. The IR "describes the unit's conceptual framework and evidence that demonstrates that the 6 [NCATE] standards are met” (ALSDE, 1988, p. 10). A unit's conceptual framework 
includes: the vision and mission of the institution; philosophy, purpose, and standards of the unit; knowledge bases of the unit; candidate proficiencies related to expected knowledge, skills, and dispositions; and a summary of the unit's assessment system (NCATE, 2008). The SAS team reviews the PEU's self-study and provides a report of recommendations for areas not in compliance with ASBE professional studies and program-specific knowledge and ability standards.

While compliance documents are being reviewed by the SAS and NCATE BOE, the PEU must construct an evidence/exhibit room which includes documentation of compliance submitted with the previous report (e.g., conceptual framework document, governance documents, teacher preparation handbooks, student work samples, etc.). The evidence/exhibit room must also include "performance-based evidence that demonstrates what candidates know and are able to do," as well as admissions and internship assessments, state licensure test score averages, and any follow-up studies (ALSDE, 1988, p. 15). In addition, the PEU must schedule faculty members, administrators, candidates, cooperating teachers, principals, alumni, and other members of the professional community for interviews; select classes that will be observed by the on-site teams; and schedule the on-site visit.

The on-site visit takes place after the initial review of compliance documents. On-site visits may be conducted concurrently by the state and NCATE BOE or separately. Both the NCATE BOE and the state team visit the PEU, review evidence, interview stakeholders, and observe courses during the 
on-site visit. Near the end of the five-day on-site visit, the NCATE BOE co-chair compiles a report of on-site team responses to the six NCATE unit standards. Where applicable, the report also includes a State Addendum referencing responses to additional state requirements. The report is submitted to both onsite teams for review, modification, and approval. At the end of the on-site visit, an exit conference is conducted with on-site co-chairs, the state consultant, the unit head, the NCATE coordinator, and university president or provost. The purpose of this conference is for the on-site review team to provide a general overview of areas of compliance and non-compliance and discuss next steps.

The final report, approved by the NCATE BOE and state team, is submitted to the dean and NCATE coordinator of the PEU. The PEU then has 30 days to submit a rejoinder acknowledging receipt of the report and indicating to both NCATE and the state superintendent of education "whether the unit will comply with any recommendations contained in the report or withdraw the affected program" (ALSDE, 1988, p. 16). If the PUE chooses to comply with recommendations, a report (with evidence) of compliance is submitted to the NCATE BOE and state on-site review team.

Final decisions regarding accreditation of the teacher education program are determined by NCATE, and submitted to the U.S. Department of Education, the institution, and the PEU. Final decisions regarding compliance with state standards are determined by the state superintendent of education, and are based on the recommendation of the state review team. Once the state superintendent of education documents that all state standards have been met, he submits a 
"program approval resolution for adoption by the ASBE" (ALSDE, 1988, p. 17). Once the ASBE approves the program, the head of the PEU and the NCATE coordinator are informed of the decision. Programs that are awarded initial or continued state and NCATE accreditation may be accredited for five years. Conditional accreditation is granted for a period of two years. A PEU may be denied NCATE accreditation while also meeting all state requirements. In this case, "the state superintendent of education will decide whether or not to appoint a team to review the unit using all state college and university standards" (ALSDE, 1988, p. 18).

Alabama's role regarding quality standards setting and enforcement in SCDTEs is clear. The Alabama State Departments of Education:

- implements federal regulations for teacher quality in teacher preparation programs and local school districts;

- develops federally-compliant state standards that will govern teacher preparation and development;

- requires SCDTEs to implement standards in their professional education programs;

- requires SCDTEs to present evidence of standards implementation during a periodic program review process;

- reviews professional education programs for non-NCATE partner institutions

- partners with NCATE to review professional education programs in NCATE partner institutions; 
- evaluates whether programs are effective in meeting standards and policies;

- approves teacher preparation programs; and

- reports, to the United States Secretary of Education, USDE-defined indicators of teacher preparation and training.

Criticisms exist regarding the ability of state agencies to sufficiently and thoroughly review teacher preparation programs in a way that would yield valid and reliable data on the quality of programs and graduates. Research indicates that the state program-approval process is typically an assessment of course offerings rather than an evaluation of what teacher education candidates learn and can do (Darling-Hammond, 2001). The assumption is that the completion of state-mandated course offerings and field experiences "would be sufficient to produce competent practitioners" (Darling-Hammond, 2001, p. 752).

One of the main problems with the state approval process is that many state departments of education have inadequate human and fiscal resources to conduct intensive reviews that would enforce the implementation of standards (Darling-Hammond, 2001). The lack of resources results in infrequent, perfunctory visits that reveal "little about the quality of experience provided by the institution" (Darling-Hammond, 2001, p. 753). Another problem is the political nature inherent in the program review and evaluation process. Teacher education programs provide substantial revenue to universities, and produce large numbers of teachers for the equally large numbers of school districts in the state (Darling-Hammond, 2001). If programs are deemed weak, "political forces 
within the state make it difficult to close them down" (Darling-Hammond, 2001, p. 753). One other problem is the difficulty in assessing the influence of decisions and actions of a wide variety of policy actors — within and outside the state-on the policy enactment and implementation process at SCDTEs.

Policy implementation is more complex than simply checking whether programs are in mere technical compliance. Such reviews yield nothing about the functionality of policy given particular contexts, conditions, interactions, and consequences. To be sure, whether programs are in technical compliance or not, policy implementers' knowledge, values, beliefs, meaning-making, interpretations, negotiations, and actions determines what the policy becomes, not what is presented as evidence of compliance. What policy actors at the lowest level of enactment and implementation do with policies and standards is what is most influential to the quality of teaching and teachers.

Standards alone will not reform the quality of the teaching force. Superficial reviews of policy and standards implementation will not reform the quality of teachers and teaching. It is important to examine whether the enactment and implementation of quality standards is having the desired effect of "changing practices and enhancing knowledge across the profession" (DarlingHammond, 2001, p. 771). Investigations into what policy actors across multiple levels of the enactment and implementation process value, think, and do on a day-to day basis; how organizational and leadership structures promote and impede implementation; and how global, national, state, and institutional sociopolitical ideology ultimately influences values and actions throughout the policy 
process is necessary to achieve this end. An examination such as the one presented in this study, will yield insight into and set the foundation for determining whether there is a causal link between the enactment and implementation of quality standards and the outcome of highly qualified teachers.

Theoretical Framework

Literature and research that specifically addresses the implementation of standards of teacher in schools, colleges, and departments of teacher education (SCDTEs) is surprisingly limited, considering the importance of teacher inputs in determining teacher quality. The few SCDTE studies that have been conducted, as well as examinations into other public policy implementation processes provide some implications for examining the implementation of quality policy in a school of education. One study found a significant correlation between percentages of states with NCATE-accredited SCDTEs and the percentage of well-qualified teachers in the state (Darling-Hammond, 2000). This finding suggests that circumstances associated with implementing NCATE standards may be linked to the quality of teacher education graduates. However, this link must be examined further to determine which factors of the NCATE program accreditation process contribute to improving teacher quality (Wilson, Floden, Ferrini-Mundy, 2001).

Another study on the implementation of NCATE/NBPTS standards in teacher education master's degree programs found six barriers to implementation: isolation and lack of collegial culture, numbers over quality, status of the master's degree, structural barriers, conceptual barriers, and 
bureaucratic barriers (Blackwell \& Diez, 1999). Faculty members were resistant to collaborating to cohesively implement standards across the curriculum. Program administrators and faculty members "did not understand the larger principle of the point" of the National Board standards and processes (Blackwell \& Diez, 1999, p. 28), indicating a disconnection between policy intent and policyin-action. Lack of administrative support and barriers associated with university bureaucracy, such as curriculum approval processes and graduate school rules and regulations, were also hindrances to implementing new standards to redesign master's programs.

A program study in Wisconsin examined conflicts between the University of Wisconsin-Madison (UW-Madison) School of Education and the Wisconsin Department of Public Instruction (WDPI) over control of teacher preparation (Prestine, 1991). Prestine (1991) found certain internal institutional variables and external environmental factors influence the implementation of state policies at the teacher education school level. UW-Madison administrator's cultural belief in academic freedom and institutional autonomy led to an isolationist attitude and resistance to external demands by the WDPI. Any effort to communicate and coordinate policy implementation was made nearly impossible by the fact that too many faculty members (from the schools of education and liberal arts \& sciences) had voting privileges. As well, the decentralized organizational structure of UW-Madison hindered "any efforts of administrators to provide strong leadership or make authoritarian decisions" (Prestine, 1991, p. 261). 
Several external factors contributed to the conflict between UW-Madison School of Education and the Wisconsin Department of Public Instruction. Administrators at the WDPI and the elected state superintendent-all of which have statutory authority over UW-Madison School of Education-were operating under the national education crisis heralded by A Nation at Risk (NCEE, 1983), and thus were politically motivated to immediate and exact action to improve the quality of teachers and teaching. WDPI administrators coordinated a task force of powerful, influential state and local stakeholders tasked with the responsibility to improve teaching and teacher education under the direction of the WDPI. This created an atmosphere of "'all the education groups versus the university"' (Prestine, 1991, p. 263).

Finally, UW-Madison lacked external support from state legislators and University of Wisconsin System administrators. All such external factors played a significant role in UW-Madison School of Education's resistance to implementing state teacher education policies. Both the Wisconsin and NCATE/NBPTS studies show that factors such as state and institution power and governance; how actors make sense of, interpret, and apply policy; how actors communicate and interact with each other; and organizational structure all play significant roles in how policies are implemented in SCDTEs.

Other research on state implementation of federally-legislated policy provides further direction for the study of policy implementation. In a study of over two hundred educational innovations developed as a result of the 1965 Elementary and Secondary Education Act (ESEA), Berman and McLaughlin 
$(1976,1980)$ found that policy and institutional characteristics both influence the implementation of innovations. The institutional characteristics included the roles of leaders and administrators, the organizational climate, and the capacity and support of the school district. As well, the availability of resources and the level and scope of policy mandates are policy characteristics which affected implementation. Wetherly and Lipsky (1977) found similar results in their implementation study. Mainly, actions of the street-level-bureaucrats and the state educational system were critical components of implementation in their study. The degree of organizational support was found to have the most influence on the actions of end-users (Wetherly \& Lipsky, 1977).

Researchers from RAND Corporation found a great deal in variation in how states and local education agencies implement NCLB teacher education requirements (Birman, et al., 2007). The findings led researchers to question whether administrators across different states institute teacher quality standards that are sufficiently rigorous (Birman, et al., 2007). Other researchers found that while some states and school districts reported they are in full compliance with NCLB teacher quality requirements, some doubt they will ever be in full compliance with federal regulations (CEP, 2007). The findings from these studies indicate that states have governance over which standards are implemented, and that although federal legislation requires states implement certain requirements, they do not all do so to the same degree. Further, if there is variation in the degree to which states implement NCLB policy, there would appear to be variation in the way SCDTEs implement state policy. An 
understanding of the power structure (i.e., how the state understands federal mandates) is critical to understanding implementation at the next level down.

What is gleaned from a review of the limited research and literature is that certain internal and external factors influence how policy is implemented. Organizational structure, governance, and power; policy culture; and sensemaking, interpretations, and interactions of policy actors all play a significant role in understanding how policy moves from intention to implementation to outcomes. As the findings make clear, policy implementation unfolds through a process of mutual adaptation, when implementers attempt to meet the demands of the policy while operating under certain contexts and conditions (Strauss, 1978; Berman \& McLaughlin, 1976; McLaughlin, 2006). However, other policy implementation theories suggest policy processes are even more complex than the limited research has shown, and provides the best framework by which to examine the implementation of quality standards in SCDTEs.

Policy as the Transformation of Intentions: Context, Culture, Power, and Interactions

Both conventional and contemporary public policy implementation theories provide clear direction for establishing a hybrid framework by which to examine the implementation of quality standards in schools, colleges, and departments of teacher education (SCDTEs). Conventional theories view policy implementation one of two ways: from the lens of the policy maker or actual policy (i.e., topdown) (Pressman \& Wildavsky, 1973; Sabatier \& Mazmanian, 1983; VanMeter \& VanHorn, 1976) or from the point of view of the end-user, practitioner, or street- 
level bureaucrat (i.e., bottom-up) (Lipsky, 2010; Weatherly \& Lipsky, 1977; Berman, 1978; Elmore, 1979, 1983; Darling-Hammond, 1990). Newer theories suggest public policy implementation is contextual and involves a series of stakeholders' decisions and actions. As such, a comprehensive approach to studying policy implementation entails examining the influence of the various factors across multiple levels.

Policy implementation should be studied with regard to how policy issues are framed; power and governance; conventions; the point-of-view of policy makers; intentions; policy implementation actors' meaning-making, interpretations, negotiations, decisions, and actions; and the conditions, processes, and consequences across multiple implementation sites (Hall \& McGinty, 1997; Hall, 1995; Strauss, 1978; Yin, 1982; Honig, 2006; Yanow, 1987; Datnow, 2006; Hill, 2006; McLaughlin, 2006; Spillane, Reiser, \& Gomez, 2006). The outcome of any policy is based on interplay of all these factors. Whether policy is implemented as intended by policymakers matters less than the sensemaking, interpretations, decisions, interactions, and actions of the policy actors at each level and site of the implementation process, as the result of all such factors combined, in fact, becomes the policy.

Conventional Framework: Top-down and Bottom-up

Top-down policy implementation researchers seek to understand whether policy has been implemented as intended by policymakers by determining the extent to which practices and procedures of the end-user coincide with the original objectives of the policy (Pressman \& Wildavsky, 1973; Sabatier \& 
Mazmanian, 1983). Successful policy implementation, from the top-down perspective, occurs when policy actions closely align with policy intentions. Topdown theorists suggest additional factors which must be examined for policy implementation research to yield valid findings. VanMeter and VanHorn (1976) suggest implementation research examines the political, social and economic climate; policy enforcement and implementation procedures; level of support for the policy; and communications between stakeholders. Sabatier and Mazmanian (1983) suggest similar critical factors: (1) the level of support for the policy, (2) the level of cooperation between implementing agencies, (3) the social and political context in which the policy is to be implemented, (4) financial resources, and (5) the skills of the organization's leader, especially in organizations where resources are scarce and complex politics are at play (Bardach, 1977).

The critique of the top-down approach is that it assumes policy processes are a "set of segmented, separated, functionally sequential stages" (Hall \& McGinty, 1997, p. 439). This ideology makes implementation administrative, apolitical, and neutral in character. Top-down theorists view policy as a product of inputs without regard to policy actors' meaning-making, interpretation, actions, and group activity and interactions. Policy actors' motivations, the nature of activity and information, how and why things work as they do, sources of change, and the influence of power are not examined with top-down approaches (Stone, 2002).

Bottom-up theorists, on the other hand, account for all such factors. Bottom-up theory suggests that street-level-bureaucrats, those who actually 
implement policy, have a great deal of policymaking power and control (Lipsky, 2010). Wetherly and Lipsky (1977) argue that the street level is where implementation can best be examined and understood. Bottom-up theorists suggest that an examination of policy implementation at the street level must account for some of the same factors as the top-down approach: context, climate, organizational structure, stakeholder support and choice, resources and external factors over which the implementing institution has little or no control (Berman, 1978; Lipsky, 2010; Wetherly \& Lipsky, 1977). Bottom-up theorists also emphasize policy meaning-making and interpretation, interactions between policy actors, and conditions and events as factors influencing policy implementation.

Both the top-down and bottom-up approaches to studies of public policy implementation suggest that certain contextual and environmental factors influence policy implementation. Context-political, social, economic, and historical-is critical to understanding policy implementation from the top-down perspective. Organizational culture and structure are critical to understanding policy implementation from the bottom-up perspective. An understanding of attitudes and actions of individual stakeholders within and across organizations is also pertinent for a deep, comprehensive understanding of policy implementation. As such, a top-down approach should not be utilized in the absence of a bottom-up approach, and vice versa. However, both approaches to studying policy implementation limit the policy process to formulation and implementation (Hall \& McGinty, 1997). 
Contemporary Framework: Policy as the Transformation of Intentions

What is missing from a combined top-down and bottom-up approach is the ideology that policy implementation is not a rational process which occurs in sequential, separate and distinct stages (Hall \& McGinty, 1997; Yanow, 1987; Stone, 2002). The policy process is complex and dynamic, and occurs temporally, through phases from formulation to implementation, and spatially across multiple, linked sites (Hall and McGinty; 1997; Hall 1995). The interplay of factors such as the language used in framing policy issues; meaning-making, interpretations, and interactions between and among policy actors; historical, political and organizational context and culture; social conventions; power and governance; and linkages between bureaucratic and legislative sites affect how policy intentions are transformed into actions (Strauss, 1978; Yin, 1982; Honig, 2006; Yanow, 1987; Datnow, 2006; Hill, 2006; McLaughlin, 2006; Spillane, Reiser, \& Gomez, 2006; Hall \& McGinty, 1997; Hall, 1995; Groggin, Bowman, Lester, \& O'Toole, 1990). Additionally, all such factors collectively enable and constrain policy activities and ultimately determine how and why policy is implemented as it is (Hall \& McGinty, 1997; Hall, 1995; Spillane, Reiser, \& Gomez, 2006; Datnow, 2006).

No one factor operates exclusively from all other factors, as conventional policy implementation frameworks incorrectly assume. As the policy process moves, multiple actors enter the process at different points and commit decisions and actions that will ultimately influence the policy outcome. Each level and site of the policy process is interdependent and inextricably linked (Honig, 2006; Hall, 
1995; Hall \& McGinty, 1997; Spillane, Reiser, \& Gomez, 2006). The policy process is highly contingent upon the interplay of decisions and actions across multiple levels and is situated in a context of time and space (Honig, 2006; Hall \& McGinty, 1997).

Policy implementation takes place through interaction and socialization. Socialization can be best understood by examining human meaning, language, thought, and action (Blumer, 1969; Strauss, 1978). Blumer's (1969) principle of meaning is central to understanding human behavior as the process of policy implementation unfolds. People interact with other people and things (e.g., policy) based on the meaning they assign to those people and things. Thus, actors' implementation of policy depends on how they view and understand their roles, the roles of each other, their subordinates, and their supervisors, as well as the way they make sense of actual policy language and intentions. As the actors engage in discourse with themselves and other actors, and negotiate meaning about policies and practices, they will begin to develop their own understanding of what the policies mean and their role in implementing such policies (Blumer, 1969; Strauss, 1978; Berman, 1978; Matland, 1995). Investigating policy actors' meaning-making processes and understandings about their role and responsibilities will yield a clearer picture of what happens during policy implementation.

Policy processes are situated in a set of nested systems where the decisions and actions that occur within and across systems influence each other. SCDTEs are nested in larger universities. Universities are nested in state 
departments of education. State departments of education in conjunction with national and regional accreditation agencies, are nested in the U.S. Department of Education. Such nesting provides historical and current socio-political contexts in which a given policy issue is framed (Honig, 2006). The foundation of every legislative action is a perceived problem the policy is intended to rectify (Hall \& McGinty, 1997). The policy problem is borne out of socio-political culture and context.

Policymakers, when framing a problem, have particular motivations and intentions. Inherent in the framing of policy issues and the drafting of policy statements is the policymakers' values, beliefs, and intentions as well as their perspective and experience regarding the historical and current context which led to policy enactment. Instinctively, policymakers formulate policy with different values and intentions, make compromises with themselves and other policy actors to get policies passed, and collectively create policies with multiple and often ambiguous values and intentions (Rein, 1976). Policymakers' intentions are then transformed into language through the drafting of policies (Hill, 2006). The meanings or definitions of such policies are left to policy implementers at subsequent levels to interpret and negotiate using power dynamics unique to more local contexts (Rein, 1976; Hall \& McGinty, 1997; Hall, 1995).

Policy statements, whether clear or ambiguous, will then get reshaped, interpreted, and reinterpreted by a series of policy actors at multiple levels as each actor makes sense of the policy (Rein, 1976; Hill, 2006; Spillane, Reiser, \& Gomez, 2006; McLaughlin, 2006; Blumer; 1969). What the policy means to 
actors, individually and collectively, at various levels of the policy process is ultimately what the policy becomes. Meanings of policy language, then, vary just as much as the people who encounter the policy. This, in turn, leads to significant opportunities for policy variation and unintended consequences.

Teacher education policy moves from the top level of enactment (i.e., federal legislation) to the national and regional accreditation levels of enactment. Regional (and national) accreditation agencies are quasi-public entities whose policy actors are responsible for enforcing teacher education policies and legislation at the next levels down: the state and university levels. Policy actors at the accreditation level operate within the cultural and political structure of the organization, and under the purview of national and state law and policy. Their actions are grounded in their own beliefs and values as well as cultural norms of the organization. As national (i.e., NCATE) and regional accreditation agency (i.e., SACS) policy actors enforce policy, they interact with state policy actors. In many states, as such is the case with the State of Alabama, regional accreditation agencies partner with state departments of education to enact federal and state legislation and accreditation policy. Ultimately, though, national accreditation agencies have the power over the state to determine the national or regional credibility of state-governed teacher education programs, suggesting an interesting power position held by the national accreditation agency.

Policy actors' meaning-making, decisions, and actions at the state level are critical to understanding how policy is formed and transformed as the policy enactment process moves closer to implementation at the street level (Hall, 
1995; Hall \& McGinty, 1997; Lipsky, 1977; Lipsky, 2010). When policy actors at the state level encounter policy and interact with other policy actors, their prior knowledge, beliefs, and values come into play as they make sense of and interpret federal legislation and accreditation requirements to establish state-level policies. State policy actors, too, have particular motivations, responsibilities, intentions, and political cultures, which may or may not match those of federal-, national-, and regional-level policy actors. State policy actors operate under the historical and current socio-political conditions of their state. Their responsibility is defined in a state context, while national- and regional-level policy actors are responsible for a broader set of value-based outcomes of the nation and region, respectively. Clearly, policy actors' motivations and intentions at and between each level may indeed be in conflict.

The next layer is the university level. University administrators and other policy actors bring their personal values and beliefs to bear as they sort through their individual and collective responsibility to their governing bodies and the public. Universities have their own historical and current socio-political context and culture. The actions of university policy actors are guided by the cultural norms of the university, the way the make sense of and interpret policy, and the way they view their role in enforcing or implementing policy in the context of the university.

The final layer in the teacher education policy enactment and implementation process is the street level (i.e., the SCDTEs); the level at which the meaning-making, decisions, and actions of policy actors perhaps has the 
greatest influence on policy outcomes (Lipsky, 2010; Weatherly \& Lipsky, 1977; Berman, 1978; Elmore, 1979, 1983; Darling-Hammond, 1990). The practices of the actors charged with de facto implementation ultimately make the policy what it is; leading to the idea that what policy is depends on who is implementing it. Policy implementation actors at the SCDTE level operate under the historical and current socio-political and organizational contexts, conditions, and cultures of their own departments and colleges, as well as that of the university. As they make sense of and interpret policy, they also bring with them their previous knowledge, values, and beliefs about the world around them (Spillane, 2004; Spillane, Reiser, \& Gomez, 2006), thus providing yet another level of differing motivations and intentions.

It is erroneous to assume policy actors at the implementation level have the same understanding, interpretation, values, and intent as policy formulators; yet all actors across all levels shape policy processes, and ultimately, policy outcomes (Honig, 2006). Each interpretation and reinterpretation of policy yields a new and different understanding of the policy (Yanow, 1987), thus affecting how the policy will function in action. Multiple policy actors negotiate interpretations and intentions of policy under conditions of organizational constraints, policy ambiguity, and varying interests (McLaughlin, 2006). The more people involved in policy formulation and implementation, the greater the potential for varied meanings, interpretations, actions, and outcomes.

Policy implementation actors operate within a particular organizational culture. What individuals and groups think, value, believe, and do make up that 
culture and influence how policy will be implemented within the organization (Spillane, Reiser, \& Gomez). The culture of the organization informs the beliefs and actions of the actors, while the beliefs and actions of the actors simultaneously shapes the culture of the organization. To understand the role of organizational culture in implementation, investigators must examine how actors make sense of policy language and symbols, how implementation actors interpret and re-interpret policy activities, the role of persuasion and negotiation in creating and destructing shared meanings of policy, and the actions of individuals and groups (Yanow, 1987; Hill, 2006; Honig, 2006; Spillane, Reiser, \& Gomez, 2006).

Throughout the entire policy enactment process, power-social and political—shapes the way policy actors make sense of, interpret, negotiate, and act on policy (McLaughlin, 2006). Power, then becomes yet another essential characteristic to be examined when investigating policy implementation. The federal and state governments have the power to frame policy issues, legislate policy solutions, and distribute fiscal resources to implementing agencies. However, given that the policy process takes places within certain contextual and cultural parameters across multiple sites, policy outcomes are dependent upon the understandings, decisions, and actions of other groups, including, powerful street-level bureaucrats.

Accrediting agencies have the power to enforce education policy by determining whether universities, colleges, and departments will be publicly perceived as being quality educational institutions. Other external educational 
groups, like lobbying and policy agencies have the power to shape agendas regarding what is important in teacher education. As well, groups within organizations, like executive administrators at the university, school, and department levels have the power to influence institutional agendas, and distribute and redistribute human and fiscal resources. Just as influential, perhaps more so, is the power of individuals such as veteran professors-the real street-level bureaucrats-who often make their own decisions about what is reasonable, practical, and important, regardless of national, state, and accreditation policies and requirements.

\section{The Transformation of Policy Intentions Framework}

Although previous research on education policy implementation in SCDTEs identifies the various characteristics which influence policy implementation, research utilizing a more comprehensive approach to studying policy implementation is needed to better understand how teacher quality policy works at the street level. The basic problem with earlier studies is that the scope was narrowly focused on the interactions and activities that took place at one level, without much regard to how policy processes are multi-layered. Such studies did not examine the interplay of context, culture, power, and interactions within and across phases and sites of the policy process.

This research delves into the black box of conditions, processes, and consequences of the implementation of teacher quality policy at a school of education in order to bring the functions of teacher quality policy-in-action into clearer relief. The research will investigate the contextual, cultural, and 
organizational factors that shape, support, and impede implementation; and examine how stakeholders at multiple levels of the policy process put such policies into action by making sense of teacher quality policy through the negotiation of meaning with themselves and others. As such, the theoretical framework utilizes a hybrid approach for studying the implementation of teacher quality policy in SCDTEs.

Using aspects of the top-down approach, the research will examine policy intentions and the way teacher quality policy is framed by policymakers. This view will include an examination of the historical and current socio-political context of policy formulation, including ideology and legislation. Aspects of the bottom-up approach that will be employed in the study include an investigation into power and governance; SCDTE organizational culture and structure; and the motivations, intentions, meaning-making, interpretations, decisions, and actions of policy actors. The Transformation of Policy Intentions Framework provides the bulk of how the research is conceptualized, as this framework enables me to show: "(1) how policy is made after legislative enactment, (2) the consequential and conditional effects of policy activity at linked sites and phases of the policy process, and (3) the policy generative forces within and between policymaking sites and phases" (Hall \& McGinty, 1997, p. 441). Hall's (1995) Transformation of Policy Intentions Framework will be extended to include certain aspects of topdown and bottom-up theories to make up this hybrid model. Table 1 illustrates the theoretical framework and data analysis matrix. 
Table 1

The Transformation of Policy Intentions (TPI) Framework \& Data Analysis Matrix

\begin{tabular}{|c|c|c|c|}
\hline $\begin{array}{l}\text { National- } \\
\text { Federal }\end{array}$ & $\begin{array}{c}\text { National- } \\
\text { Accreditation }\end{array}$ & University & SCDTES \\
\hline $\begin{array}{c}\text { Linkages: } \\
\text { National to } \\
\text { Regional }\end{array}$ & $\begin{array}{c}\text { Linkages: } \\
\text { Regional to State }\end{array}$ & $\begin{array}{l}\text { Linkages: } \\
\text { State to University }\end{array}$ & $\begin{array}{l}\text { Linkages: } \\
\text { University to } \\
\text { SCDTEs }\end{array}$ \\
\hline
\end{tabular}

Conditions

Network of Collective

Activity

Tasks

Interests/Intentions/Motiv ation

Interactions

Conventions

Resources/Power/Gover nance
Historical and current socio-political, cultural, and economic factors, circumstances, and events that broadly influence or specifically lead to the presence of the action context; ways in which the policy issue is framed or the policy problem is defined

Interactional locus and the key actors

The work and outcomes to be accomplished

Preexistent or emergent aim of key actors on the implementation of quality policy

Meaning-making, interpretations, negotiations, decisions, and actions of policy by policy actors within and across policy implementation sites

Accepted ways of accomplishing implementation activities

Advantages and means actors use to achieve their intentions collectively or against each other 
Contingencies/Opportunit Unexpected or unusual elements that grow out of or influence the ies implementation process

Consequences Content manifestations of collective activity or processually-derived implications Linkages: Formal and informal ties that constitute conditions for linkage, the patterns and specifics of collective activity that activate the linkage, and the consequences that are conveyed as conditions between sites

Note: Adapted from Peter Hall's (1995) Transformation of Policy Intentions Framework. 
A hybrid approach is supported by policy implementation theorists who argue that "policy implementation is a multi-layered policy phenomenon and each layer or level acts on the policy as it interprets intentions, resources, and regulatory frameworks" (McLaughlin, 2006, p. 212; Yin, 1982; Honig, 2006; Yanow, 1987; Datnow, 2006; Hill, 2006; Spillane, Reiser, \& Gomez, 2006; Hall \& McGinty, 1997; Hall, 1995; Groggin, Bowman, Lester, \& O’Toole, 1990). Teacher quality standards are implemented in a socio-political context rife with accountability initiatives, federal regulations, and political ideologies. The fact that state departments of education have set teacher quality standards that align with federal mandates, and SCDTEs have developed systems to link teacher inputs to student outputs points to the inherent link between environmental pressures and organizational response. The seemingly equal power positions of the state and national accrediting agencies in determining the quality and worth of SCDTEs provides more insight into the accountability context.

The Transformation of Policy Intentions Framework (Hall, 1995) is built on the notion that context, culture, power, and meaning-making, interpretations, negotiations, decisions and actions of policy actors across multiple sites either supports or impedes the teacher quality policy process as it moves from formulation to action. This framework assumes the confluence of all such factors in determining policy outcomes. In particular, conditions, processes, and consequences are situated in policy actors' interactions, which are situated in power and governance structures, which are situated in individual, group, and 
organizational culture, which are situated in historical and current socio-political contexts.

Utilizing the adapted Transformation of Policy Intentions Framework (Hall, 1995), this study is a comprehensive examination of how teacher quality policy moves from legislation at the national and state level to implementation at the university and SCDTE level. This study illuminates the various aspects that influence how policy functions in action, from the socio-political ideology which influence policy actors' thoughts and actions, to how policy issues are framed, to how policy actors across multiple sites make sense of, interpret, and act on policy initiatives. Special attention was paid to the ways in which teacher quality policy processes are situated in context, culture, and power structures and how such situations determine the way actors at a faith-based school of education in the State of Alabama implement teacher quality standards and policy. By understanding the conditions, processes, and consequences under which teacher quality standards are implemented, policymakers will gain insight into why policies succeed or fail. This investigation was guided by the following research questions.

\section{Guiding Research Questions}

1. What are the historical and current socio-political, cultural, and economic conditions and contexts under which policy actors implement quality standards in teacher preparation programs? 
2. How do conditions such as federal and state policy context influence the sense-making, interpretation, and policy activity of actors in teacher preparation programs as they implement teacher quality standards?

3. What are the processes through which policy actors in teacher preparation programs interpret and implement quality standards?

4. What are the consequences of policy actors' interpretations, negotiations, and actions as they relate to the implementation of quality standards?

5. What are the outcomes of the implementation of quality standards in teacher preparation? 


\section{CHAPTER III \\ METHODOLOGY \\ Research Design and Rationale}

This multi-level case study examined, in depth, how policy actors at a private, faith-based, traditional school of education in the State of Alabama interpreted, made sense of, and implemented federal, state, and institutional standards and policies related to teacher quality and teacher training. Because the focus of this study is on the meaning of actions of policy actors at each level of the policy system, an interpretive qualitative implementation case study design (Yin, 1982) and critical policy analysis element was employed to build an explanation of the implementation of quality standards in real-life context. The aim of interpretive research is to investigate phenomena through assessing meanings actors assign to their experiences. The emphasis is on actors' subjective consciousness of reality (Burrell \& Morgan, 1979). According to this paradigm the social world is an interpreted world, and objective reality does not exist in the same fashion as one would find in the study of physical or natural phenomena; therefore such reality cannot be discovered or replicated by researchers.

The interpretivist qualitative paradigm assumes relativist ontology and subjectivist epistemology (Burrell \& Morgan, 1979). The ontological assumption is that reality is subjectively constructed through social meanings, 
understandings, and experiences of multiple actors, and in this case, across multiple levels. According to Burrell and Morgan

The social world is no more than the subjective construction of individual human beings who, through the development and use of common language and the interaction of everyday life, may create and sustain a social world of intersubjectively shared meaning. (1979, p. 260)

The epistemological and methodological assumptions are that the knower and what is to be known cannot be separated. What is to be known is exclusive to the actors directly involved in the interactions and activities (Burrell \& Morgan, 1979). Since each person constructs his own reality, the only way to understand social processes is to delve deeply into the world of those constructing their reality. Thus, the investigator obtained first-hand knowledge and analysis of the subjective experiences of actors' meaning-making associated with the implementation of teacher quality policy and standards in the context of a traditional school of education. Additionally, the researcher's values, beliefs, experiences, and understandings related to teacher quality policy and teacher preparation were inherent in all phases of the research.

The multi-level implementation case study provides the best method for examining the implementation of quality standards at a school of education because it allows for a rich examination of implementation at one level (the school of education) as it is contextually situated or nested in other levels: the institution, the state, and the nation (Yin, 1982, 2009; Creswell, 1998; Stake, 
1995; Miles \& Huberman, 1994). In addition, implementation studies involve several key parameters, all of which are relevant to this study:

- "A series of decisions that occur over a long period of time, with no clear beginning or end point;

- Outcomes whose direct and indirect implications are too complex for single-factor theories;

- A large number of relevant participants; and

- Situations that are rather special in terms of agency context, historical moment in time, and other key elements." (Greenberg et al., 1977 as cited in Yin, 1982, p. 37)

Rather than examining implementation of standards overall, this case study was limited in scope to one teacher certification program in one state to focus on the depth of policy implementation. The Elementary and Collaborative Education Program was the focus of the implementation investigation because elementary education has been the area most impacted by NCLB. Elementary education teachers are at the center of education reform because of research and public perceptions that knowledge acquisition begins early in a child's development. A private, faith-based teacher education school located in the State of Alabama was the subject of this investigation. The research methodology processes of Yin's $(1982,2009)$ Four-Stage Case Study, Hall's (1995) Transformation of Policy Intentions Framework, and Baltodano's (2012) critical policy analysis approach we utilized in gathering, sorting, analyzing, and drawing conclusions from research data. 


\section{Research Methodology \\ Design of the Single-Case Study Protocol}

Designing the case study protocol was two-pronged: establishing the qualifications of the researcher and establishing the case study protocol (Yin, 1982, 2009). Yin (2009) presents three conditions for the design of case studies:

(1) the type of research questions, (2) the extent of control an investigator has over behavioral events, and (3) the degree of focus on contemporary events. The research questions are used to justify the type of case study utilized. The conditions, processes, and consequences questions justify the use of interpretive qualitative implementation design (Hall, 1996). The who, what, and how subquestions justify a descriptive case study method. The investigator had no control over the behavioral events that took place within school of education. Although archival evidence was used in describing conditions and contexts of the case, contemporary events were, too, examined.

Researcher as Instrument

Yin $(1982,2009)$ suggests a qualified case study investigator should be able to ask good questions and accurately interpret responses, be a good listener, be adaptive and flexible, have a firm grasp of the issues, and be unbiased to preconceived notions. The case study investigator has had over eight years experience conducting observations, interviews and focus groups in qualitative research. This experience requires that the investigator be a good questioner, good listener, and an accurate interpreter of responses. Conducting qualitative research also requires the investigator to be adaptive and flexible. 
The investigator's former experiences conducting qualitative research in K-12 and postsecondary schools, institutions which functions are inherently unpredictable, confirm these qualifications. The researcher has a firm grasp of the issues under study. The researcher's former experience as Director of Assessment at a teacher education school in Alabama enabled me to become well-versed in processes, operations, and policy implementation processes at teacher education schools in the State of Alabama. Additionally, the investigator has spent three years conducting research, reviewing research, and developing national teacher quality standards while working as a writing group member and policy developer for Council of Chief State School Officers (CCSSO) (2011) revision of Interstate Teacher Assessment and Consortium (InTASC) standards.

The researcher's previous experiences as an administrator preparing for and working through the National Council for the Accreditation of Teacher Education (NCATE) unit and program accreditation process, and more recent experiences drafting national standards of teacher quality, have led to a desire to understand better the mismatch observed between literature on the implementation of education policy and what has been witnessed in practice. Much of the policy implementation literature presents policy implementation through stage theory, or the idea that policy implementation occurs in separate and distinct phases which do not overlap and inform other stages.

Such literature also misses the human interaction and socialization aspect of policy implementation. The implementation of policy is much more complex. Policy enactment and implementation is multi-layered; is nested in various 
contexts; and is ultimately determined by the values, understandings, and actions of policy actors within and across multiple levels of the policy process. What people think and do, how they act individually and collectively, and how they make sense of and interpret policy mandates inform what policies become in practice. Additionally, socio-political global-, national-, and state-level cultural contexts greatly influence the way policy actors create or reestablish their values. This, in turn, influences their understandings and actions.

The strength of case study methodology is that it allows the researcher to provide a holistic view of a phenomenon under study (Yin, 1982, 2009; Patton, 2002). Case studies provide an analysis of a phenomenon in its real-life context and facilitate rich, theoretical development about the particular phenomenon (Yin, 1982, 2009; Stake, 1995; Miles \& Huberman, 1994). Case studies can also serve as a precursor to establishing causal relationships by illuminating the ways in which certain factors are related to each other. To accurately examine whether teacher quality standards lead to better quality teachers, an examination of what constitutes implementation and the extent to which standards are implemented must be conducted first. The use of case studies enables the researcher to deeply examine and focus on the significance of a particular phenomenon (Patton, 2002; Creswell, 1998; Miles \& Huberman, 1994).

The limitations of case studies are that they lack statistical generalizability (Yin, 1982, 2009). The case study is a descriptive methodology, where cause and effect relationships can only be drawn theoretically. The nature of this case study is to describe how policy actors at a private, faith-based school of 
education in the State of Alabama implement quality standards; and to develop a theory of quality standards and policy implementation.

\section{Case Study Protocol}

\section{Overview of the Study}

This study examined the implementation of teacher quality standards and policies by administrators and faculty at a private, faith-based school of education in the State of Alabama. The school site was chosen based on location proximity and convenience. The goal of the study was to understand how policy actors in the Elementary and Collaborative Education Teacher Preparation and Certification Program conceptualized teacher quality and implemented standards and policies of teacher quality under particular national-, state-, and institutionlevel conditions. The unit of analysis was the Elementary and Collaborative Education Program situated in the school of education, and more specifically, the interpretations of policy actors that engaged with teacher quality standards and policy. An interpretive qualitative and critical policy implementation case study design was utilized for this study.

\section{Case Selection}

One teacher education program was selected for the implementation single-case study. The institutions' Elementary and Collaborative Education Program (ECEP) was the focus of this policy implementation investigation. The case was chosen based on location convenience and access to people and data. The private, faith-based school of education is located in the State of Alabama. The institution serves predominantly Anglo students. The median socio- 
economic status of the parents of the student population is between $\$ 100,000$ and $\$ 150,000$. There are approximately 40 faculty members in the school of education. There are less than 100 students in the early childhood and elementary education programs, and combined ECEP.

The school of education had been accredited by an external teacher education accreditation body, NCATE, and was up for reaccreditation seven months following the end of the study. The institution was selected because it is an NCATE-accredited institution and policy actors were engaged in implementing NCATE standards and Alabama Teacher Quality Standards.

The institution is similar to other private teacher education institutions that are members of NCATE, as they are required to implement and show documentation of NCATE implementation to achieve NCATE accreditation. This institution is also similar to other teacher preparation institutions in the state because the Alabama State Department of Education requires all teacher preparation institutions to abide by the same legislation and policies. However, this institution may be different than other private and public institutions in the state because it has implemented program entrance and completion requirements above what is required by state law.

\section{Access}

To gain access to the school of education/institution site, the Dean was contacted via email. The initial contact explained the study, the purpose and goals of the study, and how the results of the study will contribute to a better understanding of the link between policy intentions and policy-in-action. Once 
the Dean agreed to participate in the study, other administrators, faculty, and teacher candidates were contacted and invited to participate in the study. Participant Sample Selection

Participants were selected at each level—national, state, and institutionof the teacher quality policy enactment and implementation process. There was one participant at the federal-national level. He is a senior policy advisor at the United States Department of Education. After submitting a request to the United States Secretary of Education, Arne Duncan, the investigator was referred to a senior policy advisor to be interviewed in Secretary Duncan's stead. Data was also gathered through documents relevant to this analysis. One participant served as an informant for three levels, national-NCATE, state, and other institution-level. This participant serves on the National Board of Examiners for NCATE, has served on numerous boards involved in developing teacher quality standards and policies at the state level, and is also a Certification Officer at a public teacher education institution in the State of Alabama. Although his institution is not a unit of study for this research, his discussions about policy actions at his institution informed the research. Documents were also used to supplement data collection at this level.

There were three state-level participants selected because of their activity in the field of teacher quality: an executive in the Alabama State Department of Education (ALSDE) Office of Teaching and Leading —-the office responsible for teacher preparation, certification, and development in the state; an executive in the ALSDE Office of Research and Development-the office responsible for 
restructuring the state data systems around teacher quality and student achievement; and a legislative liaison whose responsibilities include legislative analysis and development associated with teacher quality and development.

Finally, ten participants were selected at the school of education/program level: the Dean of the School of Education; the Director of Teacher Education/de facto NCATE Coordinator, who also serves as the de facto NCATE Coordinator; the Director of Field and Clinical Experiences; the mathematics methods professor; and the English/language arts methods professor. The Dean of the School of Education was selected because he is the ultimate policy actor responsible for the implementation of teacher quality standards at the institution. The Director of Teacher Education/de factor NCATE Coordinator was selected because she is a top administrator responsible for the implementation of national and state teacher quality standards at the institution. The Director of Field and Clinical Experiences was selected because she is responsible for ensuring the implementation of national and state teacher quality standards in pre-service teaching practice. The mathematics and English/language arts methods professors were selected because of the recent and current national and state teaching and learning accountability focus on reading/language arts and mathematics (NCLB, 2001).

Five teacher candidates who were enrolled in the Elementary \& Collaborative Teacher Education Program were also selected to participate in the study. A list of all participants by pseudonym and position is presented in Appendix A. The teacher candidates were selected for this study because they 
are the lowest-level policy actors. They are the policy actors who a required to know, understand, and be able to act on the standards that guide their education and career. An understanding of their knowledge, interpretations, and actions related to teacher quality standards allowed for a more comprehensive examination of teacher quality policy implementation.

\section{Data Collection}

The principles of data collection suggested by Yin $(1982,2009)$ were adhered to: the use of multiple data sources, creation of a case study database, and chain of evidence. Data collection took place in phases and lasted from February through May. Sources of evidence included semi-structured formal interviews with policy actors at each level of the policy enactment and implementation process; informal interviews with policy actors at the teacher education school; a focus group with teacher education candidates; observations of interactions at the state- and teacher education school-levels; and a review of documents, artifacts, and archival records.

Unstructured, informal discussions and observations have been noted by Yin (1982) as "critical [to]...the ultimate formulation of conclusions" (p. 44) in policy implementation studies, as critical facts and opinions about processes and sense-making are often derived. Data from observation and document reviews were used to complement semi-structured interviews, and vice versa (Yin, 1982). Documents, reports, artifacts, and archival records were reviewed throughout the data collection process. Documents were reviewed for what they revealed about the implementation process in terms of "decisions, meetings, publicly stated 
priorities or positions, or other public actions" (Yin, 1982, p.47). The following is a detailed explanation of the phases of data collection.

\section{Documents Review}

Documents for review were collected at each level of the policy enactment and implementation process. A critical textual analysis of documents took place as data were collected and reviewed. They include:

1. Review of federal legislation: Elementary and Secondary Schools Act (ESEA) (2007), Section 9401 of the Elementary and Secondary Schools Act (ESEA) (2007), Title II of the Higher Education Opportunity Act, Section 207 of the Higher Education Act (2007), Goals 2000: Educate America Act (1993), No Child Left Behind Act (NCLB) (2001), Elementary and Secondary Schools Act (ESEA) Reauthorization: A Blueprint for Reform (2010), NCLB Waivers;

2. Review of state legislation: State of Alabama NCLB Compliance Regulations, State of Virginia NCLB Compliance Regulations, Title 16 of the Code of Alabama, Chapter 290-3-3 of the Alabama Administrative Procedures Act, Alabama Plan 2020, Resolution in Support of Charter School Legislation in Alabama, Alabama Education Improvement Act (1991), Alabama School Flexibility Act (2012), Alabama Education Option Act (2012);

3. Critical textual analysis of national-level public policy documents: The Coleman Report: Equity and Achievement in Education, A Nation at Risk: the Imperative for Education Reform, Holmes Group Report: Tomorrow's 
Schools, What Matters Most: Teaching for America's Future, Race to the Top (RTTT) (2009), Teacher Quality Partnership Grant Program (Teach Grant), Our Future, Our Teachers: the Obama Administration's Plan for Teacher Education Reform and Improvement (2011b), National Board of Professional Teaching Standards (2002), NCATE Standards (2008), NCATE Blue Ribbon Panel Report (2010), Interstate New Teacher Assessment and Support Consortium Model Core Teaching Standards (INTASC, 1992), Interstate Teacher Assessment and Support Consortium A Resource for State Dialogue: A Resource for State Dialogue (InTASC, 2011);

4. Critical textual analysis of state-level public policy documents: Alabama Teacher Quality Standards (AQTS), The Alabama Continuum for Teacher Development (Continuum), Governor's Commission on Teacher Quality: Initial Report (2006), Teacher and Learning: Meeting the Challenge of High Standards (2000), EDUCATE Alabama;

5. Critical analysis of speeches: President Barack Obama, United States Secretary of Education Arne Duncan, Alabama Governor Robert Bentley, and Superintendent of Education Tommy Bice;

6. Textual analysis of national and State of Alabama digital print media related to teacher quality;

7. Textual analysis of institution-level documents: syllabi, accreditation documentation, faculty and committee meeting agendas, certification requirements, field and clinical handbook, teacher education handbook, 
teacher testing data and information, teacher candidate work samples, and curriculum and program forms; and

8. Field notes of institutional practices.

\section{Formal and Informal Interviews}

One-on-one, in-depth interviews with participants at each level of the policy enactment and implementation process, except the teacher candidates, were conducted. The teacher candidates participated in a focus group. After purposefully selecting interview participants based on their job description and relevance in the policy implementation spectrum, each participant was contacted via email to request their participation.

Formal, semi-structured interviews took place during and after the documents review and observations. Informal interviews took place throughout the data collection period. Informal interviews took place at the teacher education program level, only. The investigator spent one week in Montgomery, Alabama conducting interviews with policy actors at the Alabama State Department of Education. The investigator visited Washington, DC to conduct an interview with a senior policy advisor in the United States Department of Education. Interviews with teacher education program-level policy actors were conducted at the teacher education institution and at the P-12 partnership school site.

Each formal, semi-structured interview lasted thirty minutes to two hours. The variance in the interview time depended on the time it took to ask all initial and follow-up questions. The questions for the semi-structured interviews are 
provided in Appendix C. Components of the Transformation of Policy Intentions (TPI) Framework and information from relevant documents were used to develop interview questions. During each interview, participants were probed for understanding and clarification. Interviews were recorded via digital recording devise. Each interview was transcribed and analyzed by the researcher within two days of completing the interview. Follow-up interviews took place via email, where specific follow-up questions were sent to some participants in an effort to ask questions that were missed or to gain clarification on things that were discussed.

\section{Federal Level Interview}

One interview was conducted with one policy actor at the federal level. The interview was conducted with a senior policy advisor at the United States Department of Education. He was interviewed to provide insight into the formulation and enactment of teacher quality standards at the federal level, the meaning of the standards for state-level implementation, and the expectations of federal level policy actors for state-level implementation.

\section{National Accreditation and State Level Interviews}

An interview was conducted with one policy actor at the national accreditation level. The interview was conducted with a member of the NCATE National Board of Examiners. He was interviewed to provide insight into the formulation and enactment of NCATE accreditation standards for teacher quality, and implications for state- and teacher education program-level implementation. State Level Interviews 
Interviews were conducted with four state-level policy actors. One policy actor is a member of the NCATE State Board of Examiners and a member of the Alabama Governor's Commission on Teacher Quality (GCTQ). He was interviewed to provide insight into how state levels policy actors interpret, act on, and implement NCATE policies and standards. He was also interviewed for his insight into the process of formulating and enacting state teacher quality policies. The other three policy actors were personnel at the Alabama State Department of Education. A legislative liaison was interviewed for her insight into how state laws are formulated, how state law becomes policy, and how the state establishes and communicates expectations to lower-level policy implementers.

An executive in the Office of Research and Development was interviewed for his insight into how teacher quality policy and standards are formulated, enacted, and communicated to lower-level policy implementers. An executive with the Office of Teaching and Leading was interviewed to provide insight into teacher quality policy formulation and enactment at the state level; the influence of federal policy, national education standards, and accreditation standards on implementation at the state level; and implications and expectations for teacher

education-level implementation. All state-level policy actors also provided insight into processes associated with interpreting and implementing federal laws and national policies on teacher quality.

Teacher Education Level Interviews

Six interviews were conducted at the teacher education level. An interview was conducted with a teacher certification officer at a public institution 
in Alabama. This institution was not the institution under study. The interview was conducted to provide additional insight into processes associated with interpretation, action, and implementation of federal, national, and state laws, policies, and standards of teacher quality at the teacher education level. The other five teacher education level policy actors served in positions at the case study site. The Dean and the Director Teacher Education/de factor NCATE Coordinator were interviewed to provide insight into how teacher education-level executives interpret, act on, and implement federal, national, and state laws, policies, and standards of teacher quality.

The Director of Field and Clinical Experiences was interviewed to provide insight into how federal, national, and state laws, policies, and standards are translated into practice during field and clinical experiences. Two professors were also interviewed: an English/language arts methods professor and a mathematics methods professor. They were both interviewed because they were responsible for implementing federal, national, and state laws, policies, and standards of teacher quality in methods courses. The Director of Field and Clinical Experiences and the two methods professors were also responsible for implementing a new field and clinical experiences model. As such, they provided insight into interpretations, actions, and implementation associated with the new model.

\section{Focus Group}

A one-hour focus group with five teacher candidates at the teacher education school was conducted. For the purpose of sampling teacher 
candidates, a listing of all current Elementary \& Collaborative Teacher Education students was requested from the office of the Director of Teacher Education/de facto NCATE Coordinator. Five to seven teacher candidates were randomly selected from the list. Each teacher candidate was emailed to request their participation in the study. The first five teacher candidates who responded affirmatively were selected for the focus group. All five teacher candidates had been formally admitted into the Elementary \& Collaborative Education Program. One teacher candidate was in her student teaching semester, and the other four were between two and three semesters before their student teaching semester. The focus group was recorded via digital audio device. The focus group was transcribed and analyzed by the researcher within two days of completing the focus group.

Teacher education candidates were selected for interviews to provide insight into their knowledge and expectations regarding federal, national, and state law, policy, and standards. The questions for the focus group are provided in Appendix C. Throughout the focus group candidates were probed for understanding and clarification. Components of the Transformation of Policy Intentions (TPI) Framework and information from documents and observations were used to develop interview questions.

Formal and Informal Observations

Observations took place from February through April. Observations were conducted on- site at the school of education, off-sight at the P-12 partnership elementary school, and off-sight at the ALACTE meeting. Fifteen formal 
observations and 11 informal observations at the school of education were conducted, for a total of 29 hours of observations. During observations at the school of education, the investigator travelled the halls of the first two floors, and retired to a couch on the third floor to take notes and observe one-on-one and group interactions. Four formal observations at the $\mathrm{P}-12$ partnership elementary school were conducted. During observations at the P-12 partnership school, the investigator went to the classrooms where either English/language arts or mathematics methods were taught. The investigator sat in the back of the classroom and took notes on one-on-one and group interactions between the professor and teacher candidates. Two formal observations were conducted at the ALACATE meeting. The investigator visited the campus of the university where the meeting was being held, sat in the audience, and audio-recorded and took notes on the presentations. Components of the Transformation of Policy Intentions (TPI) Framework and information from documents and interviews were used to develop the observation protocols. The observation protocols used to guide note taking is provided in Appendix B.

The school of education was visited one or two days each week to observe in meetings, review data, and conduct interviews. Four half-days were spent observing at the elementary school. The mathematics and English/language arts methods courses were observed two times each. Teacher candidate student teaching and observation activities at the elementary school were observed on three occasions. On two occasions, the investigator accompanied the Director of Teacher Education/de facto NCATE Coordinator 
when she went to evaluate candidates' student teaching. The investigator spent two days in Montgomery, Alabama observing at the ALACTE annual meeting of teacher education school deans and administrators. The purpose of the meeting was for teacher education school deans and administrators from across the State of Alabama to discuss state review and accreditation processes.

Observations of courses and meetings took place during the documents and archival records review. The mathematics methods course and the English/language arts methods course were observed twice each. Both courses were conducted at the P-12 partnership school, Central Elementary (pseudonym). Both courses were purposefully selected because they are courses where standards were or should be linked to objectives and outcomes. Three NCATE accreditation meetings at the school of education were observed. An observation took place at the annual state-level accreditation organization meeting, Alabama Association of Colleges of Teacher Education (ALACTE). Anecdotal notes on actions, interactions, and processes related to teacher quality standards and policy implementation were taken for each observation. Field notes were recorded in a notebook and on a laptop. Write-ups of field notes were produced. Inferences were added as field notes were recorded. This produced over 200 pages of observational data.

\section{Data Analysis}

As data were collected they were analyzed and organized into a case record (Patton, 2002; Miles \& Huberman, 1994). Multiple sources of data were analyzed to triangulate the evidence and enhance reliability. Raw case 
information was edited, redundancies were removed, and the case record was topically and chronologically organized to make data more readily accessible for the final case analysis (Patton, 2002). To further enhance reliability, a chain of evidence was established which linked the raw data sources to the case record, and ultimately to the conclusions (Yin, 1982, 2009; Miles \& Huberman, 1994).

Data were analyzed in stages: pre-analysis, piecing together facts, linking implementation experiences across levels, testing alternative explanations, and explanation construction and testing (Yin, 1982). During the pre-analysis phase, preliminary data analysis and data collection occurred simultaneously, where the researcher, made "on-the-spot" judgments about which data would be included as evidence and which data would be ignored (Yin, 1982, p. 52). Decisions during the pre-analysis phase was made based on whether key concepts could be operationalized, "the depth and detail for pursuing a line of inquiry", and the evolution of themes and categories (Yin, 1982, p. 53).

\section{Conceptual Framework}

Mesodomain analysis (MA) was the data analysis technique executed to build a theory of teacher quality policy enactment and implementation processes at a private, faith-based school of education. Components of mesodomain analysis described by Hall (1995, p. 399):

1. MA systematically attends to "intersections of social action, history, and structure."

2. MA explores how past and current social conditions shape the action context. 
3. MA transforms contexts into "linkages between sites and times."

4. MA "demonstrates how collective activity is dialectically connected to its local contexts and the conditional interpenetration of structure and history. Within these active influences, collective activity is accomplished by utilization of conventions/practices and resources/power in potentially contingent ways."

5. MA "examines how actors make relevant for themselves structural and historical context in the constitution of collective activity."

6. The focus of MA is on "the network of linked sites that constitute historical, structural, and action contexts," and "clarifies how social organization emerges from collective activity/social action, how it extends across space and time, and how the units and levels fit together."

As policy implementation involves contextual, conditional, and consequential ongoing processes of sense making, interpretations, decisions, and actions by various policy actors across multiple sites, Hall's (1995) Transformation of Policy Intentions (TPI) Framework was used as a guide in determining which data was relevant. Data related to "organizational context and conventions," linkages between levels and phases of the implementation process, resource mobilization, and the "conceptualization of power" were deemed relevant evidence in elucidating how teacher quality standards and policies are transformed into practice at a private, faith-based school of education in the State of Alabama (Hall \& McGinty, 1997, p. 439). 
The elements of the TPI framework presented in Chapter 2 serve as the structure for the types of data that were analyzed. These include evidence that illuminates the following areas within the site and across levels:

- Conditions;

- Network of Collective Activity;

- Tasks;

- Interests/Intentions/Motivation;

- Interactions;

- Conventions;

- Resources/Power/Governance;

- Contingencies/Opportunities;

- Consequences; and

- Linkages.

Data from multiple sources was aggregated, synthesized, and merged to construct a comprehensive picture of the case study and the multiple levels that inform policy processes at the case level (Yin, 1982). All data sources were analyzed for emerging patterns, themes, categories, and meaning-making as it related to the guiding research questions. Facts about the case were organized topically and chronologically into a conceptually-clustered conditional matrix (Miles \& Huberman, 1994; Yin, 1982; Hall, 1995), titled the Transformation of Policy Intentions Framework and Data Analysis Matrix (as presented on p. 63). The matrix allowed data to be clustered by concept/theme across levels for easier manageability and visualization. 
This process also enhanced generalizability and deepened understanding about the particular phenomenon under study (Miles \& Huberman, 1994; Yin, 1982). Formulating the conceptually-clustered conditional matrix also allowed me to establish profiles of informants, data sources, and levels; provided "an initial test of the relationship between responses to the different questions" (Miles \& Huberman, 1994, p. 129), and made linkages between actions and levels easier to determine. A summary of findings that align with elements of the TPI Framework across levels is provided in Chapter V.

Develop Conclusions, Implications, and Recommendations

The final stage of the case study process involved "explaining why implementation occurred as it did" (Yin, 1982, p. 57). This was done through a thorough, rich descriptive writing of the final case study narrative (Yin, 1982, 2009; Patton, 2002), where causal links between raw data and conclusions are put forth assisted by categories of the TPI Framework. Conclusions were drawn from multiple sources of evidence and used to describe the implementation of quality standards in the real-life context of the school of education, and to establish a theory of quality standards and policy implementation (Yin, 1982). Meaning was generated through building a logical chain of evidence, noting and matching patterns and themes, establishing plausibility, examining the nested levels for deeper understanding, and getting feedback from informants across each level (Yin, 2009; Miles \& Huberman, 1994; Yin, 1982). Findings were confirmed through data triangulation, making meaning out of unusual findings, and replicating findings within the case, across data sources, and across levels (Miles \& Huberman, 1994). 
Validity and Transferability

A thick, detailed description of methodological processes, choices, and findings are presented so that readers may determine the coherence transferability of the case results (Yin, 1982, 2009, Patton, 2002; Creswell, 1998; Miles \& Huberman, 1994). Both internal and external validity/credibility was established through the logical chain of evidence; data triangulation; patternmatching within the case, and across levels and sources; and feedback from informants for verification of conclusions (Yin, 1982, 2009, Patton, 2002; Creswell, 1998; Miles \& Huberman, 1994). Establishing a statistical causal relationship was not the intention of this research. However, theoretical casual linkages are made.

The issue of generalizability relates to extent to which the findings can be used to apply to other teacher education institutions, both public and private. Although some findings are supported by discussions with a key policy actor at another Alabama institution that was not the unit of study, generalizability is beyond the scope of this research. The description of the context and the use of rich, thick description allow readers to make judgments about the transferability of the lessons learned in this case to other cases, depending on context. The researcher's perspective is stated in the Researcher as Instrument statement (see Research Methodology) so that consumers may judge the objectivity of the research.

Chapter IV is a presentation of findings. Findings are organized by levels of the policy enactment and implementation process and linkages across levels. 
Applications of the findings to the greater teacher education policy world are addressed in Chapter V. 


\section{CHAPTER IV}

\section{FINDINGS}

The Multi-Level Teacher Quality Policy Enactment and Implementation Process

The transformation of legislative intentions takes place through interaction and socialization of policy actors within and across multiple levels of the policy enactment and implementation process. The policy process is highly contingent upon the interplay of decisions and actions across nested systems, time, and space. Each level and site of the policy process is interdependent and inextricably linked (Honig, 2006; Hall, 1995; Hall \& McGinty, 1997; Spillane, Reiser, \& Gomez, 2006). Schools of education are nested in larger universities. Universities are nested in state departments of education and national and regional accreditation agencies. All levels thereof are nested in the United States Department of Education (USDE). Such nesting provides historical and current socio-political conditions under which policy issues are framed and enacted (Honig, 2006).

This is a case of the influence of neoliberal ideologies on the transformation of teacher quality standards and the consequences for teacher education. It examines how neoliberal influences shaped the thinking and actions taken by policy makers at the federal, regional and state levels and how those processes shaped the definition and implementation of teacher quality 
standards within a college of education. Current policies and standards related to quality in teaching, teacher education, and teacher development are enacted and implemented under global and national neoliberal socio-political conditions.

The findings show neoliberalism in action, and how policies transform from the intentions of senior managers across all levels of the policy enactment and implementation process to the actions of lower-level policy actors on the front line of policy implementation. The neoliberal characteristics evidenced from the findings include those identified by critical policy analysts (Baltodano, 2012; Giroux, 2002; Lorenz, 2012):

- The eroding or elimination of the notion of education as a common good for the public interest to be supplanted with the notion of education for the purpose of global economic competition;

- The development of new discourses, rewards, norms, institutional practices, and/or common-sense values;

- The state acquiring a new identity as the protector of capital, where its role is to enhance social and educational policies to protect the market;

- Active political intervention of schools, colleges and universities by national and state governments;

- Senior management control over policies and policy implementation actions;

- The standardization of efficient, formal input/output processes to measure quality; 
- The use of predetermined standards and measurable indicators of performance to determine quality; and

- Defining quality in education by the product of education, or the "quantitative efficiency with which the qualifications are produced." (Lorenz, 2012, p. 621)

The neoliberal conditions provide a rationale for how and why quality policy enactment and implementation at the teacher preparation program level transforms as it does.

This section is divided by each level of the policy enactment and implementation process: national; national and state linkages; state; NCATE, state, university, and program linkages; university and university and program linkages; and program. The discussions of the findings at each level are introduced with a table which provides an overview of the findings aligned with the relevant elements of the Transformation of Policy Intentions (TPI) Framework and Data Analysis Matrix. At the end of each section, a summary of how the policy has transformed from conditions to consequences is provided. 
Table 2

The National Level

Conditions

\section{Political}

1. US economy in recession

2. Cuts in federal funding to higher education

3. US and Congress politically polarize

4. The rise of Neoliberalism in the US

6. Global competitiveness of educational systems showing American public education as declining; teachers to blame 7. Public perception of problems with the quality teaching and teacher preparation programs

8. President Barack Obama's first term

9. NCLB/ESEA remains the education law of the land; Obama Administration offers NCLB relief to roughly 40 states through an NCLB waiver

10. ESEA will not be reauthorized until after the 2012 Presidential election due to partisanship and the slow legislative process in Congress

11. Obama Administration

Education Agenda: allow states to

\section{NCATE}

1. NCATE accreditation processes legitimized by the following: USDE, the Council for Higher Education Accreditation (CHEA), NCATE/State Alliances, \& NCATE partnerships with Specialized Professional Associations (SPAs)

2. NCATE accreditation perceived as the most important aspect in judging the quality of teacher preparation 3. NCATE accreditation is increasingly being perceived as not rigorous; products (i.e., teacher candidates) of NCATEaccredited institutions are not always seen as high quality 
Network of Collective Activity

Tasks trade rigorous teaching \& learning accountability and evaluation

plans for meeting NCLB

regulatory requirements; provides RTTT funding to states with most rigorous plans; Our Future, Our Teachers: The Obama

Administration Plan for Teacher

Education Reform and

Improvement

12. Arne Duncan asserts "some of our existing teacher preparation programs are not up to the job" to prepare effective teachers; places blame of failing schools on teacher education and preparation

President Barack Obama, US Congress, Secretary of Education Arne Duncan, President of NEA, Founder of TFA, President of NCATE \& CAEP, President of NCTQ, Executive Director of ATE, COE/SOE deans

1. ESEA reauthorization; currently being pursued through regulatory waivers and legislative action

2. Distribution of RTTT funding to states

3. Monitoring \& evaluation of
Secretary of Education Arne

Duncan; leaders, administrators, \& reformers working in the following organizations: NCATE, TEAC, NEA, NCTAF, CCSSO, AACTE, AFT, \& NCTQ; COE/SOE administrators, $\mathrm{P}-12$ administrators

1. NCATE revises accreditation standards to reflect more rigor, and focus more on clinical practice, diversity, continuous improvement, evidence of quality, linking student achievement to teacher and leader performance 
RTTT fund implementation

4. Development \&

implementation of a national standardized, performance-based exit exam for teacher licensure
Interests/Intentions/ Motivations
1. For the US to be "the most educated nation in the world with the highest percentage of college graduates"

\section{Get RTTT states and} traditional \& alternative route teacher education programs to create a "feedback loop" between $\mathrm{K}-12$ and higher education

3. Data-driven decision making a priority in teacher preparation and development

4. Teacher effectiveness should be based "in significant part" on student achievement

5. Require RTTT-funded states create a student-teacher link to
2. NCATE produces the Blue Ribbon Panel Report:

Transforming Teacher Education Through Clinical Practice; expects implementation in NCATE-partner institution

3. NCATE to combine with TEAC and create a larger accreditation organization, CAEP, to "create a model unified accreditation system"

4. NCATE requires schools to implement more rigorous accreditation standards immediately

1. To maintain credibility \& expand reach in determining the quality of teacher preparation programs and products 2. For NCATE/CAEP accreditation standards and processes to be deemed rigorous by teacher education stakeholders 3. For state departments of education (SDEs) to continue to partner with NCATE/CAEP in evaluating the quality of teacher preparation programs

4. For a significant part of teacher preparation to link student achievement to candidate quality 5. For teacher education reform 
map students to individual teachers and determine teacher effectiveness

6. Suggest, but not require states use student growth models, some of which are presented in the

Gates study, Measuring Effective Teaching, as models to determine teacher effectiveness

7. The goal of Obama's USDE is that every teacher receives "highquality preparation and support."

8. Obama administration supports "new pathways to teaching" to include alternative route programs, like alternative masters programs \& other nontraditional teacher preparation programs, like Teach For America 9. Use student achievement results to make human capital decisions; i.e., retaining \& firing teachers, shutting down schools 10. Apply student growth models to teacher preparation programs and use findings to determine the quality of the teacher preparation program

Conventions
1. Administrators in USDE and national education policy organizations partner to identify problems with teaching and to include the following attributes: more rigorous accountability; strengthening candidate selection and placement; revamping curricula, incentives, and staffing; support for P-12 partnerships; and an expansion of the knowledge base to identify continuous improvement models (i.e., feedback loops)

1. NCATE is a powerful player in setting the agenda for attributes of quality in teacher preparation, and gets out in front of or establishes 
teacher education, and then offer suggestions to solve the problems 2. Commissions partner with education research organizations for research-based support of the teacher preparation and development problem issue

3. Legislation (i.e., ESEA reauthorization) moves at a slow pace through Congress

4. Polar opposite political views on whose responsibility is public education \& teacher training hinders legislative action

Resources/Power/ Governance

\section{Ability to provide funding} streams to support and advance ideals; including, funding alternative route teacher education programs and favoring programs that implement their ideals of quality

2. Ability to deem organizations (i.e., TFA, NCATE, TEAC, CAEP NEA, NCTQ, ATE) and research (e.g., Gates Study) credible by virtue of collaborating with such organizations and supporting such research

3. Access to multiple mediums to express and advance

fundamental ideas

4. Symbolic mobilization or the policy issues related to teacher quality

2. NCATE traditionally grants accreditation to almost all its member institutions, suggesting a lack of rigor in the accreditation process

1. Ability to legitimize a teacher preparation program and institution by granting the unit and program(s) NCATE accreditation 2. NCATE/State alliances and NCATE partnerships with SPAs, like NAEYC, NCTM, \& NCTE, further legitimize the NCATE accreditation process \& the power of NCATE to legitimize teacher preparation programs \& institutions

3. Access to multiple mediums to express and advance fundamental ideas 5. Symbolic mobilization or the ability to influence public perceptions that NCATE is 
Contingencies/ Opportunities

Consequences ability to influence perceptions that the Obama Administration is reforming and improving teacher education and development

1. President Obama \& Secretary Duncan use budgets and discretionary authority to advance ideals of quality in teacher preparation and development through RTTT

2. Perceptions that teacher quality is in peril provided an opportunity for the USDE to partner with education policy organizations to redefine teacher quality and measures thereof

1. National climate to reform teacher preparation and development into a performancebased system of accountability

2. New definitions of teacher quality and measures of teacher quality, which have trickled down to states and teacher preparation programs

2. Alternative route teacher preparation programs seen as credible routes to prepare quality teachers reforming and improving teacher education and development

1. At a time when teacher quality is perceived as being in peril, NCATE uses its tradition, influence, power, and resources to be at the forefront of determining policy on teacher preparation quality

2. NCATE policy actors and ideas to become even more powerful with the formation of a larger national organization for teacher education accreditation, by combining efforts with TEAC and forming CAEP

1. NCATE member institutions redesigning their standards for teacher education programs to include performance accountability measures 2. Partnerships between P-12 and higher education which reflect residency models for clinical practice

3. Residency models for clinical practice pave the way for making data links between teacher candidate inputs and P-12 student 
4. Greater national support for using student growth models to determine effective teaching, which has trickled down to national accreditation requirements and state program approval requirements outputs

4. The process and procedures of meeting NCATE requirements hinders the development and implementation of institution- and state-specific reform in teacher preparation 
The socio-political, cultural, and economic factors, circumstances, and events at the national level which have specifically led to the state, university, and school of education action context regarding teacher quality policy development and enactment include: (1) a United States economy in recession, (2) a political and economic culture of neoliberalism, (3) negative national perceptions of public education and teacher quality, (4) federally-mandated policy and legislation on public education and teacher quality, (5) national education organization policy on public education and teacher quality, and (6) the senior management control over policy decisions. Within this section, such conditions will be illuminated, and will serve to link teacher quality policy processes across subsequent levels of the policy enactment process.

The state of the U.S. economy and its impact on teacher education will be discussed. The backgrounds, experiences, decisions, actions, and political stances of policy actors of the Bush and Obama administrations will be linked to theoretical constructs of neoliberal ideology. A decade's worth of federal legislation and national policy on public education and how it has framed the problem with public education around the lack of quality in teacher preparation and education will be exhibited. The power and influence of federal oversight and national accreditation in shaping teacher quality policies, standards, and implementation actions in states and teacher preparation institutions will be shown.

Within the context of the national-level conditions, the networks of collective activity, tasks, interests/intentions/motivations, 
resources/power/governance, contingencies/opportunities, and consequences that also influence how teacher quality is currently conceptualized in states will be illuminated. Moreover, the national-level conditions presented explain why policy actors at subsequent levels of the teacher quality policy enactment process interpret, decide on, develop, and act on new or reconstituted quality policies in teacher preparation as they do.

The Influence of Globalization and Neoliberalism on Policy Actions in the United States

President George W. Bush served two terms as president during a time when globalization became the common term that would describe economic, cultural, and human interactions in Twenty-first Century America. There was a book published, by author and free-trade advocate Thomas Friedman, around the time of President Bush's second inauguration, titled The World is Flat. This book provides the global context in which education policy transformed. In his book, Friedman (2005) explained the history of globalization and crystallized the common ideology which grounded how America would compete in this new "flat" world; a world where cultural ideas and economic productivity would be internationally interchangeable. In order for America to survive in this new world, Friedman (2005) suggested, the U.S. government needed to establish policies that would facilitate building a strong, globally competitive labor force, and strengthen education in the areas of science, mathematics, and technology. Neoliberal ideology, which had been on the rise since the Reagan administration, was becoming solidified through the economic and education policies of the George W. Bush Administration. 
While Congress under President G. W. Bush passed legislation that would cut taxes on wealthy Americans-under the guise that doing so would facilitate economic growth—he was also cutting funding to social programs. States were receiving less and less federal funds to support public K-12 and higher education. All the while, federal control over public education was at its peak. The most influential education reform of the Standards-based Reform Movement was taking place with the enactment of President Bush's No Child Left Behind Act of 2001. Although federal oversight over education policy began with the Reagan administration in the 1990s, NCLB crystallized federal control over education policy.

States were not only held accountable for how they educated their citizens, they were told exactly which indicators they would use to determine success in teaching and learning. States were also sanctioned, through, for example, the withholding of federal funds for education, when accountability data did not meet or exceed the evaluation criteria set forth by the United States Department of Education. The standardization of efficient, formal input/output processes, and the use of predetermine standards and measureable indicators of performance to measure quality were the foundation of President Bush's education policies.

Although the goal was to improve education to make America more globally competitive, the opposite effect occurred. Public schools were failing based on the evaluation criteria legislated in NCLB. National and global comparisons of educational systems showed American public education was 
subpar and rapidly declining. Not only did results of national standardized achievement tests contribute to the notion that American public education was in peril, reports of U.S. math and science rankings on international assessments exhibited failure, as well. For example, published results from the 2006 Programme for International Student Assessment (PISA) showed U.S. students ranked $25^{\text {th }}$ out of 30 Organisation for Economic Co-operation and Development (OECD) nations in math and $21^{\text {st }}$ out of 30 in science (Baldi, Jin, Skemer, Green, \& Herget, 2007). Both rankings are below the international average for advanced nations. Public perception was that America's schools were failing America's students. Although this perception of failure had been rising over two decades, globalization was peaking, and America needed to improve her global standing in education immediately.

The Consequences of President Bush's NCLB Policy

President Bush's 2001 Elementary and Secondary Education Act (ESEA) reauthorization, commonly referred to as No Child Left Behind Act (2001), included several regulations, which when implemented, consequently led to even more negative perceptions regarding the quality of public education. NCLB effectively framed the problem with American public education around the lack of quality and quality control in the teaching force. Two of the most notable regulations of NCLB were what counted as proof of knowledge for $\mathrm{K}-12$ students and what counted as proof of quality for their teachers. Part of NCLB (2001) included a requirement that states develop a timeline to ensure all students meet or exceed state-developed education achievement standards in reading and 
mathematics by the year 2014. This aspect of NCLB (2001) was called Adequate Yearly Progress (AYP). Another part of NCLB (2001) was that 100 percent of all teachers in core subject areas (e.g., reading and math) would be "highly qualified" to teach those subjects.

Although state education agencies had complete power to develop their own standards of teaching and learning quality, they had little power over which assessments would count for showing evidence that their students made AYP, and that their teachers were highly qualified to teach. States were allowed to develop state assessments to evaluate AYP within the state, but were required to also use scores on national standardized tests, like the Stanford Achievement Test (SAT), for national comparisons of AYP. NCLB (2001) required that states and school systems publically publish AYP results. Consequently, under this criteria, many schools across the country, especially those in traditionally lowincome and racially/culturally-diverse areas, failed to produce students whose scores indicated performance at or above proficiency in reading and mathematics. The AYP process is an example of the standardization of efficient, formal input/output structures to measure quality in education.

In addition to public comparisons of student achievement within and among states, NCLB theoretically allowed parents to make decisions about who would educate their children. This idea was referred to as "school choice". Teachers of students who were not performing at or above proficiency level on standardized assessments were deemed inadequate. Schools that did not "make AYP" were shut down or repurposed, as parents began removing students 
from "failing" schools (Baltodano, 2012). The results of parents "shopping" for better schools for their children led to the rise of charter schools. Charter schools are private schools that receive funding from federal and state governments, but are not subject to the rules and statutes of public schools. The rise of charter schools, in turn, paved the way for private corporations to develop teacher and leader programs that would staff such schools (Baltodano, 2012); thus, creating competition between $\mathrm{K}-12$ schools, as well as competition between traditional teacher preparation programs and private, alternative teacher preparation organizations.

The consequences of NCLB legislation aided in escalating the trend of negative perceptions of public education. Americans believed America's schools were failing, nationally and globally. Inevitably, something or someone had to be blamed for such failure. The NCLB requirement for schools to publish schooland teacher-linked data on student success and failure overtly placed the blame on teachers, and their preparation and development. Moreover, NCLB policy explanations written directly for parents (USDE, 2002) implied that teachers were not rigorously enforcing student learning standards; used "untested curricula" when teaching students (p. 20); and assessed student achievement through inaccurate, unreliable, and subjective measures which did nothing to show students were adequately prepared for college. The insertion of language related to adequate college preparation in NCLB policy documents is an example of the erosion of the notion of education for the common good. College preparation is a signal for preparation for global competitiveness. 
NCLB, at once, solely blamed teachers for poor student achievement on standardized tests, redefined indicators of teacher quality, legitimized standardized achievement testing as appropriate measures of student growth, and required states to use student achievement measures in determining the quality of their teachers. In addition, the link between student achievement and teacher performance that was taking place in school districts, eventually found its way into how teacher preparation programs would evaluate the quality of their graduates. The link between teacher inputs and student outputs became the common-sense discourse and value for determining quality in public education.

\section{President Barack Obama: Change We Can Believe In?}

In January 2009, Barack Obama was elected the $44^{\text {th }}$ President of the Unites States. Upon assuming the Office of the Presidency, he inherited an economy on the verge of a recession, an educational system perceived to be in grave danger of never returning to its position as world leader, and a country and Congress that was deeply polarized. As a consequence of the Bush Administration's education policy, public education—both P-12 and higher education—was becoming more and more privatized. Charter schools were popping up across the nation as viable alternatives to traditional public education. Traditional schools of education were competing with privately-funded, corporatebased purveyors of teacher education to supply teachers to traditional and nontraditional grade schools. 
The country was in economic meltdown, and Americans wanted a change from the Republican policies and ideals of the Bush Administration. President Barack Obama—perhaps because he was a Democrat—was publicly perceived as the best alternative to combat the global-market-based political agenda that had been sweeping the country throughout two terms of the Bush Administration. Although it is arguable whether Barack Obama's motivations to improve American public education are overtly grounded in neoliberal idealism, there are plenty of examples which provide evidence that Obama's education agenda is indeed contextualized under global and national neoliberal conditions.

\section{Barack Obama: The Senator}

Prior to becoming the new leader of the free world, President Obama served as a United States senator from the State of Illinois from 2005-2008. He served as U.S. Senator during a time in which his state's largest city, Chicago, was thought of as the place of neoliberal urban experimentation and restructuring (Lipman, 2009). A review of the bills Obama sponsored during his tenure as U.S. Senator reveals one that is grounded in one aspect of the neoliberal agenda to transform teacher education: fast-track alternative teacher certification. Although the Teaching Residency Act bill-introduced to the U.S. Congress in June 2007—was not enacted; it was designed around amending the Elementary and Secondary Schools Act (ESEA) of 1965 to allow the Secretary of Education to provide funding for non-education majors to receive teaching certifications (Teacher Residency Act, 2007). Although teacher residency legislation failed to be enacted, the idea was eventually inserted into other national-level policy 
through a network of collective activity between President Obama's Department of Education appointees and policy actors in national education organizations. Such policies were then transformed into teacher education implementation action, as will be discussed later.

Senator Obama also sponsored a bill that would require the President to establish a committee on science, technology, engineering, and mathematics (STEM) education, establish an office for STEM education in the United States Department of Education, require the Assistant Secretary of Education to systematically evaluate the STEM education programs administered by the USDE, and require the Secretary of Education to award grant funding to national and state efforts in STEM education. This bill is titled Enhancing Science, Technology, Engineering, and Mathematics Education Act (2009). Although both bills failed to pass in Congress, they provide insight into what Barack Obama deems important and how he sees the role of the federal government in public education. Obama's political and legislative actions as president provide more solid evidence of how his policies are congruent with President Bush's in forwarding a global-market-based, neoliberal political agenda in public education.

\section{Barack Obama: The President}

Consistent with prior neoliberal agendas to cut funding to social programs, federal funding for public higher education continued its accelerated decline during the first term of the Obama administration. To stave off some of the detrimental consequences of states having decreased revenues for public 
operations, like public sector layoffs and cuts to higher education, President Obama urged Congress to pass The American Recovery and Reinvestment Act (ARRA). Although Congress passed ARRA in February 2009, as of September of that same year, forty-three states reported major reductions in operations, including twenty-five states cutting K-12 funding and thirty-four states reporting major cuts in higher education funding (Douglas, 2010).

Although traditional funding for public education was being cut, ARRA would provide grant-based funding to states that submitted education evaluation and accountability plans aligned with President Obama's "data-driven decision making" initiative to systematically link student achievement with teacher performance (M. Smith, USDE Senior Policy Advisor, interview, May 22, 2012). By doing this, President Obama effectively used legislative and budgetary actions to control how states re-conceptualized their education systems. This is consistent with several aspects of neoliberalism: the development of new discourses, rewards, and norms (Baltodano, 2012), the standardization of input/output processes, and the introduction of measurable performance indicators (Lorenz, 2012).

\section{ESEA Reauthorization: the Blueprint versus NCLB}

When Barack Obama was elected president, NCLB/ESEA was two years past its review and reauthorization date. As well, NCLB legislation was publicly perceived as not achieving the goal of improving America's schools. There were two pieces of federal legislation which granted the President and his 
administration legal authority to enact new national policies for teaching and learning: Title II of the Higher Education Opportunity Act (2007) and the Elementary and Secondary Schools Act (1998). Title II of the Higher Education Opportunity Act (2007) granted legal authority to the federal government to regulate the quality of teacher preparation in states, while ESEA allowed for regulations in K-12 and secondary education in the states. President Obama saw NCLB as a "flawed law;" one that needed to be reshaped. Therefore, he took the opportunity to present an "outline for a re-envisioned role in federal education" (USDE, 2010, p. 2). What resulted is a policy document titled, Elementary and Secondary Education Act (ESEA) Reauthorization: A Blueprint for Reform (2010).

It is clear, from a review of the Blueprint (2010), the function of the federal government in holding states accountable for the quality of their educational systems was not going to diminish under President Obama. In fact, the redefined vision was quite similar to that of NCLB: federal control over state systems of public education. The main difference between President Bush's NCLB/ESEA reauthorization and President Obama's Blueprint/ESEA (2010) reauthorization was the funding mechanism to support states in achieving the goals set forth by the federal government. The neoliberal agenda of restructuring public education to promote economic growth remained. This is evident in the Blueprint/ESEA (2010) and other education policy documents language and the key actors chosen by President Obama to lead the charge for a "re-envisioned" national education reform agenda. 
The letter President Obama wrote introducing the Blueprint (2010) not only identifies his intent in redefining the national agenda for public education, it also presents his interests and values and continued to frame the essential problem with American education around the lack of quality in the teaching force. The President's ultimate motivation to improve public education is so that America may reclaim its standing as the number one economic and education leader of the world. This market-oriented, competitive-frame is implied in the President's statement, "The countries that out-educate us today will out-compete us tomorrow" (USDE, 2010, p. 1). His interests are to secure a more "equal, fair, and just society" by addressing the "moral imperative" of providing students with a "world-class," college- and career-ready educational system (USDE, 2010, p. 1). Preparing students for college- and career-readiness sends a signal that, according to President Obama, the purpose of public education is to prepare students to contribute to the economic growth of our country. Such a stance is in accordance with neoliberal ideals centered on developing students who will be productive contributors to America's economy; and supports the notion of education for the purpose of global economic competition.

Further, President Obama states, "We must reform our schools to accelerate student achievement" (USDE, 2010, p. 2), signaling he, too, places great value on student achievement as evidenced by standardized testing. This statement also indicates that President Obama sees high levels of achievement as critical to showing America is globally competitive. The four pillars of the Blueprint illuminate President Obama's intentions for reforming public education 
and framing the problem with public education: (1) improving teacher and leader effectiveness, (2) collaborating with families for improvements in student learning, (3) developing and implementing new standards and assessments for college- and career-readiness, and (4) improving student achievement in lowperforming schools through effective interventions (USDE, 2010). Each of the four pillars implies student achievement is the goal of a Twenty-first Century education. This aligns with the neoliberal tenets of establishing standardized, efficient formal input/output processes and the use of predetermined standards and measureable indicators of performance to determine quality in education.

According to President Obama, America's educational system is weak and teachers and leaders are not effective in moving students to where they need to be. He intends for his Blueprint and subsequent policy initiatives to be the roadmaps to achieve his goal of the U.S. leading the world in college completion by 2020 (USDE, 2010). It is not only President Obama's education policies that point to a neoliberal agenda, but the national network of collective activity perpetuated by his choice for Secretary of Education that contextualize education reform under neoliberal conditions.

\section{The President's Education Secretary}

President Obama appointed Arne Duncan to Secretary of Education to lead the charge in forwarding his national education reform agenda. Duncan's education experience is quite meager for a person appointed to the highest education office in the land. However, a closer look at Duncan's background and 
experiences yields exactly why he was appointed to such a position. A review of Duncan's career in education shows values, interests, motivations, and intentions parallel to that of neoliberal ideology. Most of Duncan's education employment point to his experiences managing education rather than being an educator.

According to his own statements, Duncan spent a year during his undergraduate studies at Harvard University tutoring children (O'Shea, 2009). His first major job in education was as director of the Aerial Education Initiative (AEI), a subsidiary of Ariel Investments, an initiative and company founded by investment banker John W. Rogers, Jr. in 1989 (USDE, 2012; Quaid, 2009). AEI was an education mentoring program instituted on the Southside of Chicago to serve economically-disadvantaged youth and assist them in advancing their educational opportunities to college (USDE, 2012; Aerial Education Initiative, n.d., para. 1). In 1996, Duncan and Rogers transformed AIE into a charter school, called Aerial Community Academy (USDE, 2012). Then, in 1998, Duncan served as head of a magnet program and was appointed deputy chief of staff of the Chicago Public School System (O'Shea, 2009).

In 2001, Duncan was appointed by Chicago Mayor Richard Daly to serve as the Chief Executive Officer (CEO) of Chicago Public Schools (USDE, 2012). He served in this position until he was appointed Secretary of Education. Duncan's chief assignment as CEO was to implement an initiative called Renaissance 2010 (Ren2010). Ren2010 was a "market-based approach" to education reform, which involved "a high level of partnership with the most powerful financial and corporate interests in [Chicago]" (Lipman, 2009, p. 4), and 
is implicated in what Lipman (2009) calls "the neoliberal restructuring of the city" (p. 4). During Duncan's tenure at the helm of Ren2010, many of Chicago's lowperforming public schools were closed or repurposed and many more small, charter, and contract schools were opened (Baltodano, 2012). The educational system Duncan assisted in structuring during his career in Chicago was based, in large part, on privatizing public schools and staffing them with teachers and leaders from private, corporate-funded education organizations. Privatization of public domains is a major tenet of neoliberalism.

Duncan's biography on the USDE website indicates he won praise for his "aggressive [education] reform agenda" in Chicago, which included "building public-private partnerships around a variety of education initiatives" (USDE, 2012, para. 4) and establishing charter schools. His biography also claims he is "credited with significantly raising student performance on national and state tests" (USDE, 2012, para. 4). Duncan deems the privatization of public education an important aspect to reforming and improving educational systems. As well, he sees high student achievement on standardized tests as a signal of education reform success.

Another important aspect of Arne Duncan's tenure as CEO of Chicago Public Schools (CPS) is his view of, and actions related to teachers. While Duncan was CEO, CPS was "recognized for its efforts to bring top teaching talent into the city's classrooms" (USDE, 2012, p. 4). It is not coincidental that Teach for America (TFA) — a corporatized, private alternative teacher program which arrived in the Chicago region in 2000—became a major supplier of teachers in 
Chicago's reconstituted schools during the time Duncan served as CEO of Chicago Public Schools. As reported by Carlo Rotella (2010) of The New Yorker, "[Duncan] used Teach for America, New Leaders for New Schools, and other such programs to bring new talent into the teaching and administrative ranks" in Chicago (p. 27).

During the Senate confirmation hearing for his appointment to U.S. Secretary of Education, Duncan applauded the efforts of Wendy Kopp, TFA's founder and chief executive officer, and said "he hoped the federal government would be able to support 'a new generation of education entrepreneurs"' in reforming the American educational system (Klein 2009, p. 3). In his 2009 speech at Columbia University Teachers College, Duncan expressed favor in "expanding high-quality alternative certificate routes, like High Tech High, the New Teacher Project, Teacher for America, and teacher residency programs" (Duncan, 2009, para. 17). Duncan's signature achievement as CEO of CPS was revamping the entire system by shutting down "poor" schools and reopening them with new staffs of teachers and leaders (Rotella, 2010). Consequently, Chicago is "one of the cities with the highest numbers of alternative [teacher] certification programs and reconstituted schools" (Ravitch, 2010, as cited in Baltodano, 2012, p. 496).

According to Marta Baltodano (2012), a critical theorist and social justice advocate, Barack Obama chose Arne Duncan as Secretary of Education precisely because of his success in pioneering "the reconstitution of [Chicago's] public schools" (p. 496). President Barack Obama appointing Arne Duncan to 
the highest education position in America shows that his motivations for education reform are, too, parallel to that of neoliberalism. Further, other legislative actions and the networks of collective activity between the federal government and national education policy organizations also illustrate the perpetuation of an agenda to reform education to meet the needs of global and national markets and competition.

\section{Linking Student Achievement and Teacher Performance through Federal Law \&} Policy

Policy actors in the Obama Administration would take specific executive, legislative, regulatory, and budgetary action to define expectations for their vision of what evaluation and accountability should look like in public education. NCLB waivers, Title II of the Higher Education Opportunity Act (2007), which includes the Teach Grant program, the Race to the Top (RTTT) (2009) competitive grant program, and a mini blueprint, titled Our Future Our Teachers (2011b) are the policy documents and actions which specify the Obama Administration's aims to control how states would define and regulate teacher quality: by linking student achievement to teacher performance. The student-teacher data link for quality control in public education is an example of the establishment of standardized, efficient formal structures of input/output and the use of performance indicators to measure quality.

Further evidence of the aim of the Obama Administration to shape state evaluation systems of teaching and learning is provided in the federal definition of teacher quality, as it was told to me by a senior policy advisor at the United 
States Department of Education. When asked how the United States

Department of Education (USDE) defines teacher quality, he stressed that each state is responsible for defining teacher quality and effectiveness. However, he continued with language that reveals USDE motivations, interests, and intentions to influence state definitions of teacher quality:

We have, however, said that the definition of teacher effectiveness should, in significant part—those are the magic words—be determined by student achievement, K-12 student achievement. We happen to think that the best means of doing that is through value-added modeling. But states are not required to do it through a value-added model. We also think that in determining teacher effectiveness, states should pursue evaluation systems that use multiple measures...By and large, we have left that to the states. We have suggested what examples of student growth would be, but not required anything [emphasis added]. (M. Smith, USDE Senior Policy Advisor, interview, May 22, 2012)

In the second half of the statement, the senior policy advisor indicates states are not required to use value-added modeling, and that states are encouraged to use "multiple measures" to determine teacher effectiveness. According to Section $1111(\mathrm{a})(2)(\mathrm{B})(\mathrm{xiii})$ of the statutory and regulatory provisions for NCLB Waivers, state assessments must "produce achievement and other data that can be used to inform determinations of teacher effectiveness for purposes of evaluation and development." References to "other data" and "multiple measures" are not described as explicitly as they description of value- 
added modeling. Encouraging the use of "multiple measures" seems to be secondary to the primary suggestion of using student achievement data to determine teacher effectiveness. More evidence to support the input/output evaluation system model intended by the USDE, including provisions for funding to states that use a form of value-added modeling, is discussed further.

The USDE Senior Policy Advisor referenced the corporate-funded Gates Foundation study, Measures of Effective Teaching as providing "good data" on measures of teacher effectiveness. He also affirms "data-driven decision making as a top priority of the Obama Administration's education reform agenda:

The [Obama] Administration has made data-driven decision making a priority of its K-12 strategic efforts. Accordingly, attached to the recovery acts-very large money that went to states—-there's a requirement that the states establish a student-teacher link, so that individual students and their academic growth...could be mapped to individual teachers for the purposes of identifying whether their teachers are effective or not [emphasis added]. (M. Smith, USDE Senior Policy Advisor, interview, May 22, 2012)

Additionally, although the senior policy advisor indicates states have the freedom to decide how they will evaluate student success and teacher quality, the Secretary of Education will not grant NCLB Waivers to states where particular measurement criteria is not outlined in their evaluation systems. Being granted an NCLB waiver is the only way a state can legally move from the Annual Yearly 
Progress (AYP) accountability system legislated under President George W. Bush. This illuminates a few central indicators of neoliberalism in action: active political intervention and manipulation of social institutions, the use of predetermined standards to measure output, and the standardization of input/output processes. Further, the power of the federal government to shape state systems of evaluation and accountability in states lay in federal legislation and provisions of funding.

NCLB Waivers: Federal Control Over State Evaluation \& Accountability Systems President Obama, in his Blueprint (2010), laid out a clear vision for what ESEA reauthorization would look like. However, he had to contend with a historically slow federal legislative process, further encumbered by a deeply polarized U.S. Congress. This meant ESEA reauthorization would not take place any time within his first term as president. Since Congress was not moving fast enough to reauthorize the President's ESEA revisions he, through Secretary Arne Duncan, took the opportunity to use legal means to forward his education reform agenda. Section 9401 of the Elementary and Secondary Schools Act would be the legal avenue by which the Obama Administration would propel America into a post-NCLB race to the top in public education (M. Smith, USDE Senior Policy Advisor, interview, May 22, 2012).

Section 9401 of ESEA authorizes the Secretary of Education to grant case-by-case "waivers of any statutory of regulatory requirement of the ESEA for a state educational agency (SEA), LEA, Indian tribe, or school (through an LEA) that receives funds under an ESEA program and requests a waiver" (Barbour, 
Feder, \& Skinner, 2011, p. 1). Secretary Duncan used his discretion to grant NCLB waivers to states who requested waivers (M. Smith, USDE Senior Policy Advisor, interview, May 22, 2012). The following excerpt from an interview with the senior policy advisor is evidence of the USDE's attempts to control state education evaluation systems:

We're granting waivers from the various provisions of No Child Left Behind in exchange for state action, state commitments. We've laid out some indicators, some things that we want, so it's kind of a deal, which makes it a little controversial. (M. Smith, USDE Senior Policy Advisor, interview, May 22, 2012)

The "deal" is that "in exchange for rigorous and comprehensive Statedeveloped plans designed to improve educational outcomes for all students, close achievement gaps, increase equity, and improve the quality of instruction" (USDE, n.d., para. 1), waiver-granted states will be granted flexibility regarding NCLB requirements. This means that states receiving NCLB waivers will supplant meeting AYP provisions of NCLB with meeting provisions of the NCLB Waiver; provisions which include an evaluation system which links teacher inputs to student outputs.

The most direct pronouncement of interests, intentions, and motivations of USDE policy actors regarding their conceptualization of what education should look like at the state level are other priorities that must be met for states to be granted NCLB waivers. The first priority is for states to develop/adopt and implement college- and career-ready standards. This priority also includes a 
sub-priority requiring states to institute statewide, annual growth or value-added measures of student achievement. The second priority is for states to develop and implement a statewide differentiated system of accountability, recognition, and support. The third priority is for states to develop/adopt guidelines for evaluation and support systems for teacher and leader effectiveness. The evaluation systems should base teacher and leader effectiveness on student achievement scores. This is yet another example of the USDE establishing standardized input/output processes and predetermined standards and measurable indicators of performance to determine quality in teaching and learning.

Essentially, states had two choices to meet federal mandates: either continue the laborious and unfunded task of collecting data and reporting on the AYP demands of NCLB or submit an education evaluation and accountability plan designed exactly around indicators current USDE policy actors deem important in showing success in teaching and learning. Approximately forty states have applied for or have been granted NCLB waivers, indicating the waiver option is more favorable than NCLB to the majority of the country's state departments of education (NCLB/ESEA Waiver Watch, 2012). Through the NCLB waiver option, the Obama Administration was successful in getting an overwhelming majority of states to directly align their education reform interests with the interests and intentions of policy actors in the USDE.

Furthermore, the USDE partnered with national education policy organizations whose policy actors' interests and motivations align directly with 
theirs; for example, American Association of Colleges for Teacher Education (AACTE), National Education Association (NEA), and Teacher for America (TFA). The USDE, with the assistance of education policy organizations, has perpetuated the development of new discourses, institutional practices, and common-sense values of how quality should be defined and measured in education.

National Network of Collective Activity to Reform Teacher Education

In September 2011, an unlikely troika of powerful education policy leaders in the U.S. formed a partnership to begin strategic efforts to reform and improve teacher education and preparation. The three leaders were U.S. Secretary of Education Arne Duncan, the President of the National Education Association (NEA), Dennis Van Roekel, and the Chief Executive Officer and Founder of Teach for America (TFA), Wendy Kopp. What resulted from this partnership was a policy document, titled Our Future, Our Teachers: The Obama Administration's Plan for Teacher Education Reform and Improvement (USDE, 2011b). Secretary Duncan, in the Forward of Our Future, Our Teachers implies that teachers and their preparation programs are to blame for the failing state of U.S. schools:

The first step is with how we handle teacher preparation...While there are many beacons of excellence, unfortunately some of our existing teacher preparation programs are not up to the job. They operate partially blindfolded, without access to data that tells them how effective their graduates are in elementary and secondary school classrooms after they leave their teacher preparation programs. Too many are not attracting top 
students, and too many states are not setting a high bar for entry into the profession. (USDE, 2011b, Forward)

This statement is laden with Secretary Duncan's values, interests, and motivations to reform teacher education and evaluation systems. Duncan places much value on using student data to determine teacher effectiveness. He also implies top-tier students, which he defines as graduating in the "top third" of their class, are the saviors of the education profession (USDE, 2011b, p. 5). As well, he plainly states that what is currently happening in teacher education is not providing education systems with effective teachers. Additionally, Duncan's choice to work with both the NEA and TFA top executive officers on perhaps the most influential policy guiding teacher education reform elevates private, corporate-funded teacher preparation programs as being on equal footing with traditional teacher preparation programs in providing future teachers to future students.

The USDE Senior Policy Advisor summarized the current USDE strategy for reforming teacher education as "seeking to reward the good, improve the middle, and transform or shut down the bad" (M. Smith, USDE Senior Policy Advisor, interview, May 22, 2012). His statement is corroborated by Duncan's own policy language in Our Future, Our Teachers, where he indicates the role of the federal government is to support "state-level policies that reward the best programs, improve the mid-performing programs, and transform and ultimately shut down the lowest performers" (USDE, 2011b, p. 8). The strategy Secretary 
Duncan is putting forth is one he carried with him from his days serving as CEO of Chicago Public Schools.

Further review of Our Future, Our Teachers (2011b) describes the challenge, the opportunity, and the plan Secretary Duncan envisions will improve teacher education in America; and further illuminates the interests, motivations, and intentions of the highest education officer in the land to reform teacher education to fit his ideological beliefs. In The Challenge, Duncan places much emphasis on the need for future teachers to be in the "top third" of their college graduating class, especially in the areas of science, technology, engineering, and math (USDE, 2011b, p. 5). This indicates Duncan sees high grade-pointaverages in subject areas that will contribute to America's global competitiveness as a sign of quality in teaching those subjects. The other challenges Duncan proposes are that there is not enough rigor in the clinical aspect of teacher preparation, and that teacher preparation programs lack accountability for their performance. Performance accountability is a common theme of neoliberalism.

To address accountability for teacher preparation program performance, specifically, Secretary Duncan would use regulatory action through Title II of the Higher Education Opportunity Act (2007). Since 1998, Title II of the Higher Education Opportunity Act (2007) has required that states identify and take steps to improve low-performing teacher education programs. Duncan indicates that in spite of this law, "few states hold programs to any meaningful standard of quality" (USDE, 2011b, p. 6). According to the USDE Senior Policy Advisor interviewed, the Obama Administration will use regulatory space provided through Title II of 
the Higher Education Opportunity Act (2007) to redesign what accountability in teacher preparation would look like:

What we're attempting to do is create a feedback loop between $\mathrm{K}-12$ and higher education on the quality and success of programs, be they traditional or alternative route, in improving $\mathrm{K}-12$ student learning outcomes, getting their future teacher candidates placed in jobs, retained in jobs, and in providing pre-service training that is satisfactory as far as the candidates go when they get out, what they thought of their trainingand their employers, what they think of their training. So we're trying to create this feedback loop between K-12 and higher education, with an eye toward higher education using the information to self- improve. (M. Smith, USDE Senior Policy Advisor, interview, May 22, 2012).

Both Duncan, in Our Future, Our Teachers (2011b), and the USDE Senior Policy Advisor, provided examples of states that are already doing this to the standard put forth by USDE. Moreover, the Obama Administration is politically intervening in state institutions' practice. The USDE is regulating specific teaching and learning accountability and evaluation systems policy actors desire by providing funding resources through two grant programs: the Teacher Quality Partnership Grant Program (Teach Grant) and the Race to the Top Grant Program (RTTT) (2009).

The Teach Grant program statute indicates the USDE will drive funding to "high quality" teacher preparation programs. Although the implementation of this grant program reveals that funding is currently going to "any institution of higher 
education with teacher preparation that wants to sign up," the goal is that institutions complying with the USDE "feedback loop" accountability design will be successful in competing for Teach Grant funds (M. Smith, USDE Senior Policy Advisor, interview, May 22, 2012). This suggests that an evaluation system that links teacher inputs to student outputs is what the USDE deems high quality in teacher preparation program evaluation systems.

Forty-six states and the District of Columbia applied for Race to the Top (2009) funds, making the initiative perhaps the most popular and most successful grant program to effectively cause winning-states to comply with the USDE model for education reform. As the USDE Senior Policy Advisor indicated, the most important requirement for competing for RTTT (2009) funds "was that there would be a teacher-student data link...and [a] mapping back [of] the results of that teacher data link to teacher preparation programs" (interview, May 22, 2012). This is yet another example of neoliberalism in practice. States who receive RTTT (2009) funds will engage in a standardized process of formal input/output structures to assess the effectiveness of teachers and teacher education programs.

In some cases, states changed their education policies, including adding value-added modeling in evaluating teacher effectiveness, to become more competitive. Forty-five states, including Alabama, and the District of Columbia adopted CCSSO's Common Core Standards in order to be more competitive in the RTTT (2009) grant competition. The Common Core Standards are especially designed around preparing students to "compete successfully in the global 
economy" (Common Core Standards, 2012, para. 1). The policy changes these states made are long-lasting regardless of whether they were awarded the funding to assist with full implementation. Part of the competition was that states had to show evidence of implementing new evaluation and accountability systems prior to applying for funding. Such a provision ensures performance accountability systems are implemented in states, and is an example of political intervention and manipulation of social institutions by a federal entity.

At the same time the federal government was cutting education funding to states, it was having states compete for much-needed funding, through the RTTT (2009) grant program. States that "won" funds are those that directly complied with the Obama Administration's vision and methods for evaluation and accountability in education. This too, is a sign of forwarding a neoliberal agenda in education in that, on the surface, states maintain the right to design and implement educational systems as they see fit, yet they are only granted muchneeded funding to do so if they structure accountability in the image put forth by federal policy. In addition to using financial resources to control state systems of education, the federal government endorses national accreditation agencies, effectively granting them power to control policy and actions in teacher education. As will be illuminated in the next section, the education policy positions of the most influential teacher accreditation organization in the nation are directly aligned with the education policy positions of the USDE. Such active networking shows a national-level interactional locus of control what matters in teaching and learning. 
The Concentration of Power in National Accreditation in Teacher Education

An important layer of power and governance at the national level, which provides an example of active political intervention of social institutions, is evidenced at the national education accreditation level. One essential theme of the research is the power of NCATE to influence state policy and legislation in teacher preparation. Such power is accorded NCATE by policy actors at all levels of the policy enactment and implementation process. The USDE recognizes NCATE as a viable accountability organization in teacher education. Secretary Duncan endorses the performance accountability structures of both the NCATE Blue Ribbon Panel clinical practice recommendations and American Association for Colleges of Teacher Education's (AACTE) work in developing a national teacher performance assessment (USDE, 2011b). All fifty states, the District of Columbia, and two U.S. territories have formed some type of standards-accountability partnership with NCATE. Teacher preparation institutions implement NCATE program review standards either in conjunction with or in lieu of the state's review processes.

As policy actors at the federal level are using their governing and fiscal power to shape how teacher quality is conceptualized in states, national education policy and accreditation organization actors are working collectively with actors at the federal level to push an equal education reform agenda at the teacher preparation program level. As a consequence of privatizing public education, schools of education are competing with private teacher education providers to maintain a place at the teacher training table. National teacher 
education accreditation is becoming increasingly more important, as accreditation is perceived as a symbol of program rigor, accountability, and excellence (Baltodano, 2012). National accreditation enables traditional schools of education to be competitive in this new market for teacher training.

Secretary Duncan, in policy documents and speeches, emphasized the importance of national accreditation. Baltodano (2012) suggests that Duncan placing such significance on national accreditation is yet another example of "his mission to align education to the needs of the market" (p. 499), as accreditation institutions "play an essential role as regulators of the educational market" ( $p$. 500). In Our Future, Our Teachers Duncan praises NCATE for calling for teacher preparation to be "'turned upside down,"” and for their "ambitious plan for reforming programs through greater selectivity, more rigorous accountability, and a focus on clinical practice" (USDE, 2011b, p. 8). In his speech at Columbia University Teachers College, Duncan expressed his approval of and desire for more states and schools of education to "shift more to the residency model of training" (Duncan, 2009b); a training model proposed by NCATE, which makes it easier to link student achievement outcomes and teacher candidate inputs.

In the current era of standards-driven accountability, NCATE has expanded its reach in teacher preparation. When the National Council for Accreditation of Teacher Education (NCATE) arrived on the scene in 1954 as an independent national teacher preparation program accrediting institution, governed by the American Association of Colleges of Teacher Education (AACTE), it had established partnerships with 44 states and the District of 
Columbia, and accredited 288 public and private schools of education in those states (NCATE, n.d.). Today, NCATE partners with all 50 states, Guam and Puerto Rico, and has more than doubled the number of public and private teacher education institutions it accredits in those states (NCATE, n.d.).

The NCATE-State Partnership Program was established in the late 1980s as a way to integrate NCATE and state teacher quality efforts and increase national-level accountability in teacher education. Through the NCATE-State Partnership Program, NCATE uses their resources to reduce expenses and the duplication of efforts at the state level. As indicated in the NCATE-State Partnership FAQs, states can save "significant time and expense" by using NCATE's findings to make decisions about the quality of teacher education institutions and programs. In 2000 , following a recommendation by the National Commission on Teaching and America's Future (NCTAF), NCATE expanded its state-partnership intentions to include a commitment by states to align state and NCATE standards for teacher preparation (NCATE, 2011). NCATE's current policy documents provide evidence of policy makers' intent to redesign teacher education to be more performance accountability driven.

NCATE standards, "which identify knowledge, skills, and professional dispositions expected of educational professionals" (NCATE, 2008, p. 10), apply to initial and advanced teacher preparation; licensure, non-licensure, off-campus, distance learning, alternative-route programs; and online institutions and nonhigher education organizations offering educator preparation programs (NCATE, 2008). The fact that NCATE accredits teacher education units provided through 
distance learning and non-higher education organizations shows that NCATE places equal value on private, corporate-funded purveyors of education and traditional schools of education in their credibility to prepare America's teachers. This is a fairly recent change in teacher education, one that aligns with transforming public education into a market-based industry.

Although NCATE policy actors periodically revise NCATE standards to reflect up-to-date research in teaching and learning, the most recent policy changes show a collaborative effort between powerful national education governing agencies to transform teacher education and preparation into a model of performance accountability. In 2010, NCATE commissioned and funded a panel of influential national education policy makers to present a redesigned system of accountability in teacher education. This network of policymakers, named the Blue Ribbon Panel, was comprised of policy actors such as USDE officials; national board certified teachers; deans and professors in teacher education institutions; school superintendents; chancellors and vice-chancellors; and program directors, executive directors, founders, presidents and CEOs of national education policy organizations and corporate alternative teacher preparation institutions (NCATE, 2010b, p. 1). This network of policymakers represents conventions, or accepted ways of accomplishing teacher quality policy implementation activities, and the use of resources to get certain interests and intentions accomplished.

NCATE's activities are funded through both public and private organizations and corporations. NCATE is a non-profit organization which 
acquires funding through three revenue streams: 35 member organizations, fees from institutions, and grants from private, corporate foundations. The fact that NCATE is funded by both public and private entities shows that their agenda to reshape teacher education is informed by the interests, motivations, and intentions of both public and private organizations. In mid-2000, NCATE was funded by the Arthur Vining Davis Foundations and MetLife Foundation to conduct a study on the effectiveness of urban teacher residency program models (UTRs). The findings from two reports suggest that although there is not enough research to determine the effectiveness of UTR graduates on student learning, UTRs are viable alternatives to traditional teacher education programs in supplying quality teachers in urban schools and districts (Barry, Montgomery, Curtis, Hernandez, Wurtzel, \& Snyder, 2008; Barry, Montgomery, \& Snyder, 2008).

The findings from both reports were used by NCATE to show promising practices to support their new teacher education clinical practice model (NCATE, 2010b); a model which is a replica of UTR programs. Despite the lack of evidence that shows the effectiveness of residency model clinical programs, NCATE's standards for their teacher preparation programs reflect requirements for programs to move toward a teacher residency model for teacher training. The USDE, as exhibited in Our Future, Our Teachers (2011b), endorses the new residency model for clinical practice.

NCATE and the USDE's endorsement and promoting of this new residency model of clinical practice align with two neoliberal ideals. The 
organizations are developing new discourses, institutional practices, and common-sense values for clinical practice in teacher preparation programs. NCATE and the USDE have determined, in a top-down manner, what makes sense in teacher preparation. NCATE has incorporated the new clinical practice model into standards and requirements for teacher preparation programs. This is an example of "active political intervention and manipulation... of social institutions" (Baltodano, 2012, p. 493).

The NCATE Blue Ribbon Panel produced a document titled, Transforming Teacher Education through Clinical Practice: a National Strategy to Prepare Effective Teachers; commonly referred to as the NCATE Blue Ribbon Panel Report (2010). The authors of the NCATE Blue Ribbon Panel Report (2010) present a national standardized model for how teacher education clinical processes and accountability methods should be structured in the Twenty-first Century. There are several themes present throughout the NCATE Blue Ribbon Panel Report (2010) which describe the interests, intentions, and motivations of the network of public and private policy actors who designed it. The standardization of an input/output model for accountability in teacher education is an example of neoliberalism in practice.

The neoliberal ideological themes of the Blue Ribbon Panel Report (2010) are similar to those of the education policy actors in the Obama Administration, and include: an implication that schools of education are not preparing quality teachers, an urgent call for the need for teachers to prepare students for college and career, a teacher- and student-link which will inform a "feedback loop" and 
determine quality in teacher education, the use of students' standardized tests to determine the quality of a teacher, and an elevation of traditional and nontraditional teacher preparation programs as equal in their credibility to prepare teachers. These are the indicators that both NCATE and the USDE point to as providing more rigor and accountability in programs that prepare teachers. All such indicators align with common elements of the neoliberal agenda to transform education and teacher education into systems of performance accountability.

The NCATE Blue Ribbon Panel Report and the Future of Teacher Education

The NCATE Blue Ribbon Panel Report (2010b) opens with a call to action which specifies that because we now live in a global economic society, this is an opportune moment to restructure teacher education around preparing teachers to educate students who will compete in a global economy. The authors place great emphasis on increased student achievement and teacher content mastery as indicators of teacher effectiveness. The panel's position is that the common goal in teacher education is to prepare "effective teachers for improved student achievement" (NCATE, 2010b, p.3), and that students' mastery of content is essential so that students "complete high school "college- and workforce-ready"" (NCATE, 2010b, p. 1). Such interests align directly with the neoliberal agenda to repurpose teacher and learning to prepare students to compete globally to assist the economic growth of the nation. The notion of education as a common good in the public interest is being supplanted with the notion of education for the purpose of competition and economic development. 
In order to achieve the goal of preparing teachers to prepare students to compete in a global economy, the report urges teacher education to turn their teacher preparation programs "upside down" by fully grounding them in clinical practice (NCATE, 2010b, p. ii), and expanding the length of time prospective teachers spend in classrooms working with students. The model—which promotes a design similar to private, corporate-funded professional development schools and teacher residency programs-is one that structures teacher preparation programs around the needs of P-12 schools. Given the current national climate of accountability, the needs of $\mathrm{P}-12$ schools are centered on increasing students' achievement test scores. Thus, the proposed model will effectively base accountability in teacher education "largely on evidence of candidates' effective performance and their impact on student learning" (NCATE, 2010b, p. ii).

The expansion of clinical experiences to include more interaction between prospective teachers and students is a new, common-sense value in that it provides more context and real-world experiences for teacher candidates. However, expanding the amount of time teacher candidates are linked with specific students effectively enables schools of education to collect evidence that shows their candidates' impact on student achievement. The teacher input/student output link cannot be effectively achieved without the new residency model. The teacher residency model is an example of establishing new discourses, norms and common-sense values in teacher preparation. National policy actors' intentions and motivations for a clinical residency model 
are grounded in the neoliberal condition of standardizing input/output processes in teacher preparation.

The Standardization of Teacher Education Program Processes

Another important aspect of the NCATE Blue Ribbon Panel Report (2010b), which provides further evidence of a collaborative national effort to redesign teacher education under neoliberal conditions, is the push to standardize measures of teacher education program effectiveness. The Blue Ribbon Panel Report states that current state models used to measure program effectiveness across the nation have a lot of variability in standards and licensure requirements (NCATE, 2010b). The panelists propose that a more rigorous model to determine quality in teacher education would have all programs held to the same standards, and a data-driven system of accountability based on "measures of candidate performance and student achievement, including gains in standardized test scores" (NCATE, 201b, p. 12). The push to standardize accountability and evaluation of teacher quality in teacher preparation is also supported by Secretary Arne Duncan (Berlak, 2010; Baltodano, 2012).

Secretary Duncan praised AACTE's leadership in "working with 21 states to develop a teacher performance assessment that will replace low-level paper and pencil licensure tests with an assessment" (USDE, 2012, p. 8) and "will measure both [teacher candidate] competence to teach and the quality of their credential program" (Berlak, 2012, para. 2). This national exam will be used by accreditation institutions in determining whether teacher preparation programs will be accredited, as programs receiving high scores on this national 
accountability exam will be rewarded (Berlak, 2010; Baltodano, 2012). Not surprisingly, organizations are being resourced through the RTTT (2009) funding initiative to "construct and promote these assessments" (Berlak, 2010, para. 2).

Such an exam will serve as a snapshot to determine the quality of teacher preparation institutions just as student achievement test scores serve as a snapshot to determine the quality of teachers, schools, and school districts. As AACTE is NCATE's governing organization, the AACTE national teachers exam may eventually serve as the sole determining factor of granting credibility to both traditional and private, corporate-funded alternative-route teacher preparation programs.

One final national-level sign of policy makers' efforts and intentions to transform teacher education under conditions of neoliberalism is the concentration of power to control what matters in teacher education in only a few national organizations. Two of the most popular national teacher education accreditation organizations, NCATE and the Teacher Education Accreditation Council (TEAC), will combine to form one large organization, Council for the Accreditation of Educator Preparation (CAEP), beginning January 2013. CAEP aims to serve as the nation's sole accreditation agency for the field of teacher education.

CAEP policymakers will be the main decision makers determining what counts as knowledge and practice in teacher education across the nation. For example, the Blue Ribbon Panel Report makes clear that they expect "this new partnership to provide accreditation with even greater leverage to implement the 
[Blue Ribbon] Panel's recommendations" (NCATE, 2012, p. iv) of residency models of teacher preparation. Such a partnership will ensure a type of national standardization in teacher education program practices, where an institutions' performance on a national teacher assessment will serve as the sole indicator of quality in teacher preparation.

Summary of the Transformation of Legislative Intentions: the National Level

The NCLB Act (2001), ESEA Waivers, the ESEA Blueprint for Reform (2010), Our Future, Our Teachers (2011b), the NCATE Blue Ribbon Panel Report (2010), political speeches, and other documents, as well as the widespread presence of neoliberal ideologues in influential positions in the federal government and national education policy organizations created a macrolevel societal climate for major reform in teacher education and preparation. Key policy actors, responding to national and international socio-political, cultural, and economic conditions, as well as their own interests, interacted to create the impetus for change and to shape what that change would look like in their own ideological image.

Teacher quality policy and standards have transformed under conditions of global and economic competitiveness. On a broader scale, the general purpose of education has been redefined as education for the purpose of college- and career-readiness. The notion of education as a common good for the public interest has been eliminated. The new purpose of education has transformed the definition of teacher quality to now be situated in the extent to which teacher inputs influence students' academic preparation for competing in 
global markets. The agendas of both the W. Bush Administration, through NCLB legislation and action, and the Obama Administration, through Blueprint/ESEA reauthorization legislation and NCLB Waivers, have affirmatively required states to evaluate teacher effectiveness through the use of student achievement scores. This system of performance accountability has transformed policies in teacher preparation programs by way of reformed teacher education accreditation standards. NCATE accreditation standards reflect systems of performance accountability. The new residency-based clinical model for teacher education is designed to enable schools, colleges, and departments of education to make evaluative links between teacher candidate inputs and student outputs.

The consequences national-level networks, interests, interactions, conventions, and power situated in neoliberal conditions are shown in the way states vied for federal funding and the way they currently structure state education and teacher education evaluation systems to reflect performance accountability. With the enactment of federal legislation, ownership of teacher quality policy enactment and implementation was transferred from state and local governments to the federal government. As a result, federal policies on teacher quality and teacher education serve as conditions under which state policies have been transformed to reflect systems of performance accountability, which link teacher inputs to student outputs to determine quality in teaching and learning. The next section presents findings from the linkages between the national and state levels of teacher quality enactment and implementation. The 
section begins with a table which presents an overview of the national and state linkages. 
Table 3

Linkages between the National and State Levels

\section{Political}

Conditions
1. NCLB legislation on "highly qualified teacher", NCLB waivers to restructure state teacher and leader assessment and evaluation systems, and RTTT grant applications for funding to support education reform in teaching and leading

2. Negative perceptions about NCLB requirements

3. NCLB-waiver states agree to the Obama Administration agenda of college- and career-readiness for students and determining teacher effectiveness, in part, by using student achievement

\section{Section 207 of Higher}

Education Act mandates collection and reporting of data on the quality of teacher preparation 5. States, including Alabama, are allowed some freedom in defining teacher quality and effectiveness 6. National research and reporting has influenced public
National Education Policy

Organizations

1. ALSDE policy actors depend on research-based standards established by professional studies organizations (e.g., NCTM, NCTE, IRA, etc.) as guides for content curricula development, policy, and law in teacher education and development 2. CCSSO INTASC (1992) standards were used to develop AQTS

3. Alabama is an NCATEvolunteer state; 21 out of 27 teacher preparation institutions are NCATE-accredited; thus, NCATE standards are used to structure teacher preparation programs policies and activities 4. NCATE-accredited institutions must prioritize NCATE accreditation requirements in developing their programs 5. Although Alabama is an NCATE-volunteer state, Alabama 
perception that the problem with education is teacher quality

Network of Collective Activity

Tasks
ALSDE, USDE, national policy actors served on the committee to develop AQTS

1. Mandatory reporting to USDE of quality of teacher preparation attributes, as defined by Section 207 of the Higher Education Act 2. Alabama applied for NCLB waiver through Plan 2020; granted one-year freeze on the student testing standard

3. Alabama applied for, but did not receive RTTT funding, but passed influential education is part of the NCATE-State

Alliance

6. Alabama joins NCATE State Alliances for Clinical Preparation, indicating a move toward a sweeping transformation of clinical preparation to align with NCATE standards

7. ALACTE is a state

organization, of teacher education school deans and representatives, charged with forwarding the agendas of AACTE and NCATE

CCSSO/INTASC, national

professional studies organizations, ALSDE, NCATE, Alabama Association of Colleges for Teacher Education (ALACTE), influential state policy actors serve on NCATE boards

1. NCATE and state visits or will visit NCATE-member teacher education institutions for unit and program reviews

2. NCATE schools are required to implement most recent NCATE (2008) standards, the Blue Ribbon Panel Report: Transforming Teacher Education Through Clinical Practice, and any other standards and policy changes 
Interests/Intentions/ Motivations reform legislation in anticipation of immediately

funding

4. Alabama State Board of

Education to design and

implement plan to address how

teacher preparation \&

development, student learning,

and schools overall will be

assessed

5. Plan 2020, Alabama's plan for transforming the state education

system, to be implemented

1. Republican-led Alabama wants to take back full control of education from the USDE, but like most states, funding is needed from the federal government 2. The era of accountability has led to an alignment of interests of traditionalist Alabama and the federal government

3. The Obama Administration allows some leeway to states in designing their own education reform plans, but the plans must include key components of Administration's education agenda: college and career readiness for students, linking student achievement to teacher effectiveness; Alabama's Plan 2020 includes each component
1. NCATE institutions will embrace, conceptualize, and implement continuous improvement models that consistently observe the link between student achievement and teacher effectiveness

2. NCATE institutions revamp their teacher education program(s) to strengthen $\mathrm{P}-12$ partnerships and have clinical experiences as the central focal point of teacher preparation

3. State policy actors who serve on NCATE boards have a dual interest in forwarding the agendas of the state and NCATE 
Conventions

Resources/Power/ Governance
1. States design, implement, and monitor their own education agenda, and report technical compliance to USDE; no direct USDE oversight

2. States must be in direct compliance with USDE regulations to receive funding support for their education agenda

1. USDE can and has withheld funding to states when states are not in compliance with USDE regulations

2. RTTT funding is a way for USDE to garner more control over States' education agendas by withholding much-needed education funding in a recessed economy

3. USDE conception of teacher education and preparation transformation seen as common sense
1. When professional studies organizations update standards, ALSDE policy actors revisit and revise state standards

2. Both the ALSDE representatives and NCATE visit teacher preparation institutions together for accreditation and approval of programs

3. The ALSDE relies heavily on NCATE resources in the state program review and approval process

1. Influential state policy actors have dual positions with NCATE and the state; they have the power to infuse NCATE policies with state policies

2. NCATE institutions pay accreditation dues and fees related to accreditation visits 3. By Alabama combining their program approval process with the NCATE accreditation process, the state saves significant time and expense

4. Alabama relies on the rigor of the NCATE accreditation process in determining the quality of institutions' programs 
Contingencies/

Opportunities

Consequences
1. Presidential election year, therefore no reauthorization of NCLB/ESEA

2. Since NCLB/ESEA has not been reauthorized, Alabama's new governor and state education superintendent are taking the opportunity to reform education within the state, and taking advantage of NCLB waivers 3. ALSDE policy actors took advantage of poor public perceptions of teacher quality in the state to transform teacher education and development policies

1. The development of state standards (i.e., AQTS) and evaluation systems (i.e., AQTS Continuum \& EDUCATE Alabama) aligned closely with national and USDE criteria for transforming teacher education into a system of performance accountability

2. Alabama takes control (via active political intervention and manipulation) of state's education agenda by proposing extensive legislative, regulatory, and budgetary reform which align closely with the national education
1. By partnering with NCATE, Alabama can rely more on the NCATE accreditation and review process to determine the quality of teacher preparation in NCATE member institutions

2. Since an overwhelming majority of Alabama teacher preparation institutions (21 of 27) partner with NCATE, the state is urging, but not requiring, the other institutions to partner with NCATE 3. The ALSDE uses many NCATE indicators in their state review and approval of programs

1. NCATE accreditation is an important indicator of quality 2. The majority of institutions in the State of Alabama are or plan to transform clinical requirements for teacher preparation into a residency model

3. The NCATE Clinical Residency Model enables teacher candidate input and P-12 student output measures to be established to determine quality in teacher preparation

4. The development of a standardized assessment which will be used to eventually 
reform agenda (e.g., Plan 2020, Resolution to Support Charter School Legislation in Alabama, School Flexibility Act of 2012, etc.) to design evaluation systems as performance accountability systems

3. Content knowledge becomes main indicators in determining teacher quality

4. Teacher testing in content knowledge is a precondition for teacher certification; high scores represent high quality

5. What counts as content knowledge acquisition has been expanded to include more hours of coursework in English/language arts, math, science, and social science for prospective elementary teachers measures teacher preparation effectiveness in NCATE institutions 
Throughout the Twentieth Century, responsibility for accountability in public education evolved from being solely under the control of state and local education agencies to being under the purview of the federal government. Accountability is now heavily controlled by the federal government, and indicators of quality and the measurement are greatly influenced by the private national education agencies they collaborate with, support, and endorse. Consequently, the national level of teacher quality policy enactment is linked to the state level through federal legislation and policies; federal funding mechanisms; research, standards, and policies endorsed by policy actors in the United States Department of Education (USDE) and national education agencies; and teacher accreditation organization standards and policies.

No Child Left Behind (2001) legislation, NCLB waivers, and Race to the Top (RTTT) (2009) grant application requirements are the three most influential national level legislative conditions which currently shape teacher quality policy and enactment processes in the State of Alabama. NCATE accreditation standards and policies around teacher qualifications and clinical experiences currently shape expectations for state-level reform in teacher education. An inter-organizational network of policy experts who commission research, disseminate information, and facilitate action around teacher quality and teacher education reform strongly influenced state actors in Alabama to develop and implement policy and legislation aligned with national interests and intentions to redesign accountability in public education into a system of performance accountability. 
As well, the socio-political environment of a perceived lack of quality and quality control in teaching, perpetuated by national-level policy actions, provided a common-sense rationale for policy actors in Alabama to immediately propose changes to law and policy through the development of quality standards for teaching, measures of teacher quality, and the revision of state law to allow for the implementation of new standards and measures of teacher quality in school districts and teacher preparation programs.

Although the political culture in the State of Alabama has historically been referred to as traditionalistic (Elazar, 1984)—a type of culture where the interests of the state are often at odds with the interests of the federal government-the era of federal accountability for quality control in public education, as well as America's participation in a global society, has led to an alignment of national and state interests around restructuring educational systems to meet the needs of global competitiveness. This section will describe the aforementioned linkages between the national and state levels that facilitated the development of current conceptions of teacher education quality laws, policies, and standards in the State of Alabama. Later, an explanation of how such linkages have led to changes in teacher quality policy implementation at a private school of education whose operations effectively serve as model for all teacher preparation institutions in the State of Alabama.

\section{Legislative Linkages}

The current enactment of teacher quality laws, policies, and standards in the State of Alabama are directly linked to the "highly qualified teacher" statute of 
NCLB (2001), the $10^{\text {th }}$ anniversary of NCTAF's (1996) What Matters Most call for the nation to provide all children with a "qualified" teacher (Rogers \& Thacker, 2006), and the INTASC Model Standards for Beginning Teachers developed by CCSSO in 1992 (T. Johnson, ALSDE Office of Teaching and Leading, interview, February 28, 2012). Approximately four years before the enactment of NCLB federal legislation holding states accountable for the quality of their teaching force, Alabama Republican Governor Fob James established a state Task Force on Teaching and Learning (ALSDE, 2006).

The Task Force, comprised of public policy representatives, business leaders, and educators, was charged with taking a critical look at the impact teachers have on student achievement. The policy report created by the Task Force, titled Teaching and Learning: Meeting the Challenge of High Standards (2000), indicate the state's interests, intentions, and motivations to raise student achievement by establishing high standards for teachers and to reform teacher preparation to include "extensive clinical experiences and strict accountability for results" (ALSDE, 2006, p. 4).

Although education policy actors in Alabama were already addressing the issue of teacher quality in the state, the enactment of NCLB provided the legal context by which policy actors developed state standards for teacher quality, and created and modified laws and policies that would require the implementation of such standards in teacher preparation and teaching as a whole (T. Johnson, ALSDE Office of Teaching and Leading, interview, February 28, 2012). The NCLB "highly qualified teacher" statute was used by policy actors in the Alabama 
State Department of Education (ALSDE) to institute teacher testing as a precondition for initial certification and to change the content requirements for initial certification in elementary education.

The NCLB "highly qualified teacher" statute specifically required that elementary education teachers pass a standardized test to prove they were highly qualified to teach. Prior to NCLB, Alabama only tested prospective teacher education students using a standardized basic skills assessment called the Alabama Prospective Teachers Test (APTT). This assessment was used as a precondition for admittance into teacher preparation programs. Prior to NCLB, an exit exam was not a condition for teacher education certification in the State of Alabama.

ALSDE policy actors, many education deans in the state, and the public favored a teacher testing certification requirement, yet litigations since 1981 prevented Alabama from instituting teacher testing for initial certification ( $T$. Johnson, ALSDE Office of Teaching and Leading, interview, February 28, 2012). The enactment of NCLB provided an opportunity for policy actors in the ALSDE and the Alabama State Board of Education (ALBOE) to petition the court for such an allowance. This issue was clarified by a top official in the ALSDE Office of Teaching and Leading:

When the NCLB was implemented and made effective retroactively, we could not test teachers for certification purposes with anything other than a basic skills test which does not measure content knowledge. So we used 
[the NCLB] impetus to go back to court and say to the judge, 'We are in a difficult position, the federal law is requiring us to test elementary teachers.' The resolution of that was that Judge Myron Thompson said, 'the Alabama Board of Education and the State Department of Education has done everything that I required of them in 1981. And we are setting aside the court ruling with prejudice... and Alabama may implement a teacher testing program for all teachers. (T. Johnson, ALSDE Office of Teaching and Leading, interview, February 28, 2012).

Judge Thompson's ruling opened the door for Alabama to legally implement a teacher testing policy for initial certification.

The other impact the NCLB "highly qualified teacher" statute had on initial certification in elementary education was the requirement of the number of courses that counted as content knowledge. In order to be in compliance with NCLB, the ALSDE "prescribed" that any student recommended for elementary education certification after June 30,2005 had to have "12 hours of academic credit in each of four disciplines: English/language arts, mathematics, science, and social science" (T. Johnson, ALSDE Office of Teaching and Leading, interview, February 28, 2012). For many of the teacher preparation institutions in the state, it increased the number of content hours elementary education majors had to earn in mathematics and science (T. Johnson, ALSDE Office of Teaching and Leading, interview, February 28, 2012). 
The change also required any student pursuing alternative baccalaureate certification "to have as much content area knowledge as if they had done an undergraduate program" in, for example, mathematics, science, language arts, or social sciences (T. Johnson, ALSDE Office of Teaching and Leading, interview, February 28, 2012). With one broad stroke of accountability-cloaked legislation, content knowledge became a major indicator of teacher quality for prospective and in-service teachers at both the federal and state levels.

Following the changes to certification requirements was the statewide reconceptualization of what teacher quality means. In January 2006, Republican Governor Bob Riley formed a commission, named the Governor's Commission on Quality Teaching (GCQT, 2006a), to "examine, recommend, and work to implement laws, policies, and practices affecting teachers and teaching effectiveness to ensure student success in Alabama's public schools" and to "promote the aggressive recruitment, preparation, support, retention, and growth of quality teachers in order to raise student achievement in Alabama" (p. 1). Within the GCQT were five task forces, including one task force each for standards, teacher preparation, and certification.

The GCQT consisted of educators, education policy makers, and business leaders within the State of Alabama. According to one ALSDE official who was deeply involved in leading the efforts to re-conceptualize teacher quality in the State of Alabama, the Commission's recommendations were guided by influential policy actors in national level, private educational policy organizations.

According to K. Holmes, a senior manager in the ALSDE Office of Research and 
Development, GCTQ's collaboration with Tom Carroll of the National Commission on Teaching and America's Future (NCTAF), Barnett Berry of the National Council on Teacher Quality (NCTQ), and Caroline Novak and Jackie Walsh consultants with the Alabama Best Practices Center, "was very beneficial to [the Commission] in helping [them] to integrate a national approach into [their] state initiative" (interview, March 12, 2012).

Jackie Walsh "advocated that [the Commission] take a strong look at" exemplary teacher preparation programs across the nation (K. Holmes, ALSDE Office of Research and Development, interview, March 12, 2012). Not only did Commission members consult national-level policy actors in their initiative to reform teacher quality in the state, but the initial report from the GCQT also indicates they examined research on policy action and best practices in teacher preparation programs identified by Linda Darling-Hammond and Arthur Levine as exemplar. The aspects Darling-Hammond and Levine identify as exemplars are directly aligned with the interests and intentions of the federal government, national education policy organizations, and national accreditation organizations for reform in teacher education into a model of performance accountability. These include, linking teaching success with student achievement, reconceptualizing clinical programs to be lengthier and based on P-12 needs, and raising the requirements for admittance to teacher preparation programs and teacher education certification. One such teacher education institution recommended was University of Virginia's Curry School of Education (K. Holmes, ALSDE Office of Research and Development, interview, March 12, 2012). 
The Alabama Quality Teaching Standards (AQTS) and its companion piece, the Alabama Continuum for Teacher Development (the Continuum), were two policy documents produced by the GCQT to provide "a comprehensive underpinning for Alabama's teaching profession" (GCQT, 2006b, p. 3). The development of the AQTS was heavily influenced by national-level policy. The AQTS "reflect and expand upon what was called Professional Studies Standards and those grew out of the Model Standards for Beginning Teachers, which originated from the INTASC group at CCSSO" (T. Johnson, ALSDE Office of Teaching and Leading, interview, February 28, 2012).

Developed in the early-1990s, INTASC standards have become a national symbol for quality teaching standards. According to an ALSDE policy actor, the GCTQ placed high value on INTASC (1992) standards: "The feeling amongst the people in the Commission is that [INTASC standards] were almost universally accepted as a good set of standards to move forward" (K. Holmes, ALSDE Office of Research and Development, interview, March 12, 2012). Although the final AQTS product is quite different from the 1992 INTASC standards, the INTASC influence is evident in the language and indicators designated as important in teacher quality; for example, content knowledge, assessment, teaching and learning, diversity, literacy, diversity, professionalism, collaboration (Morton, 2007).

There is another important convergence of interests between the national and state levels that was perpetuated by the socio-political impact of NCLB implementation and the Obama Administration's use of NCLB's failures to 
forward their educational reform agenda. By the time Alabama elected a new Republican governor in 2010, the consequences of NCLB implementation were seen in the negative feelings the public, educators, and policy makers in the state had about the federal legislation. Teachers were spending more time developing "their HOUSSE portfolios" to show proof that they were highly qualified rather than spending time on teaching duties (T. Johnson, ALSDE Office of Teaching and Leading, interview February 28, 2012).

Although local education agency and state administrators were cooperative in assigning staff to technically review teachers' highly qualified statuses, the state-level NCLB implementation process "led to a lot of hard feelings [and] animosity" among them (T. Johnson, ALSDE Office of Teaching and Leading, interview February 28, 2012). Parents were confused as to why a teacher who had taught their children for many years was required to prove she was qualified to teach under the new law. "[Parents] didn't want to hear about federal legislation" (T. Johnson, ALSDE Office of Teaching and Leading, interview February 28, 2012). Such contingencies provided a context for Alabama to jump at the opportunity to move beyond NCLB accountability requirements when it was presented through NCLB waivers by the Obama Administration.

Republican Governor Bentley was elected at a time when President Obama and the U. S. Department of Education (USDE) were engaged in implementing Secretary Duncan's ESEA waiver authority, referred to as the NCLB waiver. Policy actors in Alabama took the NCLB waiver opportunity as a 
sure way to move past the strict accountability requirements of NCLB. At the direction of Governor Bentley, the Alabama State Department of Education's (ALSDE) submitted Alabama Plan 2020: ESEA Flexibility Request (Plan 2020) to the USDE in hopes of being granted an NCLB waiver (ALSDE, 2012).

Plan 2020 is not only the state's ESEA flexibility request, but it is also the state's plan for a "comprehensive and strategic progression...that will culminate in a system that will use the college- and career-readiness of its graduates as its measure of success" in education (ALSDE, 2012, p. 16). The three priorities of the NCLB waiver application are: "college- and career-ready expectations for all students; state-developed differentiated recognition, accountability, and support; and supporting effective instruction and leadership" (ALSDE, 2012, p. 24). Consequently, Plan 2020 has as its central focus improving student achievement by preparing students for college and career; a redesign plan for accountability and support; and new standards, policies, and measures of teacher and leader quality. Plan 2020 "is not only completely aligned with the principles of [the] Elementary and Secondary Education Act (ESEA) flexibility waiver request, [the ESEA waiver principles are] its foundation" (Alabama School Connection, 2012a, p. 9).

In addition to the alignment of state and national priorities, the language of Plan 2020 suggests the USDE and the ALSDE are on one accord with measures of student and teacher effectiveness. Plan 2020 specifies that student achievement will be measured through standardized tests and value-added or growth measures (ALSDE, 2012). The effectiveness of teachers and leaders will 
be determined by an evaluation system which is centered on teachers' impact on student achievement (ALSDE, 2012). As evidence that state policy actors plan to use national legislation as a rationale to link teacher inputs and student achievement in evaluating the effectiveness of educators, Alabama's NCLB waiver application states, "This ESEA Waiver Application, and the flexibility that it would afford should it be approved, would provide additional impetus for the state to create a viable, valid and reliable evaluation system that links [teacher and leader] effectiveness to student achievement" (ALSDE, 2012, p. 27).

The other condition that constitutes a linkage between the national and state levels is the dependence on education funding Alabama has on the federal government. As a policy actor in the ALSDE Office of Research and Development said, "Quite frankly, because of our [low] tax structure in [Alabama], we have a dependence on federal funds. And recognizing that dependence, obviously we have to look at what the federal government is doing and making sure we stay within the guidelines of the federal government" (K. Holmes, ALSDE Office of Research and Development, interview, March 12, 2012). The power of the federal government to control state educational systems through funding mechanisms is exhibited in how Race to the Top (RTTT) (2009) funding was awarded. Some key characteristics for RTTT (2009) awards were the use of value-added modeling in teacher evaluations, making provisions for the establishment and expansion of charter schools, and the adoption of the Common Core Standards for K-12 education. In order to be more competitive in 
winning RTTT (2009) funds, Alabama legislatures changed some fundamental aspects of the Alabama educational system.

In 2010, the same year the Phase 1 RTTT (2009) applications were due to the USDE, policy actors in the ALSDE, led by Governor Bob Riley, passed resolutions that mirrored requirements for RTTT (2009) funding. "The State Board adopted a resolution saying that ultimately we're going to have to be able to tie summative assessment to multiple measures of student achievement, to at least some degree" (K. Holmes, ALSDE Office of Research and Development, interview, March 12, 2012). This resolution was passed in the midst of debate among state-level policy actors on the fairness of using student achievement results to hold teachers accountable. In January 2010, "the State Board of Education unanimously adopted Resolution in Support of Charter School Legislation in Alabama" (ALSDE, 2010); an action done in an effort to increase the likelihood of being granted RTTT (2009) funds (J. Miller, ALSDE Legislative Liaison, interview, March 12, 2012). The Common Core Standards, the performance standards for P-12 education, were adopted by the State BOE in November 2010.

Alabama applied for Round 1 and Round 2 of RTTT (2009), both with unsuccessful results. It is not clear whether policy actors in the ALSDE and state BOE used the potential for RTTT (2009) funding as a means to forward their preestablished agenda to reform education in the state, or if the state education reform agenda was a consequence of Alabama's need for additional funding for 
public education. When state-level policy actors were asked specifically about the timeline, mixed responses were given:

Researcher: So did the Race to the Top funding propel the State to make changes to the teacher evaluation system?

K. Holmes: To make sure we link teacher effectiveness to student achievement scores. In some ways. Yes. It is amazing the tension that occurs within these states that got RTTT money, and are required to have these systems in place at the end of the year. Some of them are saying, 'I don't know how. I don't know how we're going to do it.' Basically because you can craft something that looks good on paper, but will it withstand the legal challenges that are sure to occur when you start to make decisions about someone's future based on student achievement. There's always that in the background. I think we have done an exceptional job in $\mathrm{AL}$, in that we have crafted an online formative assessment piece, with the premise that if we can help every teacher grow, then every student benefits, Educate AL.

Researcher: Was this assessment piece active when the state applied for Race to the Top?

K. Holmes: Some of it, yes. (K. Holmes, ALSDE Office of Research and Development, interview, March 12, 2012)

In an interview with a top official in the ALSDE Office of Teaching and Leading, the response was less direct: 
Researcher: Did value-added teacher evaluations, the charter school expansion, and the adoption of the Common Core happen before the Department of Education applied to Race to the Top? Was all that instituted before?

T. Johnson: Well, we had to show we had those things in place on the application. But when Alabama submitted two applications for Race to the Top funds, it was not funded. There are some individuals who believe that was a blessing. And one of the discussions was, is it fair to expect children to progress and to hold teachers accountable, and is it fair to assume that every child who enters 6 th grade will be at the 6th grade level and will be at 6 years plus 9 months at the end of 6 th grade, and how do you know? It's an ongoing discussion.

Researcher: So you're saying the state had a student-teacher model in place before the Race to the Top application?

T. Johnson: That's still an ongoing discussion. But we're working on a model that works.

Researcher: What about the charter school resolution?

T. Johnson: That may have been a result of the funding application. I'm not sure. (T. Johnson, ALSDE Office of Teaching and Leading, interview, February 28, 2012) 
There is a direct alignment between certain aspects of RTTT (2009) funding requirements and components of legislation approved by the ALBOE around the time Alabama submitted applications for RTTT (2009) funding: valueadded modeling to assess teacher effectiveness, provisions for charter school establishment and expansion, and the adoption of the Common Core Standards. An ALSDE legislative liaison stated that the state charter school resolution is directly tied to the RTTT (2009) funding application:

[Race to the Top] was a grant application. States could get so many dollars if you met, or if you scored whatever. It was being spear-headed by the federal government, and the state could get so much money with regard to their application for this grant. And you had to meet certain criteria. And at that time one of the criteria was if you had charter schools in the state. So that kind of tied in with when the legislation was being proposed with regard to that (J. Miller, ALSDE Legislative Liaison, interview March 12, 2012).

Legislative resolutions passed around the time of the RTTT (2009) application show the intentions of the ALSDE to reform Alabama's educational system into a system of performance accountability. For instance, one policy actor stated:

As a matter of fact, the State Board adopted a resolution saying that ultimately we're going to have to be able to tie summative assessment to multiple measures of student achievement, to at least some degree. That has been adopted by the State Board of Education. (K. Holmes, ALSDE Office of Research and Development, interview, March 12, 2012) 
The Alabama State Board of Education actions of passing resolutions to establish and expand charter schools, and link student and teacher data for evaluations of teacher effectiveness; as well, as the adoption of the Common Core Standards, provides several examples of the national and state levels aligning under conditions of neoliberalism. Linkages between the state and national education policy organizations provide further examples.

Linkages between National Education Policy Organizations and the State Another important linkage between the national and state levels is in the power national education organizations have to influence state education policies, especially policies on teacher quality. Policy actors at the ALSDE depend on research-based standards established by professional studies organizations to provide direction on how content curricula should be structured. Organizations like CCSSO and NBPTS provide frameworks of indicators of quality teaching, overall. As previously mentioned, policy actors at the ALSDE used INTASC (1992) standards as a starting point when developing their state standards for teacher quality.

The National Council for the Accreditation of Teacher Education (NCATE) standards provide indicators of content, pedagogy, professionalism, and clinical program structure. NCATE is one of the most influential organizations that shapes how many states structure their teacher preparation programs, especially in states where NCATE accreditation is mandatory. Although Alabama is an NCATE-volunteer state, meaning teacher education institutions are not 
mandated to be accredited by NCATE, NCATE standards and policies have shaped state standards, policies, and actions in teacher education.

NCATE and national education professional organizations like the National Councils of Teachers of English, Mathematics, and Science directly shape Alabama state law and policy regarding teacher quality in teacher preparation. Policy actors in professional education organizations have the power to set the course for what counts as content knowledge in teacher preparation programs in Alabama. Whenever professional organizations update their standards, policy actors in the ALSDE's Office of Teaching and Leading commission content-area experts to review and revise state standards. According to a policy actor in the ALSDE Office of Teaching and Leading this conventional process has been going on in Alabama for almost thirty years:

Years ago, an organization called NASDTEC, which is the National Association for State Directors of Teacher Education and Certification, set recommended standards for the various teaching fields and instructional support areas...NASDTEC stopped that effort when the NCATE became more instrumental in working with the specialty organizations that represent different parts of the profession; such as the National Council of Teachers of English, National Association of Science Teachers, etc. So NASDTEC moved away from that, but you can still go back in Alabama program approval standards and find some updated wording that was generated from those old NASDTEC standards. And when I say NASDTEC gave out that effort, it was probably about 1985 . So we 
continue now to be guided by the National Standards for Teachers of English, Math, and Science, and all of the different disciplines. And those standards are updated periodically, and whenever they are we take a look at our standards, the standards adopted by the State Board of Education. If there are major changes then we can move forward to make changes in our standards. (T. Johnson, ALSDE Office of Teaching and Leading, interview, February 28, 2012)

Not only do professional studies standards dictate the bulk of the content that will be implemented in teacher preparation programs in Alabama, but the state teacher education program approval process includes a technical review of professional studies standards implementation. The NCATE accreditation review process includes an evaluation of the implementation of professional studies standards in teacher preparation programs, as well. Since Alabama is an NCATE-volunteer state, the ALSDE has "chosen to do the program review" separately from the NCATE process (T. Johnson, ALSDE Office of Teaching and Leading, interview, February, 28, 2012). This means that in the 21 of 27 teacher preparation institutions in Alabama, NCATE and the state conduct a joint review of teacher education programs; while in the six non-NCATE institutions the state program approval process includes a non-NCATE-related technical review of professional studies standards implementation.

Another linkage between NCATE and the state level is the establishment of a state organization, the Alabama Association of Colleges of Teacher Education (ALACTE), which effectively serves as a committee to forward the 
agendas of American Association of Colleges of Teacher Education (AACTE) and NCATE in Alabama's NCATE partner institutions (ALACATE, 2004). ALACTE member institutions must be "regionally accredited colleges and universities in Alabama which are AACTE member institutions. Regionally accredited colleges and universities in Alabama which are not affiliated with AACTE are eligible for associate membership" (ALACTE, 2004, para. 5). ALACTE officers are elected by individuals from the member institutions, and include officials such as deans, department chairs, teacher certification officers, and teacher education faculty members at NCATE-accredited institutions within the state. The interests and intentions of ALACTE members are to collaborate and negotiate with NCATE and state department of education to better understand the policies and standards they are required to implement in their respective schools of education.

A review of 2012 ALACTE meeting notes reveals a state agenda to transform quality control in NCATE partner institutions into a system of performance accountability. The documents also reveal an interesting parallel in education policy actions between the ALSDE and the USDE. Much like the federal-level NCLB waiver, the ALSDE plans to grant teacher education institutions "flexibility with regard to state laws, including State Board rules, regulations and policies, in exchange for exceptional levels of results-driven accountability" (ALACATE, 2012, para. 1). Additionally, flexibility contracts will be granted to institutions "to support innovation in their programs, particularly with regard to developing more clinically-based programs as outlined in NCATE's 
Blue Ribbon Panel (BRP) Report" (NCATE, 2010b, p. 1). The results-driven accountability and residency model for teacher education clinical experiences are directly aligned with USDE indicators of quality teacher preparation programs.

This indicates an interesting power dynamic occurring within the NCATEState partnership in Alabama. State policy actors who also serve on NCATE boards use their power and influence to achieve common NCATE-State intentions. As an NCATE-volunteer state, no teacher education program in Alabama is required to implement NCATE standards and policies. However, influential teacher education policy makers in the state serve on several NCATE boards. For example, the head of the ALSDE Office of Teaching and Leading, the most influential policy actor responsible for the implementation and oversight of state quality policies in teacher education, sits on the NCATE Board of Examiners (BOE). The NCATE BOE determines the accreditation status of NCATE-institutions, develops standards and procedures for accreditation of teacher education units and programs, and oversees site visits to NCATE institutions (NCATE, 2012).

A teacher certification officer-at a teacher education institution not under investigation in this study — who was heavily involved in the development of the Alabama Quality Teacher Standards (AQTS), and is often called upon to serve on state committees to revise standards, has a dual role serving on NCATE committees. He serves on the NCATE steering committee, is a member of the Board of Examiners at the state and national level, and is the NCATE chair at his institution. 
Serving as both a State policy maker and an NCATE policy maker means that there is role in forwarding the interests of both the state and NCATE. As such, it is no surprise that NCATE standards and policies for clinical preparation are being used to establish Alabama standards and policies for clinical preparation. Two State education policy actors who also serve on NCATE boards make reference to state policy actors' interests in implementing the new residency model for clinical preparation in all teacher preparation programs in the State of Alabama:

One of the things we talked about extensively [with the Alabama Teacher Quality Standards] was the need to contextualize teacher preparation to the $\mathrm{K}-12$ setting as more of a residency model. And we have that occurring across the state at differing degrees. So being able to get in a classroom on a regular basis for an extended period is something that needs to occur in teacher preparation throughout the state. (K. Holmes, ALSDE Office of Research and Development interview, March 12, 2012)

The other policy actor said:

I know a lot of people have talked about the medical model, the clinical rounds model. I think that would probably strengthen teacher education. (E. Jones, NCATE National-State BOE Member, interview, March 5, 2012)

One purpose of the NCATE-State Alliances for Clinical Teacher Preparation is for NCATE partner institutions to serve as sites for the implementation of the new residency model of clinical preparation proposed in 
the NCATE Blue Ribbon Panel Report (Howey, 2011). The teacher preparation institution involved in this research study serves as the state model for implementing NCATE's "upside down" clinical practice model (K. Holmes, ALSDE Office of Research and Development, interview, Mach 12, 2012).

Before NCATE revised standards for clinical models, the partnerships between schools of education and P-12 schools were designed where a teacher candidate was assigned to a school, a class, and a cooperating teacher. Under the tutelage of the cooperating teacher, the student was only required to meet the needs of the students in the class. The teacher candidate had no additional school-wide responsibilities. Such an arrangement placed the university and student at the top of the clinical model. The "upside down" clinical model flips clinical experiences by placing the P-12 school and class at the top of model. The goal of the new model is to provide teacher candidates with a more realworld professional learning experience. Teacher candidates have a responsibility to conduct themselves as they would if they were the full time teacher-of-record. This involves such responsibilities as interacting with administrators, serving on school-wide improvement teams, engaging in learning communities with other teacher candidates and teachers, and ultimately meeting the needs of the school and the class, rather than meeting the needs of the class and cooperating teacher only.

The "upside down" clinical model converts clinical experiences into the onthe-job-training residency model; a model also endorsed by the USDE. Statelevel policy actors' attempts to implement this clinical residency model throughout 
the State of Alabama represents the neoliberal characteristic of the state establishing new institutional norms, practices, and common-sense values. The new model for clinical practices also enables the establishment of direct links between teacher candidate inputs and student outputs. If implemented as intended by NCATE and the State, teacher candidates will serve as the teacherof-record for an extended period of time. This will make it easier to establish a teacher candidate evaluation system that links student achievement to teacher

inputs. Such a structure enables the application of the neoliberal characteristic of efficient, formal input/output processes in teacher preparation.

Summary of the Transformation of Legislative Intentions: National and State Linkages

Teacher quality policy enactment and implementation are linked at the national and state levels through federal accountability legislation, a national socio-political environment of a perceived lack of quality in teaching and teacher education, NCATE accreditation standards and policies on teacher qualifications, and an inter-organization network of national policy actors' research and action around teacher quality and teacher education reform which inform the decisions of policy actors' at the state level. Performance accountability policies of the federal government have trickled into teacher quality accountability policies, processes, and actions at the state level, resulting in an alignment of national and state interests and intentions. As such, teacher quality legislation, policies, actions, and decisions in the State of Alabama have been transformed to closely resemble legislation and policies at the national level. 
NCLB transformed state policies in teacher education and preparation by having states require more content courses and teacher certification examinations as proof of content knowledge. Content knowledge, then, became a significant indicator of teacher quality in the State of Alabama. NCLB and the national focus on redefining teacher quality led to the policy action of Governor Bob Riley establishing a commission to review research, draft policy and standards, and recommend actions related to teacher quality preparation and development and teacher certification. The Governor's Commission on Teacher Quality (GCTQ) collaborated with policy actors in private national education policy organizations to draft teacher quality policy documents and evaluation systems which reflect characteristics of national-level interests and intentions to redesign teacher education evaluation into a system of performance accountability.

For example, during discussions about Alabama's quality teacher standards and policies, the GCTQ sought the advice of Tom Carroll, from the National Commission on Teaching and America's Future (NCTAF) and Barnett Berry, from the National Council on Teacher Quality (NCTQ) (K. Holmes, ALSDE Office of Research and Development, interview, March 12, 2012). Governor Riley's policy actions and the actions of policy actors on the GCTQ are an example of conventions used by politicians to accomplish their interests and control the direction of policy.

The NCLB waiver application requirements, put forth by policy actors in the Obama Administration, provided the context for Alabama's current governor, 
Robert Bentley, to reform significant aspects of Alabama's educational system, including adding evaluation systems which tie teacher inputs to student outputs, passing a resolution to establish and expand charter schools, and the adopting national-level Common Core Standards for K-12 education. All such policies and actions were required to be active in states submitting applications for NCLB waivers and Race to the Top (2009) funding. Alabama was granted an NCLB waiver, but was denied RTTT (2009) funding. However, the policy changes which reflect a teaching and learning evaluation system of performance accountability remain in place.

The network of collective activity between state and NCATE policy actors, as well as the State of Alabama joining the NCATE-State Alliance for Clinical Teacher Preparation, has set conditions for a performance accountability system at the state level to be transformed into a similar system at the teacher preparation program level. The new residency model for field and clinical experiences will allow policy actors in the state and NCATE to make program approval and national accreditation decisions, respectively, based on teacher candidates' impact on student achievement.

There are several neoliberal conditions exhibited through national and state linkages. The USDE, NCATE, and the state are actively intervening and manipulating policies in $\mathrm{K}-12$ and/or teacher education institutions by legislating requirements for evaluations systems in teaching and learning. The teacher input/student output processes and standardized, predetermined measurable indicators of performance provide a system of performance accountability where 
it will become easier for systems and the state to make human capital decisions. As such, the state has acquired a new identity as the "protector of capital" (Baltodano, 2012, p. 493) where its new role is to enhance social and educational policies to protect the market. A system of performance accountability reduces the complexities of teaching and learning to snapshots of achievement to quickly determine competitiveness—among students, districts, states, and ultimately the nation-in a global society. The next section, which begins with a summary table, presents findings at the state level of teacher quality enactment and implementation. 
The State Level

Table 4

The State Level

Conditions

1. A low-tax state with a traditionally low-level of expenditures for public education

2. A traditionalist socio-political context situated in a national neoliberal socio-political context

3. Negative state perceptions of public education and teacher quality

4. An alignment of state and national policy and legislation on public education and teacher quality

5. An alignment of national education organization and state policy on public education and teacher quality. 6. Traditionally, the purpose of education has been to prepare students to work in the state's manufacturing and industrial industries

Network of Collective Activity

Tasks

Interests/Intentions/ Motivations
Governor as the president of the BOE, State Superintendent of Education, ALSDE policy actors, Alabama State Board of Education, national policy actors who served on the committee to develop AQTS, education deans, department chairs, and designees, state business leaders

1. Mandatory reporting to USDE of quality of teacher preparation attributes, as defined by Section 207 of the Higher Education Act

2. ALSDE to design and implement plan to address how teacher preparation \& development, student learning, and schools overall will be evaluated and assessed

3. Implement AQTS, the AQTS Continuum, EDUCATE Alabama

4. Plan 2020, Alabama's plan for transforming the state education system, to be implemented

5. Structure the ASLDE to maximize the link between teacher inputs and student outcomes by creating a datadriven symbiotic system of all things related to teacher education and development and student achievement 6. Implement a residency model for clinical preparation in teacher education programs

1. Performance-accountability systems in P-12 and teacher education, preparation, \& development through establishing data-driven systems tying teacher quality to 
student achievement

2. Increased student achievement, teacher

effectiveness, teacher retention, and teacher distribution

3. College- and career- readiness for P-12 students

4. Reform teacher education, preparation, \& development to improve education systems, through aggressive implementation of AQTS standards in teacher preparation programs

5. Holding universities accountable for offering exemplary teacher preparation programs

6. Creating competition among teacher education providers

7. Increase efficiency in state education delivery, \& assessment and evaluation systems

8. Standardized teacher preparation programs, including clinical experiences and program evaluations

Interactions

Conventions

Resources/Power/ Governance
1. State policy actors collaborated with national education policy actors \& researched model teacher education programs from across the nation to make decisions about how to structure state teacher quality policies and standards

2. Influential state policy actors serve dual roles on national education committees (e.g., NCATE) and use such experiences to make decisions about state education policies in teacher education

1. Governor serves as state board of education president

2. Education law and policy governed by state legislature and ALSDE

3. Education law and policy procedures promulgated by the ALSDE as delineated in Title 16 and Chapter 290-3-3 of the Code of Alabama and the Alabama Administrative Procedures Act, respectively

4. Education law and policy typically initiated by state legislatures and ALSDE policy actors

5. Business leaders (along with education policy actors) have historically serves as resources in developing state education initiatives and plans

1. Governor serves as the president of the State Board of Education

2. The state establishes quality laws and policies that are required to be implemented in teacher preparation programs

3. The state holds teacher preparation institutions 
Contingencies/

Opportunities

Consequences accountable for aligning program standards with state and national standards through regular reviews of programs

4. Influential state policy actors have dual positions with NCATE and the state; they have the power to infuse NCATE policies with state policies

5. Alabama relies on the rigor of the NCATE accreditation process in determining the quality of institutions' programs

1. Through education tasks forces, commissions, laws, and policies, like the Alabama Education Improvement Act (1991) and the Governor's Commission on Teacher Quality (2006), Alabama governors have taken advantage of the national Standards-Based Reform Movement and attempted to align state education initiatives with national standards

2. Due to NCLB legislation, the ALSDE took the opportunity to institute state-wide teacher certification testing and increase the number of content credit hours required to complete most education programs

3. As a result of NCLB "highly qualified teacher" initiative, state policy actors took the opportunity to blame the state's failing schools on the lack of quality in the teaching force

1. State education and teacher preparation program assessment and evaluation systems modeled after national systems of performance accountability

2. Mandated teacher certification testing

3. Mandated increased content, through credit hours, required for certification in most education programs 4. Quality teaching standards (i.e., AQTS, AQTS Continuum) aligned with national education policy standards centered on performance accountability 5. Establishment and expansion of charter schools through the Education Options Act (2012)

6. Flexibility in improving under-performing schools through the School Flexibility Act (2012), which is a replica of Race to the Top

6. Adoption of national Common Core Standards (performance accountability standards for P-12 students) 
As neoliberal ideology influences economic and political action, the state assumes a new role as the protector of capital and, for education, the enactor of social and educational policies to nourish and protect the market (Brown, 2003, as cited in Baltodano, 2012, p. 493). The socio-political, cultural, and economic factors, circumstances, and events at the state level which have specifically led to the university and teacher preparation program action context regarding teacher quality include: (1) a low-tax state with traditionally low-level expenditures for public education, (2) a traditionalist socio-political context situated in a national neoliberal socio-political context, (3) negative state perceptions of public education and teacher quality, (4) an alignment of national and state policy and legislation on public education and teacher quality centered on performance accountability, and (5) an alignment of national education organization and state policy on public education and teacher quality centered on performance accountability.

Within this section, such conditions will be illuminated, and will serve to link teacher quality policy processes at the university and program levels of the policy enactment and implementation process. Alabama's dearth of expenditures in public education and its influence on education policy actions in teacher education will be reviewed. The backgrounds, experiences, decisions, actions, and political stances of policy actors in five governorships will be linked to theoretical constructs of neoliberal ideology. The educational system in Alabama has historically been designed to serve the needs of the state economy. This aligns directly with neoliberal ideology. The power and influence of federal 
and state oversight, and the role of national accreditation in shaping teacher quality policies in the state and teacher preparation institutions will also be reviewed. Finally, ways in which the political structure in Alabama provides opportunities for state policy actors to pass education reform laws with little to no political consequence will also be discussed.

Within the context of state-level conditions, networks of collective activity, tasks, interests/intentions/motivations, resources/power/governance, contingencies/opportunities, and consequences that also influence how teacher quality is currently conceptualized in the State of Alabama and in a program in one teacher preparation institution will be reviewed. The state-level conditions, nested in national-level conditions, explain why policy actors at the teacher preparation program level interpret, decide on, act on, and develop implementation activities as they do.

\section{Sweet Home Alabama: A Traditionalistic Political State}

In order to fully understand the transformation of teacher quality policy in teacher preparation programs in the State of Alabama, an understanding of the historical socio-political context under which education policy formulates and is enacted is necessary. The State of Alabama has a long and checkered history of racially- and economically-based segregation in public schools; significant race- and socioeconomic-based gaps in student achievement, as evidenced by standardized test scores; and low investment in public education. The socio- 
political culture in Alabama, like most southern states, has been characterized as traditionalistic (Elazar, 1984; Thomas \& Stewart, 1988; Johnson, 1976).

In a traditionalistic political culture, the role of government is for the societal elite to serve in high office, and govern in a way that maintains the existing social and economic hierarchy (Elazar, 1984). In a traditionalistic culture, a system of one-party politics is instituted and maintained in which, "policy is not determined by competing group forces or shared concerns for the public interest, but by self-interested individuals seeking to maintain their social, economic, and political positions of power" (Permaloff \& Grafton, 2008, p. 64). Another significant factor of a traditionalistic political culture is that the politics and interests of the state are often divergent from that of the national government (Elazar, 1984; Permaloff \& Grafton, 2008).

In the State of Alabama, power and control over law and policy rests solely in the governor, lieutenant governor, and state legislature. For most of the Twentieth Century these positions were dominated by an alliance of socially conservative Democratic Party politicians whose major concerns were grounded in building the industrial and agricultural sectors of the state economy (Permaloff \& Grafton, 2008; Thomas \& Stewart, 1988). As such, the intention of this alliance was to establish laws and policies which ensured low taxes, an education system for the purpose of building the state's farm and factory labor force, "no effective labor unions, a small electorate, and racial segregation" (Permaloff \& Grafton, 2008, p.1). The powerful political alliance achieved their vision through the 
disenfranchisement of voters and maintaining control of the legislature (Permaloff \& Grafton, 2008; Thomas \& Stewart, 1988).

Socially conservative Democrats effectively maintained control over the state legislature from 1825 until 1987, when the voters elected their first socially conservative Republican governor. In 2010, for the first time in 136 years, control over both houses of the Alabama legislature was shifted to the Republican Party. Although political party rule has changed, the purpose of education to prepare students to contribute to the growth of the state economy remains intact, and is now aligned with national neoliberal interests of global economic growth and competitiveness.

Education Law and Policy Processes in the State of Alabama: Teacher Quality

In the State of Alabama, the teacher quality policy enactment process occurs in three phases: the legislative phase, the policy development phase, and the implementation phase. Processes at the state legislative level provide the legal conditions under which teacher quality law is mandated across the state. Policy and standards documents serve to operationalize the law. Local school systems and teacher preparation institutions use the language of the policy and standards documents in the implementation phase. The first two phases of the enactment process are controlled by a select few powerful political leaders in the state. The third phase is controlled by three groups of street-level bureaucrats at the teacher preparation institution level: (1) the senior managers, who are the deans and directors; (2) the program implementers, who are faculty members; 
and (3) teacher education program candidates. As will be explained in depth later, the latter group, the teacher candidates, are unaware of the political aspects of their profession despite being the group most affected by teacher quality law, policy, and standards. The teacher candidates are the group most responsible for P-12 students' academic and social development, as they will eventually serve as full time teachers.

Education law and policy in the State of Alabama are governed by the state legislature and the Alabama State Board of Education (ALSDE). The two most powerful leaders in the ALSDE are the governor, who also serves as the president of the state board of education, and the state superintendent of education. Education law and policy procedures are promulgated by the ALSDE as delineated in Title 16 and Chapter 290-3-3 of the Code of Alabama and the Alabama Administrative Procedures Act, respectively. Education law and policy in Alabama are typically initiated one of two ways: through state legislatures or through policy actors in the ALSDE (J. Miller, ALSDE Legislative Liaison, interview, March 12, 2012).

When legislation dealing with public education is introduced in the state legislature, the state superintendent of education is responsible for formulating the ALSDE position for or against the legislation. Conflict usually arises when a legislator's ideas either unknowingly violates federal law or is so outlandish that the ALSDE will not stand behind it (J. Miller, ALSDE Legislative Liaison, interview, March 12, 2012). When there is conflict between the state legislative position and the ALSDE position, policy actors from both entities work together to 
reach common ground. The appropriate ALSDE legislative liaison would review the legislation and ensure it is in compliance with Title 16 of the Code of Alabama and aligned with the ALSDE's formal position on the issue to determine the ALSDE level of support for the legislation (J. Miller, ALSDE Legislative Liaison, interview, March 12, 2012).

There are also times when policy actors in the ALSDE seek to construct or influence legislation. This typically happens when someone discovers policy implementation is not in compliance with board policy or state law, and when policy actors notice that legislative changes may lead to a more efficient implementation process. An example was provided in an interview with a legislative liaison:

Normally the way that's handled is that if there's a [department] in the [ALSDE] that either has an idea or wants something implemented, and there's something in the Code that we know that either is outdated or we need to address to update. Normally what they would do is they'll present that to the state superintendent. The superintendent will present it to the [ALSDE]. Then, we'll make a determination that way. (J. Miller, ALSDE Legislative Liaison, interview, March 12, 2012)

A few years ago, for example, legislation with regard to provisional certificates for alternative-route teacher education certification was originated by a policy actor in the Office of Teaching and Leading when it was determined that the state 
needed to "expand" how they were issuing such certificates (J. Miller, ALSDE Legislative Liaison, interview, March 12, 2012).

The Alabama Administrative Procedure Act of the Code of Alabama is the overarching law which grants the ALSDE legislative oversight of powers and duties. Chapter 290-3-3 of the Alabama Administrative Code, titled Teacher Education, outlines the rules of the ALSDE as they relate to teacher education and professional education services. Chapter 290-3-3 outlines legal requirements for initial and advanced teacher education certification, including teacher testing, and delineates the Alabama Quality Teaching Standards (AQTS). The most recent iteration of the Teacher Education section of the Code, which currently governs teacher education quality policy processes in Alabama, was adopted in August 2007 in the midst of NCLB (2001) "highly qualified teacher" regulations.

The language of the current edition of the AQTS (2007) reflects interests and intentions - aligned with both federal law and policy and national policy—to link teacher inputs to student outputs, and place student achievement at the center of teacher effectiveness; for example:

290-3-3.04(1)(b) Content Knowledge. Rationale. Researchers identify a strong relationship between teachers' content knowledge and the achievement of their students.

290-3-3-.04(2)(a) Teaching and Learning. Overview. To increase student achievement of every student... 
290-3-3-.04(2)(b) Teaching and Learning. Rationale. Research provides compelling evidence relating student achievement to teachers' use of appropriate instructional strategies...

290-3-3-.04(3)(a) Literacy. Overview. To improve student learning and achievement...

290-3-3-.04(5)(a) Professionalism. Overview. To increase achievement of all students...

290-3-3-.04(5)(b) Professionalism. Rationale. Current research relates teacher collaboration, shared responsibility for learning, and jobembedded learning in professional community to higher levels of student achievement.

This language provides evidence that the intended purpose of teaching and teacher education in the state is to increase student achievement. The authors of the AQTS (2007) provide research-based rationales for why it is commonsense practice to link teacher inputs and student outputs, a marker of neoliberal influences on policy.

The Governor as the State Education Leader

Since the governor serves as the president of the state board of education in Alabama, it is important to highlight a few historical legislative and political actions related to education reform in the state. Such actions situate the conditions under which teacher quality policies have transformed in the state. 
The historical political actions, beginning at the onset of the nationwide Standards-based Reform Movement and continuing to present day, also show the evolution of a state socio-political culture now aligned with national interests grounded in neoliberal ideology.

The Standards-based Reform Movement marked the beginning of a national push to reform state public education systems into models of performance accountability. Early on in the Movement, the State of Alabama was transitioning from a political system ruled solely by Democrats for over a century to a system of two-party politics. Although the parties have different names, a review of state policy actions and stances reveals there is very little difference in how the purpose of education was viewed by its education leaders from both parties. The purpose of education in Alabama has historically been to prepare students to work in the state's manufacturing and industrial corporations (Webb \& Armbrester, 2001). Alabama's governors have historically formulated strong partnerships with the state's business leaders (Webb \& Armbrester, 2001). Education leaders in Alabama have also historically provided the states' business and industry leaders a seat at the table when education reform initiatives are being addressed.

The election of Republican Governor Guy Hunt in 1987 provides the first hints of Alabama's leadership aligning with national interests to establish standards-based reform in the state education systems. Hunt's governorship (1987-1993) is marked by the establishment of several commissions to study education, and a legislature-thwarted attempt to restructure the state's revenue 
system and increase funding for public education. Under Governor Hunt's leadership, the Alabama legislature passed the Alabama Education Improvement Act (1991), a symbolic, unfunded piece of education reform legislation proposing, among other things, competence testing for teachers and increasing schoolchoice for students and parents in an effort to force accountability and improvements in low-performing schools (Webb \& Armbrester, 2001).

Subsequently, the Alabama legislature designated the Alabama Education Study Commission (AESC) as a standards-on-excellence commission (AESC, 1991). The AESC was charged with examining P-12 public education and reporting findings to the governor, legislature, state board of education, and general public. The Study Commission's research included examining prospective teachers' course content and testing requirements, P-12 student assessment programs, and performance-based accreditation standards.

Alabama's education reform initiatives continued to be aligned with federal and national education reform under the leadership of Republican Governor Fob James. When Governor James was elected in 1995, President Clinton's outcomes-based Goals 2000 (1993) initiative was being implemented in some states. The moderate-turned-individualist states' rights advocate, Fob James, refused funding from the USDE Goals 2000 (1993) initiative because he thought it would increase federal involvement in the state's education reform efforts. However, Governor James' policy actions reveal a direct alignment of state and national interests in attempts to reform the state educational system by addressing the quality of its teaching force. In 1997, under James' leadership, 
Alabama began focusing their education reform efforts on the impact teachers have on student achievement, and "resolved to use teacher quality as a tool for school improvement," (ALSDE, 2006, p. 3).

Governor James commissioned a state Task Force on Teaching and Learning to lead the education reform initiative. The composition of Governor James' task force was important for policy transformation, and is an example of political conventions used to influence the transformation of policy intentions. The report drafted by members of the Task Force named four critical components to enhancing the quality of Alabama's teaching force: standards of teacher quality; "high quality undergraduate and graduate teacher preparation programs with extensive clinical experiences and strict accountability for results" (p. 4); sustained and focused professional development for in-service teachers; and school organization focused on teacher effectiveness (ALSDE, 2006). The components are aligned with the tenets of Goals 2000 (1993). In Governor James' final year in office, the Governor's Commission on Instructional Improvement and Academic Excellence in Alabama's Public Schools was established by legislative action.

The Instructional Improvement Commission recommended that Alabama's teacher preparation institutions needed to revamp their programs "to better prepare teachers for today's student achievement expectations [emphasis added]" (ALSDE, 2006, p. 12). As a result of the Instructional Improvement Commission's conclusions, the Alabama State Board of Education (ALSDE) passed a resolution requiring teacher preparation institutions to document "that 
the teacher candidates demonstrate knowledge of subjects they will be certified to teach as a pre-condition for certification" (ALSDE, 2006, p. 12).

This resolution requires institutions to report the percentage of teacher candidates who meet or do not meet the state-approved minimum score on the Praxis II teacher certification test. The legislation broadly links teacher content knowledge to student achievement, and designates teacher content knowledge as an indicator of teacher preparation program quality. Although Governor James resisted federal involvement and control over state education initiatives, his policy actions indicate that he, like national level policy actors, saw the connection between teacher effectiveness and student achievement as pertinent to improving educational systems, overall.

When Democrat Don Siegelman was elected governor of Alabama in 1999, President Clinton was in his second term in office, and the USDE continued to implement President Clinton's outcomes-based education reform initiative, Goals 2000 (1993). Just as the crux of Goals 2000 (1993) was to reform education to prepare students to compete in a national and global economy by increasing student achievement in math, science, and literacy, so too were the education initiatives of Governor Siegelman. The governor's office and the Alabama State Department of Education (ALSDE) joined efforts and collaborated to receive a three-year grant from the USDE, the Teacher Quality Enhancement Project, to "improve public education by improving teacher effectiveness" (ALSDE, 2011, para. 1). The goals of the grant were to strengthen teacher evaluations, improve recruitment and retention of qualified 
teachers, and provide targeted professional development for teachers with below-average evaluation ratings. The grant focused on induction and mentoring in-service teachers; not on teacher candidates in teacher preparation programs. Governor Siegelman appointed a Task Force on Teacher Quality to implement the grant project in eight school systems across the state. This policy action is another example of politicians using conventions to accomplish policy transformation.

Governor Siegelman's biggest education reform fete was the statewide expansion of the Alabama Reading Initiative (ARI). ARI is a nationallyrecognized, statewide initiative mandated by the Alabama State Board of Education. ARI was started with the help of public and private partners. One of the key elements of $A R I$ is that $P-12$ schools establish partnerships with local businesses to understand the needs of industry in implementing education programs; an example of defining the purpose of education around the needs of the market. Governor Siegelman's push for school-industry partnerships is not surprising because his election and governorship were strongly supported by Alabama's business leaders (Webb \& Armbrester, 2001). ARI was founded on the principle that literacy is the foundation of all learning and is essential to economic development in the state. ARI is the foundation of the reading Literacy section of Alabama Teacher Quality Standards (AQTS), and is currently mandated to be implemented in teacher preparation programs and school systems statewide. 
By the time Republican Bob Riley was elected Alabama's $52^{\text {nd }}$ governor in 2003, the biggest shift in federal control over education had taken place with the enactment of NCLB (2001). Governor Riley continued Siegelman's popular statewide reading initiative, and even obtained an increase in funding for ARI from the federal government. Governor Riley's efforts to improve education in the state also included establishing commissions to address teacher quality and student achievement. In 2006, Governor Riley formed a state Task Force on Teaching and Student Achievement. One aspect of the task force was a formulation of a committee, named the Governor's Commission on Teacher Quality (GCTQ), to examine teacher quality practices, and formulate law and policy language on teacher effectiveness in the state.

Educators, education policy actors, business leaders, and national education policy actors formed the GCTQ. Policy recommendations borne out of the Commission collectively reflect the interests of the members' respective constituencies. The interests of the state education lobby, the Alabama Education Association (AEA); teachers; principals; superintendents; national and state education policy actors; and the "college- and career-ready" interests of business leaders were all considered in this teacher quality reform initiative ( $\mathrm{K}$. Holmes, ALSDE Office of Research and Development, interview, March 12, 2012).

According to the authors of the GCTQ Initial Report, GCTQ was created during a "propitious...moment in the history of the national teacher quality movement" (GCTQ, 2006a, p. 4). As a consequence national conditions such 
as, NCLB "highly qualified teacher" legislation and research and policy efforts of national education policy organizations, the problem with America's failing schools was attributed to the lack of quality in the teaching force. As such, Governor Riley had widespread support of education policy actors, legislators, teachers, educational leaders, and the general public in his efforts to continue to reform education by addressing teacher quality (ALSDE, 2006). The GCTQ was established as the "originating source" of state standards of teacher quality that would "serve as a foundation for forthcoming recommendations for a statewide teacher mentoring program, multi-level certification, differentiated compensation, professional development accountability, and revision to teacher preparation programs" (ALSDE, 2006, p. 11).

The GCTQ went through a "beneficial" "thinking" and "conversational" process that shows a state-led effort to move away from a process-based system of accountability to an outcomes-based system of accountability (K. Holmes, ALSDE Office of Research and Development, interview, March 12, 2012). When discussing the GCTQ, an influential member of the Commission said, "I think there was a gradual move afoot to concentrate more on outcomes than process...I think that it's a logical extension for teacher preparation programs to move in that direction" (K. Holmes, ALSDE Office of Research and Development, interview, March 12, 2012).

In addition to discussions about the standards that would drive teacher quality reform, the Commission on Teacher Quality engaged in serious discussions about pay-for-performance and the expansion of clinical experiences 
to be grounded in the needs of $\mathrm{K}-12$ schools. The GCTQ also had many discussions about "increasing the quantity and quality of the laboratory experiences" in teacher preparation programs, including using the structure of University of Virginia's Fifth Year program as a guide (K. Holmes, ALSDE Office of Research and Development, interview, March 12, 2012). As a result of the GCTQ's recommendations, the ALSDE adopted a resolution to tie teacher evaluations, for both pre-service and in-service teachers, to student achievement (K. Holmes, ALSDE Office of Research and Development, interview, March 12, 2012).

The GCTQ's Standards Task Force subcommittee produced a policy document which resembled national level teacher quality policy ideas tailored to the needs of the State of Alabama (K. Holmes, ALSDE Office of Research and Development, interview, March 12, 2012). The AQTS is a set of 139 indicators identified by the Commission as pertinent to teacher education and development. The AQTS indicators are divided into five overarching standards: Content Knowledge, Teaching and Learning, Literacy, Diversity, and Professionalism. The Alabama Continuum for Teacher Development was another document produced by the GCTQ.

The Continuum breaks the AQTS indicators into a smaller, more manageable set of 39 indicators. The Continuum "describes those indicators in continually more effective levels of practice:" pre-service, emerging, applying, integrating, and innovating (K. Holmes, ALSDE Office of Research and Development, interview, March 12, 2012). The goal for the GCTQ in creating the 
Continuum was to develop a companion document that would operationalize teacher quality standards for the purpose of evaluating teacher effectiveness throughout the career of a teacher (E. Jones, NCATE National-State BOE Member, interview, March 5, 2012). This is an example of teacher quality policy being transformed into a teacher evaluation system of performance accountability.

Certain key terms from the Commission's Initial Report (2006b) provide clear evidence that the national and state policy actors' interests, motivations, and intentions were to transform teacher quality in Alabama into a system of performance accountability. In the Vision section of the report, the authors indicate they foresee a teaching profession in which "universities are held accountable for offering exemplary preparation programs" and a compensation system based on effective practice (GCTQ, 2006b, p. 5). The GCTQ's work focused on what they named as the "four major challenges that must be addressed to realize the vision articulated by the Commission" (GCTQ, 2006b, p. 7): increased student achievement, teacher effectiveness, teacher retention, and teacher distribution. The authors designate increased student achievement as the "raison d'être" the GCTQ exists, and teacher effectiveness as the "engine that drives increased student achievement" (GCTQ, 2006b, p. 7).

This language shows the intent to define student achievement as the main indicator of teacher quality and effectiveness. Furthermore, the authors indicate that research and evaluation efforts related to the reform strategies recommended by the Commission be linked to student performance. The 
GCTQ's work, in keeping with a national teacher quality reform agenda, designates student achievement as the foundation of success in teaching and learning. The Alabama Teacher Quality Standards (AQTS) and the Alabama Continuum for Teacher Development (the Continuum), two documents born out of the Commission's work, are the policy documents which serve to operationalize the Commission's recommendations, and are currently being implemented in school districts and teacher preparation programs throughout the state. In fact, the Commission intended that "special emphasis be placed on ensuring that preparation programs aggressively integrate the standards into their programs" (ALSDE, 2006, p. 12). The GCTQ's work provides shows direct attempts by the state to standardized efficient, formal input/output structures and use predetermined standards and measurable indicators of performance to determine quality in teaching and teacher education.

\section{Education Policy in Alabama: a Direct Alignment with National Interests}

Republican Governor Riley's performance accountability-structured state education and teacher quality reform agenda was expanded by Alabama's current governor, Republican Robert Bentley, and his state superintendent of education. Bentley's state education and teacher quality reform agenda is in direct alignment with the national level education reform agenda centered on performance accountability. In 2010, political actors from the Republican Party won control over both houses in the state legislature and the governorship. Republican Governor Robert Bentley was elected leader of the state and president of the state board of education. Governor Bentley appointed Tommy 
Bice as the new state superintendent of education. A look into policy statements and documents of both Republican men reveals great similarities between their interests, intentions, and motivations and those of policy actors at the national level to design a performance accountability system for teaching and learning in the State of Alabama. Despite an historical traditionalist stance in Alabama politics, there is much evidence which shows convergent rather divergent interests of Alabama legislators and that of the nation in reforming public education under conditions of neoliberalism.

In January 2012, Governor Robert Bentley and other legislative leaders proposed a new state education agenda. At a news conference held in Birmingham, Alabama, Governor Bentley and members of the state legislation expressed a commitment to ensure Alabama's schools would provide all students with "equal access" to the highest quality education in the nation. They promised to offer parents "more public school options" so that they can find the best education fit for their children. They promised local education agencies more flexibility in how they would improve under-performing schools and programs.

In February 2012, members of the state legislature presented a four-point plan to reform public education in Alabama. The plan includes, a small tax credit for teachers to purchase classroom supplies; a provision allowing LEAs to circumvent state law and policy on student achievement, called the School Flexibility Act of 2012, a provision for an establishment of charter schools, called the Education Options Act of 2012; and, a provision for linking student 
achievement data to teacher performance for evaluating teacher quality. Three of the four points of the plan show an alignment of interests, intentions, and motivations between the national and state levels in transforming education laws and policies to align with several tenets of neoliberal ideology: performance accountability, privatization, and increased market competition.

The school reform legislation passed in Alabama, named the School Flexibility Act of 2012 is almost an exact replica of the United States Department of Education (USDE) NCLB waiver. This law, which has been criticized as turning public schools into charter schools, indeed grants traditional public schools the same flexibility afforded charter schools. Local education agencies may be granted flexibility in meeting state NCLB accountability requirements "in exchange" for agreeing to "greater accountability for student achievement and system performance that exceeds but does not conflict with existing State accountability standards and assessments" (Alabama School Connection, 2012b, para. 17). This provision was made legally possible because Alabama applied for an NCLB waiver and was granted a one-year freeze on the student testing standard (Phillips, 2012).

The charter school debate and the subsequent provision for the establishment and expansion of charter schools is something new to the State of Alabama. It reflects a sign of current times in education reform nationally and how national interests influence state interests and operations. Although charter schools legislation was heavily contested by many stakeholders in the state, the Education Options Act of 2012 was amended and passed in both legislative 
houses (J. Miller, ALSDE Legislative Liaison, interview, March 12, 2012). This is not surprising given the history of who holds the power in the state. The Education Options Act of 2012 gives the state and local education agencies (LEAs) more control over shutting down and/or repurposing underperforming public schools, and allows charter schools to be opened in their stead. It also grants LEAs flexibility in hiring the teachers who would staff the charter schools.

Around the same time the Education Options Act of 2012 was being passed, Teach for America (TFA) began operating in the Black Belt region of the state (TFA, 2011), a region with some of the lowest performing schools in the state and country. TFA has now expanded to other regions of the state. With TFA operating in the state, LEAs have an expanded pool of prospective teachers to choose from when staffing schools. It also means that traditional teacher preparation institutions in the state are now in competition with at least one private purveyor of teacher education; one that is heavily criticized for recruiting non-teacher education students into its workforce and placing their teachers in out-of-field positions (Donaldson \& Johnson, 2012). One state-level policy actor interviewed warned, state schools of education "must build a quality teaching force, an effective teaching force in the state... If we don't do it, there's going to be somebody out there that will...Whether we agree or disagree, in a free market you almost have to let the market decide" (E. Jones, NCATE National-State BOE Member, interview, March 5, 2012).

According to an NCATE National-State BOE Member, creating competition among teacher education providers may be the intent of the new 
governor and state superintendent (E. Jones, National-State BOE Member, interview, March 5, 2012). As federal and state funding for public education continues to decrease, the state will be forced to become more innovative in how they restructure traditional teacher preparation programs. The idea of reducing the number of traditional providers of teacher education to increase efficiency and quality is currently being floated in the state (E. Jones, NCATE NationalState BOE Member, interview, March 5, 2012). An example of how traditional teacher preparation institutions are addressing competition is seen in the quality policy enactment and implementation processes of the teacher preparation program examined in this study.

The Alabama State Superintendent's Education Reform Agenda A review of a speech, given by the current State Superintendent of Education Tommy Bice, to school of education deans and designees at the annual Alabama Association of Colleges of Teacher Education (ALACTE) meeting held April 16, 2012, further shows a state-led effort to reform public education into an outcomes-based system of performance accountability. Comments from the speech show a narrowing of the focus on education for the purpose of preparing students for college and career. In his speech, Superintendent Bice expressed an education reform ideology similar to what is being forwarded at the national level. Here is an excerpt from Superintendent Bice's speech:

Plan 2020 is where we expected education to be in this state. Surprisingly, even though we've had aspiration goals, in Alabama for 
public education programs for a long time, we have not really put metrics with them so that they're measurable and we can know in a timeline what we're doing. The four areas that we're focusing on are student learners 2020, 2020 support systems, 2020 professionals, and 2020 school systems. Let me give you an example of just how specific we're going to be. In the 2020 learners. Let me post this so you can take a look at it. [Observer note: Dr. Bice walks over to the computer and projects a screen with a diagram of '2020 Learners and Goals' across the top and arrows pointing to 'college- and career-readiness,' 'graduate and prepared,' and 'student achievement' in the center. He is moving about the front of the auditorium and shifting his focus back-and-forth from the audience and the PowerPoint display.] The 2020 learners. If we shift the goal of being a graduate with being a graduate and prepared around college- and career-readiness, that changes the whole conversation about public education. So that's where we're going. But it's gon' require pre-K, elementary, high school, 2-year colleges, and 4-year colleges get together on how we define a college- and career-ready high school graduate. Because as I was leading into this new definition of where we wanna take kids, I challenged the post-secondary institutions that we're ready to hit a target. But we can't get a target when there're 26 different definitions from 26 different institutions. Business and industry gets this. They understand that it is virtually impossible for us to produce what they need if we don't have a clear target of what that means. So, that's gonna be a big piece. 
Come together and collectively agree on what are the academic skills and the other skills that kids need to be successful. [Observer note: the audience seems receptive to Dr. Bice's comments. It is very quiet in the room. Most people are looking directly at Dr. Bice and the PowerPoint projection. Many people are nodding their heads as he speaks. A lady who is sitting next to me continues to comment, 'Uh huh' indicating she agrees with his comments.] (Tommy Bice, remarks to ALACTE, April 16, 2012)

Superintendent Bice's comments directly align with the national focus on transforming the purpose of education and teacher education to prepare students for market competition. Superintendent Bice discussed his transformational agenda for policy actors in the state and in teacher preparation institutions in achieving this end. His remarks reflect his perception that high grade-pointaverages and high test scores equal better quality. He urges the ALACATE policy actors to come together and agree on standardized measures of teacher preparation program entrance and exit requirements; requirements that better reflect teacher inputs that will positively impact P-12 students' college- and career-readiness. His comments also outline a budgetary agenda designed to recruit high-achieving students into teacher education, and leverage monies to redesign teacher preparation program practices to resemble teacher residency models:

We have a window of opportunity to transform the profession of teaching. Over the next five to seven years we're gonna need, nationally, over half a 
million new teachers because of the baby boomer retirement cliff is about to be realized. So it gives us an opportunity, if we seize it, to really look at what we can do in teacher preparation to inform a new generation of teachers that, if they stay the course, will impact students for the next 30 years. So I see this is a huge, huge opportunity. I've shared this before. Last year I was asked to go to Finland with a group of educators. When I went to Finland, I was approached by the Minister of Education who told me that the research they used to reform their education system is the research from the Unites States that clearly states that the number one variable to move children from point $A$ to point $B$ is the classroom teacher. So, I came back and looked at our budgets. How much money do you think we use to recruit the very brightest students out of high school into the teaching profession? [Observer note: there was a 2-second pause. The lady sitting next to me replied aloud, "None."] Zero. How much money did we put into expanding the clinical experience of the teacher? We give you zero. We want the teacher residency model. Once a teacher graduates, how much money is used on induction and mentoring? Zero. We have to leverage our money better. We need resource teachers better. What I want us to do, this group, is have some serious conversations about what it means to be a teacher. What the entrance requirements are. What the exit requirements are to get out of teacher preparation. Do those requirements reflect what a teacher needs to prepare students to be college- and career-ready? I don't think so. 
Teacher candidates' test scores and GPAs don't reflect that they are prepared for that. I'm challenging us. I'm not afraid to be bold on this. I'm willing to take a lawsuit of two if we are willing to move the bar up. And if you don't make it, we're sorry. (Tommy Bice, remarks to ALACTE, April 16, 2012)

Superintendent Bice also proudly spoke about reorganizing and restructuring the Alabama State Department of Education (ALSDE) to "leverage human and fiscal pieces" in order to be more "efficient" in implementing Governor Bentley's Plan 2020 (Tommy Bice, remarks to ALACTE, April 16, 2012). The goal is to structure the ASLDE to maximize the link between teacher inputs and student outcomes by creating a "data-driven" symbiotic system of all things related to teacher education and development and student achievement (Tommy Bice, remarks to ALACTE, April 16, 2012). The restructured ALSDE resembles a business management model. According to a top official in the newly-formed Office of Research and Development, Superintendent Bice is "utilizing Michael Barber's work, Deliverology, to kind of change the focus and the culture of the ALSDE to one that's more data-driven" (K. Holmes, ALSDE Office of Research and Development, interview, March 12, 2012).

Deliverology is a "best-in-class performance management" strategy based on Michael Barber's work with the government of the United Kingdom (Barber, Kihn, \& Moffit, 2010). Deliverology has at its center three critical components: the formation of a delivery unit, data collection, and the establishment of routines for consistently reviewing performance and making decisions (Barber, Kihn, \& 
Moffit, 2010). An organizational structure based on Barber et al. (2010) is one that aligns with particular neoliberal characteristics: the development of new institutional practices and common-sense values and the standardization of efficient, formal input/output processes to measure quality.

Superintendent Bice values content knowledge as an essential indicator of quality in preparing teachers. He spoke in depth about the importance of focusing on pre-service teachers' acquisition of "more knowledge," and referred to Finland's teacher education system as a common-sense rationale to support his position (Tommy Bice, remarks to ALACTE, April 16, 2012). Prospective teachers in Finland are required to get a degree in their content area first, and then they are required to go back to school for a "teacher" degree (Tommy Bice, remarks to ALACTE, April 16, 2012). Bice's intention to restructure the college and university system to achieve the same end is evident here:

I'm not saying we need to go there next week. But I do think there's opportunity. There's an opportunity for us to have possibly more collaborative relationships with Arts and Sciences. Not to do away with education; I feel very strongly about my profession. But we have some things that we could be doing jointly. (Tommy Bice, remarks to ALACTE, April 16, 2012)

Bice places much emphasis on teacher content knowledge was seen in how the focus of part of his speech was on teacher inputs, specifically content knowledge acquired prior to and during teacher preparation. He mentioned how 
he is "disturbed by" the findings from his research on Alabama's teacher preparation program low entrance and exit requirements (Tommy Bice, remarks to ALACTE, April 16, 2012). He is "alarmed" by the "average ACT score" of teacher candidates and the Praxis II scores of elementary teachers across the state (Tommy Bice, remarks to ALACTE, April 16, 2012).

Other state policy actors who presented at the ALACTE meeting expressed the intent of the ALSDE to standardize clinical experiences and evaluations of teacher preparation program practices across the state. An Associate Dean and Certification Officer at a public teacher education institution in the state discussed the importance of institutions implementing NCATE's "upside down" model of clinical experiences across all NCATE partner institutions in the state. She provided the example of a "teaching hospital," where the focus of clinical experiences would be placed on the achievement needs of the "the patient" (i.e., the student), and teacher candidates being a part of a "hospital team" that works to raise student achievement (remarks to ALACATE, April 16, 2012). She also expressed the intent of the ALSDE in placing its accountability focus more on outcomes, and shared that the department embraces the implementation of the standardized Teacher Performance Assessment currently being developed by American Association of Colleges of Teacher Education (AACTE) to evaluate teacher preparation programs.

Superintendent Bice and other state-level policy actors expect that if teachers are prepared better in content knowledge, they will positively impact student achievement and prepare P-12 students for college and career. Their 
remarks indicate they value performance accountability in education and teacher education. Their interests reflect the gamut of neoliberal ideology: the elimination of the notion of education as a common good; the development of new discourses, institutional practices, and common-sense values; the state acquiring a new identity as the protector of capital, where its role is to enhance social and educational policies to protect the market; active intervention of schools, colleges, and universities by the state; senior management control; and the use of standardized input/output processes and predetermined standards and measurable indicators of performance to determine quality.

\section{Summary of the Transformation of Legislative Intentions: the State Level}

Under conditions of neoliberalism, the role of the state is to enact education legislation and policies that will serve to nourish and protect state markets and capital, which in turn will nourish and protect national capital. Under such socio-political conditions, education policies in the State of Alabama have transformed to replicate performance accountability systems reflective of the new public management philosophy. The teacher quality policy transformation process began in the late-1980s, around the time of the Standards-based Reform Movement. Alabama governors and other influential policy actors began establishing policies on teacher quality and quality in teacher preparation that were based on teachers' acquisition of more content and subject matter knowledge, performance-based accountability, student achievement on standardized tests, and links between teacher inputs and student outputs. By the time NCLB was in full swing, state education policy actors were already in the 
process of examining teacher quality indicators and formulating laws, policies, and standards that would shape the way teacher quality and quality in teacher preparation and development is conceptualized in the state today. Alabama policy actors established state standards for teacher quality which reflect indicators directly aligned with national interests and intentions.

Education legislation and policy in the State of Alabama continue to transform and mirror national reform initiatives with the current governor's administration. In an effort to obtain Race to the Top (2009) funding, policy actors in the state passed unprecedented education legislation. Although Alabama did not receive the much-needed funding, the laws and policies passed remain in place. Such controversial education policies as the School Flexibility Act of 2012, where local education agencies submitted applications to the ALSDE requesting to circumvent NCLB laws on student achievement tracking and reporting; the state-legislated establishment and expansion of charter schools; and provisions for using student achievement data to determine the effectiveness of teachers and teaching are ways in which Alabama's education legislation and policies have been transformed under conditions of neoliberalism. Legislation has transformed into policies related to quality in teacher preparation, which have then transformed into indicators for model of performance accountability. The quantity of content courses and scores on standardized achievement tests for teacher now serve as significant indicators of teacher quality. Field and clinical experiences are being transformed into teacher residency model that will be standardized across all state teacher preparation 
programs; a model which will pave the way for performance accountability links between teacher candidate inputs and K-12 student outputs. State policy actors have embraced the national teacher education reform effort to create standardized performance assessments for the purpose of evaluating all teacher preparation programs.

Since the enactment of NCLB, there has been a national push for increasing teacher content knowledge and linking teacher knowledge to student achievement to be the most significant factors in determining education qualifications. In the State of Alabama, under the leadership of the current governor and state superintendent of education, policy actors in the state are being held accountable for implementation activities which center on this narrow definition of teacher quality. Based on a critical examination of policy and standards implementation at the teacher preparation institution at the center of this study-an institution that will serve as the state model for teacher education reform — teacher content knowledge and teacher candidate-student data links are indeed the central focus of implementation activities. Federal and state law and policy implementation activities associated with performance accountability constitute conditions for linkages at university and program levels of the teacher quality policy enactment and implementation process.

The next section presents findings from the university level and linkages between the National Council for the Accreditation of Teacher education (NCATE), the state, the university, and teacher preparation program levels. The section begins with a table which presents an overview of the linkages. 
Linkages between NCATE, the State, the University, and Program Levels

Table 5

Linkages between NCATE, the State, the University, and Program Levels

Conditions

1. The state partners with NCATE to complete program review and approval in NCATE-partner schools

2. NCATE accreditation is seen as a pertinent indicator of quality of teacher education schools and programs by the state, the University, and the Program

Network of Collective Activity

ALSDE policy actors, NCATE, policy actors at the program level (some of which serve on state and NCATE commissions and boards)

Tasks

1. Joint State-NCATE review and approval of programs

2. Teacher education programs implement state and NCATE standards

Interests/Intentions/ Motivations

Interactions

NCATE accreditation \& State approval of programs

Program-level policy actors perceive state program review and approval processes as technical and menial, and NCATE reviews as more meaningful and rigorous

Conventions

NCATE and the state conduct the review and approval of schools and programs jointly

Resources/Power/

The state relies on NCATE resources in its program Governance

Contingencies/ approval review

Opportunities

The state implements a performance accountability system in NCATE-member institutions based on NCATE accreditation criteria

Consequences

1. The implementation of a performance accountability system in teacher preparation

2. NCATE quality policies and transformed to state quality policies in teacher preparation 
The major factors that constitute linkages between the state and Teacher Preparation Program level are (1) the importance of NCATE accreditation and (2) the NCATE/State joint review, approval, and accreditation of programs. The linkages have set conditions for the action context in teacher preparation centered on the implementation of standards and policies which resemble performance accountability systems and the quantity of implementation actions to represent quality. The school of education investigated in this study is an NCATE member institution, meaning the school is required to successfully implement NCATE policies to be nationally accredited.

Policy actors at the state level, university level, and program level view NCATE accreditation as an important factor in determining the quality of teacher education programs. As policy actors at the state and teacher preparation program levels were interviewed, the one theme that continued to arise was the significance of NCATE accreditation. Policy actors placing high value on NCATE accreditation is an example of neoliberalism in practice, as teacher education accreditation is publically perceived as a symbol of program rigor, accountability, and excellence (Baltodano, 2012), thus a making nationally-accredited teacher preparation program perceptibly more marketable.

The state review of programs is conducted jointly with the NCATE review. As part of the state on-sight review process, the ALSDE sends a "small team that works hand-in-hand with the NCATE team" (T. Johnson, ALSDE Office of Teaching and Leading, interview, February, 28, 2012). The state relies heavily on NCATE resources and processes in determining whether programs are 
approved. In the State of Alabama, traditional teacher preparation programs that partner with NCATE are required to implement Alabama Quality Teaching Standards (2007), NCATE accreditation standards, and professional studies standards, like ones published by National Council for Teachers of Mathematics (NCTM). Additionally, "the institution has to demonstrate that the AQTS knowledge and ability will be addressed in required coursework and other experiences in their preparation program" (T. Johnson, ALSDE Office of Teaching and Leading, interview, February 28, 2012).

The state relies on the institution's documentation of checklists and tracking data as proof that each program is implementing state and institution standards and policies. Performance Assessment Templates (PATs) are used to track the implementation of knowledge and ability standards codified in the Alabama Administrative Code through program coursework and field and clinical experiences. Programs are also required to implement a testing policy which includes successful completion of a basic skills test, named the Alabama Prospective Teachers Test (APTT), before entrance into the teacher education program, and passing the required Praxis II content-area certification exams prior to completing the program. There are state-legislated GPA requirements and course content requirements that must also be implemented. State regulations allow institutions to go beyond the minimum entrance and exit requirements. An explanation was provided by a state policy actor:

[An] institution could say, well in addition to getting your GPA up to a 2.5, you need to take these courses and you need to do these experiences in 
schools to get your certification. So, it's up to the institution to take it beyond the minimum requirements. To take it a step further than the minimum requirement. ( $T$. Johnson, ALSDE Office of Teaching and Leading, interview, February 28, 2012)

Policy actors show evidence of teacher candidates meeting testing and GPA requirements by providing the states with a populated list of teacher candidates, APTT and Praxis II test scores, and program and overall GPAs.

Discussions with policy implementers at the state and program levels revealed perceptions that the state process is more of a technical review of compliance and the NCATE process is more comprehensive and rigorous. This indicates that policy actors in the state are concerned with quantity of implementation activities evidenced through checklists rather than the quality of implementation activities. Terms like "compliance" and "checklist" riddled explanations of the state review process. The state review process is explained by a top official in the ALSDE Office of Teaching and Leading:

We used to review every five years. So what we do now is that we have the institutions on a cycle. If their on-sight visit is scheduled, for example, fall 2012 or spring 2013, the institution submits paperwork, or electronic now; documentation of compliance with the AQTS and all other applicable standards by the July first before their on-sight visit... Then the institution, after the summer process, receives a report for all of the standards: AQTS, the elementary standards, math, biology, etcetera, saying 'You documented compliance' or 'There's a problem here.' The institution fixes 
it. And we don't go to the State Board of Education for approval of programs until they've documented compliance of all the standards. (T. Johnson, ALSDE Office of Teaching and Leading, interview, February 28, 2012)

A review of the program checklists, Alabama Quality Teaching Standards (AQTS) alignment documents, and assessment templates—at the teacher education school investigated in this study and one other teacher education school in Alabama-corroborates the technical-compliance nature of the state review process. At the institution investigated in this study the chair of the education department keeps a binder she refers to as her standards-compliance "Bible" (A. Belcher, Director of Teacher Education/de facto NCATE Coordinator, interview, April 24, 2012). The binder includes program checklists, which are a list of content and pedagogy courses for each certification program, and a table with program-specific requirements (i.e., elementary education, early childhood education, special education, etc.) from the Teacher Education section of the Alabama Administrative Code. Next to the Code language are the applicable AQTS indicators. Penciled next to the AQTS indicators are the course numbers where requirements are addressed and assessed.

The certification officer at the other teacher education institution provided an example of how he documents AQTS compliance through Performance Assessment Templates (PATs):

[The PATs] take the Code language, the legalese, and puts them into a template that allows each institution to tell the state how they are going to 
measure the criteria... This particular area relates it back to the Code language. This is in $3 \mathrm{C} 1$. So it ties back to the Code. And then the institution has an opportunity to present evidence to the state that in ED347, which is a course in elementary ed, is where we address that standard. It's gotta be at least an objective [in a course]. It's gotta be listed two times in a course. It can't just be listed as a topic of interest. It has to have an assessment component with it...Each institution submits to the state their plan of how they're going to meet the AQTS. (E. Jones, NCATE National-State BOE Member, interview, March 5, 2012)

Performance Assessment Templates (PATs) transform the AQTS standard language into performance indicators, thus aligning with the neoliberal principle of using predetermined standards and measurable indicators of performance to determine quality.

The Certification Officer, who also serves as an NCATE National-State BOE Member, perceives the NCATE review process is as one that enables institutions to move from mere technical compliance with state policies and standards to actions related to what NCATE refers to as a "continuous improvement" model. During an interview, the certification officer discussed how the "new standards, the new model" enacted by NCATE allows policy actors at his institution to do what her refers to as "internalizing" the assessment of programs and teacher candidates:

I can do a standards-based report and tell you exactly how proficient $X$ student is on X standard on the PAT or X standard on the AQTS. That's 
something that's part of the NCATE process, but the PATs and AQTS are required by the state. But you use them to determine performance. (E. Jones, NCATE National-State BOE Member, interview, March 5, 2012)

The certification officer's explanation provides further evidence of a teacher preparation program evaluation system based on predetermined standards and measurable indicators of performance; an example of neoliberalism in action.

Summary of the Transformation of Legislative Intentions: NCATE, State, University, and Program Linkages

Heavy reliance, by policy actors at the NCATE, state, and program levels, on NCATE implementation practices to show quality in teacher education has transformed the teacher quality policies at the state and institution/program levels into systems of performance accountability. By partnering with NCATE in reviewing the quality of teacher preparation programs, the state is complicit in forwarding an agenda of performance accountability. The technical review of the state review of programs defines quality in education by the product of education.

As long as policy actors of the program level show documentation that standards are aligned with courses, course objectives, and assessments, state policy actors assume that teacher candidates are experiencing what has been documented, and conclude programs show quality and should be approved. Findings presented in the Teacher Preparation Program Level section provide additional, detailed evidence of NCATE requirements being the impetus behind the implementation of policies and activities related to performance 
accountability. The next section presents finding from the university level and linkages between the university and teacher preparation program levels. 
The University and University and Program Linkages

Table 6

The University and University and Program Linkages

Conditions

Network of Collective Activity

Tasks
University Level 1. Accountability oversight is under the purview of the University Board of Trustees 3. SACS accreditation requires universities to have each school or college make valid \& reliable assessment systems available online

4. SACS accreditation requires colleges and schools to document research conducted by faculty

University President \& designees, Dean of Education School \& designees, SACS, NCATE

1. Obtain SACS accreditation

2. Increase research or documentation of research by faculty

3. Increase university enrollment
University \& Program Linkages 1. ALSDE has no real oversight over University practices related to teacher education schools \& programs

2. NCATE accreditation requires colleges and schools to document research conducted by faculty

3. NCATE accreditation requires SACS accreditation

\section{Obtain SACS \& NCATE} accreditation

2. Increase research or documentation of research by faculty

3. Establish documented, valid \& reliable assessment system in the school of education for both NCATE \& SACS accreditation 4. Increase teacher education enrolment 
Interests/Intentions/

Motivations

Interactions

Conventions

Resources/Power/

Governance

Contingencies/

Opportunities

Consequences
1. University President's desire for SACS \& NCATE accreditation

2. University President is motivated by increasing enrollment university-wide
University President \& Dean of

School of education are interested in NCATE accreditation and in increasing enrollment in the school of education

1. The University President and school of education Dean value accreditation as a significant factor in quality and marketability 2. The school of education Dean sees increasing enrollment numbers and ensuring accreditation as a significant part of his role

The University President expects the dean to keep abreast of and implement all the necessary laws, policies, standards, and activities to ensure accreditation \& State program approval without having any real hands-on accountability responsibilities

1. University and School of Education policy actors use the importance of SACS \& NCATE accreditation, and State program approval as a means to ensure compliance with accreditation standards

2. University and School of Education policy actors use the importance of the University and it's colleges \& schools to be perceived as high quality as a means to ensure compliance with accreditation standards

Emphasis on faculty conducting more research (as required SACS \& NCATE accreditation)

1. The SACS requirement adds another layer of accountability for teacher education programs

2. Accreditation research requirements are difficult to obtain
1. Increased accountability responsibilities placed on the Dean by University President for school of education to increase enrollment 
for faculty at "teaching

universities"

3. SACS accreditation leads to public perceptions of quality and may translate to increased

enrollment
2. Responsibility to ensure NCATE accreditation

3. SACS \& NCATE accreditation leads to public perceptions of quality and may translate to increased enrollment 
The university level is loosely linked to policy enactment and implementation processes related to teacher quality. In the State of Alabama, the Alabama State Department of Education (ALSDE) has no real oversight over processes and practices at the university level. The lack of oversight is quite unlike the accountability the ALSDE has over K-12 education in the state. As was explained to me by a legislative liaison at the ALSDE:

There is nothing that $\mathrm{K}-12$ does that either we're not accountable for or that's not transparent...But with regard to our two-year and four-year there is not quote-unquote accountability on the books for them. That's literally left up to a board of trustees for a college. (J. Miller, ALSDE Legislative Liaison, interview, March 12, 2012)

There is more of a direct link of accountability between the school of education and the ALSDE Office of Teaching and Leading. The Director of the Office of Teaching and Leading is responsible for "helping the COEs make sure that the accountability is in place for requiring teachers to know the things that they have to know in regards to the programs that they're going through so that they can become a certified teacher" (J. Miller, ALSDE Legislative Liaison, interview, March 12, 2012).

At the center of the linkage between the university and programs levels is accreditation. The push for regional and national accreditation is a sign of neoliberal times in that accreditation translates into perceptions of quality. There are few university level accreditation processes that impact school of education 
quality policy implementation. The Southern Association of Colleges and Schools (SACS), which is a regional organization responsible for accrediting colleges and universities, requires the university to have each college or school implement "valid, reliable" assessment systems for all programs. This process was noted by the dean as being yet another layer of "paperwork" that makes the implementation of accountability requirements "overwhelming" (S. Carter, Dean, interview, April 4, 2012). NCATE policies designate university-level SACS accreditation as a pre-condition for school of education accreditation. Therefore, requirements for SACS accreditation become equally important for NCATE accreditation.

Another influence of the university on the implementation practices at the program level stems from the university president's interest in the school of education gaining national accreditation. The interest in NCATE accreditation is also shared by the school of education Dean. When discussing conditions for SACS and NCATE accreditation, the Director of Teacher Education/de facto NCATE Coordinator at the school of education investigated mentioned the university president's pushing for more research to be conducted by faculty ( $A$. Belcher, Director of Teacher Education/de facto NCATE Coordinator, interview, April 24, 2012). A faculty member expressed concern about meeting the research requirement:

[Research] was one of the areas that was a target area for [SACS and NCATE]. Because I think faculty members haven't been publishing. We are a teaching university, so it does make it a lot more difficult for 
undergraduate [faculty] especially, graduate [faculty] too, but we have heavy teaching loads. So sometimes that keeps us from focusing. Although we enjoy research, it is more difficult sometimes for us to do research. (M. Wilson, English/language arts methods professor, interview, March 15, 2012)

Although the faculty research requirement poses a problem for faculty at a "teaching university," the dean and university president expect for faculty to show evidence of research for accreditation purposes. The university president and dean's push for more research by faculty is an example of senior management taking control over policies and policy implementation activities; a characteristics of neoliberalism.

One final university-level condition that broadly influences the action context at the school of education level is that the university President and the dean of the SOE both have a shared interest in increasing enrollment. The Director of Teacher Education/de facto NCATE Coordinator mentioned there being "a huge push for recruitment of students into the [Elementary and Collaborative Education] program; keeping those numbers up" as the only university-wide policy, besides more research by faculty, that she sees as a result of increased accountability and oversight (A. Belcher, Director of Teacher Education/de facto NCATE Coordinator, interview, April 24, 2012). The Dean, when asked about the impact of university policy on school of education activities, also expressed the pressure from the university president to increase enrollment: 
As you may be aware, colleges of education have traditionally been university cash cows. By that I mean, enrollment in colleges of education significantly impact university enrollment numbers. That's no different today. And it might be even more of an issue with all this competition between schools and Teach for America too. (S. Carter, Dean, interview, April 4, 2012)

Competition between traditional and non-traditional, corporate-funded schools of education is a sign of neoliberal times.

Summary of the Transformation of Legislative Intentions: University Level and University and Program Linkages

Policy actions at the university level related to school of education policy implementation are centered on ensuring university and school of education accreditation. The importance of accreditation has transformed into policy requirements to increase amounts of research conducted by faculty and to increase enrollment numbers. As a result of the university president's desire for accreditation, the dean and faculty of the school of education have an additional level of accountability, outside of national, NCATE, and State requirements. While school of education faculty are required to implement a plethora national, NCATE, and State quality standards, as well, as meet all requirements on State compliance checklists, the university president is also requiring the Dean to ensure teaching faculty are producing and publishing research. The research requirement at a teaching university is an example of the development of new institutional practices. 
Additionally, the Dean has to balance ensuring the implementation of more requirements teacher candidates to obtain teacher education degrees, perpetuated by national- and state-level conditions, with ensuring enrollment numbers increase, a university-level condition. Increasing enrollment numbers is a program with more requirements that other programs in the state will not be an effortless task. This is an example of organizational life being governed by a corporate culture of senior management control. The university president, the senior manager, is concerned with increasing enrollment numbers, which may also lead to more teacher education degrees as products of the university, which may lead to public perceptions of the university (and school of education) as a quality institution. Thus, the quality of education is redefined "as the quantitative efficiency with which the qualifications are produced" (Lorenz, 2012, p. 621). 
The Teacher Preparation Program Level

Table 7

The Teacher Preparation Program Level

Conditions

1. Neoliberal socio-political environment at national and state levels

2. The high value placed on NCATE accreditation

3. Values, interests, dispositions, attitudes, and actions of senior managers (Dean \& Director of Teacher

Education/de facto NCATE Coordinator)

4. State policy actor's desire for creating a replicable, marketable teacher preparation institution

5. An overwhelming amount of accountability and oversight that resulted in intense, sustained implementation of one set of standards and processes (i.e., NCATE) above others

6. The small school size (i.e., low enrollment and small faculty) allowed for the authoritarian leaderships styles of the Dean and Director of Teacher Education/de facto NCATE Coordinator to flourish

7. Culture of senior management control

8. The compliant disposition of lower-level policy actors (faculty)

Network of Collective Activity

Dean, Director of Teacher Education/de facto NCATE Coordinator, Director of Field and Clinical Experiences, program faculty, policy actors in the ALSDE Office of Teaching and Leading, NCATE

Tasks

1. Implement \& document NCATE standards, policies, and activities, including NCATE Clinical Residency Model

2. Document the compliance of State standards, policies, and activities

3. Go beyond base State requirements by implementing all of the following requirements in a 3-year time frame: the six main faith-based goals of the mission and vision of the university; Alabama Quality Teaching Standards (ATQS); the Alabama Continuum for Teacher Development; professional studies standards for early childhood education, early childhood/special education, elementary education, general special education, collaborative education, and reading; Performance Assessment Templates (PATs); NCATE standards; the new NCATE Clinical Model; and, internal assessments, checkpoints, and three national certification exams 
4. Gather/create evidence to support implementation activities

5. Fast-track implementation of the NCATE Clinical Residency Model and other implementation activities 6. Gain NCATE accreditation and State approval of programs

Interests/Intentions/ Motivations

Interactions
1. NCATE accreditation and State program approval paramount

2. NCATE policy, standards, and clinical residency model implementation vital to the marketability of the school and programs

3. Evidence \& data collection took place for the purpose of showing (rather than actually doing) implementation of policies, standards, \& activities

4. Senior level policy actors (Dean \& Director of Teacher Education/de facto NCATE Coordinator) view teacher quality in the context of the impact of teachers on student achievement

5. Lower-level policy actors view teacher quality in the context having compassion, serving the community, \& equal and quality service to all $\mathrm{P}-12$ students

6 . Policy actors' desire to go beyond base State standards in an effort for their teacher candidate/graduates to be more marketable

7. Policy actor's desire for school and programs to serve as a model for the state

8. The Dean serves as the leader of the school of education and as the President of ALACTE (the statelevel NCATE organization), and thus has dual roles to equally enforce State and NCATE requirements

1. The Dean is a veteran NCATE implementer, and sees his role as ensuring NCATE accreditation; steps in to take over processes when he perceives it's necessary 2. The Dean puts the right people in place to enforce NCATE implementation; i.e., the authoritarian Director of Teacher Education/de facto NCATE Coordinator as the de facto NCATE coordinator, and compliant, willing faculty to implement NCATE Clinical Residency Model 3. Literal, surface-level interpretations of standards (e.g., NCATE, AQTS) by senior level and lower level policy actors.

4. The process of understanding standards takes place in NCATE meetings (and in informal meetings) where faculty engage in discussions asking questions such as, 
Conventions

Resources/Power/ Governance

Contingencies/

Opportunities

Consequences
What does this mean? What is it saying? What would it look like? What would be the evidence?

5. Policy actors perceive the NCATE standards as common sense and a way to ultimately provide a quality program and produce quality teachers

6. Policy actors view the overabundance of standards as overwhelming

7. Policy actors view NCATE standards and rigorous and State compliance standards as weaker

8. Lower-level policy actors were frustrated with the fasttrack implementation of the NCATE Clinical Residency Model and other policy implementation activities, but engaged in symbolic implementation

Reactive rather than proactive implementation of standards, which includes creating evidence of implementation activities before the activities take place

1. The Dean employs a covert authoritarian leadership style by appointing an overt authoritarian (the Director of Teacher Education/de facto NCATE Coordinator) as the NCATE enforcer

2. The Dean and Director of Teacher Education/de facto NCATE Coordinator used NCATE accreditation as a bargaining chip to get lower-level policy actors to act on NCATE implementation activities

3. The Director of Teacher Education/de facto NCATE Coordinator used her authoritarian leadership style and the compliant nature of lower level policy actors to take over and control implementation activities

The Director of Teacher Education/de facto NCATE Coordinator has a close relationship with a local principal, and used that relationship to establish a partnership to ensure the implementation of the NCATE Clinical Residency Model

1. Policy actors focus their attention, time, and efforts on implementing what they perceive as the most important, time-intensive, and rigorous of the requirements: NCATE 2. Internal program activities and restructuring ceased so that policy actors would focus on implementing NCATErelated activities

3. The Director of Teacher Education/de facto NCATE Coordinator inserted herself into the role of Field \& Clinical Experiences Director to enforce the 
implementation of the NCATE Clinical Residency Model 4. Policy actors appear to be in a perpetual state of catching up, or they create evidence of implementation practices that are either not taking place or taking place on a much more minimal level that what is indicated in the documentation

5. Symbolic vs. meaningful implementation of policies, standards, \& activities; i.e., curricula and program practices have been narrowed to focus only on processes related to showing evidence of standards and policy implementation rather than on actual implementation 6. Policy actors were engaged in a dichotomous process of either working backwards to link data to program changes or instating new policies and actions that reflected their interpretation of the NCATE policy and standards language.

7. The implementation of the NCATE Clinical Residency Model took precedence over the conventional process of field \& clinical experiences, and resulted in teacher candidates missing significant learning experiences 8. There was no buy-in from the teachers at the partner school where the NCATE Clinical Residency Model was implemented (only buy-in from the administration); this led to disorganized, incomplete, \& unsuccessful implementation and teacher candidates feeling lost for much of the semester

9. Evidence and data collection to show the implementation of policies, standards, \& activities lacks integrity

10. Meaningful implementation, and data collection for the purpose of improving programs did not take place as intended by policies and standards

11. Teacher candidates graduate with four teacher education certifications

12. Quality in education is defined by the product of education, represented in activities, certifications 13. Teacher candidates are unaware of the politics of their profession and do not take ownership of the standards for which they are held accountable. They view the quality standards as the responsibility of the faculty

14. The school of education serves as a state model for education schools and programs; as such the stage is set for standardization of implementation practices across all schools of education in the state 15. Policy actors, including teacher candidates, perceive 
their degrees as more marketable than others graduates' degrees in the state

16. Policy actors, including teacher candidates, perceive graduates as being of more quality than other graduates in the state

The major interconnected national, state, and university conditions for the development and implementation of quality policy at the teacher preparation program level were: (1) neoliberal socio-political ideology trickling down from national and state levels policy activities; (2) the high value placed of NCATE accreditation by national- and state-level policy actors, and senior managers and lower-level policy actors at the program level; (2) values, interests, and actions of senior managers; (3) state policy actor's desire for creating a replicable, marketable teacher preparation institution; (4) an overwhelming amount of accountability and oversight; (5) the small school size; (6) a culture of senior management control; and (7) the compliant dispositions of faculty. The conditions had to be filtered through the cultural and organizational context of senior management control at the university and program levels. Standards and policy implementation practices under such conditions provide insight into what neoliberal ideology looks like in practice at one of the lowest levels of the teacher quality enactment and implementation process, the school of education and program level.

The university at the policy implementation level of this research study is a small private, faith-based university located in the State of Alabama. There were roughly 1,300 students enrolled in all undergraduate and graduate programs at 
the time of this study. The mission of the university includes such terms as personhood, nurture, faith, ethics, social and civic responsibility, service, community, intelligence, and creativity. The median income of the parents of students attending the university is $\$ 100,000$ per year. The culture of the institution has been described as a "safe place," an "ivory tower" where students "are not comfortable leaving the warm and fuzzy bubble" (M. Wilson, English/language arts methods professor, interview, March 15, 2012). More on the culture of the institution was garnered from observations and interviews. The cultural aspects that provide a context for the implementation of teacher quality standards and policies are associated with religion, socioeconomics, organizational structure, and the leadership dispositions of senior-level policy actors.

\section{Description of the School Context}

The school of education, the New School (TNS) (pseudonym), is located in two buildings, one two-story building and one three-story building. Both buildings are situated in the center of the university campus. Administrator and faculty offices are located in the two-story building, while classrooms, conference rooms, and a large meeting space are located in the three-story building. Faculty and students typically congregate on the third floor of the three-story building, an area commonly referred to as the Library. The third floor layout includes a large room which resembles a library; with the library desk at the center of the room and open spaces surrounding the desk. Overstuffed chairs and couches, and tables with chairs are located in the open spaced. Bookshelves filled with 
education philosophy and other academic books, such as grade school- and college-level history and science texts, line the walls. Offices are tucked away at opposite ends of the room. There are also three classroom-like rooms off the outer walls of the Library. One classroom is a computer laboratory. Another room appears to be a media room, with up-to-date technology, long, rectangularshaped tables, and 15 chairs. The other room has the appearance of a conference room or a classroom for courses with small enrollment numbers. The bottom two floors of the building are only classrooms, hallways, and bathrooms.

There are approximately 40 faculty members at the New School. There are less than 100 students in the early childhood and elementary education programs. Students were either in classes, or students and faculty—usually alone or in pairs-passed through the hallways, some days. There is very vibrant, friendly, collaborative atmosphere in the Library. There would be small groups of students sitting at tables. The students would be engaged in nonschool-related discussions or working together on class projects. Oftentimes a faculty member would pass through the room and a student would call the person over. Students would ask the faculty member questions about a project. The students and faculty member would sometimes engage in non-schoolrelated discussions. There were often expressions of "Thank you God," "Praise God," and "I prayed..." during the discussions. There is very little faculty-onfaculty interaction in the Library. There were times when a faculty member sat alone at a table, eating, grading papers, or reading. Sometimes there are faculty members engaged in hushed discussions. 


\section{Sample Contextual Overview of Observations: NCATE Meetings}

During the three NCATE planning meetings, which occurred in February, March, and April, 2012, faculty seemed highly focused on gaining clear direction and understanding on NCATE-related tasks. The faculty engaged in very little discussions outside of those related to NCATE responsibilities. Full group NCATE planning meetings were held in different classrooms around the building. Meeting attendees would be faculty members who were writing a response to a particular standard and those working on gathering evidence for a particular standard. The Dean would also attend the full-group meetings, which included faculty assigned to work on all standards, but he rarely spoke to the whole group. The leader of each meeting was the Director of Teacher Education/de facto NCATE Coordinator. Faculty members gathered at tables based on the NCATE Standard they were charged with organizing; for example, all faculty responsible for writing and gathering evidence for NCATE Standard 1 sat at a table together.

After the Director finished introducing the purpose of the meetings, a faculty member would usually jump in with a question to clarify their group's charge. Then, within-group discussions were held. Conversations centered on trying to make meaning of what a standard required. There were often exchanges like, "What do you think they want here?" "What does this mean?" "Ask the dean what they used last time for this one." "I don't think we have evidence of that." "I'll bring the data from my office." And "Will you write this part up if I take this part?" Discussions suggested a collaborative effort to interpret NCATE standards in a literal manner. Meetings generally culminated with faculty 
being assigned a particular NCATE-related task of either writing up or gather evidence for write-ups of particular standards.

The leader of the meetings, the Director of Teacher Education/de facto NCATE Coordinator, also appeared to be the unofficial NCATE person, assigned as the de facto NCATE Coordinator by the Dean. She will be referred to throughout this section as the Director of Teacher Education/de facto NCATE Coordinator, and the pseudonym A. Belcher. Once the meetings were over, faculty disbursed to their respective offices or classes. There was some friendly or non-NCATE-related conversation as people left the room, but not much. The meetings were focused; questions and answers were very direct and to-the-point; specifically about making meaning of NCATE-related responsibilities and actions. The Director of Teacher Education/de facto NCATE Coordinator disclosed that during the times between the full NCATE meetings, each standard committee met on their own to work on their respective standard. NCATE subcommittee meetings were not observed.

\section{Organizational Structure \& Leadership Styles of Senior Managers}

The full NCATE meetings indicate there exists an unspoken hierarchy that allows the Dean to covertly achieve his intentions in ensuring the institution and programs are NCATE-accredited. The person with the power to command actions appeared to be the Director of Teacher Education, the de facto NCATE coordinator. The Dean, who is steeped in NCATE knowledge and processes, was assigned to one of the NCATE Standards subcommittees. He would 
engage in one-on-one conversations answering NCATE-related questions amongst his subcommittee members during full NCATE meetings. However, he appeared to be a meeting participant, quite like the faculty members, rather than the official leader of the implementation process. The senior managementcontrolled leadership structure observed during NCATE meetings were also supported by interview data collected from the Dean, faculty members, and teacher candidates.

\section{The Dean}

When asked about his leadership philosophy, the Dean provided conflicting perceptions of himself as a leader:

We like to have an organizational chart that shows I'm in the middle and the spokes go out. Not top-down. So, a facilitator. I'm not authoritarian. Because I think top-down... first of all, it isn't my personality. Second of all, I believe in servant leadership. If I err, it is on the side of not being authoritarian enough. But I think that I'm more authoritarian because I will come in here and obsess about it. (S. Carter, Dean, interview, April 4, 2012)

Interviews with the Dean and observations of the Dean's interactions with faculty revealed that the Dean is a covert authoritarian. Covert authoritarianism is a leadership style where a leader exhibits outward dispositions of democratic leadership, but uses power and authority to appoint others to execute authoritative control. The covert authoritarian appears as a democratic leader 
who openly involves others in decision making, while in reality, all decisionmaking control rests solely in the leader. The Dean achieves his interests by putting assertive people in power positions. The following three excerpts from interviews with the Dean show a covertly authoritative leadership style:

See, I get [A. Belcher, Director of Teacher Education/de facto NCATE Coordinator] to 'enforce' the law around here. [Interviewer note: he chuckled.] We think the same in a lot of ways, but she is able to get people to do, where I don't want to because that's not my style. (S. Carter, Dean, interview, April 10, 2012)

A different interview with the Dean also provides an example:

I have to ensure that we pass. Because I was an adjunct faculty, faculty, chair, associate dean, then dean, I sort of like, some people like coming through the ranks, other people are new. Because I was the NCATE coordinator and [A. Belcher] is now. I still know what it takes. I think that's a benefit, because not only do I put the right people in place to make it pass to get things done. But now I think my job is to be supportive and calm even though I would like to be more assertive. (S. Carter, Dean, interview, April 4, 2012)

See, I chose G. Rice and M. Wilson [faculty members] to do clinicals at Central [Elementary] because I knew they would get it done and do it like [A. Belcher and I] expect...For example, the 10 AQTS [Alabama Quality Teaching Standards], let's say they send them out to the institution, and of 
course we're aware of them, then [A. Belcher] would be like...I would be aware of them, but [A. Belcher] goes with me to the meetings...then I would get her to say it to the faculty. She would explain what they have to do, and get them to do it. (S. Carter, Dean, interview, April 4, 2012)

The Dean's covert authoritarian leadership style was also observed in two different NCATE meetings:

A. Belcher (Director of Teacher Education/de facto NCATE Coordinator) just finished explaining what some the assessment system evidence should look like. She mentions that faculty should make sure the assessments align with the AQTS indicators and the professional studies indicators. Faculty is discussing the evidence they can locate so that it can be uploaded into a technology interface called LiveText. A few faculty members say that they do not have certain pieces of evidence and that aligning standards "may be hard after the fact." S. Carter (Dean) inconspicuously catches A. Belcher's eye. Faculty does not seem to notice the Dean getting A. Belcher's attention. They walk and meet at the front of the side of the room [Observer note: near where I am sitting to take notes.] In a stern, hushed tone the Dean tells A. Belcher that she must "tell them it's not an option. They "must go back and get it." [Observer note: the faculty members seem to think they are only speaking loud enough for the people at their table to hear, but the Dean appears to be paying attention to what different groups are discussing while not 
exactly looking like he's paying attention.] (NCATE Meeting Observation 1 Notes, February 27, 2012)

In a different meeting:

The Dean and A. Belcher (Director of Teacher Education/de facto NCATE Coordinator) are speaking outside the NCATE meeting before they walk in. The Dean tells A. Belcher, "Now [A. Belcher] you know you are responsible for making sure they do this [NCATE documentation] stuff right. I can't be the one to get on them. We discussed what needs to be done." [Observer note: In a discussion last week the Dean was complaining to A. Belcher about not having enough evidence for the assessment part of NCATE standards. She told A. Belcher that she needed to be more direct in recruiting people who would work hard to get the evidence needed.] (NCATE Meeting Observation 2 Notes, March 12, 2012)

During an interview, and the discussion about his leadership style, the Dean enthusiastically pointed to a book on a bookshelf behind him by author, business consultant, and former Stanford University Graduate School of Business faculty member Jim Collins, titled Good to Great:

There's one little book up there that I read that's like in order for an organization to be successful it has to be healthy and has to be smart...So I would say, if you're sort of looking for an overall philosophy we would look at Jim Collins and his work with get the right people in the right place. 
And then certainly strength finders. (S. Carter, Dean, interview, April 4, 2012)

The Dean referenced his wealth of experience on serving on NCATE committees and going through the NCATE accreditation process many times. He referenced his often difficult-to-execute, resistance to step in and take over the NCATE process. However, he also expressed that throughout the NCATE process he will indeed "take over" by revising writings and documentation to be sure they fit into his understanding of what NCATE expects:

Sometimes I hesitate because I want to get in and do it like I did last time...[When our assessment person left] I wanted to step in, take charge, and say 'Now I'm coordinator.' But I didn't feel like that was the right thing to do. [The Director of Teacher Education/de facto NCATE Coordinator] is the [NCATE] coordinator. Taking over now would be very, it wouldn't be fair to her...So l'm still trying to guide it while they're doing it, but yet I am having to make sure that there's no way that we're going to not pass...So what I've gotta do is what I'm doing now, is to take every piece that I can get my hands on and read it as if I'm doing it. To make sure everything is covered. (S. Carter, Dean, interview, April 4, 2012)

This comment reveals as much about the dean's covertly authoritarian leadership style as it reveals about the NCATE process and the senior managers' motivations behind implementing NCATE standards. The goal, according to the Dean, is to "ensure we pass." Therefore, he "puts the right 
people in place to make sure [they] pass" (S. Carter, Dean, interview, April 4, 2012). The "right people" include selecting faculty members who "enjoy writing" as the people who write the text of each standard, assigning the authoritative Director of Teacher Education as the de facto NCATE coordinator, and assigning "two new enthusiastic faculty members" to implement NCATE's Clinical Residency Model because "a lot of faculty don't like to go into the schools, so it's better to choose the ones who do" (S. Carter, Dean, interview, April 4, 2012). This is an example of resources and power, through conventions, impacting the network of policy actors.

The Director of Teacher Education/de facto NCATE Coordinator

The Director of Teacher Education/de facto NCATE Coordinator was assigned by the Dean to serve as the de facto NCATE Coordinator. She is the person faculty members named when they were asked about who they go to for leadership and understanding of AQTS and NCATE Standards. She was named by teacher candidates when they were asked who has the power to get things done. In an interview, a mathematics methods professor was asked who she consults when she needs to understand quality standards:

Researcher: How do you make sense of NCATE and AQTS standards or requirements by the state?

G. Rice: Ask [A. Belcher]. [Interviewer note: she chuckled.]

Researcher: So, [A. Belcher] explains state and NCATE policies and standards? 
G. Rice: Well, she knows what their looking for. She goes with [the Dean] to all the state stuff. And she is the NCATE person. She explains things to us about what evidence should look like, what they want. Stuff like that. (mathematics methods professor, interview, March 13, 2012)

A discussion with teacher candidates showed they perceive the Director of Teacher Education/de facto NCATE Coordinator as a person of power in the institution:

Researcher: I want to know about the culture of Samford and who has the power to get things done? Who is listened to?

Teacher Candidate 5: Mrs. [Belcher].

Teacher Candidate 1: If you want something done, she's the woman to go to, even my professors know that. (Teacher Candidates, focus group, May 3, 2012)

While the Dean is covert in his authoritative leadership, the Director of Teacher Education/de facto NCATE Coordinator is overtly authoritarian. The Director of Teacher Education/de facto NCATE Coordinator is the "right" person to put in place if your goal is to make sure people implement specific actions in a very structured, literal, and direct manner. When asked about her leadership style, the Director of Teacher Education/de facto NCATE Coordinator provided comments that support the teacher candidates' and faculty's views of her. She mentioned her experience serving in public education for nearly thirty years. She discussed her experiences moving from classroom teacher to a leadership role in 
the same school where she taught. In an introspective way, she mentioned being "resented" and that her authority was snuffed by her colleagues when she assumed a leadership position:

I think they thought I was coming in there like Superman. I probably had that attitude that I could fix everything. They didn't think they were broken. I am the kind of person that if there's a job that needs to be done, you jump in and do it. That was not the best leadership style in that situation, because they really need to get to know me. (A. Belcher, Director of Teacher Education/de facto NCATE Coordinator, interview, April 24, 2012)

A. Belcher's comments about her previous experiences also revealed her intentions, motivations, and expectations when it comes to implementing mandated standards and policies. She spoke with pride about "finally" teaching the teachers-at the school where she served as both a teacher and leaderhow "they were supposed to teach state standards" (Director of Teacher Education/de facto NCATE Coordinator, interview, April 24, 2012). She mentioned "doing exactly what the standards say do," revealing she interprets standards and policies in a very literal, direct way (Director of Teacher Education/de facto NCATE Coordinator, interview, April 24, 2012).

Discussions with the Director of Field and Clinical Experience revealed that A. Belcher brought the same authoritarian style to her job as Director of Teacher Education/de facto NCATE Coordinator. According to the Director of Field and Clinical Experiences, A. Belcher circumvented her authority and took 
over the conventional process of organizing clinical experiences to institute the NCATE Clinical Residency Model instead. The restructuring was done while the Director of Field and Clinical Experiences was on personal leave. The Director of Field and Clinical Experiences mentioned not being asked for input, but being blamed for the disorganization of the implementation of the clinical residency model after she returned to work. The Director of Field and Clinical Experiences referred to A. Belcher as a "standards-driven" leader whose "demeanor" is "very intimidating to some people" (K. Spacey, Director of Field and Clinical Experiences, interview, March 26, 2006).

The Dean, however, seemed to appreciate the Director of Teacher Education/de facto NCATE Coordinator's "take-charge," "get-things-done," "noexcuses" nature (S. Carter, Dean, interview, April 4, 2012). In one interview, he discussed how he consults the Director of Teacher Education/de facto NCATE Coordinator whenever he discovers faculty are not attending to NCATE activities how he thinks they should, saying "If there's a problem, I would go and talk to [A. Belcher] about it" (S. Carter, Dean, interview, April 4, 2012). The Dean used his position and leadership authority to put the people in place who he thought would successfully execute his intentions. The policy actors the Dean puts in place also utilized their power, resources, and opportunities in order to successfully execute their charges. The Director of Teacher Education/de facto NCATE Coordinator discussed how she would often use NCATE accreditation as a bargaining chip to get faculty to implement NCATE standards and policies. For 
example, when asked about how she gets unenthusiastic faculty to implement the NCATE Clinical Residency Model, she replied:

We need to know what $\mathrm{P}-12$ is doing right now so we can adjust...One of the things I hold over their heads is NCATE... They've said everything has to be turned upside down and we need to have P-12 involved. The state has mandated that your methods course needs to be co-taught by someone in the schools like we do at [Central Elementary]. (A. Belcher, Director of Teacher Education/de facto NCATE Coordinator, interview, April 24, 2012)

Her comment reflects how she uses her authority and power to network and interact with lower-level policy actors as a resource to achieve organizational intentions.

\section{Organization Size}

The small size of the school is another factor which enables senior managers to achieve their intentions. According to the Director of Teacher Education/de facto NCATE Coordinator, low program enrollment and small faculty enable "better collaboration and accountability" of teacher candidate development and program processes; "what NCATE wants" (Director of Teacher Education/de facto NCATE Coordinator, interview, April 24, 2012). There were about thirty students enrolled in the Elementary and Collaborative Education Program (ECEP) at the time of this research study. One faculty member, who is part of a two-person team charged with implementing the NCATE Clinical 
Residency Model in the P-12 partnership school, explained the benefits of having small faculty and teacher candidate enrollment:

[The English Language Arts professor and I] collaborate closely with the SPED and assessment professors in structuring the students' Planning Effective Instruction course that we created...So, the students are able to go to any of us and say, 'Can you help me with this piece? Can you work with me on this piece?' I think that it just makes for better accountability for everybody. And that we all have our hands in each project; in each piece. And it helps us to know the students' abilities, their weaknesses. And we're just able to address much of that as a small team. So when we sit down—maybe about four times each a semester-including our chair, we're able to look at growth plans of each student. We have a small faculty and small enrollment in our programs. So it's pretty easy to do what NCATE wants. (G. Rice, mathematics methods professor, interview, March 13, 2012)

Not only do small teacher candidate enrollment and the small number of faculty members contribute to more purposeful implementation of standards and activities, it also enables senior management control. Authoritarian practices such as those engaged in by the Dean and Director of Teacher Education/de facto NCATE Coordinator flourish in such a setting. 


\section{Organizational Culture}

One final aspect of the institution that provides a context for the implementation of teacher quality standards and policies is the Anglo-Saxon religious cultural factor. The values of the lower-level policy actors (i.e., faculty and teacher candidates) at this level are steeped in their faith. The lower-level policy actors' religious values shape their definitions of teacher quality and provide insight into why policy actions are implemented as they are. Lower level policy actors at the program level have very similar values about teacher quality and effectiveness. However, as will be discussed in depth later, their values are different from policy actors at all other levels of the teacher quality policy enactment and implementation process; including the senior managers at the program level (i.e., Dean and Director of Teacher Education/de facto NCATE Coordinator). Faculty perceive teacher quality in more of an abstract way, where quality is defined first by having the disposition (i.e., good heart, nurturing, caring, etc.) for teaching, while content knowledge and impact on student achievement are secondary and tertiary aspects of teacher quality. This contrasts with the conditional neoliberal, data-driven, input/output processes that senior managers at the national, state, and program levels use to define teacher quality.

Lower level policy actors at the program level view themselves as having a subservient, "service to mankind" disposition. They view the standards are a way to engage in "social justice by providing a quality education to all students" (M. Wilson, English/language arts methods professor, interview, March 15, 2012). They take a compliant role when it comes to immediate supervisors. As 
such, it becomes easier for an authoritative leader to convince them that by engaging in particular implementation activities they are serving the teacher candidates and P-12 students in an equitable manner.

One faculty member charged with implementing the NCATE Clinical Residency Model revealed how her religious values shape her definition of teacher quality:

Although our focus has really changed, probably along with our guiding organizations, to be very standards-based, very accountable, and loyal to what the standards are, we still want [teacher candidates] to understand their service to the Lord and service to those children, and their responsibility to teach the whole child. Not just increase student achievement; although you must do that too. (G. Rice, mathematics methods professor, interview, March 13, 2012)

Another faculty member, also charged with implementing the clinical residency model, views herself as having a "servant's heart" and being a "servant" leader. She mentioned that she instills in teacher candidates their responsibility for "being intentional," "purposeful," and extending "grace" in their teaching (M. Wilson, English/language arts methods professor, interview, March 15, 2012). She referenced using a text by Donovan Graham, titled Teaching Redemptively, as she led a "cadre" of teacher candidates who were completing their religion credits. 
[Teaching Redemptively] talks about how to bring grace into your classroom... It's about how to have a classroom full of grace. And understanding that we as humans, and by nature, we fall and we make mistakes. But to understand that's your nature as well. I think that pairs well with the standards, because one of the standards is recognizing how your own bias is going to affect teaching. (M. Wilson, English/language arts methods professor, interview, March 15, 2012)

The Director of Field and Clinical Experiences also showed values situated in religion when she discussed her definition of teacher quality. She mentioned that it is important to "instill in teachers that they have a responsibility to serve God through teaching...And when you do what you are supposed to do as far as learning, your students will learn. But your heart has to be in the right place" (K. Spacey, Director of Field and Clinical Experiences, interview, March 26, 2012). The teacher candidates' comments also represent dispositions of service to mankind:

Teacher Candidate 2: Our job is to serve all students no matter what...

Teacher Candidate 5: Yeah, we have to be committed to serving with a good heart to be a good teacher.

Teacher Candidate 1: Um hm. (Teacher Candidates, focus group, May 3, 2012)

Teacher candidates also mentioned appreciating teacher quality standards in a general context of teaching and reaching all students: "The [Alabama Teacher 
Quality Standards] might be the only way to hold [teachers] accountable and hold all [teacher education schools] in common to produce a good teacher to teach all students" (Teacher Candidate 3, focus group, May 3, 2012).

As evidenced in the following section, faculty members' and teacher candidates' definitions of teacher quality reflect that although they are aware of the socio-political context of accountability in education and teacher education, their ideas about teacher quality do not align with neoliberal ideology. Faculty and teacher candidates' definition of teacher quality is more abstract and grounded in difficult-to-measure indicators of teacher quality; like nurturing, caring, and servant leadership. This is starkly different from the ways in which senior managers at the upper levels of the quality policy enactment and implementation process view quality in teaching and learning. Senior managers' definitions of quality in teaching and teacher education are grounded in a structure of input/output processes and measurable indicators of performance.

\section{Program Level Definitions of Teacher Quality}

\section{Senior Managers}

At the program level there were differences in how teacher quality was defined between the lower level policy actors (i.e., faculty and students) and the senior managers (i.e., Dean and Director of Teacher Education/de facto NCATE Coordinator). Dean and Director of Teacher Education/de factor NCATE Coordinator at program level, like policy actors at the national and state levels, consistently spoke on one accord about quality and effectiveness being 
inextricably linked to teachers' abilities to increase student achievement. Comments of the Dean and Director of Teacher Education/de facto NCATE Coordinator, when asked about quality in teaching and teacher education, reveal how they place value on indicators that align with neoliberal ideology. When it came to the importance of accreditation, the Director of Teacher Education/de facto NCATE Coordinator stated:

Faculty wanted to redesign the programs to kind of go away from, well, not go away from, but to not have some much focus on student achievement. But I told them, right now NCATE says we have to show evidence of impact on student achievement. So, that's what we're gonna do. We have to do it for our accreditation. (A. Belcher, Director of Teacher Education/de facto NCATE Coordinator, interview, April 24, 2012)

\section{The Dean said:}

S. Carter: "You have to add all this and do all this to be accredited. So we want our programs to be accredited. We want to be a [faith-based] university with high academic standards. When we meet high academic standards, by doing all these things, doing them right, it shows we are a credible high academic education school who produces good teachers." (S. Carter, Dean, interview, April 4, 2012)

In addition, observations indicated.

The Dean is speaking to faculty about getting more evidence of the assessment system. "We have to pass. Our assessment system, the way 
it is now, is not passing." [Observer note: I have noticed that most of the time in the NCATE meetings is devoted to the Dean and/or Director of Teacher Education/de facto NCATE Coordinator repeatedly appealing to faculty to gather assessment data. There is also the constant refrain of "We have to pass." It is as if nothing is more important than passing NCATE. When faculty say they do not have the proper evidence to support the assessment system, the response from the Dean and/or Director of Teacher Education/de facto NCATE Coordinator is, "You have to get it."] (NCATE Meeting Observation 3 Notes, April 9, 2012)

With regards to more content knowledge signifying a better prepared teacher, the Dean stated:

Because of [NCLB], we had to increase the number of content courses they had. We had to meet and even create a couple of new classes, but also change it around and probably add more to it, which made it a longer program, a program with a lot more requirements. But that is okay because they need the content. (S. Carter, Dean, interview, April 4, 2012)

The Director of Teacher Education/de facto NCATE Coordinator said:

We have done a lot to show NCATE and the state department that our teachers have more content and experiences that other teachers in the state. We have added these mini courses so that we can teach them more content that they are not getting in their classes. We have the partnership with [Central Elementary] just like the Blue Ribbon panel says 
clinical experiences should be done. I think our teachers will be better prepared. (A. Belcher, Director of Teacher Education/de facto NCATE Coordinator, interview, April 24, 2012)

Regarding links between teacher inputs and student outputs as an important way to determine teacher effectiveness, the Dean stated:

We would probably put learning first. Then, we would also, and I guess since we've been working on NCATE, a teacher's quality can be the ability to impact student learning. (S. Carter, Dean, interview, April 4, 2012)

The Director of Teacher Education/de facto NCATE Coordinator said:

[Teacher Candidates] really need to know to know how to assess, how to use data, how to plan, how to accommodate, how to get those students achievement up. Those are the things I really want them to know." (A. Belcher, Director of Teacher Education/de facto NCATE Coordinator, interview, April 24, 2012)

I called down to the state department and said, 'I need data on the test scores of students of our graduates who are new teachers. I need to know this. You cannot ignore student achievement data if you want to know if your programs are effective. Because how are we gonna know how effective they are in teaching if we don't look at those test scores?" (A. Belcher, Director of Teacher Education/de facto NCATE Coordinator, interview, April 24, 2012) 
In addition, observations supported this finding:

The Director of Teacher Education/de facto NCATE Coordinator is stressing the significance of gathering data that shows the impact of teacher candidates on student achievement. Faculty are asking about ways they can reasonably show such evidence if a teacher candidate is not teaching for an extended period of time. A. Belcher explains, "We know that unless we show impact on student achievement there is no proof the kids are learning...We have to create situations, maybe small group activities, where they teach students a small lesson and record their scores on a test." (NCATE Meeting Observation 2 Notes, March 12, 2012)

The comments of the Dean and Director of Teacher Education/de facto NCATE Coordinator show interests, intentions, and motivations to narrowly define quality in teacher education using teacher inputs, teacher inputs linked to student outputs, and national accreditation. Their ideas of quality were translated into practice through the way in which they pressed for the implementation of the NCATE standards, including NCATE Clinical Residency Model, which provides an environment for data to be collected which links teacher candidate inputs to P12 student outputs.

Lower-Level Policy Actors

The faculty and teacher candidates' ideas about teacher quality were different from those of the Dean and Director of Teacher Education/de facto NCATE Coordinator. As discussed in Organizational Culture, faculty and teacher 
candidates understood the accountability context in which teaching and learning is grounded, but this understanding did not translate into a performance-based accountability mindset for defining teacher quality. Lower-level policy actors' definitions of teacher quality are grounded in indicators that are more difficult to measure than impact on student achievement.

When asked to define teacher quality, the two faculty members who are charged with implementing the NCATE Clinical Residency Model discussed their intentions to instill qualities that are difficult to measure. A faculty member mentioned teacher candidates developing "grace and mercy;" an understanding of the "learning differences of students;" how their "own biases" impact how they teach; and being "faithful and obedient to God" in serving students, other teachers, and school leaders (M. Wilson English/language arts methods professor, interview, March 15, 2012). In her definition of teacher quality, another faculty member discussed the changing, accountability-driven landscape of teacher quality and contextualized her definition of teacher quality within the accountability landscape:

Good teaching can be achieved by being loyal to what [teacher quality] standards are, the accountability, your own personal professionalism, your disposition, your level of content knowledge, your level of understanding of pedagogy," but "what's most important is your heart and willingness to reach all children, taking ownership of the lives of those children. You will meet the standards when you focus on the things that are more important. (G. Rice, mathematics methods professor, interview, March 13, 2012) 
The Director of Field and Clinical Experiences, who also serves as a faculty member, mentioned meeting the spiritual needs of students:

A quality teacher is someone who exemplifies knowledge and ability to focus on the needed skills to help students move from one place to another. It's really about taking children where they are and moving them where they need to be academically and spiritually. You have to make sure all the needs of the children are met, not just their academic needs. I think they will do fine academically when you think of it that way. (K. Spacey, Director of Field and Clinical Experiences, interview, March 26, 2012)

The teacher candidates defined teacher quality as "a teacher that can engage students in learning and make it fun," "a teacher that can teach effectively and engage the students of all types of learning and abilities," being "knowledgeable and flexible," "organized enough to meet the needs of all the students all day," "having a heart for teaching," "loving children and loving to teach children," and "serving the Lord through your teaching" (Teacher Candidates, focus group, May 3, 2012).

Faculty and teacher candidates understand they are required to teach and learn standards, respectively. However, their interpretation of the purpose of the standards is not anchored by teacher impact on student achievement. Neither faculty nor teacher candidates overtly mentioned impact on student achievement in the context of their definitions of teacher quality. When asked directly about a 
teacher's impact on students' achievement, teacher candidates' responses were "oh yeah" and "of course" (Teacher Candidates, focus group, May 3, 2012). For faculty and teacher candidates, student achievement is a result of "intentional" "graceful" and "merciful" service to students.

In contrast, the senior managers spoke intently and directly about student achievement as an indicator of teacher quality. Although socio-political conditions of neoliberalism exist at all levels of the teacher quality enactment and implementation process, faculty and teacher candidates-the implementers at the street level-intentions and motivations do not have a neoliberal ideological bent. The definitions of teacher quality and the understanding of the purpose of teacher quality standards between senior managers and lower-level policy actors diverge, yet senior managers have no trouble controlling the direction of teacher quality policy and standards implementation.

The Quality Standards \& Policies Implemented at the New School

Teacher candidates graduating from the Elementary and Collaborative Education Program (ECEP) are awarded four teacher education certifications: early childhood, elementary, collaborative, and special education. When the Dean, Director of Teacher Education/de facto NCATE Coordinator, and faculty were asked about the standards they are responsible for implementing, they each mentioned one or more of the following: the six main faith-based goals of the mission and vision of the university; Alabama Quality Teaching Standards (ATQS); the Alabama Continuum for Teacher Development (the Continuum); 
professional studies standards for early childhood education, early childhood/special education, elementary education, general special education, collaborative education, and reading; Performance Assessment Templates (PATs); NCATE standards; and the NCATE Clinical Residency Model. No one individual mentioned all standards. Below are several example of responses from policy actors when they were asked, "Tell me the quality standards and policies you are responsible for implementing." The Dean's response was:

AQTS, NCATE, we have the professional organization which are lined up with the state. For example, NAEYC. Then NCTM and again, there's an A-plus best practices center. We try to go beyond the standards, the minimal standards. We have our religious standards too, although I think that should be called our mission. I don't think they are standards, but we have to include those. (S. Carter, Dean, interview, April 4, 2012)

The Director of Teacher Education/de facto NCATE Coordinator mentioned four sets of standards:

The quality standards, and now the Continuum. I don't know if I should call these standards, but we have to do this clinical model for NCATE. Oh, and the PATS. (A. Belcher, Director of Teacher Education/de facto NCATE Coordinator, interview, April 24, 2012)

The Director of Clinical Experiences mentioned the responsibility of implementing different sets of standards in courses and in field and clinical experiences: 
Well, we have to do the NCATE. But we also have professional standards, like reading education, for me. We have PATs, we call 'em PATS. I don't remember what that stands for. We have this new Continuum stuff, but it's just a smaller version of the AQTS. (K. Spacey, Director of Field and Clinical Experiences, interview, March 26, 2012)

A faculty member mentioned two sets of standards and included how they are required to be listed on syllabi:

The AQTS. Professional standards. They are in our syllabi. We list them in our syllabi. (M. Wilson, English/language arts methods professor, interview, March 15, 2012)

In addition to the abundance of standards, policy actors are required, by the state, to implement assessments and other checkpoints which document a teacher candidate's progression from program admittance to graduation. A state and NCATE Board of Examiners member who serves as certification officer at a teacher education institution not investigated in this study explained the State's minimum requirements for the checkpoints:

Our job we're charged with producing teachers. And this is our quality control. We've got to make sure that know where the tolerances are. We know what's an acceptable deviation. And we're measuring along the way. It's not just a one point in time measure. We're measuring in coursework. First of all, we measure at admission. We're saying you've got to at least have a 2.5 GPA. You've got to have proven yourself in the 
first 64 hours of undergraduate. We admit as a junior. The first 64 hours in your coursework in general studies have to be at least at a B level. So that's our first check of quality. Then there's another check there that they've got to be proficient as measured by the APTT. That's applied mathematics, reading for information, and writing. They've got to prove to us that they are there. Our charge with the AQTS, PATs Analysis Forms is to value add to that. We've got to assess them in content. We've got to assess them in pedagogy. Hopefully, along the way their GPA will increase, as evidence of that. Their proficiency measures we measure on a 4-point scale on all of these [PATs, AQTS], we want you at least at a 3 before we allow you to finish the program. Then, internally our grading performance and courses. Then we have another check before we allow them to go out to the internship. They have to be content-level tested, which is the Praxis II. (E. Jones, NCATE National-State BOE Member, interview, March 5, 2012)

The language he used in his explanation (e.g., "quality control," "acceptable deviation," "producing teachers," etc.) reflects the neoliberal conditions of quantitative efficiency, performance accountability, defining quality of education by the product of education, and the use of formal input/output processes to measure quality. The values E. Jones expressed are important to teacher quality policy in the state because he was heavily involved in the development of the Alabama Quality Teaching Standards. 
The Dean has instituted assessment policies which extend beyond state regulations by requiring teacher candidates to achieve a 3.0 grade point average (GPA) in all education and non-education coursework. The state GPA requirement is 2.5. Candidates must complete 12 hours of coursework in each of the following content areas: mathematics, science, social studies, and English/language arts. Another program-level requirement, beyond what is required by the state, is the addition of a content knowledge and certification exam in reading education. Teacher candidates at the New School must pass four national standardized assessments to graduate the Elementary \& Collaborative Education Program (ECEP) program: one basic skills exam and three teacher certification exams. Prior to being admitted into the Elementary \& Collaborative Education Program (ECEP), teacher candidates must pass a basic skills test, the Alabama Prospective Teachers Test/Praxis I. Teacher candidates must also pass three Praxis II certification exams prior to graduating the ECEP: elementary education, special education, and reading.

Prior to the start of the 2011-2012 academic year, teacher candidates were only required to pass one Praxis II certification exam, elementary education. The addition of the other two Praxis II certification exams is a result of the state finally setting a cut score for the special education Praxis II, and the institution going beyond minimal state certification requirements in an attempt to make their graduates more qualified because they will have an additional certification in reading education (A. Belcher, Director of Teacher Education/de facto NCATE Coordinator, interview, April 24, 2012). The requirement for 
passing four content examinations to show teacher knowledge acquisition is an example of how national-level policy (i.e., NCLB) sets conditions for policy implementation at the state and program levels. The national-level NCLB "highly qualified" teacher legislation regarding content knowledge was transformed into a state policy, which was then required to be implemented at the teacher preparation program level.

The Dean, Director of Teacher Education/de facto NCATE Coordinator, Director of Field and Clinical Experiences, and English/language arts and mathematics methods professors each mentioned being overwhelmed by the amount of state and institution-level standards, policies, and requirements they are charged with implementing. The English/language arts methods professor referred to the AQTS as "a mile wide and an inch deep," and said that having so many "standards on top of standards...spreads us too thin" (M. Wilson, English/language arts methods professor, interview, March 15, 2012). She expressed a desire for the state to allow all institutions to focus on the Continuum which reduces the amount of measurable indicators from hundreds to about forty. The mathematics methods professor, referred to the difficulty of addressing the overwhelming amount of AQTS indicators saying, "It's a challenge, really, for our programs...to meet the AQTS in a meaningful way: to make sure they are not only noted in the syllabus, but to make sure that are addressed and developed over a period of time" (G. Rice, mathematics methods professor, interview, March 13, 2012). 
The Dean mentioned that although he encourages the faculty to "go beyond the [AQTS] standards...there are too many [other standards they] are required to do" (S. Carter, Dean, interview, April 4, 2012). When asked how he deals with faculty being overwhelmed by the amount of standards and requirements, he provides a conflicting response about there being "a lot" of state-mandated requirements to implement, but that faculty could "add other things." Yet, he also mentioned how he uses his position with the state to try and influence reducing the requirements:

A lot of it is mandated by the state, so faculty doesn't have much wiggle room at all...or the student is not certified. And yet, I try to deal with the faculty as even though it's mandated, you know we still have to do it. But we could add other things. Then at the state level, I'm trying to work with ALACTE to try not to have so many (S. Carter, Dean, interview, April 4, 2012)

State mandates are an example of active political intervention of program level processes. The Dean expressing a point of view that although there are "too many" standards, faculty could do more indicates the notion of quantity over quality. Quantity over quality and active political intervention of the state in program level practices are both characteristics of neoliberalism in action.

Faculty indicated the state review and program approval process focuses on checking an alignment of AQTS to courses, course objectives and goals, course assignments, field and clinical experiences, and assessments. This 
process was observed in standards alignment documents and observations of methods courses. A review of syllabi and observations of both the English/language arts and mathematics methods courses showed the way in which faculty conducted the alignment of standards, coursework requirements, and assessments. Table 8 is an example of the alignment of English/language arts and mathematics course content, standards, and assessments. 
Table 8

Sample of Standards Alignment

Course EDU 326: Language Arts Methods Course

Course

Objective

$\begin{array}{llll}\text { English/ } & \text { (2)(c)5.(v): } & 3.7 & 3,4,6, \\ \text { language } & \text { assessment } & , & 7 \\ \text { arts: } & \text { (2)(c)4.(vi): } & 2.1 & \\ \text { Demonstrate } & \text { differentiatio } & , & \\ \text { the ability to } & \mathrm{n} & 6.6 & \\ \text { select } & (2)(\mathrm{c}) 5 .(\mathrm{ix}): & \\ \text { appropriate } & \text { rubrics } & \\ \text { modes of } & \text { (2)(c)5.(x): } & \\ \text { classroom } & \text { performance } & \\ \text { assessment } & \text { assessment } \\ \text { of language } & & \\ \text { arts with } & & \\ \text { special } & & \\ \text { emphasis } & & \\ \text { placed on } & \\ \text { the Alabama } & \\ \text { Writing } & \\ \text { Assessment } & & \end{array}$

Assignment Assessment

1. 6 Trait Modes of Writing/Mode Writing $s$ of Writing Lesson plan,

2. Assessing to include the modes of rubric (with writing differentiation ) for assessing the writing mode

\begin{tabular}{|c|c|c|c|c|c|c|}
\hline $\begin{array}{l}\text { Mathematics } \\
: \text { Teach } \\
\text { concepts of } \\
\text { geometry }\end{array}$ & $\begin{array}{l}\text { (2)(c)3.(vi): } \\
\text { communicat } \\
\text { e math } \\
\text { concepts } \\
\text { (2)(c)5.(v): } \\
\text { assessment }\end{array}$ & $\begin{array}{l}5.3 \\
2.4\end{array}$ & 3 & $\begin{array}{l}1 . \\
2 .\end{array}$ & $\begin{array}{l}\text { Develop a } \\
\text { lesson plan } \\
\text { around a } \\
\text { geometry } \\
\text { concept (to } \\
\text { be assigned } \\
\text { Develop an } \\
\text { assessment } \\
\text { of the } \\
\text { geometry } \\
\text { concept } \\
\text { taught }\end{array}$ & $\begin{array}{l}\text { Lesson plan, } \\
\text { handouts, } \\
\text { rubric }\end{array}$ \\
\hline
\end{tabular}

AQTS = Alabama Teacher Quality Standards $P S=$ Professional Studies Standards $\mathrm{SOE}=$ School of Education 
Both course syllabi are structured in the same manner. The first page has the following headings: Course Description, Relationship to the Conceptual Framework, Prerequisites, Credits, Textbook, Course Teaching and Learning Strategies, and a table of Course Objectives, which are aligned with the AQTS or Professional Assessment Templates (PATS), professional studies standards, and assessments (as shown in Table 8). The Director of Teacher Education/de facto NCATE Coordinator mentioned that "by the end of summer and before our NCATE/State visit," (A. Belcher, Director of Teacher Education/de facto NCATE Coordinator, interview, May 1, 2012) the content and objectives of all courses will be aligned with AQTS, professional studies standards, the New School standards, and assessments. She also mentioned that course syllabi will be standardized to reflect the same headings in the same order.

In a different discussion about NCATE versus the state review, the Director of Teacher Education/de facto NCATE Coordinator said, "The state will just check to make sure the syllabi look right and are aligned with the standards" (A. Belcher, Director of Teacher Education/de facto NCATE Coordinator, interview, April 24, 2012). The process of standardizing the alignment of syllabi, and the state review activity of checking documentation of alignment are examples of the use of standardized processes to measure quality.

Observations in the English/language arts and math methods courses, provided evidence of teacher candidates engaged in coursework which directly reflected a knowledge or application indicator in the AQTS. For example, one of the AQTS standards implemented in the mathematics methods course is 
(2)(c)3.(vi): Ability to communicate with others about mathematical concepts, processes, and symbols. The following is an excerpt from an observation of this standard being implemented:

Teacher candidates are milling about the room discussing their lesson plans and sharing the lessons they will have to teach in class today. Two teacher candidates are reading over papers at their desks. The others are talking and visiting with each other. One teacher candidate (whose facial expression exhibits excitement) asks another teacher candidate, "Did you get spatial visualization for your topic?" The other teacher candidate responds in an exasperated voice, "Yeah, I'm not sure if I understand what I'm talking about but." The mathematics methods professor enters the room [Observer's note: she had been in the hallway talking with the English/language arts methods professor about this activity being one that is "good NCATE evidence"]. The professor greets the teacher candidates and says, "Are you guys ready to teach your mini math lessons?" She then turns to me and says, "One of the standards is that they have to teach each other, or communicate to each other math concepts they will teach. So, we're doing that today." The professor turns back to the teacher candidates and asks, "Who wants to go first?" Four of the teacher candidates raised their hands. A few look worried; especially the girl who mentioned earlier that she doesn't know what she's talking about. A teacher candidate is chosen. The topic of her lesson is Geometry: Similarity and Congruence. She distributes a handout which has 
definitions and examples of similarity and congruence; two games, one each with directions for how to play Fishing for Congruency and Mr. Similarity; and, one lesson assessment. The professor tells the class to pretend they are in fifth grade. The teacher candidate teaches the lesson as if she is teaching grade school students. (mathematics methods course observation 2, March 13, 2012)

The examples of the English/language arts and mathematics methods courses alignment of standards, objectives, and assessments shows evidence of documentation that certain standards are taught and assessed in courses. When the Director of Teacher Education/de facto NCATE Coordinator mentioned that all course syllabi will be standardized before the NCATE and state review, she provides evidence that the top priority of senior managers is showing that compliance requirements are documented. The observation of the methods courses provides evidence that the lower-level policy actors, the faculty, are responsible for not only the tedious work of aligning objectives, standards, and assessments, but also ensuring standards are taught and assessed in courses.

Faculty is overwhelmed, but they also think more equals better. When discussing the overwhelming responsibilities of quality standards alignment and implementation, policy actors referred to NCATE requirements and four sets of professional study standards as "overwhelming, but beneficial" (G. Rice, mathematics methods professor, interview, March 13, 2012). The Dean, Director of Teacher Education/de facto NCATE Coordinator, and faculty all spoke with pride about the advantage their graduates had over graduates from other teacher 
education institutions in the state because of being certified in four content areas and having a "wealth of field experiences" (K. Spacey, Director of Field and Clinical Experiences, interview, March 26, 2012).

The Dean, Director of Teacher Education/de facto NCATE Coordinator, and faculty placed value on the quantitative documentation of policies implemented. Such values align with neoliberal ideology and the idea that quality in teacher education can be defined in terms of the accumulation of representations of quality.

\section{Perceptions that More Equals Better Quality}

There were fundamental differences in how lower level policy actors (i.e., faculty) and senior managers (i.e., the Dean and Director of Teacher Education/de facto NCATE Coordinator) viewed the meanings of teacher quality and effectiveness. Yet, there are specific factors-two of which are characteristics of neoliberal condition—which led to policy actors strictly adhering to literal interpretations of the language of state and NCATE policies and standards during the implementation process. The neoliberal factors are: organizational life governed by senior management control and the "product of education as qualification" (Lorenz, 2012, p. 621). The other factors are policy actors' perceptions that national accreditation equals quality and the compliant nature of the lower-level policy actors (i.e., faculty) charged with implementation. Lower-level policy actors viewed state and NCATE standards as common-sense approaches to improving the quality of their teacher education programs and 
candidates. As such, the differences in fundamental values between the senior managers and lower level policy actors were inconsequential.

Interests and motivations between senior managers and lower level policy actors in implementing state and NCATE standards converged around the idea that with the implementation of NCATE and state standards, more content knowledge, and the new clinical residency model, teacher candidates would graduate better qualified than teacher candidates in other teacher preparation programs in the state. The senior level managers and faculty agreed that NCATE accreditation and state approval, including implementing all NCATE standards and the NCATE Clinical Residency Model, is pertinent to achieve a teacher education program publically perceived as higher quality, more marketable, and one that would serve as an exemplar for the state.

Senior level managers, faculty, and teacher candidates perceived value in the implementation of additional content and program requirements, beyond the content required by the Alabama State Department of Education (ALSDE). Senior managers' values a placed in institution marketability and NCATE accreditation. Lower level policy actors perceive that more standards equal higher quality graduates. Discussions with the Dean, Director of Teacher Education/de facto NCATE Coordinator, faculty, and teacher candidates yielded evidence of their perceptions. For example, in two separate interviews, the Dean mentions or implies competitiveness: 
See we have added things to our programs that the state does not require. Our teachers take the Reading Praxis. They do all these workshops to get more content. Ask [A. Belcher]. She works with faculty to set all that up. She even does some of the workshops herself. Our teachers will be qualified in elementary education, early childhood education, special ed, and reading ed. Other schools just can't say that [emphasis added]. (S. Carter, Dean, interview, March 25, 2012)

Arne Duncan had NCATE, well encouraged NCATE, to come up with this Blue Ribbon report that says the best way to do field and clinical is to have the teacher-in-residence. If we want our programs to be competitive, people to want to come to our school, we have to do it. And we are doing it. The state really encourages us. [A. Belcher] has set everything up over at [Central Elementary]. (S. Carter, Dean, interview, April 4, 2012)

In two separate interviews, the Director of Teacher Education/de facto NCATE Coordinator implied perceptions that more content signals a better quality program to NCATE and the state:

And then when we heard all this [about a Clinical Residency Model] from the NCATE Blue Ribbon report we were like, well this is exactly what they want. And I have been asked by some faculty members, 'Do we really have to do that?' I say 'It's great for our students. And it looks really good for our program' Then I say, 'This is what NCATE expects now, and the 
state. So just do it [emphasis added].' (A. Belcher, Director of Teacher Education/de facto NCATE Coordinator, interview, April 11, 2012)

One of the things I always hold over their heads is NCATE. We want to be accredited. Period. They've said everything has to be turned upside down and we need to have P-12 involved. The state has mandated that your methods courses need to be co-taught by someone in the schools like we do at [Central]. So that's there. And we jumped to do this. So our program is a model for the state [emphasis added]. (A. Belcher, Director of Teacher Education/de facto NCATE Coordinator, interview, April 24, 2012)

Interviews with The Director of Field and Clinical Experiences and one faculty member reflect perceptions that more content equals better qualified graduates:

Our kids get a lot. But it will all help them be better, or highly qualified teachers. Even the new field and clinicals. I don't agree with how [A. Belcher] took it over from me, but NCATE says it's better than the old way. And the Reading Praxis. Our students get more content in reading than any other teachers in the state. So, it's all a good thing for [teacher candidates] and the program [emphasis added]. (K. Spacey, Director of Field and Clinical Experiences, interview, March 26, 2012)

We implement all these things. It's very technical. It's very specific. And this new thing where we want our students in the field longer, that takes a lot of work and preparation. But it is all worth it. We have to make sure our students are qualified for anything they may face as a new teacher, a 
teacher. And our graduates will be more qualified [emphasis added]. (G. Rice, mathematics methods professor, interview, March 13, 2012)

The following exchange, in an interview with the teacher candidates, provides evidence of their perceptions that more content equals better quality:

Researcher: I want to talk about the standards, assignments, and the workshops you have to do outside of class. Tell me about that. What do you think about it?

Teacher Candidates 5: There are a million standards. I don't, we don't know them. Then we have to add differentiation on our lesson plans. And we have to work in these learning groups. We have stuff to do outside of our classes that's required. And we have to pass three Praxis tests. It's a lot. But my friends at other schools are not getting what I am getting. So I'm glad we do all this. It makes us better.

Teacher Candidate 2: We have so many assignments and so much stuff to do. You really have to be very organized. But that's good teaching anyway. The whole new field experiences is very disorganized, but I see why we need to do it. Just like I see why we need to be certified in four areas

Researcher: Why? Why do you think you need to do all this?

Teacher Candidate 2: To be better, to be better teachers. [emphasis added] (Teacher Candidates, focus group, May 3, 2012) 
There is a difference in how senior managers discussed their perceptions of value in implementing more standards. The Dean and Director of Teacher Education/de facto NCATE Coordinator mentioned institution marketability/competitiveness and NCATE accreditation, respectively. The Director of Field and Clinical Experiences, mathematics methods professor, and teacher candidates perceive that the more content acquired the better quality the teacher preparation program and graduates. This is an example of the neoliberal ideal of quantity over quality. The perceptions of senior managers however, show a view of the product of education indicating education qualifications. The idea is that as long as quality activities are shown to be implemented and teacher candidates are exposed to more opportunities for content knowledge, a quality teacher preparation program has resulted. The consequences of senior managers' interests, intentions, and motivations, and lower-level policy actors' perceptions that more content equals better quality set conditions for symbolic implementation.

Symbolic implementation is implementation actions that signal meaningful or instrumental implementation (Smith, Miller-Khan, Heinecke, \& Jarvis, 2004). Such actions yield no meaningful information that can be used to determine impact. In symbolic implementation, there is no relationship between means and ends (Smith, Miller-Khan, Heinecke, \& Jarvis, 2004). An example of symbolic implementation, which will be discussed more in depth later, is the implementation of the NCATE Clinical Residency Model at the New School. The New School collected data and evidence for the purpose of showing the clinical 
residency model was implemented. However, the evidence does not reflect the reality of disorganized implementation that was observed. However, graduates will be able to say they experienced a clinical residency model during their teacher preparation program. As well, anyone who was not involved in and did not observe the haphazard implementation process_for example, policy actors at the NCATE and state level—may assume the clinical residency model was implemented as intended. The ends are disconnected from the means.

\section{The Implementation of NCATE Policies \& Standards at the New School}

Although policy actors mentioned many sets of standards and policies they are responsible for implementing, a sustained, intense focus on implementing NCATE standards, the NCATE Clinical Residency Model, and a documented alignment of AQTS and professional program standards with program practices and assessments was observed. The dual state-NCATE roles of the senior managers, and the high value placed on NCATE accreditation by policy actors across all levels of the teacher quality enactment and implementation process provided the conditions for NCATE policies and processes being viewed as essential elements in improving teacher quality. Discussions with senior managers and faculty, and observations of NCATE meetings revealed that NCATE was the main focus of all implementation practices. In an interview with the Dean, he discussed the importance of passing NCATE: 
We have to pass NCATE. We have to get our programs approved by the state too, but NCATE is more difficult. We have to collect evidence of everything we say we're doing with NCATE. So, our programs will probably be approved. We have our checklists and our alignments done, or we will have them done, for the state. But we have to get our assessment system in order and our field and clinical partnership done. I am worried about those things. We can't just say we're doing them. We have to have evidence to show we're doing them. (S. Carter, Dean interview, April 4, 2012)

In an interview, the Director of Teacher Education/de factor NCATE Coordinator also stressed the importance of focusing on NCATE activities:

The state just comes in, they really have checklists they monitor. They're really not about how to change. And if you really want to change, you've gotta have evidence of what's happened. You've gotta know your data and how you're going to change and adjust. That's what NCATE is looking for, evidence. So, we've gotta concentrate on getting our evidence. We don't have a lot of time. NCATE comes in December. I'm getting pressure from [the Dean], so I have to put pressure on the faculty. (A. Belcher, Director of Teacher Education/de facto NCATE Coordinator interview, April 24, 2012) 
The Director of Field and Clinical Experiences explained, in an interview, how the Director of Teacher Education/de factor NCATE Coordinator used her authority to get faculty to focus on NCATE implementation activities:

Since [the Director of Teacher Education/de facto NCATE Coordinator] took over everything related to NCATE, that's all we do now. NCATE. NCATE. NCATE. We have to do a new thing with field and clinicals. Well, she just took over that and got her friend to set up the whole thing at [Central Elementary]. No one consulted with me. I was told by [the Dean] to support [the Director of Teacher Education/de facto NCATE Coordinator] because she knows what we have to do to pass NCATE in that area. So, I'm being a team player and making sure we get the evidence. (K. Spacey, Director of Field and Clinical Experiences, interview, March 26, 2012)

An observation at an NCATE meeting also provides evidence that the focus of policy and standards implementation was centered on NCATE activities:

There are questions going back and forth between A. Belcher, the Director of Teacher Education/de facto NCATE Coordinator, and faculty. Faculty is negotiating reducing their work load associated with NCATE and state implementation activities. Most questions are about whether one implementation activity can be used for both the state review and NCATE. A faculty member raises her hand as $A$. Belcher is stressing the importance of collecting evidence for the assessment system. The faculty member says, "I have to align all these different standards with my 
courses and make sure I have my assessments? Is that also evidence of the assessment system?" A. Belcher replies, "Yes. Guys, as I have said, we have to do the alignment for the state. But we also have to do it for NCATE. Right now we're focusing on NCATE. But some stuff for NCATE will be good for the state. The state only wants to see the alignment on your syllabi. NCATE is gonna check to make sure you are doing what's in your syllabi in your courses. So, it doesn't stop with the alignment. You have to assess whatever standards you have aligned with your objectives. And it must go: objective, standard, assessment." (NCATE Meeting Observation 1 Notes, February 27, 2012)

An exchange with the Dean also provides additional evidence of NCATE being the main focus of standards implementation practices:

Researcher: I was told by [an official in the Alabama State Department of Education Office of Teaching and Leading] that programs cannot pass NCATE without being state approved. Which one is most important to you, state approval or NCATE?

S. Carter: You have to have the state or you lose your program. There are two reviews, state and NCATE. State is state-level, NCATE's national. And you have to have the state in order to have your programs. NCATE won't take it away, it just won't be accredited. So really state is probably more important just in the state, because you could make it in the state without NCATE. But, see here, as far as the university, they want us 
to be nationally. And I want us to be nationally. And since NCATE has more stuff, more evidence, more things we have to do or show, I guess it's more important in that way. That's really our focus right now. That's where I worry.

Researcher: So, for you, NCATE accreditation is more important.

S. Carter: I would say yes. Yes right now. The state is important. We have lots to do to get ready. I'm more concerned with NCATE. I think the state is fine. (S. Carter, Dean, interview, April 4, 2012)

Discussions with the Dean, Director of Teacher Education/de facto NCATE Coordinator, and Director of Field and Clinical Experiences, and observations of NCATE meetings reflect policy actors' urgency to focus on implementing NCATE activities. The Dean made it clear that his focus "right now," is on implementing NCATE activities. The Director of Teacher Education/de facto NCATE Coordinator stressed the importance of collecting documentation and evidence of NCATE activities. She also indicated she gets "pressure" from the Dean to "pressure" the faculty to implement NCATE activities. The Director of Field and Clinical Experiences explained how senior managers have taken control over program practices and focused faculty attention on implementing NCATE activities, like the NCATE Clinical Residency Model. During an observation of an NCATE meeting, as faculty were trying to make sense of their implementation responsibilities for the state and NCATE, the Director of Teacher Education/de facto NCATE Coordinator stressed the 
importance of focusing on NCATE above state activities. This is an example of senior managers using authority and power through conventions to achieve their intentions.

Serving in dual roles as the Dean of the School of Education and President of ALACTE, the state-level NCATE partner, the Dean has a responsibility to ultimately ensure all teacher education programs are approved by the state and that NCATE standards are implemented to the degree that will result in national accreditation. The Director of Teacher Education/de facto NCATE Coordinator-who also served in a leadership position on the development of the Alabama Quality Teaching Standards—has a dual role in ensuring teacher education programs are state approved and that NCATE standards, policies, and processes are implemented to ensure accreditation.

According to the Dean and Director of Teacher Education/de facto NCATE Coordinator, as evidenced above, the state review of programs is a technical check of documents which align standards with objectives, and assessments in courses and field and clinical experiences. The NCATE process was perceived by policy actors as being more rigorous. Thus, it became the focal point of policy and standards implementation practices.

The Director of Teacher Education/de facto NCATE Coordinator, when explaining the difference between the NCATE and state reviews, provided further insight into the way in which NCATE influenced policy actions above state 
requirements. Her statement also provides evidence of senior management perceptions that the NCATE process is more rigorous:

NCATE comes in December [2012] and the state comes with them. The state just wants you to do all these standards, that you're teaching them and assessing them...All they want to see is that they are taught and they are assessed. NCATE wants to see that you are looking at candidates throughout the program, our key assessments, how we make decisions based on data, what evidence we have. They really are a whole evidence-based system. The state should be really moving to model NCATE, but they aren't. This is something I want to address with the state once we get through NCATE...That we have evidence and data. [The state] should ask for the same thing. Because that's the way you know if you have a good candidate. Checklists are just monitoring and it's just that. (A. Belcher, Director of Teacher Education/de facto NCATE Coordinator, interview, April 24, 2012)

The Director of Teacher Education/de facto NCATE Coordinator also mentioned how all internal program activities ceased at the start of the fall semester of 2011 so that NCATE requirements could be implemented. The usual faculty meetings were halted and full and subcommittee NCATE meetings were instituted instead. Faculty and leadership had been "in the middle of" redesigning and restructuring their Elementary \& Collaborative Education Program, but they "stopped that for NCATE because it was too complicated to focus on both" (A. Belcher, Director of Teacher Education/de facto NCATE Coordinator, interview, April 24, 2012). 
The perceived intention of NCATE is that teacher education programs would implement a continuous improvement model, where appropriate data is continually and consistently used to improve programs and teacher candidate outcomes (E. Jones, NCATE National-State BOE Member, interview, March 5, 2012). However, although senior managers and faculty discussed implementing NCATE standards and requirements, practices that reflected a continuous improvement model were not observed. Rather, an institutional model where policy actors were in a perpetual state of catching up, or symbolically implementing standards, was observed. The Dean mentioned the catching up process as conventional program-level practice in the implementation of NCATE standards:

I'm sort of knowing that we're in the right pattern. And [the faculty] would say, 'We're not gonna do this next time. We are going to be prepared.' But see, we said that last time, and we didn't keep up. I think we still will be unprepared. I've heard this before. And you hate to be like that, but it's probably because I've been through three NCATEs. And they're like, 'We've gotta do this. We've gotta do that.' But it's always like, 'We're not gonna be like this next time.' But I know we will. (S. Carter, Dean, interview, April 4, 2012)

Observations and discussions with lower-level policy actors triangulated well with the Dean's explanation of faculty engaged in catching up rather than meaningfully implementing NCATE standards. Faculty were engaged in a dichotomous process of either working backwards to link data to program 
changes or instating new policies and actions that reflected their interpretation of the NCATE policy and standards language. The Dean and Director of Teacher Education/de facto NCATE Coordinator encouraged the invention of evidence and data, or the quick implementation of activities as evidence of implementation:

Whatever data we don't have, we have to have. We have to get it. This summer we will be aligning all syllabi. I just hope the faculty has done assessments in their courses to match, because NCATE will ask students. (A. Belcher, Director of Teacher Education/de facto NCATE Coordinator, interview, April 9, 2012)

In an interview, the Dean said:

Yesterday, I was telling them they have to get what they don't have. They have to design tests that will show evidence in our assessment system. And they have to hurry up because they need to give those tests to the students to show they are implementing the standards. It can't just be on paper for NCATE. (S. Carter, Dean, interview, February 28, 2012)

An observation of two faculty members engaged in aligning course objectives, standards and assessments, at the end of the semester, reflects a reactive process of implementation:

I walked into the third-floor seating area/lounge/library and notice two faculty members, one of I have interviewed (M. Wilson, the English/language arts methods professor) and one I have never seen before, engaged in a discussion. They have papers spread across a table 
at the back of the room. I moved closer to them and notice two syllabi, pens, chart paper, and chart markers. [Observer note: The Dean and Director of Teacher Education/de facto NCATE Coordinator are constantly pleading with faculty to be sure to get their courses aligned with standards. It appears that this is what they are doing.] One faculty member is using chart paper and a marker. M. Wilson is flipping through a binder with AQTS standards listed. The other faculty member is writing a number and phrases on the chart paper, for example: (2)(c)(ii) - role of language. The chart paper is a full page of numbers and phrases associated with language arts learning written in large print. M. Wilson says, "Ok. I think that's all the ones that apply to your course and mine. Stick that sucker on the wall." [Observer note: She is referring to mounting the chart paper to the wall for easier viewing.] They are both looking at their syllabi and writing the numbers from the chart paper next to the objectives on the syllabi. This process continues for about 40 minutes. There is little communication and eye contact between the two faculty members. Comments like, "No this goes there," "That's that one," and "I think this one is this and that" are made. [Observer note: Their comments are referring to which AQTS standards align with a particular objective.] After about 40 minutes, the faculty member says, "I have my assessments that I've already been doing. Will I have to change them?" M. Wilson replies, "I would make them fit." [Observer motes: It seems that she is referring to retroactively making the assessments fit with the alignment of 
the objectives and standards. They both laugh at this.] M. Wilson says, "Let me go ask [the secretary for the Director of Teacher Education/de facto NCATE Coordinator] for the template to do the syllabus." The faculty member exasperates, "Oh God! That friggin template." M. Wilson walks out of the room. The other faculty member continues to write numbers next to objectives on a syllabus. (Informal Observation 2 Notes, April 17, 2012)

The two faculty members are engaged in aligning standards, course objectives, and assessments at the end of the semester. There will be very little time to show evidence of meaningful implementation. In order to be sure they have the proper documentation of implementation evidence, the English/language arts methods professor suggests to "make [the assessments] fit" the alignment process. The alignment observation and the comments of the Dean and Director of Teacher Education/de facto NCATE Coordinator are examples of symbolic implementation. The reactive implementation practices of the faculty members are also an example of the compliant nature of policy actors at the street level of implementation. They do what senior managers require them to do.

Further examples of symbolic implementation, and evidence of senior management control, are also evidenced in the implementation practices of the senior managers. In the summer of 2011, the Director of Teacher Education/de facto NCATE Coordinator inserted herself into the role of Director of Field and Clinical Experiences. She modified the traditional process of placing teacher 
candidates in schools. The Director of Field and Clinical Experiences explained the conventional process of partnerships with P-12 schools:

My job has been, ever since l've been here is to contact, we send out letters to superintendents for agreements every year before we place our students in there. We ask them can they come in as an aid or intern or to student teach. They have those options to check off. And they let us know what we can do. And from there, I contact principals. And I ask, 'Can our students come for these blocks? Can they come on these certain days, for fall, then spring, then next fall, and then they student teach.' $(K$. Spacey, Director of Field and Clinical Experiences, interview, March 26, 2012)

The Director of Field and Clinical Experiences also mentioned that sometimes principals will ask for students to be placed with particular teachers because the teachers' students' are performing poorly on standardized tests. The practice was to oblige the needs of the principal. The Director of Field and Clinical Experiences went on to explain that the process was changed by the Director of Teacher Education/de facto NCATE Coordinator as soon as she was hired by the Dean. Her perspective was that the Director of Teacher Education/de facto NCATE Coordinator used her power positions as leader of the department and de facto NCATE coordinator, as well as her friendship with a principal at an elementary school as "the opportune time" to implement the NCATE Clinical Residency Model: 
I know for a fact that our chair knew the principal at [Central Elementary] because they had been in their doctoral program together...I think that because of their friendship that she felt, she being our chair, that it was the, as she told me, 'the opportune time' to do the NCATE model. So she jumped on it and just decided this is what we're gonna do. (K. Spacey, Director of Field and Clinical Experiences, interview, March 26, 2012)

The Director of Teacher Education/de facto NCATE Coordinator taking advantage of "the opportune time" to implement the NCATE Clinical Residency Model was supported by the Dean: "The set up of the school allows for the NCATE medical model where our faculty and our candidates can be part of a medical team...I am very happy with this partnership [A. Belcher] set up" (S. Carter, Dean, interview, April 4, 2012). The Director of Field and Clinical Experiences complied with the desires of senior managers, although she did not agree with the process of implementation.

The teacher quality policy implementation actions discussed above provide examples of neoliberalism in action. The neoliberal characteristics exhibited are organizational life governed by a corporate culture of senior management control and the definition of the product of education as qualification expressed in terms of the accumulation of implementation activities that show quality program processes. Quality in the teacher preparation program at the New School is being redefined as "the quantitative efficiency with which the qualifications are produced" (Lorenz, 2012, p. 621). 
The Dean and Director of Teacher Education/de facto NCATE Coordinator, the senior managers, have taken control over conventional program practices and focused all faculty attention on collecting or inventing documentation to serve as evidence for the implementation of NCATE standards. Senior managers have dictated what faculty will do, including halting all program implementation activities not associated with NCATE, and faculty has complied. The fact that NCATE is the central focus of program activities, also points to the socio-political condition of neoliberalism. In the age of accountability, national accreditation is a signal of quality.

Implementing the NCATE Clinical Residency Model: Symbolic versus Meaningful

The process of implementing the NCATE Clinical Residency Model provides additional evidence of two neoliberal characteristics: a corporate culture of senior management control and quantity representing quality. The senior managers, Director of Field and Clinical Experiences; the two faculty members assigned to teach English/language arts and mathematics methods courses at the P-12 partnership school, Central Elementary; and the teacher candidates all perceived the NCATE Clinical Residency Model as beneficial to the Elementary \& Collaborative Education Program (ECEP). However, the interests, intentions, and motivations of the senior managers were different from those of the lowerlevel policy implementers.

When discussing the NCATE Clinical Residency Model with the Dean and Director of Teacher Education/de facto NCATE Coordinator, it appeared they 
perceived the model as beneficial to their programs and teacher candidates. However, they both followed up their praise of the "beneficial" clinical residency model with references to how faculty needed to take immediate action to implement the model for the purposes of "passing NCATE" and the Elementary and Collaborative Education Program serving as a model for the state. In an interview, the Dean stated:

We're a part of the national group working with NCATE [on the new residency model of clinical experiences]. We are one of the 12 states. K12 needs to be on board just like higher ed because it is a true partnership. I think it's supposed to be more embedded than in the past because we've always had clinical, and it's easy for everyone to say 'Well we have clinicals. We send them out into the schools.' But it's really more than that. It's really making the clinical meaningful partnerships. And this is what our partnership with [Central Elementary] is about. It is not perfect; not right now. Of course it is something we want to get better at. There's a lot to work on from what I hear. But like I told [the English/language arts and mathematics methods professors] we have to make this work. It's crucial. The state is looking to us to get it right. And NCATE expects to see that we are already doing it because we said that's what we're doing. (S. Carter, Dean, interview, April 4, 2012)

The following exchange from an interview with the Director of Teacher Education/de facto NCATE Coordinator shows that she too perceived the clinical residency model as beneficial to teacher candidates. However, it also reveals 
motivations to implement the NCATE Clinical Residency Model for accreditation and program approval purposes over motivations to better prepare teacher candidates.

Researcher: Tell me about implementing the new partnership at [Central Elementary].

A. Belcher: I really love being involved in where our clinical are going to be, having these partnerships, making sure our students walk out of here knowing they can walk in any classroom in any place and teach and be effective. That's my dream. Our partnership with [Central Elementary] is how we're doing it. We have two of our courses taught there. We have students going into classes to teach early. We have a lot to work out, but we're doing it now.

Researcher: When you say you have a lot to work out, what do you mean?

A. Belcher: Well [Interviewer note: She chuckled.], let's just say that everything is not going exactly as me and the principal planned it. But we're moving forward. (A. Belcher, Director of Teacher Education/de facto NCATE Coordinator, interview, April 24, 2012)

In a follow-up discussion about implementing the clinical residency model, the Director of Teacher Education/de facto NCATE Coordinator downplayed the negative impact of hasty implementation: 
Researcher: The Dean, faculty, and students mentioned problems with implementing the model. Tell me what you have experienced.

A. Belcher: Sure there are problems. Anything new is going to have problems. But see, we don't have time to make it perfect. We have to do this now. NCATE is coming in December, and the state. We said we have this partnership, well, we better have evidence of it. We'll get better next semester and after that. It's new. So there will be problems.

Researcher: What do you think gets lost in not having time to implement the model, as you say 'perfectly.'

A. Belcher: A lot gets lost. But, like I said, there will be problems with new things. Of course people were frustrated. I was frustrated. But no one will complain when we pass NCATE and when the state uses our program as the model for other schools. (Director of Teacher Education/de facto NCATE Coordinator, interview, May 2, 2012)

The responses of the Director of Teacher Education/de facto NCATE Coordinator provide examples of the "product of education as qualification" (Lorenz, 2012, p. 621), and symbolic implementation. The products are a teacher education program with a perceived higher quality field and clinical experiences model, and graduates perceived to have engaged in richer, higher quality field and clinical experiences. The reality is that there are serious flaws in the way the model was implemented. As described below, the reality of implementation was control by senior-level managers; disorganization; and 
confusion amongst P-12 school personnel, program faculty, and teacher candidates. The policy actors did not meaningfully implement the NCATE Clinical Residency Model, but the evidence and data collected and developed by senior managers and faculty will imply qualification. The teacher candidates did not engage in higher quality field and clinical experiences, but their diploma and certifications will imply such qualifications.

The lower-level policy actors expressed deep frustration about the process of implementing the new model. The Director of Field and Clinical Experiences expressed concern that teacher candidates were not getting exposure to the early childhood clinical and reading aspects of their degree program because the implementation of the clinical residency model took precedence over the conventional process of field and clinical experiences.

Conventional field and clinical experiences had been designed so that teacher candidates experience three different types of settings: urban, rural, and suburban. Within each setting, teacher candidates rotate about every two weeks, which gives them six to seven classroom placements per setting. Because teacher candidates receive four certifications, they are also required to serve in an early childhood, elementary, and early childhood/elementary special education classroom. Teacher candidates are also required to infuse specific teaching-of-reading activities—structured around the Alabama Reading Initiative (ARI) training they receive and aligned with the Praxis II reading education certification assessment—-throughout their field and clinical experiences. 
Teacher candidates begin field and clinical experiences in an early childhood block, which is grades kindergarten through two. From there, they move to the elementary block, which is grade three through five. Then, they move to the special education block, which is preschool through grade six. The teacher candidates' final field and clinical placement is their student teaching experience, where they are placed in one K-6 classroom. Additionally, teacher candidates are required to complete two clinical requirements on their own time: one first-day-of-school observation and a "January Term" experience where they serve in a school for three weeks from 8:00 a.m. until 3:00 p.m.

Each field experience has assignments attached which align with the ability standards in the Alabama Quality Teaching Standards (AQTS). Teacher candidates are observed by faculty and evaluated using the four-point scale of the Continuum, an evaluation instrument which takes the AQTS standards and turns them into performance assessment language. Teacher candidates must score at a level of three on all Continuum indicators in order to successfully complete their student teaching experience and graduate the Elementary and Collaborative Education Program (ECEP); an example of the use of measurable indicators of performance to determine quality.

The Director of Field and Clinical Experiences expressed deep frustration with teacher candidates not being allowed to complete "proper early childhood and teaching-of-reading placements" (K. Spacey, Director of Field and Clinical Experiences, interview, March 26, 2012). She explained that because the Director of Teacher Education/de facto NCATE Coordinator was so focused on 
implementing the NCATE Clinical Residency Model, she deferred to the needs of the principal at Central Elementary and disregarded program requirements and the educational needs of the teacher candidates:

In those K-2 clinicals, we really need to focus on developmental learning, where our candidates will be able to know what it's like to teach children in kindergarten, and first grade, and second grade. What they do during reading time. How do they transition? And that is where the break down came in with doing this partnership. The principal wanted candidates in the upper grades where the test scores were failing. Our candidates were placed in fourth grade and did not get their early childhood placements...Also, our candidates have to take the Praxis II in reading this fall. Many of them will not have had that background knowledge in seeing reading taught in K-2 classes because they were never in one. (K. Spacey, Director of Field and Clinical Experiences, interview, March 26, 2012)

Not only was the Director of Field and Clinical Experiences frustrated about teacher candidates not having access to important classroom experiences, she, as well as other faculty and the teacher candidates, expressed frustration with the fast-track implementation of the NCATE Clinical Residency Model. In an interview, the mathematics methods professor, one of two professors assigned with implementing the new model in the P-12 setting, explained that the only buyin they achieved with implementing the new partnership model was from the Dean, Director of Teacher Education/de facto NCATE Coordinator, and the 
principal of Central Elementary. There was no buy-in by from the teachers who would host the teacher candidates in their classrooms (G. Rice, mathematics methods professor, interview, March 13, 2012). The Director of Field and Clinical experiences said that although teachers expressed their enthusiasm for accommodating the teacher candidates, no accommodations were made. She concluded, "Simply put, the teachers were not on board" (K. Spacey, Director of Field and Clinical Experiences, interview, March 26, 2012).

The faculty member responsible for implementing the English/language arts methods course in the P-12 setting further explained the lack of teacher buyin and consequences of fast-track implementation:

That's the area where we're going to work on this summer, toward getting more buy-in from the teachers. Because it was too fast and furious at the beginning of the year, that I feel like they were kind of left behind...We overwhelmed them with the number of students...And with the way the schedule worked out, we had to have three students to one classroom. It was overwhelming for the teachers. But we had to do it for NCATE...What we're working toward is that we're trying to establish a better working relationship with the teachers here. We have a great relationship with the principals. But working with the teachers takes time. We needed more time. (M. Wilson, English/language arts mathematics professor, interview, March 15, 2012) 
The sentiment about the amount of time it takes for successful implementation of the NCATE Clinical Residency Model was also shared by the Director of Field and Clinical Experiences and the teacher candidates. The Director of Field and Clinical Experiences stated:

NCATE is wanting institutions to buy in to the concept of a real partnership, where you're basically partnering with certain schools, and you go in, and your vision, and their vision, and teachers and faculty work really closely, and even faculty teaches classes at the school site. That tends to be hard when not enough time is put into the planning up front, like this situation. Everybody needs to be on board. Especially, the teachers in the school, which would be our candidates' mentor teachers. Those people need to be on board, and we need to have the same vision. But all [The Director of Teacher Education/de facto NCATE Coordinator] was focused on was 'we gotta get the data for NCATE.' (K. Spacey, Director of Field and Clinical Experiences, interview, March 26, 2012)

The faculty comments regarding the implementation of the clinical residency model reveal interests, intentions, and motivations to better prepare teacher candidates for real world teaching experiences. As cited previously, the Director of Field and Clinical Experiences expressed concern that as a result of the hastily implemented clinical model, teacher candidates were not getting the proper training in early childhood and reading education. The English/language arts and mathematics methods professors also cited concerns about the hasty implementation of the model negatively impacting teacher candidates' training. 
Both professors were asked, "Do you think anything gets lost when you are heavily focused on getting the new clinical model implemented? If so, what?" The mathematics methods professor replied:

[M. Wilson, English/language arts mathematics professor] and I talked about this before. I'm not sure I would refer to it as what gets lost, but [the teacher candidates] have a lot of content knowledge and pedagogy to get down, not just math. They have four certifications. Before they can really start teaching and co-teaching, and having this partnership like NCATE wants, I'm not sure if they are prepared. (G. Rice, mathematics methods professor, interview, March 13, 2012)

The English/language arts methods professor said:

I know this is a trial period for the new clinicals. But we're treating it like it's not. See, for example, we have to place the [teacher candidates] in situations where they teach and test students on say language arts concepts. Well, I think they may know the content, the material, but I just don't see how, I mean, more thought needs to go into how we will use tests from students to see what our teachers can do. I just don't think we should use this data as [Interviewer note: she does air quotes with her fingers] evidence of how our candidates can teach. I told [A. Belcher] it just needs to be worked out more. (M. Wilson, English/language arts methods professor, interview, March 15, 2012) 
The Director of Teacher Education/de facto NCATE Coordinator's narrow focus on gathering data for the NCATE report was a subject of frustration for teacher candidates as well. Teacher candidates expressed being overwhelmed with the disorganization of the clinical residency model implementation process. Teacher candidates were asked about their experiences with the NCATE Clinical Residency Model. In a focus group interview, they expressed:

Teacher Candidate 1: They've changed a lot of things this year. We have to do a lot of stuff that nobody else had to do.

Teacher Candidate 2: I think they're trying to give the students a more real world experience, which is why I think they started this partnership at [Central]. It's great, but it's been rough on us because they keep saying, 'It's gonna work this way.' And then they realize, no that doesn't work, and they change it. And things change, and change, and change.

Teacher Candidate 3: And then it took forever to get going. They took like maybe be three or four weeks to get our schedule down.

Teacher Candidate 2: That is so true.

Teacher Candidate 4: Yeah. We would go out there to class and we didn't know what we were supposed to be doing. I don't think we talked about anything until the third or fourth week. We didn't even start learning stuff until like a month after the semester started. 
Teacher Candidate 2: Like the partnership at [Central] was new. So I guess they were working that out.

Teacher Candidate 5: They were working out if we were gonna be at [Central]. Then, they said, 'Wait. We've gotta get the teachers lined up.' And we had some teachers at the beginning of the semester that did not want us at the end.

Teacher Candidate 4: Yeah. That's still happening this semester.

Teacher Candidate 5: But they didn't change how much they wanted us to do. Basically, they chopped off a month and said, 'Well, you'll still have to do the whole semester's worth of work. Like, we need the data. We need the data.

Teacher Candidate 2: And we had an action research project where we had to teach and show how our teaching improved the kids' scores. We were supposed to have three weeks straight in a classroom.

Teacher Candidate 3: And you were supposed to be the only student in the classroom.

Teacher Candidate 2: Yeah well, like, it turned out that we went the full semester at [Central] and didn't go to our other placements. And we only went into the class for our project once a week. And you shared that classroom with like, well like... 
Teacher Candidate 3: I had three other people in my classroom. But they weren't in there while I was in there. But we had to do this action research project with a group of students. And it really messed up our research because being there once a week for twenty minutes and sharing with other students...

Teacher Candidate 2: And you can't, like how do you know the other students that are in there, like how do you know that are not affecting your research. And how can you know with being in there just 20 minutes once a week. And you're supposed to be like helping a struggling reader or whatever.

Teacher Candidate 4: Yeah, I mean, like you can't really know what you did to help that child. But [Interviewer note: she holds up her fingers in air quotes] data, data, data. We still had to show our scores and write how we increased the scores.

Teacher Candidate 1: I guess this is what they meant by being 'flexible.' That's what they kept saying last semester. But it's not fair because I don't wanna say those scores are mine when they could be because of somebody else being in there. (Teacher Candidates, focus group, May 3 , 2012)

Teacher candidates expressed frustration at the disorganization of senior managers and faculty in implementing the NCATE Clinical Residency Model. They shared how they were confused about their placements early on in the 
implementation process. They mentioned how they would start working with one cooperating teacher and how their placement would abruptly change. Teacher candidates also conveyed the pressure put on them by senior managers to collect student achievement data which would reflect the impact of their teaching. They mentioned that disorganization led to multiple teacher candidates teaching the same P-12 students to which they were assigned. They questioned the integrity of the data collection process. Their comments reflect an understanding—shared by leading education researchers, like Goe (2008)-of a major flaw in using the teacher-student data link to determine quality in teaching: the influence of multiple, unintended variables. The responses provide more examples of symbolic implementation, the corporate culture of senior management control, and quantity over quality.

The faculty and teacher candidates' comments show how senior managers were more concerned with showing implementation of NCATE policies rather than doing meaningful implementation. Conventional processes for clinical experiences, including ones perceived to greatly benefit teacher candidate knowledge and experience, were put on hold. The focus was to collect data the senior managers perceived would be appropriate to show NCATE and the state that they were implementing the clinical residency model. Integrity of data collection took a back seat to symbolic implementation. An NCATEintentioned P-12 clinical partnership model would be impossible to achieve when activities were being implemented and data collected in a symbolic rather than 
meaningful way. Implementation was done for the purpose of "passing" NCATE, not for the purpose of improving teacher candidate and programs outcomes.

Another example of symbolic implementation, senior management control, and quantity over quality was the way in which methods courses were taught in the P-12 partnership school setting. As explained by the Director of Field and Clinical Experiences, the intention of NCATE P-12 partnerships is "meaningful" collaboration between P-12 teachers and university faculty; collaboration, which includes establishing a shared vision and co-teaching methods courses (K. Spacey, Director of Field and Clinical Experiences, interview, March 26, 2012). There was no collaboration to establish a shared vision between P-12 teachers and faculty because there was no teacher buy-in, as shown previously from discussions with faculty.

The Director of Teacher Education/de facto NCATE Coordinator, her principal "friend," and the Dean determined the vision of the partnership, as shown in the following excerpt:

The principal at [Central Elementary] was State Teacher of the Year. She and I are friends, and we just happened to run into each other, and I said that our faculty wants a school to partner with, where they can actually go teach classes. She said, 'Our school was built for that and we don't have a partnership anymore with [another university]!' So she and I got together to decide what our teachers would do. And NCATE said her teachers had to be involved too. So I left that up to her. But after we got our plan, I told 
[the English/language arts and mathematics methods professor], well I talked to [the Dean] first about who would be best to send over there. We decided to send [the English/language arts and mathematics methods professors]. I basically said take this Blue Ribbon report and do it! [Interviewer Note: She chuckled.]. (A. Belcher, Director of Teacher Education/de facto NCATE Coordinator, interview, February 27, 2012)

Observations of the mathematics and English/language arts methods courses being taught at Central Elementary, and discussions with faculty, revealed the only thing that changed about implementing methods courses in the P-12 partnership school was the location. The courses were no longer taught at the university, but the expectation that P-12 mentor teachers co-teach the courses was not implemented. This was explained by a faculty member:

[The Director of Teacher Education/de facto NCATE Coordinator] started a partnership with her friend of classmate or something at [Central Elementary]. She recruited [the mathematics methods professor and I] to teach our classes over there. We were supposed to co-teach with some of the teachers there, and help them with their EDUCATE Alabama, so we plan to do that. But the teachers seem very overwhelmed with us being there. So, I don't know." [Interviewer note: EDUCATE Alabama is the state teacher evaluation system.] (M. Wilson, English/language arts methods professor, interview, March 15, 2012) 
It is further evidenced in an excerpt from an observation of a mathematics methods course taught at Central Elementary:

Before walking into the math class, I am talking with the English/language arts and mathematics methods professor. I ask them about observing them co-teaching with a P-12 teacher: 'I remember one of you mentioning co-teaching. I would love to observe. When will I get to?' The mathematics methods professor says, 'You must have heard that from [M. Wilson, the English/language arts methods professor].' She walks into her classroom and I hear her telling the teacher candidates that class will starts soon. (Observer note: Her comments make me think she does not plan to do co-teaching). The English/language arts professor says, 'We're supposed to do that. I still haven't arranged it for my class. I don't think it's gonna happen because it's late in the semester. But I will let you know when I do it." [Observer note: On the four occasions I have visited [Central Elementary] I have not observed the co-teaching scenario in either the language arts methods class or the math methods course. I assume it has not occurred. When I asked about observing co-teaching, I think one of them would have mentioned that I missed it. I was told by the English/language arts methods professor that she would let me know when co-teaching took place. However, because the semester will end in a few weeks, I do not think I will get the opportunity to observe coteaching.] (Mathematics Methods Course Observation 2, April 19, 2012) 
The courses were no longer taught on the campus of the New School, but that did not yield the "meaningful" collaboration and co-teaching expected by NCATE. When asked about co-teaching with P-12 teachers, the professors responded, "We're working on that" (mathematics methods professor, interview, March 13, 2012), and "That's gonna have to come later. We have to get buy-in first" (English/language arts methods professor, interview, March 15, 2012).

Discussions with the Director of Teacher Education/de facto NCATE Coordinator, faculty, and teacher candidates confirm that the process of implementing standards was focused a great deal on collecting data which would show NCATE program processes were being implemented to ensure national accreditation of the teacher education school and approval of the Elementary \& Collaborative Education Program. Discussions with the English/language arts methods professor revealed that the NCATE Blue Ribbon Report (2010b) was essentially being used as a guidebook to restructure program processes, $\mathrm{P}-12$ partnerships, and field and clinical experiences. In an interview, she stated:

We're looking at the NCATE Blue Ribbon report. And we're going through it. We're picking it apart. And we're saying, 'You know what: Yes!'...We read that report. And that's the reason why we're starting the English language labs in the mornings here. That's the reason we're doing that. Because we read the report, and we said, 'You know what: they are right. They are right about that.' I want them to know that we are reading what they say. And we're looking at it. And we're saying, 'they're right about this and they're right about that. How can we take the report and put it 
into action?' (M. Wilson, English/Language Arts Methods Professor, interview, March 15, 2012)

The NCATE Blue Ribbon Panel Report (2010b) promotes a commonsense notion that field and clinical practices should resemble a residency model. The English/language arts methods professor's comments reflect that faculty sees the clinical residency model as common-sense, as well. Comments about the haphazard, disorganized nature of the implementation of the clinical residency model show that senior managers are more interested documenting data that shows evidence of implementation rather meaningful implementation. The professor's comments show that faculty is willing to comply with senior managers' conditions. This is an example of senior management control and how neoliberal conditions influence policy thoughts and actions through the development of new discourses, institutional practices, and common-sense values.

Although senior managers and faculty perceive the NCATE standards are beneficial to their programs and teacher candidates, their intentions differ. Where senior managers are mainly focused on "passing NCATE," faculty is mainly focused on improving education and training for teacher candidates. Senior managers have taken control over program processes. Because faculty sees the clinical residency model as a common-sense approach to improving their program and teacher candidates' experiences, they have complied with fasttrack implementation of the model, despite their concerns about quality. As long as the quantity of implementation activities is documented, quality is perceived. 
Other Activities that Represent Symbolic Implementation, Senior Management Control, and Quantity over Quality

Program processes other than those related to $\mathrm{P}-12$ partnerships also show examples of symbolic, reactive implementation practices; senior management taking control over conventional teacher preparation program processes; and the notion that the more activities implemented and evidenced the better quality the program and graduates. The Director of Teacher Education/de facto NCATE Coordinator-in an attempt to meet NCATE's teacher candidate-student data link—contacted the ALSDE and requested "data on the test scores of graduates who are new teachers" (A. Belcher, Director of Teacher Education/de facto NCATE Coordinator, interview, April 24, 2012).

Her rationale was that it is "impossible to know how effective" their programs are if they do not have "data linking recent graduates to their students' achievement test scores" (A. Belcher, Director of Teacher Education/de facto NCATE Coordinator, interview, April 24, 2012). This indicates she supports the narrow national-level focus of using student achievement data as a main indicator of teacher quality. It also indicates she is reactively collecting data to represent the Elementary and Collaborative Education Program (ECEP) is meeting an NCATE requirement of linking teacher and student data for program improvement purposes.

Moreover, faculty and teacher candidates were encouraged by senior managers to create or find data that links teacher candidates to the achievement 
scores of the P-12 students in which they interact. The following are an example of this from observation notes and discussions with teacher candidates:

The Director of Teacher Education/de factor NCATE Coordinator is stressing the significance of gathering data that shows the impact of teacher candidates on student achievement. Faculty are asking about ways they can reasonably show such evidence if a teacher candidate is not teaching for an extended period of time. A. Belcher explains, "We know that unless we show impact on student achievement there is no proof the kids are learning...We have to create situations, maybe small group activities, where they teach students a small lesson and record their scores on a test." (NCATE Meeting Observation 2 Notes, March 12, 2012)

In a focus group, teacher candidates shared their experiences with data collection data that shows teacher-student links:

Teacher Candidate 2: And we had an action research project where we had to teach and show how our teaching improved the kids' scores. We were supposed to have three weeks straight in a classroom.

Teacher Candidate 3: And you were supposed to be the only student in the classroom.

Teacher Candidate 3: I had three other people in my classroom. But they weren't in there while I was in there. But we had to do this action research project with a group of students. And it really messed up our research 
because being there once a week for twenty minutes and sharing with other students...

Teacher Candidate 2: And you can't, like how do you know the other students that are in there, like how do you know that are not affecting your research. And how can you know with being in there just 20 minutes once a week. And you're supposed to be like helping a struggling reader or whatever.

Teacher Candidate 4: Yeah, I mean, like you can't really know what you did to help that child. But data, data, data. We still had to show our scores and write how we increased the scores. (Teacher Candidates, focus group, May 3, 2012)

The intense focus on linking teacher candidate data to P-12 student outcomes is an example of the neoliberal condition of establishing efficient, formal structures of input/output processes. Although there are many factors that influence a teacher candidates impact on student achievement (e.g., other teachers, other teacher candidates, student aptitude, etc.), the teacher-student data link requirement, as interpreted by policy actors at the program level is quite literal: have a student teach and assess a lesson, and use students' test as evidence of teacher candidate impact.

The creation of activities to gather data linking teacher candidate inputs to P-12 student outputs is an example of symbolic implementation and quantity over quality. In discussions with the Director of Teacher Education/de facto NCATE 
Coordinator, there was no mention of any practical purpose of linking teacher candidate inputs to P-12 student outputs; aside from determining teacher effectiveness in increasing achievement scores of students and showing evidence of meeting standards for NCATE.

Another example of senior management control and quantity over quality is the Director of Teacher Education/de facto NCATE Coordinator engaging faculty in symbolically restructuring program processes to resemble P-12 environments. A new course was added, titled Planning Effective Instruction (PEI), so that program practices would reflect NCATE standards related to collaboration and linking course objectives and goals to assessments. Professional Learning Communities (PLCs) and Professional Growth Plans (PGPs) were also instituted. Discussions with faculty and teacher candidates reveal that implementation of the PEI course, PLCs, and PGPs was haphazard, disorganized, and not meaningful. The Director of Field and Clinical Experiences explains her perception of the implementation process:

K. Spacey: [The Director of Teacher Education/de facto NCATE Coordinator] has all this stuff we gotta do for NCATE. All these little outside groups. Chile, I don't think folks are doing anything. And the students aren't learning anything. But they have to get grades for this stuff because it's activities and stuff we don't have time to put in our classes.

Researcher: What do you mean? Give me an example. 
K. Spacey: Ok. Let's say one of my students is just not grasping, getting a concept in reading development. I teach that course. Well, I tell her to put it on her learning plan. I don't know if she did or didn't. But the person who teaches that little mini class has to give her a grade for improving. But nobody asked me if she's improving. (K. Spacey, Director of Field and Clinical Experiences, interview, March 26, 2012)

The English/languages arts methods professor also shared her experiences:

"I lead one of the [professional learning communities]. I've been trying to get a better structure down. Sometimes we meet and sometimes not. I want to be consistent. But it's hard. I know what PLPs are supposed to look like, but there is just not enough time to make it look like it looks in schools, not with the students. And they have so much already. But I have to have deliverables because they get a grade. (M. Wilson, English/language arts methods professor, interview, March 15, 2012)

The teacher candidates revealed more evidence of the disorganized nature of the "mini" classes. Their responses in a focus group interview also reveal how data will have to be created to show evidence of implementation:

Teacher Candidate 3: This year we were assigned PLPs.

Teacher Candidate 1: We have PLP groups and PLC groups.

Teacher Candidate 2: Our PLP group never met. 
Teacher Candidate 5: Yeah, ours didn't either. Wait. We met once in like February. But we're supposed to get grades. So...

Teacher Candidate 1: The PLP group is like you focus on one thing like, we did that survey last year after our math final, like the, with the standards I guess.

Teacher Candidate 3: And like areas of weakness, and they assigned you to like whatever seemed to be your area of weakness or area you felt to be your area of weakness... or that you were interested in, like there's an assessment one. There's an English language learner.

Teacher Candidate 5: I think that's mine.

Teacher Candidate 1: Basically, just getting together and talking about your own issues and things. But you get a grade. I don't know.

Teacher Candidate 3: Like I know the assessment one, like how you can better incorporate assessment better into the classroom or your lessons, if there's something you don't understand about assessment, you can do that one. I was on the science and technology team at [Central Elementary] so there's like three of us that had to go there, so ours was like how you can incorporate science and technology into like classrooms and different areas, kind of like whatever yours was assigned to.

Researcher: How do you get grades if some of you are not meeting with your groups? 
Teacher Candidate 5: I don't know.

Teacher Candidate 2: I guess they give them some way. Like we have to do stuff, like do assignments

Teacher Candidate 3: I don't know. They're probably still working that out. It's a pilot. We just have to be flexible, I guess. (Teacher Candidates, focus group, May 3, 2012)

Teacher candidates' comments reflect confusion about program implementation activities in which they are responsible for engaging. Although senior managers and faculty will assign grades on the activities, teacher candidates either are not engaged in the activities or do not understand the activities. This is an example of senior management control and symbolic implementation. Senior managers are symbolically implementing activities which will document quality policy standards implementation regardless of the meaningfulness of the activities.

Data being collected to document such activities do not reflect the reality of implementation as it was explained by faculty and teacher candidates. The documentation reflects that all Elementary and Collaborative Education Program (ECEP) teacher candidates are put on Professional Growth Plans where they self-assess their teaching abilities and work with faculty to make improvements. This process matches that of the new EDUCATE Alabama formative teacher evaluation system currently being implemented in school districts throughout the state. After completing the growth plan, teacher candidates are placed in Professional Learning Communities "based on their area of need" (A. Belcher, 
Director of Teacher Education/de facto NCATE Coordinator, interview, April 24, 2012). A faculty member is assigned to each PLC to help teacher candidates improve on their self-defined weaknesses. When I asked teacher candidates about their experiences with Professional Growth Plans and Professional Learning Communities, responses varied. Two teacher candidates did not know to what I was referring. Teacher Candidate 5 mentioned that her PLC group met once at the start of the semester. Teacher Candidate 3 said, "I'm learning so much from my group and faculty leader!" (Teacher Candidate, focus group, May 3, 2012)

A review of five teacher candidates' Professional Growth Plan (PGP) shows evidence of the implementation of the Professional Learning Communities and Professional Growth Plan. Each PGP is a document with the following headings: Self-identified Area of Weakness, Faculty-identified Area of Weakness, Professional Develop/Professional Learning Community Activity, and Improvement. Table 9 is a sample taken from the PGP documents review conducted May 3, 2012 following a focus group with the teacher candidates. The ' $\mathrm{X}$ ' denotes there was no data represented for a particular section. 
Table 9

Sample of Professional Growth Plan Documents Review

$\begin{array}{cccc}\begin{array}{c}\text { Self- } \\ \text { Identified }\end{array} & \begin{array}{c}\text { Faculty- } \\ \text { Identified }\end{array} & \begin{array}{c}\text { Professional } \\ \text { Development/PLC }\end{array} & \text { Improvement } \\ \text { Area of } & \text { Area of } & & \\ \text { Weakness } & \text { Weakness } & & \end{array}$

Teacher

Math

$X$

Assessment

$X$

Candidate 1 workshop [the

New School]

Teacher

$X$

$X$

$\mathrm{X}$

$X$

Candidate 2

Teacher

STEM

X

-STEM Team at

X

Candidate 3

[Central]

-Tech

Presentation to

teachers at

[Central]

Teacher

X

X

X

Candidate 4

Teacher

ELL

X

Intro Class

X

Candidate 5

02/24/12

None of the five teacher candidates interviewed recalled the Planning Effective Instruction (PEI) course. When asked about the PEI course, teacher candidates made no verbal response, but their faces showed confusion. This is evidenced in an excerpt from the focus group interview with teacher candidates:

Researcher: Tell me about the PEI. I think it stands for Planning Effective Instruction. 
Teacher Candidates: [Interviewer Note: no verbal response; looks of confusion, raised eyebrows, looking around the room, looking at each other.]

Researcher: Is it a course or one of those out-of-course workshops?

Teacher Candidates: [Interviewer note: no verbal response.] (Teacher Candidates, focus group, May 3, 2012)

Yet, faculty and teacher candidates said grades and documentation would be used to show evidence of such activities. The assumption is that such documentation, including grades would either have to be created or fast-track implementation of certain activities will have to be conducted.

One final example of policy practices being implemented for the sake of having data to show evidence of standards implementation is the symbolic implementation action of aligning AQTS standards with courses, coursework, and assessments. According to state and NCATE requirements, programs are supposed to align standards with courses, course assignments, field and clinical experiences, and assessments. This process of alignment is not simply to show documentation of alignment. If implemented as intended, the alignment process should yield data that can be used to determine whether standards are met and whether program changes are needed (E. Jones, NCATE National-State BOE Member, March 5, 2012). From discussions with the Dean, Director of Teacher Education/de facto NCATE Coordinator, Director of Field and Clinical Experiences, and observations of faculty interactions, it became clear the 
documentation of aligning standards with course activities and assessments had not been completed. An excerpt from an interview with the Director of Teacher Education/de facto NCATE Coordinator provides an example:

Whatever data we don't have, we have to have. We have to get it. This summer we will be aligning all syllabi. I just hope the faculty has done assessments in their courses to match, because NCATE will ask students. (A. Belcher, Director of Teacher Education/de facto NCATE Coordinator, interview, April 9, 2012)

Another example is provided from an observation at an NCATE meeting:

A few faculty members say that they do not have certain pieces of evidence and that aligning standards "may be hard after the fact." $\mathrm{S}$. Carter (Dean) inconspicuously catches A. Belcher's eye. Faculty does not seem to notice the Dean getting A. Belcher's attention. They walk and meet at the front of the side of the room [Observer note: near where I am sitting to take notes]. In a stern, hushed tone the Dean tells A. Belcher that she must "tell them it's not an option. They "must go back and get it." [Observer note: the faculty members seem to think they are only speaking loud enough for the people at their table to hear, but the Dean appears to be paying attention to what different groups are discussing while not exactly looking like he's paying attention.] (NCATE Meeting Observation 1 Notes, February 27, 2012) 
Toward the end of the semester, two faculty members were engaged in aligning standards, objectives, and assessments for the courses they were currently teaching; as evidenced in this observation note:

I walked into the third-floor seating area/lounge/library and notice two faculty members, one of I have interviewed (M. Wilson, the English/language arts methods professor) and one I have never seen before, engaged in a discussion. They have papers spread across a table at the back of the room. I moved closer to them and notice two syllabi and chart paper. [Observer note: The Dean and Director of Teacher Education/de facto NCATE Coordinator are constantly pleading with faculty to be sure to get their courses aligned with standards. It appears that this is what they are doing.] One faculty member is using chart paper and a marker. M. Wilson is flipping through a binder with AQTS standards listed. The faculty member with the chart paper is writing a number and phrases on the chart paper, for example: (2)(c)(ii) - role of language. There is a full page of numbers and phrases associated with language arts learning written in large print. M. Wilson says, "Ok. I think that's all the ones that apply to your course and mine. Stick that sucker on the wall." [Observer note: She is referring to mounting the chart paper to the wall for easier viewing.] They are both looking at their syllabi and writing the numbers from the chart paper next to the objectives on the syllabi. This process continues for about 40 minutes. There is little communication and eye contact between the two faculty members. 
Comments like, "No this goes there," "That's that one," and "I think this one is this and that" are made. [Observer note: Their comments are referring to which AQTS standards align with a particular objective.] The faculty member says, "I have my assessments that l've already been doing. Will I have to change them?" M. Wilson replies, "I would make them fit so you'll have evidence. You know they want evidence." [Observer note: $M$. Wilson makes air-quotes when she says the word evidence.] They laugh. M. Wilson says, "Let me go ask [the secretary for the Director of Teacher Education/de facto NCATE Coordinator] for the template to do the syllabus." M. Wilson walks out of the room. The other faculty member continues to write numbers next to objectives on her syllabi. (Informal Observation 2 Notes, April 17, 2012)

When asked about the alignment process that would take place the following summer, the Director of Field and Clinical Experiences mentioned how she was currently engaged in creating a document which shows linkages between AQTS and Continuum indicators and course activities and assessments associated with field and clinical experiences. This is evidenced in an excerpt from an interview:

Researcher: How do you think the summer is going to be with faculty taking on this standards-alignment process?

K. Spacey: I think it's going to be a challenge, but the one plus will be because we have had to go back, like now, all the syllabi should have 
been redone, with the new Continuum. Some people might have to still do that. So they're being adjusted, they've had [the New School] standards added in. They've had the NCATE or the InTASC. Then they had the content-related. So really, all of the standards that we need to put into a document for clinical will and should be already in place. I don't know if they are. I am actually, right now, making sure the alignment for the field and clinicals is done. It's just a matter of going back and checking, and adding whatever is not there.

Researcher: If it's done after the semester has ended, how will you know the benefits? Like, how will you know that the [teacher candidates] actually learned what they needed to learn and were assessed in the courses?

K. Spacey: Like I said, it should have been done. We do a lot in the courses. Documentation is another issue. We've just got to go back and document. Hopefully, it's just a matter of pulling it together. (Director of Field and Clinical Experiences, interview, March 26, 2012)

Discussions with senior managers and faculty indicated alignment activities would become completed in time to show evidence of standards alignment during the state/NCATE review. Since such alignments had not been completed, it should be difficult for policy actors to show evidence of using the alignment process to evaluate teacher candidates and programs during the state/NCATE Review. The Dean was asked about the difficulty of gathering such evidence. He replied, "We have the data" and "we simply have to match 
everything" (Dean, interview, April 4, 2012). The Director of Teacher

Education/de facto NCATE Coordinator also mentioned that documenting and matching data is an activity the faculty will engage in during the summer, saying, "We have the data, or we will have the data. We just have to put it where it goes and make sure it reflects our conceptual framework and assessment system as we say on paper" (Director of Teacher Education/de facto NCATE Coordinator, interview, April 24, 2012).

The examples provided indicate a reactive process of implementation, symbolic nonetheless, and unlike what the state and NCATE intends. Just as the intention of NCATE is for the institution to engage in continuous improvement model and a meaningful P-12 partnership, the point of aligning standards with activities and assessments is to use data to understand where candidates and programs are improving or lacking. Although the policy actors at the New School are engaged in activities that show they have implemented a continuous improvement model, they do not appear to be engaged in a meaningful process of using data to improve candidate and program outcomes. However, the evidence they collect will serve to quantify their qualifications. The more quality implementation activities policy actors have evidence they are implementing, the more likely NCATE and the state perceive such products as evidence of qualifications for the program and the teacher candidates. 


\section{Consequences of Symbolic Implementation}

There are positive and negative consequences of the way in which policy actors at the New School interpret and implement quality standards and policies in a symbolic rather than meaningful way. Expectations from the state- and institution-level policy actors that the New School serve as a model for all teacher preparation programs in the state means higher expectations, more standards, and no additional time to implement such standards and activities. High expectations of state- and program-level policy actors have led to the implementation of many additional policies and standards above the minimum state requirements, like the 3.0 GPA requirement, four education certifications, and clinical residency model.

Consequentially, such practices may influence public perception that The New School graduates are more qualified to teach than other teacher education graduates in the state, as was expressed by senior managers, faculty, and teacher candidates. However, there are essential learning and developmental elements lost when so many additional standards and policies must be implemented in the same three-year timeframe as other teacher education programs in the state. The Elementary \& Collaborative Education Program (ECEP) and its graduates may indeed be perceived as higher quality, but the question remains whether a higher quality education program and program graduates are actually achieved. 
There are so many standards and policies to implement, senior managers and faculty engage in reactive, symbolic implementation processes and consolidate policy activities to focus on what they perceive as the important elements to achieve state approval of programs, national accreditation, and competitive, higher quality graduates. Faculty members, because they believe in improving programs and teacher candidate outcomes to create better prepared teachers, bought into the new institutional practices, norms, and common-sense values instituted by senior managers. However, the amount of time faculty have to implement such standards and policies, and the amount of time teacher candidates have to acquire new knowledge, skills, and abilities is the same as it was when teacher candidates obtained only two teacher education certifications: three years. Therefore, quality is being sacrificed for quantity. As the mathematics methods professor explained:

Because of the way the program is set up and the degrees that are obtained—because they end up with four different degrees—it is important that they have a lot of content within that time. There's lots to do...But it is necessary. If done right, [the teacher candidates] will have more knowledge and experience and be better prepared as new teachers ( $G$. Rice, interview, mathematics methods professor, March 13, 2012).

Senior managers have narrowed the curricula and program practices to focus only on processes related to showing evidence of standards and policy implementation rather than on actual implementation. NCATE's continuous improvement is designed so that policy actors can implement meaningful 
activities and assessments that will yield valid, reliable data that may be used to improve program processes and teacher candidate outcomes. The entire point of the continuous improvement model is lost in the process of ensuring the institution "passes NCATE" and programs are approved by the state. However, this may indicate to the state and NCATE there are too many standards and policies to implement. Policy actors at the teacher preparation program level must sacrifice quality for quantity for the school to be accredited and the programs to be approved.

The abundance of standards and the way in which standards and policies are implemented has resulted in negative unintended consequences associated with teacher candidates' growth and development. Teacher candidates do not take ownership of the standards that serve to guide their career development. They are unaware of the politics of their profession. Teacher candidates do not exhibit characteristics of neoliberal ideals, yet they are operating under conditions of neoliberalism which, whether inadvertent or intentional, model behavior for the actions they should exhibit in the classrooms in which they will eventually teach. A teacher candidate discussed aligning Common Core Standards in her syllabus. The explanation of her actions, detailed in a focus group interview, resemble that of senior managers and faculty during their standards alignment process:

Teacher Candidate 2: The standards that our [professors] have to teach us, they list them on all of our syllabus. We have a list of their standards [emphasis added]. 
Researcher: What do you mean by 'their' standards?

Teacher Candidate 2: When we write a lesson plan for our [P-12] students we have a list of [Common Core] standards to base that lesson around. They have to do the same thing. They group them all together on the syllabus. There are like 50 of them. Like on our lesson plans, we list standards for our students. And we have to make sure to list how the standard matches the objective and how we will test for it. (Teacher Candidates, focus group, May 3, 2012)

Teacher candidates also referred to the Alabama Quality Teaching Standards (AQTS), the standards deigned to drive quality in her profession, as "their standards." Her comments indicate she thinks the AQTS standards are for faculty to monitor their own teaching, not quality standards she needs to know to enhance her professionalism. Teacher candidates were probed further about their understanding of AQTS. Responses continued to reflect their perception that AQTS are for the faculty, not them. Comments also provided further evidence that faculty model to teacher candidates the symbolic standards alignment process they may eventually employ as teachers. In a focus group interview, teacher candidates stated:

Teacher Candidate 3: Our standards are the ones we have to teach our students. I mean, the ones you are talking about, they like check off when they come observe us. But that's for them. 
Teacher Candidate 1: Yeah, we're aware of what those are. But I couldn't tell you what they are or what they mean.

Teacher Candidate 4: I'm not sure if those are on our observation sheet. You mean like when they observe and give us one, two, three, four?

Teacher Candidate 3: I don't know. But I feel like there's some number next to them that says, 'Alabama...'

Teacher Candidate 1 [Observer note: She withdrew a binder from her book bag. She showed me a course syllabus.] Is this what you mean? Yeah, yeah, like three is proficient and zero is the lowest. This is for them to keep track. Not us. But they have them for us to see.

Teacher Candidate 5: Yeah, and we have to do the same thing. We have to make sure we document the Common Core Standards to show that we are teaching them.

Researcher: Do you actually teach them?

Teacher Candidate 5: Right now this is for practice. But I guess we will. Well, our lesson plans have to show we are and then we will teach our lesson plans.

Teacher Candidate 1: I just make sure my lesson plan looks like that template. I got in trouble for that before. I did a good job with my lesson but [the observer] wanted my lesson plan to look just like that example 
they gave us. So that's what I do now. (Teacher Candidates, focus group, May 3, 2012)

Teacher candidates being unsure or unaware of the standards that serve to guide their profession and practices contradict the professionalism language and purpose of the AQTS and NCATE standards themselves. This discussion also shows that teacher candidates are compliant in implementing activities that reflect quality, without fully understanding the way in which the activity prepares them to be better teachers.

There are positive consequences that may result from more standards and higher expectations, as well. If the P-12 partnership and clinical residency model is implemented in a meaningful way, teacher candidates will exposed to the real world of teaching by being placed in schools earlier in their careers. Although the diversity of their experiences may take a back seat to arranging better P-12 partnerships to conform to the NCATE Clinical Residency Model, exposure to the real world of teaching helps to affirm a teacher candidate's career choice or serves to weed out people who may not have the disposition for teaching (E. Jones, NCATE National-State BOE Member, interview, March 5, 2012).

Policy actors at the New School are willing to implement a large quantity of implementation activities that reflect quality. Therefore, another positive consequence, as perceived by program-level policy actors, is that graduates of the Elementary and Collaborative Education Program may be perceived as more 
qualified, and may therefore hold a more marketable degree than graduates of other programs in the State of Alabama and across the nation. Marketability of programs and graduates is an important factor for the university president and senior managers at the program level. The most recent years' (2012) job placements statistics of the New School Elementary and Collaborative Education Program graduates indicates that $90 \%$ are employed as full time teachers in their certification field upon graduation.

Summary of the Transformation of Legislative Intentions: the Program Level

The major interconnected national, state, and university conditions that led to the presence of the action context at the New School include: (1) neoliberal socio-political ideology trickling down from the national and state levels; (2) the high value placed of NCATE accreditation by national- and state-level policy actors, and senior managers and lower-level policy actors at the program level; (2) values, interests, and actions of senior managers; (3) state policy actor's desire for creating a replicable, marketable teacher preparation institution; (4) an overwhelming amount of accountability and oversight; (5) the small school size; (6) a culture of senior management control; and (7) the compliant dispositions of faculty.

Such conditions provided the context for school- and program-level policy actors to engage in an intense, sustained focus on symbolically implementing a large quantity of policy actions and activities which would lead to the appearance of quality in teacher preparation. This is an example of the quality of education 
being redefined "as the quantitative efficiency with which the qualifications are produced."

Influential policy actors at the national level—USDE and NCATE—have established legislation, policies, and standards which support a neoliberal sociopolitical agenda to transform public education and teacher education and preparation into a system of performance accountability. NCLB, NCLB/ESEA Waivers, the ESEA Blueprint for Reform, Our Future, Our Teachers, NCATE Standards, and the NCATE Blue Ribbon Panel Report, which promotes a residency model for field and clinical experiences, are neoliberal-conditioned legislation, policies, and standards which have trickled down from the national level and directly influenced state definitions and actions related to teacher quality. The traditionalistic culture of the State of Alabama's political system combined with neoliberal conditions of global and national economic and education competition has resulted in an alignment of national and state interests and intentions relative to education reform. Teacher quality legislation, policies, actions, and decisions Alabama have been transformed to resemble legislation and policies at the national level.

As a result of NCLB, the State of Alabama passed legislation requiring more content courses and achievement scores on teacher certification exams as proof of content knowledge for teacher education graduates; making content knowledge a significant indicator of teacher quality. The NCLB Waiver and Race to the Top (2009) grant competition requirements were transformed into significant education reform legislation and policies in the state including, the 
adoption of the Common Core performance standards for K-12 education, the establishment and expansion of charter schools, the allowance of corporatefunded private purveyors of teacher education, and the development of an education evaluation system which uses standardized, efficient, formal input/output processes to measure quality in education and teacher education. Through a network of collective activity between USDE and NCATE policy actors, NCATE accreditation standards also reflect a system of performance accountability in teacher preparation.

State-level legislation and policies on education and teacher quality have been transformed into a standards and performance-based assessments for accountability in teacher education and development. The Alabama Quality Teaching Standards, the Alabama Continuum for Teacher Development (the Continuum), and Performance Assessment Templates (PATs) are standards and evaluation instruments that reflect the use of predetermined standards and measureable indicators of teacher performance to determine teacher quality. NCATE's continuous improvement and clinical residency models, and state teacher quality standards and performance measures have transformed policies at the school of education and program levels.

The consequences of national and state influence on standards and policy implementation practices in teacher preparation are plentiful. The consequences are also damaging to the notion of the purpose of education for the common good and the public interest. The traditional purpose of education has been supplanted with education for the purpose of global and national competition. 
Thus, the purpose of teacher education is to prepare teachers to prepare students for global competition. Teacher quality at the program level has been redefined to center on content knowledge and teacher candidate impact on student achievement. Teacher candidates are required to complete content courses and supplemental out-of-course content-based workshops in order to acquire the knowledge necessary for certification in four content areas: early childhood education, elementary education, special education, and reading education. In addition, teacher candidates are required to pass three standardized teacher education content certification examinations: elementary education, special education, and reading education.

National accreditation and state approval of programs has become a main focus of quality standards implementation in teacher preparation. Senior managers, the Dean and Director of Teacher Education/de facto NCATE Coordinator, took control of program implementation practices. This created conflict and dissonance among faculty and teacher candidates. Program activities associated with meaningful transformation of teacher education program practices were replaced by the symbolic implementation of NCATE and state policy- and standards-related implementation activities. Program practices were narrowed to focus on the implementation of activities that showed evidence of implementation rather than the implementation of activities that effected change and transformation in teacher preparation program quality.

Faculty and teacher candidates complied with the symbolic implementation of policy activities because senior managers had created a 
culture of top-down control. Senior managers also controlled faculty and teacher candidate actions by stressing the importance of NCATE accreditation and state approval of programs; perceived indicators of quality by all policy actors.

Program-level policy actors were engaged in a dichotomous process of working backwards to create and link data to program changes or symbolically implement activities that would yield data to use as evidence of implementation for accreditation and program approval purposes. The hasty, symbolic implementation of the NCATE Clinical Residency Model took precedence over the conventional process of field and clinical experiences, resulting in faculty concern that teacher candidates were missing significant teaching and learning experiences. The clinical model intended by NCATE became a disorganized model which overwhelmed faculty, teacher candidates, and P-12 teachers. P-12 teachers did not support or engage in activities related to the clinical residency model, resulting in a surface-level P-12 partnership where program faculty simply moved methods courses from the university to the grade school campus; not the collaborative, shared-vision, co-teaching partnership expected from NCATE.

Senior managers encouraged faculty to engage in creation of situations for opportunities to link teacher candidate data to P-12 student achievement data. Teacher candidates questioned the integrity of collecting P-12 student data which would show evidence of their impact on achievement when they were not the exclusive teacher of record for the students to which they would be linked. Yet, because of senior managers' intentions to pass NCATE, integrity in research and data collection took a back seat to ensuring data were collected. Teacher 
candidate input and student output links were not used to inform the policy actors of program and teacher candidate strengths and weakness, rather such data were used to show NCATE and the state the data collection implementation activities were completed in a given time frame.

Despite all the content requirements, standards alignments, and standards-based performance measurements, teacher candidates are not familiar with nor take ownership of the standards designed to drive professionalism in teaching. They view the Alabama Quality Teaching Standards as the responsibility of the faculty, rather than their responsibility to know and internalize. Yet they are held accountable for performing up the standards. Teacher candidates are left utterly unaware of the politics of their profession. Yet as teachers, they will be operating under the neoliberal political conditions of which they are unaware. They will be required to meet performance-based standards that they know and understand very little about.

The intention of NCATE is for policy actors in schools of education to implement policies and procedures which yield valid and reliable data that will enable continuous school, program, and teacher candidate improvement. The State of Alabama, by virtue of partnering with NCATE in reviewing the quality of schools and programs, shares NCATE's interests. However, the intention of NCATE and state standards and policies are confined by the realities of time. It is difficult, almost impossible, to meaningfully implement so many policies and standards in the conventional length of time of a teacher preparation program. What the quality policies have become in practice-at one of the most important 
levels of implementation-are actions that show quality on paper rather than cause effectual change in reality.

The concluding chapter, Chapter V, reviews the transformation of policy intentions across all levels and linkages of the policy enactment and implementation process. Implications for and applications to the wider teacher quality policy world are provided. 


\section{CHAPTER V DISCUSSION}

This is a case of the influence of neoliberal ideologies on the transformation of teacher quality standards and the consequences for teacher education. It examines how neoliberal influences shaped the thinking and actions taken by policy makers at the federal, regional and state levels and how those processes shaped the definition and implementation of teacher quality standards within a college of education. Current policies and standards related to quality in teaching, teacher education, and teacher development are enacted and implemented under global and national neoliberal socio-political conditions. The socio-political conditions under which quality policies in teacher education are developed, enacted, and implemented are grounded in eight components of neoliberal ideology. They include:

- The eroding or elimination of the notion of education as a common good for the public interest to be supplanted with the notion of education for the purpose of global economic competition;

- The development of new discourses, rewards, norms, institutional practices, and/or common-sense values; 
- The state acquiring a new identity as the protector of capital, where its role is to enhance social and educational policies to protect the market;

- Active political intervention of schools, colleges and universities by national and state governments;

- Senior management control over policies and policy implementation actions;

- The standardization of efficient, formal input/output processes to measure quality;

- The use of predetermined standards and measurable indicators of performance to determine quality; and

- Defining quality in education by the product of education, or the "quantitative efficiency with which the qualifications are produced." (Lorenz, 2012, p. 621)

This study examined how teacher quality policy implementation is situated in a broad frame of socio-political conditions; policy actors' values, experiences, and interests; and varying and interconnected organizational contexts. The research evolved from a description of policy implementation processes and actions to a deeper investigation of the phenomenon regarding how standards and policies are understood, negotiated, acted upon, and implemented under particular sociopolitical conditions and within various contexts.

Six themes arose from the analysis across two or more levels of the quality policy enactment and implementation process: (1) the value policy actors 
place on NCATE accreditation; (2) more standards, policies, and assessments related to teacher quality, which is grounded in the idea that more equals better quality; (3) symbolic implementation of standards and policies, as a result of an overabundance of policies and standards; (4) developing and implementing systems of performance accountability in teacher preparation by linking teacher inputs to student outputs as the predominant way to define and determine teacher quality; (5) shared interests in establishing replicable program practices using the school of education as a model for the state; and (6) shared interests in the marketability of the Elementary and Collaborative Education Program.

In the end, what the study documented was not the influence of neoliberalism as an external force acting upon policy makers and participants, but the process of "neoloberalizing" teacher education through the quality standards implementation process (Hall \& McGinty, 1997). The study provided evidence about the process by which individuals and groups of actors interact within a political, ideological, and economic context to produce neoliberal outcomes and consequences for teacher education. In essence, this study contributes to the academic literature in teacher education policy by revealing the process of "neoliberalizing" teacher education (Hall \& McGinty, 1997). 
Summary of the Transformation of Legislative Intentions: National to Program Levels \& Linkages

The National Level

The NCLB Act (2001), ESEA Waivers, the ESEA Blueprint for Reform, Our Future, Our Teachers, the NCATE Blue Ribbon Panel Report, political speeches, and other documents, as well as the widespread presence of neoliberal ideologues in influential positions in the federal government and national education policy organizations created a macro-level societal climate for major reform in teacher education and preparation. Key policy actors, responding to national and international socio-political, cultural, and economic conditions, as well as their own interests, interacted to create the impetus for change and to shape what that change would look like in their own ideological image.

Teacher quality policy and standards have transformed under conditions of global and economic competitiveness. On a broader scale, the general purpose of education has been redefined as education for the purpose of college- and career-readiness. The notion of education as a common good for the public interest has been eliminated. The new purpose of education has transformed the definition of teacher quality to now be situated in the extent to which teacher inputs influence students' academic preparation for competing in global markets. The agendas of both the W. Bush Administration, through NCLB legislation and action, and the Obama Administration, through Blueprint/ESEA reauthorization legislation and NCLB Waivers, have affirmatively required states to evaluate teacher effectiveness through the use of student achievement scores. 
This system of performance accountability has transformed policies in teacher preparation programs by way of reformed teacher education accreditation standards. NCATE accreditation standards reflect systems of performance accountability. The new residency-based clinical model for teacher education is designed to enable schools, colleges, and departments of education to make evaluative links between teacher candidate inputs and student outputs.

The consequences national-level networks, interests, interactions, conventions, and power situated in neoliberal conditions are shown in the way states vied for federal funding and the way they currently structure state education and teacher education evaluation systems to reflect performance accountability. With the enactment of federal legislation, ownership of teacher quality policy enactment and implementation was transferred from state and local governments to the federal government. As a result, federal policies on teacher quality and teacher education serve as conditions under which state policies have been transformed to reflect systems of performance accountability, which link teacher inputs to student outputs to determine quality in teaching and learning.

\section{National and State Linkages}

Teacher quality policy enactment and implementation are linked at the national and state levels through federal accountability legislation, a national socio-political environment of a perceived lack of quality in teaching and teacher education, NCATE accreditation standards and policies on teacher qualifications, and an inter-organization network of national policy actors' research and action 
around teacher quality and teacher education reform which inform the decisions of policy actors' at the state level. Performance accountability policies of the federal government have trickled into teacher quality accountability policies, processes, and actions at the state level, resulting in an alignment of national and state interests and intentions. As such, teacher quality legislation, policies, actions, and decisions in the State of Alabama have been transformed to closely resemble legislation and policies at the national level.

NCLB transformed state policies in teacher education and preparation by having states require more content courses and teacher certification examinations as proof of content knowledge. Content knowledge, then, became a significant indicator of teacher quality in the State of Alabama. NCLB and the national focus on redefining teacher quality led to the policy action of Governor Bob Riley establishing a commission to review research, draft policy and standards, and recommend actions related to teacher quality preparation and development and teacher certification. The Governor's Commission on Teacher Quality collaborated with policy actors in private national education policy organizations to draft teacher quality policy documents and evaluation systems which reflect characteristics of national-level interests and intentions to redesign teacher education evaluation into a system of performance accountability.

The NCLB waiver application requirements, put forth by policy actors in the Obama Administration, provided the context for Alabama's current governor, Robert Bentley, to reform significant aspects of Alabama's educational system, including adding evaluation systems which tie teacher inputs to student outputs, 
passing a resolution to establish and expand charter schools, and the adopting national-level Common Core Standards for K-12 education. All such policies and actions were required to be active in states submitting applications for NCLB waivers and Race to the Top (2009) funding. Alabama was granted an NCLB waiver, but was denied RTTT (2009) funding. However, the policy changes which reflect a teaching and learning evaluation system of performance accountability remain in place.

The network of collective activity between state and NCATE policy actors, as well as the State of Alabama joining the NCATE-State Alliance for Clinical Teacher Preparation, has set conditions for a performance accountability system at the state level to be transformed into a similar system at the teacher preparation program level. The new residency model for field and clinical experiences will allow policy actors in the state and NCATE to make program approval and national accreditation decisions, respectively, based on teacher candidates' impact on student achievement.

There are several neoliberal conditions exhibited through national and state linkages. The USDE, NCATE, and the state are actively intervening and manipulating policies in $\mathrm{K}-12$ and/or teacher education institutions by legislating requirements for evaluations systems in teaching and learning. The teacher input/student output processes and standardized, predetermined measurable indicators of performance provide a system of performance accountability where it will become easier for systems and the state to make human capital decisions. As such, the state has acquired a new identity as the "protector of capital" 
(Baltodano, 2012, p. 493) where its new role is to enhance social and educational policies to protect the market. A system of performance accountability reduces the complexities of teaching and learning to snapshots of achievement to quickly determine competitiveness_among students, districts, states, and ultimately the nation-in a global society.

\section{The State Level}

Under conditions of neoliberalism, the role of the state is to enact education legislation and policies that will serve to nourish and protect state markets and capital, which in turn will nourish and protect national capital. Under such socio-political conditions, education policies in the State of Alabama have transformed to replicate performance accountability systems reflective of the new public management philosophy. The teacher quality policy transformation process began in the late-1980s, around the time of the Standards-based Reform Movement.

Alabama governors and other influential policy actors began establishing policies on teacher quality and quality in teacher preparation that were based on teachers' acquisition of more content and subject matter knowledge, performance-based accountability, student achievement on standardized tests, and links between teacher inputs and student outputs. By the time NCLB was in full swing, state education policy actors were already in the process of examining teacher quality indicators and formulating laws, policies, and standards that would shape the way teacher quality and quality in teacher preparation and development is conceptualized in the state today. Alabama policy actors 
established state standards for teacher quality which reflect indicators directly aligned with national interests and intentions.

Education legislation and policy in the State of Alabama continue to transform and mirror national reform initiatives with the current governor's administration. In an effort to obtain Race to the Top (2009) funding, policy actors in the state passed unprecedented education legislation. Although Alabama did not receive the much-needed funding, the laws and policies passed remain in place. Such controversial education policies as the School Flexibility Act of 2012, where local education agencies submitted applications to the ALSDE requesting to circumvent NCLB (2001) laws on student achievement tracking and reporting; the state-legislated establishment and expansion of charter schools; and provisions for using student achievement data to determine the effectiveness of teachers and teaching are ways in which Alabama's education legislation and policies have been transformed under conditions of neoliberalism.

Legislation has transformed into policies related to quality in teacher preparation, which have then transformed into indicators for model of performance accountability. The quantity of content courses and scores on standardized achievement tests for teacher now serve as significant indicators of teacher quality. Field and clinical experiences are being transformed into teacher residency model that will be standardized across all state teacher preparation programs; a model which will pave the way for performance accountability links between teacher candidate inputs and K-12 student outputs. State policy actors 
have embraced the national teacher education reform effort to create standardized performance assessments for the purpose of evaluating all teacher preparation programs.

Since the enactment of NCLB, there has been a national push for increasing teacher content knowledge and linking teacher knowledge to student achievement to be the most significant factors in determining education qualifications. In the State of Alabama, under the leadership of the current governor and state superintendent of education, policy actors in the state are being held accountable for implementation activities which center on this narrow definition of teacher quality.

Based on a critical examination of policy and standards implementation at the teacher preparation institution at the center of this study-an institution that will serve as the state model for teacher education reform—teacher content knowledge and teacher candidate-student data links are indeed the central focus of implementation activities. Federal and state law and policy implementation activities associated with performance accountability constitute conditions for linkages at university and program levels of the teacher quality policy enactment and implementation process.

National, State, University, and Program Linkages

Heavy reliance on NCATE implementation practices to show quality in teacher education has transformed the teacher quality policies at the state and institution/program levels into systems of performance accountability. By 
partnering with NCATE in reviewing the quality of teacher preparation programs, the state is complicit in forwarding an agenda of performance accountability. The technical review of the state review of programs defines quality in education by the product of education.

As long as policy actors of the program level show documentation that standards are aligned with courses, course objectives, and assessments, state policy actors assume that teacher candidates are experiencing what has been documented, and conclude programs show quality and should be approved. Findings presented in the Teacher Preparation Program Level section provide additional, detailed evidence of NCATE requirements being the impetus behind the implementation of policies and activities related to performance accountability.

\section{University Level and University and Program Linkages}

Policy actions at the university level related to school of education policy implementation are centered on ensuring university and school of education accreditation. The importance of accreditation has transformed into policy requirements to increase amounts of research conducted by faculty and to increase enrollment numbers. As a result of the university president's desire for accreditation, the dean and faculty of the school of education have an additional level of accountability, outside of national, NCATE, and state requirements. While school of education faculty are required to implement a plethora national, NCATE, and state quality standards, as well, as meet all requirements on state compliance checklists, the university president is also requiring the Dean to 
ensure teaching faculty are producing and publishing research. The research requirement at a teaching university is an example of the development of new institutional practices.

Additionally, the Dean has to balance ensuring the implementation of more requirements teacher candidates to obtain teacher education degrees, perpetuated by national- and state-level conditions, with ensuring enrollment numbers increase, a university-level condition. Increasing enrollment numbers is a program with more requirements that other programs in the state will not be an effortless task. This is an example of organizational life being governed by a corporate culture of senior management control. The university president, the senior manager, is concerned with increasing enrollment numbers, which may also lead to more teacher education degrees as products of the university, which may lead to public perceptions of the university (and school of education) as a quality institution. Thus, the quality of education is redefined "as the quantitative efficiency with which the qualifications are produced" (Lorenz, 2012, p. 621).

\section{The Program Level}

The major interconnected national, state, and university conditions that led to the presence of the action context at the New School include: (1) neoliberal socio-political ideology trickling down from the national and state levels; (2) the high value placed of NCATE accreditation by national- and state-level policy actors, and senior managers and lower-level policy actors at the program level; (2) values, interests, and actions of senior managers; (3) state policy actor's 
desire for creating a replicable, marketable teacher preparation institution; (4) an overwhelming amount of accountability and oversight; (5) the small school size; (6) a culture of senior management control; and (7) the compliant dispositions of faculty. Such conditions provided the context for school- and program-level policy actors to engage in an intense, sustained focus on symbolically implementing a large quantity of policy actions and activities which would lead to the appearance of quality in teacher preparation. This is an example of the quality of education being redefined "as the quantitative efficiency with which the qualifications are produced."

Influential policy actors at the national level_USDE and NCATE—have established legislation, policies, and standards which support a neoliberal sociopolitical agenda to transform public education and teacher education and preparation into a system of performance accountability. NCLB, NCLB/ESEA Waivers, the ESEA Blueprint for Reform, Our Future, Our Teachers, NCATE Standards, and the NCATE Blue Ribbon Panel Report, which promotes a residency model for field and clinical experiences, are neoliberal-conditioned legislation, policies, and standards which have trickled down from the national level and directly influenced state definitions and actions related to teacher quality.

The traditionalistic culture of the State of Alabama's political system combined with neoliberal conditions of global and national economic and education competition has resulted in an alignment of national and state interests and intentions relative to education reform. Teacher quality legislation, policies, 
actions, and decisions Alabama have been transformed to resemble legislation and policies at the national level. As a result of NCLB, the State of Alabama passed legislation requiring more content courses and achievement scores on teacher certification exams as proof of content knowledge for teacher education graduates; making content knowledge a significant indicator of teacher quality.

The NCLB Waiver and Race to the Top (2009) grant competition requirements were transformed into significant education reform legislation and policies in the state including, the adoption of the Common Core performance standards for K-12 education, the establishment and expansion of charter schools, the allowance of corporate-funded private purveyors of teacher education, and the development of an education evaluation system which uses standardized, efficient, formal input/output processes to measure quality in education and teacher education. Through a network of collective activity between USDE and NCATE policy actors, NCATE accreditation standards also reflect a system of performance accountability in teacher preparation.

State-level legislation and policies on education and teacher quality have been transformed into a standards and performance-based assessments for accountability in teacher education and development. The Alabama Quality Teaching Standards, the Alabama Continuum for Teacher Development (the Continuum), and Performance Assessment Templates (PATs) are standards and evaluation instruments that reflect the use of predetermined standards and measureable indicators of teacher performance to determine teacher quality. NCATE's continuous improvement and clinical residency models, and state 
teacher quality standards and performance measures have transformed policies at the school of education and program levels.

The consequences of national and state influence on standards and policy implementation practices in teacher preparation are plentiful. The consequences are also damaging to the notion of the purpose of education for the common good and the public interest. The traditional purpose of education has been supplanted with education for the purpose of global and national competition. Thus, the purpose of teacher education is to prepare teachers to prepare students for global competition.

Teacher quality at the program level has been redefined to center on content knowledge and teacher candidate impact on student achievement. Teacher candidates are required to complete content courses and supplemental out-of-course content-based workshops in order to acquire the knowledge necessary for certification in four content areas: early childhood education, elementary education, special education, and reading education. In addition, teacher candidates are required to pass three standardized teacher education content certification examinations: elementary education, special education, and reading education.

National accreditation and state approval of programs has become a main focus of quality standards implementation in teacher preparation. Senior managers, the Dean and Director of Teacher Education/de facto NCATE Coordinator, took control of program implementation practices. Program activities associated with meaningful, instrumental transformation of teacher 
education program practices were replaced by the symbolic implementation of NCATE and state policy- and standards-related implementation activities.

Program practices were narrowed to focus on the implementation of activities that showed evidence of implementation rather than the implementation of activities that effected change and transformation in teacher preparation program quality.

Symbolic implementation can be distinguished from meaningful implementation "by judging whether their goals have credible relationship to the means provided or suggested to achieve them" (Smith, Miller-Kahn, Heinecke, \& Jarvis, 2004, p. 29). The goal of quality policies in teacher preparation is to enhance the effectiveness of teacher candidates and the programs that serve them. The means to achieve the goals were actions that resemble instrumental policy implementation, with no assessment of the effects of such actions; thus, yielding little more than documented evidence of quality control and enhancement rather than evidence of real effects.

Program-level policy actors were engaged in a dichotomous process of working backwards to create and link data to program changes or symbolically implement activities that would yield data to use as evidence of implementation for accreditation and program approval purposes. The hasty, symbolic implementation of the NCATE Clinical Residency Model took precedence over the conventional process of field and clinical experiences, resulting in teacher candidates missing significant teaching and learning experiences. The clinical model intended by NCATE became a disorganized model which overwhelmed 
faculty, teacher candidates, and P-12 teachers. P-12 teachers did not support or engage in activities related to the clinical residency model, resulting in a surfacelevel P-12 partnership where program faculty simply moved methods courses from the university to the grade school campus; not the collaborative, sharedvision, co-teaching partnership expected from NCATE.

Senior managers and faculty were engaged in creating situations for opportunities to link teacher candidate data to P-12 student achievement data. The research integrity of data collection took a back seat to ensuring data were collected. Teacher candidate input and student output links were not used to inform the policy actors of program and teacher candidate strengths and weakness, rather such data were used to show NCATE and the state the data collection implementation activities were completed in a given time frame.

Despite all the content requirements, standards alignments, and standards-based performance measurements, teacher candidates are not familiar with nor take ownership of the standards designed to drive professionalism in teaching. They view the Alabama Quality Teaching Standards as the responsibility of the faculty, rather than their responsibility to know and internalize. Yet they are held accountable for performing up the standards. Teacher candidates are left utterly unaware of the politics of their profession. Yet as teachers, they will be operating under the neoliberal political conditions of which they are unaware. They will be required to meet performance-based standards that they know and understand very little about. 
The intention of NCATE is for policy actors in schools of education to implement policies and procedures which yield valid and reliable data that will enable continuous school, program, and teacher candidate improvement. The State of Alabama, by virtue of partnering with NCATE in reviewing the quality of schools and programs, shares NCATE's interests. However, the intention of NCATE and state standards and policies are confined by the realities of time. It is difficult, almost impossible, to meaningfully implement so many policies and standards in the conventional length of time of a teacher preparation program. What the quality policies have become in practice-at one of the most important levels of implementation-are actions that show quality on paper rather than cause effectual change in reality.

\section{Conclusion}

The research determined that the personal interests, intentions, motivations, values, \& experiences of policy makers and teacher educators are the key influences in the implementation of teacher quality policies and standards in teacher education. These are influenced by the neoliberal socio-political conditions under which problems are framed, and by which policy is formulated and enacted. Networks of collective activity between and among policy actors occur across and within governmental levels, where influential policy actors interact and negotiate to get their interests achieved. Influential policy actors across all levels of the enactment and implementation process used power and resources to transform organizational life into corporate cultures of senior management control. Thus, making is easy to standardize efficient, formal 
structures and input/output processes which can be quantified and controlled by senior managers. Conventions, or accepted ways of accomplishing implementation activities, become the new discourses, institutional practices, norms, and common-sense values established by policy makers and senior management.

Policy intentions are either transformed or reinforced as they cross levels of implementation depending on context and policy actors' interpretations. In some cases, policy intentions from the top are enacted with little transformation or resistance. In other cases, the original intentions create a conflict and dissonance for practitioners. In this case, teacher education faculty believed in the values represented in the standards language. However, they expressed frustration with being responsible for implementing such a large quantity of standards and implementation activities. They believed that a reduction in standards and requirements would yield meaningful implementation of activities, and would result in a better program and better qualified graduates. Yet they had no power to enforce such reductions. Although they resisted the notion of symbolic implementation, by trying to make standards activities more meaningful in their courses, senior managers' control over program processes resulted in faculty compliance.

Faculty were concerned that essential teaching and learning elements may be missed when activities were not implemented for the purpose of developing teacher candidates' knowledge and abilities. However, their concerns were trumped by senior management control. Senior managers 
continually stressed the importance of NCATE accreditation and program approval. The Dean and Director of Teacher Education/de facto NCATE Coordinator used the threat of the institution not being accredited and programs not being state-approved as scare tactics to enforce their will on faculty. If the institution is not accredited and programs not approved it may lead to public perceptions of low quality. Public perceptions of low quality may lead to a decrease in enrollment numbers. A decrease in enrollment numbers may lead to faculty losing their jobs. National accreditation and approval of programs is essential in the age of accountability and neoliberalism where stamps of approval serve as symbols of quality.

The elimination of the "notion of education as a common and public good in the public interest" (Luke, 2005 as cited in Baltodano, 2012, p. 493) is evident in the way education policy actors across all levels of the quality policy enactment process have systematically redefined the purpose of education to center on college and career readiness. College and career readiness is an important reason to prepare P-12 students. However, college and career readiness should not be the sole purpose of education. Enlightenment, the pursuit of knowledge for the sake of knowledge, encouraging a passion for learning, and developing an informed citizenry who effectively participates in a democracy are also important reasons for education. Neoliberal policy actors have determined the sole reason a citizenry should be educated is to contribute to the economic growth of the country and world (Giroux, 2002; Baltodano, 
2012). This determination has now become a new discourse and commonsense value in America (Giroux, 2002; Baltodano, 2012; Lorenz, 2012).

Education is being restructured, through "active political intervention and manipulation of all social institutions" by a handful of powerful policy actors, to only focus on indicators that will lead to an individual's marketability in a global economy (Brown, 2003, as cited in Baltodano, 2012, p. 493). Teacher educators are complying with these restructuring processes with little evidence of resistance, in this case. Although there are myriad examples of USDE intervention and manipulation of State Departments of Education and teacher preparation institutions, the "most important protagonist of all" in the "active political intervention and manipulation of all social institutions" is the state (Brown, 2003 as cited in Baltodano, 2012, 493). Specifically, the State of Alabama has acquired "a new identity as the "protector of capital"' and "its role has been reduced to the enhancement of...educational policies to nourish and protect the market" (Brown, 2003 as cited in Baltodano, 2012, 493).

The State of Alabama established this new identity through the actions of five governorships, beginning in the 1980s. Although the socio-political culture in Alabama has historically been traditionalistic, the era of federal accountability for quality control in public education, as well as America's desire to compete at high levels in a global society, has led to an alignment of national and state interests around restructuring educational systems for global competitiveness, apparently trumping Alabama's political culture. Local control is not so local anymore or the parameters of local control have been greatly expanded. Influential policy actors 
in the State of Alabama have embraced national and global competition. Therefore, laws, standards, and policies related to quality in teacher education and student learning increasingly reflect the drive to prepare students for collegeand career- readiness.

The development of "new discourses, institutional practices, rewards, norms, and new common-sense values" (Brown, 2003 as cited in Baltodano, 2012, 493) are evident in the way Alabama's new state superintendent of education has restructured the Alabama State Department of Education into a "best-in-class performance management" system (Barber, Kihn, \& Moffit, 2010). This new organizational structure has been instituted for the purpose of linking teacher inputs to student achievement outcomes under the rationale that high quality teachers produce increased student achievement test scores. This new public management system has been transformed into program practices in teacher preparation programs with the induction of a clinical residency model.

The ultimate goal of performance accountability systems to determine teacher quality and effectiveness -in the State of Alabama and across the nation-is the development of efficient, formal structures of input/output that reward and sanctions teachers. State-level discourses around student-teacher data links have transformed into teacher preparation program practices, partly because many of the policy actors at the program level have a dual role in serving the needs of their institutions while also serving the interests of NCATE and the state. The discourses have led to institution-level policy actors' perspectives of common-sense notions of teacher training for the purpose of 
increasing student achievement test scores. This is perpetuated by the global and national conception that an increase in test scores signals college and career readiness and academic success for students.

Other aspects of neoliberal ideology seen in teacher quality policy enactment and implementation processes include: organizational life governed by a corporate culture of "senior management control" (Giroux, 2002; p. 429); the state's and NCATE's standardization of efficient, formal structures of inputoutput processes, which can be quantified and controlled by senior management; the "use of predetermined standards to measure output;" and the introduction of measurable indicators of performance" (Lorenz, 2012; p. 608). Policy actors at the state level, as well as the Dean and the Director of Teacher Education/de facto NCATE Coordinator at the program level effectively serve as the senior managers and key actors in the "neoliberalizing" process (Hall \& McGinty, 1997).

The authoritarian leadership styles and power positions of the Dean and Director of Teacher Education/de facto NCATE Coordinator, as well as organizational structures and institutional culture, reflecting the authority of the state, enabled them to convince, persuade, or coerce lower-level policy actors to implement standards and policies based on their preferred interpretations of what the state and NCATE expects. Both senior managers used the threat of the Elementary and Collaborative Education program not being nationally accredited and approved by the state to achieve their intentions. When implementation activities were not instituted to the senior managers' approvals, they both took control over implementation activities, and assumed the roles of lower level 
policy actors. The Dean planned to review all NCATE reports and documentation and make changes to aspects he perceived were not up to NCATE standards. The Director of Teacher Education/de facto NCATE Coordinator took control over the field and clinical processes and implemented the NCATE Clinical Residency Model without any discussion or agreement with the Director of Field and Clinical Experiences. Compliant faculty were recruited to implement the clinical residency model; a model envisioned and designed by senior managers with little to no input from lower-level policy actors. Teacher candidates were expected to engage in symbolic implementation activities regardless of the activities' lack of substantive contribution to their professional growth. This is an example of using power and resources to circumvent conventions to achieve interests and intentions.

The technical, checklist nature of the state program review exhibits standardization of input/output structures and processes that can be quantified and controlled by senior managers. The state program review process is a check of on-paper documentation of the alignment of teacher quality standards with courses, coursework, field and clinical experiences, and assessments. The Dean and Director of Teacher Education/de facto NCATE Coordinator either created alignment documents or commanded lower-level policy actors to create such documents. The purpose of the alignment process is to improve the program and teacher candidate outcomes. This purpose took a back seat to senior managers making sure the process of aligning standards was documented on paper. Policy actors, therefore, could not observe the impact of the alignment 
processes because they were engaged in documenting the process rather than utilizing it for improvement. The state assumes on-paper documentation of the alignment of standards and practices means policy actors are actually utilizing the process to improve the quality of programs and teacher candidates; and example of quantity representing quality.

This is the same problem inherent in some aspects of the NCATE Accreditation Review process. NCATE accreditation standards require policy actors to link teacher candidate inputs with P-12 student outputs, like achievement scores. As such, senior managers instituted fast-track implementation activities, including implementing the NCATE Clinical Residency Model and creating superficial situations for teacher candidates to interact with students, teach lessons, and assess the students. Implementation took place in a disorganized fashion and only for the purpose of collecting data. The actual effects of implementing the P-12 clinical partnership will be difficult to determine because the data collected is neither valid nor reliable.

Observations yielded implementation practices that were reactive rather than proactive. Symbolic implementation took place as policies and standards were implemented for the purpose of collecting data that would show policy actors were engaged in a continuous improvement model. Actions by policy actors would serve as signals to the state and accreditation organization that standards and policies were meaningfully implemented (Smith, Miller-Kahn, Heinecke, \& Jarvis, 2004). In fact, policy actors were engaged in the surface implementation of activities that would yield the data that would fit their 
interpretation of what NCATE and the state would deem acceptable implementation of standards and policies. The continuous improvement model intended by NCATE standards was only represented in documents.

Such actions of senior managers may result from what Weick (1976) refers to as loosely-coupled systems (Weick, 1976), where the senior managers are protecting the institution and programs from external policy demands. The means by which senior managers operate will achieve the desired result of accreditation and program approval. Perhaps after the institution is NCATEaccredited, and programs are approved by the state, policy actors can resume the meaningful restructuring of program practices that were halted in the wake of preparation for accreditation; and repeat the NCATE/State Review preparation fiasco five years later. Perhaps, because of increased accountability and oversight, policy implementation practices will continue to be symbolic.

The observed impact of teacher quality policy and standards implementation on faculty instructional practices was an alignment of standards with course objectives, activities, and assessments. Faculty implemented, through teaching, and assessed, through projects and tests, quality and professional standards indicators in their courses. However, faculty discussed the process of alignment as something that would help them satisfy NCATE accreditation and state program approval requirements. There was no observation or discussion of how the alignment process would collectively enhance the quality of the graduates and program. 
The final aspect of neoliberal ideology observed in the implementation of teacher quality standards and policies is how the definition of teacher quality itself was transformed. Teacher quality is defined in terms of more education, more knowledge, and how teacher qualifications impact student achievement. The definition of the "product of education as qualification" (Lorenz, 2012, p, 621) expressed in terms of course credits and the accumulation of diplomas is evident in the policy implementation practices at the program level. Elementary and Collaborative Education Program graduates take three certification examinations and receive four teacher education certifications. This means that the amount of content and pedagogical knowledge they must obtain in a three-year period is multiplied by four. What is valued is the accumulation of more knowledge as an indicator of teacher quality. The depth of such knowledge is sacrificed for the breadth. This has implications for faculty in teacher education schools controlled by neoliberal senior managers. Senior managers and external policy actors will be the deciders of what counts as knowledge in teacher preparation.

The largely on-paper-based evidence of the implementation of quality standards and policies and narrowly-defined indicators of quality, like links between teacher inputs and student outputs and teacher candidates' accumulation of more knowledge symbolized in certifications and degrees is symbolic accountability. In symbolic accountability what matters is that quality is documented and shown regardless of the actual process of enhancing quality. The ends justify the means. This practice is perpetuated by the USDE, NCATE, and Alabama State Department of Education. Rather than understanding the 
actual nature of standards and policy implementation, these agencies continue to define more requirements for teacher preparation programs to implement. As long as qualifications are produced in a quantitatively efficient manner, reforms in teacher education will continue to appear effective, yet P-12 students' social and academic needs will continue to go unmet. Symbolic accountability and symbolic implementation are symbiotic. In such systems, it will be impossible to determine whether more accountability, more standards, and higher-level requirements yield better quality teachers because there is no clear relationship between means and ends (Smith, Miller-Khan, Heinecke, \& Jarvis, 2004).

\section{Implications}

The research has contributed to the literature on quality policy enactment and implementation in teacher preparation in a number of ways. While such analysis has been conducted in the areas of career ladder policy (Henson \& Hall, 1993), multicultural education policy (Hall, 1997), and desegregation policy (Heinecke, 1996; Arias, 2010), critical analysis of ways in which policy actors within and across major levels enact and implement teacher quality policy under socio-political conditions of neoliberalism has not been done prior to this study. Understanding the broader socio-political context in which policy decisions are formulated and enacted is essential for a comprehensive appreciation of how policies transform from intentions to actions, and their ultimate consequences for outcomes. Questions about why policy at the street level often appears different than what was intended at the problem-formulation and enactment level can be 
answered more effectively by understanding what this research brought into clear relief.

This research has provided a replicable model for conducting an interpretive qualitative implementation case study with a critical policy analysis component. The study connects the interpretive and qualitative approach of Hall's (1995) Transformation of Policy Intentions framework, with the more critical policy analysis framework suggested by Baltodano (2012). This theoretical integration adds a micro-analytic lens to the more macro-analytic lens of critical discourse analysis. We are able to expose the everyday life construction of neoliberalizing policy processes.

The results of this study will also contribute to the knowledge base of various policy actors. It raises the critical question about the motives of policy makers and policy actors up and down the chain of enactment and implementation. Policy actors at the formulation and enactment stage of policy processes should garner from this study that it is not enough to include street level policy actors in the process of formulating and drafting policy. They must acquire comprehensive knowledge and experience of how policy language is translated into practice at the local level. It is critical for policy developers to understand that as the policy process moves, multiple actors enter the process at different points and commit decisions and actions that will ultimately influence the policy outcome. Decisions and actions are situated in historical and current socio-political conditions and are reflective of personal and professional values and experiences of policy actors. 
This raises the question about ethical motivations behind policy itself. Is policy something that is done to professionals and practitioners? Or is policy enactment and implementation a negotiated process between policy actors across levels? Berman and McLaughlin (1979) conducted early RAND studies, and concluded that top-down policy was adapted in a negotiated process. This study provides insight into the process of policy adaptation.

In this study, policy actors adapted to policy demands by symbolically implementing standards and policies. As such, it would be difficult to evaluate whether meaningful change in graduates and program outcomes would result from such practices. The negotiation between faculty and teacher candidates and senior managers was that the lower-level policy actors would comply in engaging in actions that documented satisfaction of accreditation and program approval requirements. Will symbolic implementation practices be supplanted with meaningful implementation practices once the threat of national accreditation and program approval is over? Or will the continuous cycle of accountability lead to permanence in symbolic implementation?

This presents dire implications for faculty who teach in teacher education schools where neoliberal senior managers control program processes. Faculty will need to decide whether they will allow increased accountability and senior management control to define best practices in teacher preparation. In this case, faculty complained about the overabundance of standards and the fast-track, symbolic implementation of activities. They were concerned that teacher candidates were missing valuable learning opportunities, yet they had little 
control, outside of lessons taught in courses, over implementation processes. Serious discussions amongst faculty and administrators in schools of education are warranted regarding professionalism and academic freedoms.

Neoliberal policies challenge the very notion of professionalism. If teacher educators are not defining teacher quality, then someone else is defining it for them. By definition, this de-professionalizes the profession of teaching. The same national and state standards documents that include standards of professionalism—like National Board of Professional Teaching Standards (NBPTS), Interstate Teacher Assessment and Support Consortium (InTASC), and Alabama Quality Teaching Standards (AQTS)--erode the very notion of professionalism when policy actors other than teachers define what professionalism means.

Should policy actors at the national and state levels relinquish control of being the deciders of best practices for implementers at the local level? Should policy actors at the street level, in this case the teacher preparation program level, play in policy definition and adaptation? Lower-level policy actors are the most knowledgeable about the research and norms of practice most influential to the particular set of teachers and students they serve. Yet, there is very little input from teacher educators, other than symbolic placement on standards development committees, on the standards and policies that guide their profession. 
Standards, assessment and evaluation systems are important aspects in determining quality. However, such processes should not be used as mechanisms to reward and sanction teachers and teacher preparation programs. A broader definition of teacher quality is warranted; one that cannot be transformed into indicators of performance accountability. Yet the power dynamics of policy transformation marginalizes the professionals who are most closely aligned with policy in experience.

What is at stake is the definition of educational practice. Professional teachers are being trained within a neoliberal context shaped by teacher quality policy implementation in its variable instantiations. The newly-formed teacher education accreditation agency, Council for the Accreditation of Educator Preparation (CAEP), presents a powerful level of accountability and oversight, and shows the expansion of neoliberal ideology in teacher education. CAEP policymakers will be the main deciders of what counts as knowledge and practice and proof of knowledge and practice in teacher education across the nation.

Policy actors at CAEP are currently working to nationally standardize teacher education program practices. They are also developing a national teacher performance evaluation assessment where results will be used as the sole indicator to determine quality in teacher preparation. The definition of education practice is being usurped by policy actors who value the standardization of efficient, formal input/output processes, predetermined standards, and measurable indicators of performance to determine quality in teaching and teacher education. 
Each teacher a student encounters is part the student's collective learning experience; a learning experience that should result in the student becoming a fully-functioning adult who is able to understand and participate in basic functions of adulthood, who positively contributes to a civil society, and who makes sound decisions that lead to a self-defined better life for the individual, the individual's family, and the individual's community. This definition of teacher quality cannot be quantified in achievement test scores, but rather in self-defined successes of well-informed, thinking individuals and collective communities. A quality teacher is a teacher who will guide each student toward self-actualization. This definition of teacher quality is eviscerated in the discourse of neoliberal policy transformation. 


\section{REFERENCES}

Aerial Education Initiative. (n.d.) Retrieved from

http://www.arielinvestments.com/content/view/106/1066/.

Alabama Association of Colleges for Teacher Education (ALACATE). (2004, April 20). Constitution of Alabama Association of Colleges for Teacher Education. Retrieved from http://www.alacte.com/ALACTE Constitution.pdf.

Alabama Association of Colleges for Teacher Education (ALACTE). (2012, June 22). Notes: Alliance Advisory Committee. Retrieved from http://www.alacte.com/2012.06.22 Alliance Meeting Summary.pdf.

Alabama Education Study Commission (AESC). (1991). Education study commission designated as standards of excellence: Responsibilities of commission. Retrieved from http://codes.Ip.findlaw.com/alcode/16/6/16-6-

$\underline{5.1}$.

Alabama School Connection. (2012a, August 9). Alabama State Board of Education Elementary/Secondary Education Special Work Session. Retrieved from http://alabamaschoolconnection.org/tales/wpcontent/uploads/2012/08/BOEWorkSessionAgenda081012.pdf. 
Alabama School Connection. (2012b, March 12). The School Flexibility Act of 2012 and the Innovation of School Systems Resolution of 2010. Retrieved from http://alabamaschoolconnection.org/2012/03/12/the-school-flexibilityact-of-2012-and-the-innovation-school-systems-resolution-of-2010/.

Alabama State Department of Education (ALSDE). (1988). NCATE/state partnership protocol for first/continuing/probation reviews of professional education units in the State of Alabama. Retrieved from http://www.alsde.edu/html/sections/documents.asp?section=66\&sort=23\&f ooter=sections

Alabama State Department of Education (ALSDE). (2006). The Alabama model for identifying highly qualified teachers. Retrieved from http://www.alsde.edu/TEXT/sections/teachercertAnswers.asp?section=66 \&sort=6\&id=559\&footer $=$ sections.

Alabama State Department of Education (ALSDE). (2006, July). State plan for highly qualified teachers: Alabama's teacher equity plan. Retrieved from http://www2.ed.gov/programs/teacherqual/hatplans/alep.doc.

Alabama State Department of Education (ALSDE). (2010, February). Charter schools in Alabama? Alabama Education News, 33(5). 
Alabama State Department of Education (ALSDE). (2011). ALSDE: Teacher quality enhancement project. Retrieved from http://web.alsde.edu/home/Sections/SectionInfo.aspx?SectionID=75.

Alabama State Department of Education (ALSDE). (2012, June 7). Alabama plan 2020: ESEA flexibility request. Retrieved from https://docs.alsde.edu/documents/908/Alabama\%20Flexibility\%20Plan\%2 09-5-12.pdf.

American Association of Colleges for Teacher Education (AACTE). (2010). History. Retrieved from http://aacte.org/index.php?/AboutUs/History/history-aacte.html.

Angrist, J. D., \& Guryan, J. (2005, February). Does teacher testing raise teacher quality? Evidence from state certification requirements. Discussion Paper No. 1500. Cambridge, MA, National Bureau of Economic Research.

Arias, M. B. (2010). School desegregation, linguistic segregation and access to English for Latino students. Journal of Educational Controversy, 2. Retrieved from http://www.wce.wwu.edu/Resources/CEP/eJournal/v002n001/a008.shtml.

Baker, E. L., Barton, P. E., Darling-Hammond, L., Haertel, E., Ladd, H. F., Linn, R. L.,...Shepard, L. A. (2010, August). Problems with the use of student 
test scores to evaluate teachers. Economic Policy Institute Briefing Paper \#278. Retrieved from http://epi.3cdn.net/724cd9a1eb91c40ff0 hwm6iij90.pdf.

Baldi, S., Jin, Y., Skemer, M., Green, P.J., \& Herget, D. (2007). Highlights from PISA 2006: Performance of U.S. 15-year-old students in science and mathematics literacy in an international context (NCES 2008-016). Washington, DC: National Center for Education Statistics, Institute of Education Sciences, U.S. Department of Education.

Ballou, D. (2009). Test scaling and value-added measurement. Education Finance and Policy, 4, 351-383.

Ballou, D. \& Podgursky, M. (2000). Reforming teacher preparation and licensing: What is the evidence? Teachers College Record, 102(1), 1-27.

Baltodano, M. (2012, May 8). Neoliberalism and the demise of public education: The corporatization of schools of education. International Journal of Qualitative Studies in Education, 25(4), 487-507.

Barber, M., Kinn, P., \& Moffit, A. (2010). Deliverology 101: A field guide for educational leaders. Thousand Oaks, CA: Corwin Press.

Barbour, E., Feder, J., \& Skinner, R. (2011, June 28). Secretary of education's waiver authority with respect to Title I-A provisions included in the 
Elementary and Secondary Education Act. Memorandum. Washington, DC. Retrieved from http://edworkforce.house.gov/uploadedfiles/june 282011 crs report.pdf.

Bardach, E. (1977). The implementation game: What happens after the bill becomes a law. Cambridge, MA: The MIT Press.

Barr, A., Burton, W., \& Brueckner, L. (1938). Supervision: Principles and practices in the improvement of instruction. New York, NY: AppletonCentury.

Barry, B., Montgomery, D., Curtis, R., Hernandez, M., Wurtzel, J., \& Snyder, J. (2008, August). Creating and sustaining urban teacher residencies: A new way to recruit, prepare, and retain effective teachers in high-needs school districts. Washington, DC: National Council for the Accreditation of Teacher Education (NCATE).

Barry, B., Montgomery, D., \& Snyder, J. (2008, August). Urban teacher residency models and institutions of higher education: Implications for teacher preparation. Washington, DC: National Council for the Accreditation of Teacher Education (NCATE).

Berlak, A. (2010). Coming soon to your favorite credential program: National exit exams. Rethinking Schools, 24(4), 41-45. Retrieved from 
http://www.rethinkingschools.org/restrict.asp?path=archive/24 04/24 04 exams.shtml.

Berman, P. (1978). The study of macro- and micro- implementation. Public Policy, 26 (2), 157-184.

Berman, P., \& McLaughlin, M. W. (1976). Implementation of educational innovation. The Educational Forum, 40(3), 344-370.

Berman, P., \& McLaughlin, M. W. (1979). An exploratory study of school district adaptation. Santa Monica, CA: RAND Corporation, 1979. Retrieved from http://www.rand.org/content/dam/rand/pubs/reports/2006/R2010.pdf.

Berman, P., \& McLaughlin, M. W. (1980). Factors affecting the process of change.

In Milstein, M. (Ed.), Schools, conflict, and change (pp. 57-71). New York, NY: Teachers College, Columbia University.

Berry, B., \& Hirsch, E. (2005, October 27). Recruiting and retaining for hard-tostaff schools. NGA Center for Best Practices. Retrieved from http://www.nga.org/Files/pdf/0510recruitingteachers.pdf.

Birman, B., Le Floch, K. C., Klekotka, A., Ludwig, M., Taylor, J., Walters, K.,... O'Day, J. (2007). State and local implementation of the No Child Left 
Behind Act: Volume II: Teacher quality under NCLB: Interim report. Santa Monica, CA: RAND Corporation, 2007. Retrieved from http://www.rand.org/pubs/reprints/RP1283.

Blackwell, P. J., \& Diez, M. (1999). Achieving the new vision of master's education for teachers: NCATE/NBPTS partnership for graduate programs. Washington, DC: National Council for the Accreditation of Teacher Education.

Blumer, H. (1969). Symbolic interactionism: Perspective and method. Englewood Cliffs, NJ: Prentice-Hall, Inc.

Borman, G. D., \& Kimball, S. M. (2005). Teacher quality and educational equality: Do teachers with higher standards-based evaluation ratings close student achievement gaps? The Elementary School Journal, 106(1), 3-20.

Boyd, D., Grossman, P., Lankford, H., Loeb, S., Wyckoff, J. (2008, August). Teacher preparation and student achievement. (Working Paper No. 20). Washington, DC: National Center for Analysis of Longitudinal Data in Educational Research. Retrieved from http://www.caldercenter.org/PDF/1001255 teacher preparation.pdf. 
Breneman, D. (2002, June 14). For colleges, this is not just another recession. The Chronicle of Higher Education: The Chronicle Review. Retrieved from http://www.nyu.edu/pages/classes/jepsen/chronicleJun1402.pdf.

Brophy, J. E., \& Good, T. L. (1986). Teacher behavior and student achievement. In Wittrock, M. E. (Ed.), Handbook of research on teaching, $3^{\text {rd }}$ Edition (pp. 328-375). New York, NY: Macmillan.

Burrell, G. \& Morgan, G. (1979). Sociological paradigms and organizational analysis. London: Ashgate Publishing. Center on Education Policy (CEP). (2007, August). Implementing the No Child Left Behind teacher requirements. Retrieved from http://cssp.us/pdf/NCLBTeacherRequirements.pdf.

Clotfelter, C. T., Ladd, H. F., \& Vigdor, J. L. (2006). Teacher-student matching and the assessment of teacher effectiveness (NBER Working Paper No. 11936). Cambridge, MA: National Bureau of Economic Research.

Cohen, D., \& Hill, H. (2000). Instructional policy and classroom performance: The mathematics re-form in California. Teachers College Record, 102, 294343.

Coleman, J. S. (1990). Equality and Achievement in Education. Boulder: Westview Press. 
Common Core State Standards Initiative. (2012). Home. Retrieved March 28, 2012, from http://www.corestandards.org/.

Council of Chief State School Officers (CCSSO). (2011, April). Interstate Teacher Assessment and Support Consortium (InTASC) Model Core Teaching Standards: A Resource for State Dialogue (Draft for Public Comment). Washington, DC: Author.

Creswell, J. W. (1998). Qualitative inquiry and research design: Choosing among five traditions. Thousand Oaks, CA: Sage Publications.

Crissy, W. J. E. (1942, May). The national teacher examinations. The Phi Delta Kappan, 24(9), 353-356.

Curran, B., Abrahams, C., \& Clarke, T. (2001, February). Solving teacher shortages through licensing reciprocity. Denver, CO: State Higher Education Executive Officers (SHEEO). Retrieved from http://www.sheeo.org/quality/mobility/reciprocity.PDF.

Daniels, P. K., \& Swartz, C. A. (Eds.). (1994). Encyclopedia of associations, $28^{\text {th }}$ Edition, (Vol. 1). Detroit, MI: Gale Research.

Danielson, C. (1996). Enhancing professional practice: A framework for teaching. Alexandria, VA: Association for Supervision and Curriculum Development (ASCD). 
Darling-Hammond, L. (1990). Instructional policy into practice: The power of the bottom over the top. Educational Evaluation and Policy Analysis, 12(3), 339-347.

Darling-Hammond, L. (1996, November). What matters most: A competent teacher for every child. The Phi Delta Kappan, (78)3, 193-200.

Darling-Hammond, L. (2000). Teacher quality and student achievement: A review of state policy evidence. Educational Policy Analysis Archives, 8(1). Retrieved from http://epaa.asu.edu/epaa/v8n.

Darling-Hammond, L. (2001). Standard setting in teaching: Changes in licensing, certification, and assessment. In Richardson, V. ( Eds.), Handbook of research on teaching, $4^{\text {th }}$ Ed. (pp. 751-776). Washington, DC: American Educational Research Association (AERA).

Darling-Hammond, L. (2004). Standards, accountability, and school reform. Teachers College Record, 106(6), 1047-1085.

Darling-Hammond, L., \& Berry, B. (1988, March). The evolution of teacher policy. Santa Monica, CA: RAND Corporation.

Darling-Hammond, L., Berry, B., \& Thorenson, A. (2001). Does teacher certification matter? Evaluating the evidence. Educational Evaluation and Policy Analysis, 23, 57-77. 
Darling-Hammond, L., Holtzman, D., Gatlin, S. J., \& Heilig, J. V. (2005). Does teacher preparation matter? Evidence about teacher certification, Teach for America, and teacher effectiveness. Education Policy Analysis Archives, 13(42). Retrieved from http://epaa.asu.edu/epaa/v13n42/.

Darling-Hammon, L., Wei, R. C., Andree, A., Richardson, N., Orphanos, S. (2009, February). Professional learning in the learning profession: A status report on teacher development in the United States and abroad. Dallas, TX: National Staff Development Council.

Darling-Hammond, L., \& Youngs, P. (2002). Defining "highly qualified teachers": What does "scientifically-based research" actually tell us? Educational Researcher, 31(9), 13-25.

Datnow, A. (2006). Connections in the policy chain: The "co-construction" of implementation in comprehensive school reform. In Honig, M. I. (Ed.), New directions in education policy implementation: Confronting complexity. Albany, NY: State University of New York Press.

Decker, P. T., Mayer, D. P., \& Glazerman, S. (2004, June). The effects of Teach for America on students: Findings from a national evaluation. Princeton, NJ: Mathematica Policy Research, Inc. 
Denning, P. J. (1983). A nation at risk: The imperative for educational reform. Communications of the ACM, 26(7), 467-478.

Donaldson, M. L., \& Johnson, S. M. (2010, Spring). The price of misassignment: The role of teaching assignments in Teacher for America teachers' exit from low-income schools and the teaching profession. Educational Evaluation and Policy Analysis, 32(2), 299-323.

Douglas, J. A. (2010, February). Higher education budgets and the global recession: Tracking varied national responses and their consequences. Research and Occasional Paper Series: CHSE 4.10. Berkeley, CA: Center for Studies in Higher Education.

Dreeben, R. (2000). Structural effects in education: A history of an idea. In Hallinan, M. T. (Ed.), Handbook of the sociology of education (pp. 107135). New York, NY: Kluwer Academic.

Duncan, A. (2009). Teacher preparation: Reforming the uncertain profession. New York, NY: Columbia University Teachers College. Retrieved from http://www.ed.gov/news/speeches/teacher-preparation-reforminguncertain-profession.

Duncan, M. J., \& Biddle, B. J. (1974). The study of teaching. New York, NY: Holt, Rinehart, and Winston. 
Earley, P. (1994). Goals 2000: Educate America Act: Implications for teacher educators. (AACTE Publication No. 20036-1186). Washington, DC: American Association of Colleges for Teacher Education. (ERIC Document Reproduction Service No. ED367661).

Ehrenberg, R. G., \& Brewer, D. J. (1994). Do school and teacher characteristics matter? Evidence from High School and Beyond. Economics of Education Review, 13, 1-17.

Elazar, D. J. (1984). American federalism: A view from the states, $3^{\text {rd }}$ Edition. New York, NY: Harper and Row.

Elementary and Secondary Schools Act of 1998, 20 U.S.C. $\S 6319$ (1998)

Elmore, R. F. (1979). Backward mapping: Implementation research and policy decision. Political Science Quarterly, 94 (4), 601-616.

Elmore, R. F. (1983). Forward and backward mapping: Reversible logic in the analysis of public policy. Seattle, WA: Washington University, Seattle Institute for Public Policy and Management. (ERIC Document Reproduction Service No. ED258011).

Ferguson, R.F. (1991, Summer). Paying for public education: New evidence on how and why money matters. Harvard Journal on Legislation, 28(2), 465498. 
Ferguson, R. F., \& Ladd, H. F. (1996). How and why money matters: An analysis of Alabama schools. In Ladd, H. F. ( Eds.), Holding schools accountable: Performance-based reform in education (pp. 265-298). Washington, DC: Brookings Institution.

Fetler, M. (1999). High school staff characteristics and mathematics test results. Education Policy Analysis Archives, 7(9). Retrieved from http://epaa.asu.edu/epaa/v7n9/.

Finn, C.E. (1999). Foreword. In Kanstoroom, M. \& Finn, Jr., C. (Eds.), Better teachers, better schools. Washington, DC: The Thomas B. Fordham Foundation.

Friedman, T. (2005). The world is flat: A brief history of the twenty-first century. New York, NY: Farrar, Straus, \& Giroux.

Frome, P., Lasater, B., \& Cooney, S. (2005). Well-qualified teacher and highquality teaching: Are they the same? (Research Brief). Atlanta, GA: Southern Regional Education Board (SREB). Retrieved from http://www.sreb.org/programs/hstw/publications/briefs/05V06 Research B rief high-quality teaching.pdf.

Gallagher, H. A. (2002, April). The relationship between measures of teacher quality and student achievement: The case of Vaughn Elementary. 
Washington, DC: National Institute on Educational Government, Finance, Policymaking, and Management. (ERIC Document Reproduction Service No. ED468254).

Gallagher, H. A. (2004). Vaughn Elementary's innovative teacher evaluation system: Are teacher evaluation scores related to growth in student achievement? Peabody Journal of Education, 79(4), 79-107.

Gardner, D. P. (1983). A nation at risk: The imperative for educational reform. Washington, DC: U.S. Government Printing Office.

Garet, M., Birman, B., Porter, A., Yoon, K., \& Desimone, L. (2001). What makes professional development effective? Analysis of a national sample of teachers. American Educational Research Journal, 38, 915-945.

Girod, G. R. (2002). An overview of teacher work sample methodology. In Girod, G. R. (Ed.) Connecting Teaching and Learning: A Handbook for Teacher Educators on Teacher Work Sample Methodology (pp. 111-128). Washington, DC: AACTE Publications. ERIC Document Reproduction Service No. ED463282.

Giroux, H. A. (2002, winter). Neoliberalism, corporate culture, and the promise of higher education: The university as a democratic public sphere. Harvard Educational Review, 72(4), 425-463. 
Glanz, J. (1998). Histories, antecedents, and legacies of school supervision. In Gerald, F. \& Pajak, E. (Eds.), Handbook of research on school supervision (pp. 35-79). NY: Simon and Schuster Macmillan.

Goe, L. (2008). Approaches to evaluating teacher effectiveness: A research synthesis. Washington, DC: National Comprehensive Center for Teacher Quality.

Goddard, R. D., Hoy, W. K., \& Hoy, A. W. (2000). Collective teacher efficacy: Its meaning, measure, and impact on student achievement. American Educational Research Journal, 37(2), 479-507.

Goldberg, M., \& Harvey, J. (1983, September). A nation at risk: The report of the national commission on excellence in education. The Phi Delta Kappan, 65(1), 14-18.

Goldhaber, D., \& Anthony, E. (2005). Can teacher quality be effectively assessed? National Board Certification as a signal of effective teaching (Working Paper). Seattle, WA: Center on Reinventing Public Education. Retrieved from http://www.crpe.org/workingpapers/pdf/NBPTSquality report.pdf.

Goldhaber, D., \& Brewer, D. J. (1997). Evaluating the effect of teacher degree level on educational performance. In Fowler, W. (Ed.), Developments in 
school finance, 1996 (pp. 197-210). Washington, DC: National Center for Education Statistics.

Goldhaber, D. \& Brewer, D. J. (2000). Does teacher certification matter? High school teacher certification status and student achievement. Educational Evaluation and Policy Analysis, 22(2), 129-145.

Goldhaber, D., \& Hansen, M. (2008). Is it just a bad class? Assessing the stability of measured teacher performance. (Working Paper 2008-5). Seattle, WA: University of Washington, Center on Reinventing Public Education.

Governor's Commission on Quality Teaching (GCQT). (2006a). Governor's commission on quality teaching: Mission, vision, and goals. Montgomery, AL: Office of Governor Bob Riley. Retrieved from http://ti sp.alsde.edu/qt/Shared\%20Documents/Forms/DispForm.aspx?ID $=21 \&$ Source=http $\% 3 \mathrm{~A} \% 2 \mathrm{~F} \% 2 \mathrm{Fti}$ sp.alsde.edu\%2Fqt\%2Fdefault.aspx\%3 FSortField\%3DLinkTitle\%26SortDir\%3DAsc\%26View\%3D\%257b34FC4D 74\%252d5CC3\%252d4E76\%252dBA96\%252d1B1595737DEB\%257d\&R ootFolder=\%2Fqt\%2FShared\%20Documents.

Governor's Commission on Quality Teaching (GCQT). (2006b). Governor's commission on quality teaching: Initial report to Governor Bob Riley. Montgomery, AL: Office of Governor Bob Riley. Retrieved from 
http://ti sp.alsde.edu/qt/Shared\%20Documents/GCQT\%20INITIAL\%20RE PORT.pdf.

Groggin, M. L, Bowman, A., Lester, J. P., \& O'Toole, Jr., L. I. (1990). Implementation theory and practice: Toward a third generation. Glenview, IL: Scott Foresman.

Haefele, D.L. (1993). Evaluating teachers: A call for change. Journal of Personnel Evaluation in Education, 7(1), 21-31.

Hall, P. M. (1995). The consequences of qualitative analysis for sociological theory: Beyond the microlevel. The Sociological Quarterly, 36(2), 397-423.

Hall, P. M. (Peter Mandel) (1997). Race, ethnicity, and schooling in America: An introduction. In P. M. Hall (Peter Mandel) (1997), Race, ethnicity, and multiculturalism: Policy and practice. New York, NY: Garland Publishing.

Hall, P. M., \& McGinty, P. J. W. (1997, Summer). Policy as the transformation of intentions: Producing program from statute. The Sociological Quarterly, 38(3), 439-467.

Hamilton, L. S., Stecher, B. M., and Yuan, K. (2008). Standards-based reform in the United States: history, research, and future directions. Washington, DC: RAND Corporation. 
Haney, W., Madaus, G., \& Kreitzer, A. (1987). Charms talismanic: Testing teachers for the improvement of American education. In E. Z. Rothkopf (Ed.), Review of research in education (Vol. 14). Washington, DC: American Educational Research Association.

Hanushek, E. A. (1971). Teacher characteristics and gains in student achievement: Estimation using micro data. The American Economic Review, 61(2), 280-288.

Hanushek, E. A. (1992). The trade-off between child quantity and quality. Journal of Political Economy, 100(1), 84-117.

Hanushek, E. A. (2003, February). The Failure of Input-Based Resource Policies. Economic Journal, 113(485), F64-F68.

Hanushek, E. A., Kain, J. F., O’Brien, D. M., \& Rivkin, S. G. (2005). The market for teacher quality (Working Paper No. 11154). Cambridge, MA: National Bureau for Economic Research.

Harper, C. A. (1970). A Century of Public Teacher Education. Westport, CT: Greenwood Press.

Harris, D. N., \& Sass, T. R. (2007). The effects of NBPTS -certified teachers on student achievement. Washington, DC: National Center for Analysis of 
Longitudinal Data in Educational Research. Retrieved from http://www.caldercenter.org/PDF/1001060 NBPTS Certified.pdf.

Harris, D. N., \& Sass, T. R. (2008). Teacher training, teacher quality, and student achievement (Working Paper No. 3). Washington, DC: National Center for Analysis of Longitudinal Data in Educational Research. Retrieved from http://www.caldercenter.org/pdf/1001059 teacher training.pdf.

Heinecke, W. F. (1996). Desegregation policy as the transformation of intentions: The case of East Valley High School. (Unpublished doctoral dissertation). Arizona State University, Temple, AZ.

Henson, B. E., \& Hall, P.M. (1993, March). Linking performance evaluation and career ladder programs: reactions of teachers and principals in one district. Elementary School Journal, 93(4), 323-353.

Hill, H. C., Rowan, B., Ball, D. L. (2005, Summer). Effects of teacher's mathematical knowledge for teaching on student achievement. American Educational Research Journal, 42(2), 371-406.

Holmes Group. (1990). Tomorrow's schools: Principles for the design of professional development schools. East Lansing, Ml: The Holmes Group Inc. 
Honig, M. I. (2006). Complexity and policy implementation: Challenges and opportunities for the field. In Honig, M. I. (Ed.), New directions in education policy implementation: Confronting complexity. Albany, NY: State University of New York Press.

Hotzapple, E. (2003). Criterion-related validity evidence for a standards-based teacher evaluation system. Journal of Personnel Evaluation in Education, 17(3), 207-219.

Howey, K. R. (2011, November). NCATE state alliances for clinical teacher preparation: a framework for setting priorities and building partnership prototypes. Washington, DC: National Council for the Accreditation of Teacher Education (NCATE).

H.R. 1804--103rd Congress. (1993). Goals 2000: Educate America Act.

Retrieved from http://www.gpo.gov/fdsys/pkg/BILLS-

103hr1804enr/pdf/BILLS-103hr1804enr.pdf.

H.R. 2710--111th Congress: Enhancing Science, Technology, Engineering, and Mathematics Education Act of 2009. (2009). In www.GovTrack.us. Retrieved March 1, 2012, from http://www.govtrack.us/congress/bills/111/hr2710 
H.R. $4137-110^{\text {th }}$ Congress. (2007). Higher Education Opportunity Act. Retrieved from http://www.govtrack.us/congress/bills/110/hr4137.

Hursh, D. (2001a, spring). Social studies within the neoliberal state: The commodification of knowledge and the end of imagination. Theory and Research in Social Education, 29(2), 349-356.

Hursh, D. (2001b). Neoliberalism and the Control of Teachers, Students, and Learning: the rise of standards, standardization and accountability. Cultural Logic, 4(1). Retrieved from http://clogic.eserver.org/41/hursh.html.

Hursh, D., \& Martina, C. A. (2003, October). Neoliberalism and schooling in the U.S.: How state and federal government education policies perpetuate inequality. Journal for Critical Education Policy Studies, 1(2). Retrieved from http://www.jceps.com/print.php?articlelD=12.

Interstate Teacher Assessment and Support Consortium (INTASC). (1992). Model standards for beginning teacher licensing, assessment and development: A resource for state dialogue. Washington, DC: Council of Chief State School Officers. ERIC Document Reproduction Service No.ED369767. 
Jacob, B. A., \& Lefgren, L. (2005). Principals as agents: Subjective performance measurement in education (Faculty Research Working Paper Series RWP05-040). Cambridge, MA: Harvard University.

Johnson, C. A. (1976, August). Political culture in the United States: Elazar's formulation examined. American Journal of Political Science, 20(3), 491 509.

Kaestle, C. (1983). Pillars of the republic: Common schools and American society, 1780-1860. New York, NY: Hill and Wang.

Kane, T. J., Rockoff, J. E., Staiger, D. O. (2006, March). What does certification tell us about teacher effectiveness? Evidence from New York City (NBER Working Paper No. 12155). New York, NY: National Bureau of Economic Research.

Kauchak, A. C. \& Levine, D. U. (2007). Introduction to teaching: Becoming a professional, ( $3^{\text {rd }}$ Ed.). Upper Saddle River, NJ, Merrill Prentice Hall.

Klein, A. (2009, January 13). Nothing but praise for Duncan in senate hearing. Education Week, 28(18). Retrieved from http://www.csun.edu/ krowlands/Content/SED610/sec\%20of\%20ed/Nothi ng\%20But\%20Praise\%20for\%20Duncan.pdf. 
Koedel, C. \& Betts, J. R. (2005). Re-examining the role of teacher quality in the education production function. (Working Paper). San Diego, CA: University of California.

Koedel, C., \& Betts, J. R. (2009, July). Does student sorting invalidate valueadded models of teacher effectiveness? An extended analysis of the Rothstein critique. (Working Paper WP-09-02). Columbia, MO: University of Missouri-Columbia, Department of Economics. Retrieved from http://economics.missouri.edu/working-papers/2009/WP0902 koedel.pdf.

Kotz, D. M. (2002, Summer). Globalization and neoliberalism. Rethinking Marxism, 12(2), 64-79.

Kraft, N. P. (2001, April). Standards in teacher education: A critical analysis of NCATE, INTASC, and NBPTS. Paper presented at the annual meeting of the American Educational Research Association.

Lang, W. S, \& Wilkerson, J. R. (2008, March). Measuring teacher dispositions with different item structures: An application of the Rasch model to a complex accreditation requirement. American Educational Research Association. ERIC Document Reproduction Service No.ED502965. 
La Paro, K. M., Pianta, R. C., \& Stuhlman, M. (2004). The Classroom Assessment Scoring System: Findings from the Prekindergarten Year. The Elementary School Journal, 104(5), 409.

Leana, C. R., \& Pil, F. K. (2006). Social capital and organizational performance: Evidence from urban public schools. Organizational Science, 17(3), 353366.

Learning Point Associates. (2007). Understanding the no child left behind act: Teacher quality. Retrieved from http://www.learningpt.org/pdfs/qkey6.pdf.

Leedy, P. D., \& Ormrod, J. E. (2001). Practical research: Planning and design ( $7^{\text {th }}$ Ed.). Upper Saddle River, NJ: Merrill Prentice Hall.

Levine, A. (2006). Educating school teachers. New York: The Education Schools Project.

Lipman, P. (2009, January). Making sense of the renaissance 2010 school policy in Chicago: Race, class, and the cultural politics of neoliberal urban restructuring. A Great Cities Institute Working Paper. Chicago, IL: Great Cities Institute, College of Urban Planning and Public Affairs, University of Illinois at Chicago. Retrieved from http://www.uic.edu/cuppa/gci/publications/workingpaperseries/pdfs/GCP09-02 Lipman.pdf. 
Lipsky, M. (2010). Street-Level Bureaucracy: Dilemmas of the Individual in Public Services. New York, NY: Russell Sage Foundation.

Lorenz, C. (2012, spring). If you're so smart, what are you under surveillance? Universities, neoliberalism, and new public management. Critical Inquiry, 38(3), 599-629.

Markley, T. (2004). Defining the effective teacher: Current arguments in education. Essays in Education. Retrieved from http://www.usca.edu/essays/vol112004/markey.pdf.

Matland, R. E. (1995). Synthesizing the implementation literature: The ambiguityconflict model of policy implementation. Journal of Public Administration Research and Theory, 5(2), 145-174.

McLaughlin, M. W. (1990). Embracing contraries: Implementing and sustaining teacher evaluation. In Millman, J., \& Darling-Hammond, L. (Eds.) The new handbook of teacher evaluation. Newbury Park, CA: Sage.

McLaughlin, M. W. (2006). Implementation research in education: Lessons learned, lingering questions and new opportunities. In Honig, M. I. (Ed.), New directions in education policy implementation: Confronting complexity. Albany, NY: State University of New York Press. 
McQuaid, J. (2009, Fall). Will Obama's choice change education in America? Ed. The Magazine of the Harvard School of Education. Retrieved from http://www.gse.harvard.edu/news-impact/2009/09/will-obamas-choicechange-education-in-america/?show=all.

Meyer, R. (1996). Value added indicators of school performance. In Hanushek, E. A. \& Jorgenson, D. (Eds.), Improving America's schools: The role of incentives. Washington, DC: National Academy Press.

Milanowski, A. (2004). The relationship between teacher performance evaluation scores and student achievement: Evidence from Cincinnati. Peabody Journal of Education, 79(4), 33-53.

Miles, M. B., \& Huberman, A. M. (1994). Qualitative data analysis: An expanded resourcebook ( $2^{\text {nd }}$ Ed.). Thousand Oaks, CA: Sage Publications.

Monk, D. H. (1994). Subject area preparation of secondary mathematics and science teachers and student achievement. Economics of Education Review, 13, 125-145.

Monk, D. H. (2007, Spring). Recruiting and retaining high-quality teachers in rural areas. Future of Children, 17(1), 155-174.

Monk, D. H., \& King, J. R. (1994). Multi-level teacher resource effects on pupil performance in secondary mathematics and science: The role of teacher 
subject matter preparation. In Ehrenberg, R. (Ed.), Contemporary policy issues: Choices and consequences in education (pp. 29-58). Ithaca, NY: ILR Press.

Morton, J. B. (2007, March). Alabama Quality Teaching Standards. Retrieved from http://www.alsde.edu/html/sections/documents.asp?section=66\&sort=8\&fo oter=sections.

Murnane, R. J., \& Phillips, B. (1981). What do effective teachers of inner-city school children have in common? Social Science Research, 10(1), 83100.

National Association of State Directors of Teacher Education (NASDTEC). (2009). NASDTEC general information. Retrieved from http://www.nasdtec.org/about.php.

National Board of Professional Teaching Standards (NBPTS). (2002, August). What teachers should know and be able to do. Retrieved from http://www.nbpts.org/UserFiles/File/what teachers.pdf.

National Board of Professional Teaching Standards (NBPTS). (2010). The five core propositions. Retrieved from http://www.nbpts.org/the standards/the five core proposition. 
National Council for the Accreditation of Teacher Education (NCATE). (n.d.a). NCATE accredited institutions. Retrieved from http://www.ncate.org/tabid/176/Default.aspx.

National Council for the Accreditation of Teacher Education (NCATE). (2006). What makes a teacher effective? A summary of key research findings on teacher preparation. Washington, DC: NCATE. ERIC Document Reproduction Service No.ED495408.

National Council for the Accreditation of Teacher Education (NCATE). (2008, February). Professional standards for the accreditation of teacher education institutions. Retrieved from http://www.ncate.org/documents/standards/NCATE\%20Standards\%20200 8.pdf.

National Council for the Accreditation of Teacher Education (NCATE). (2010a). About NCATE. Retrieved from http://www.ncate.org/public/aboutNCATE.asp.

National Council for the Accreditation of Teacher Education (NCATE). (2010b, November). Transforming teacher education through clinical practice: A national strategy to prepare effective teachers: Report of the blue ribbon 
plan on clinical preparation and partnerships for improved student learning. Washington, DC.

National Council for the Accreditation of Teacher Education (NCATE). (2011). NCATE State Partnership Program FAQ. Retrieved March 25, 2012, from http://www.ncate.org/States/NCATEStatePartnershipProgram/StatePartne rshipProgramFAQ/tabid/219/Default.aspx.

National Council for the Accreditation of Teacher Education (NCATE). (2012). Retrieved April 3, 2012 from http://www.ncate.org/Governance/BoardsandCommittees/UnitAccreditatio $\underline{\text { nBoard/tabid/171/Default.aspx. }}$

National Commission on Excellence in Education (NCEE). (1983). A nation at risk: The imperative for educational reform. Washington, DC: Government Printing Office.

National Commission on Teaching and America's Future (NCTAF). (1996). What matters most: Teaching for America's future. New York: NY: Teachers College, Columbia University.

NCLB/ESEA Waiver Watch (2012). About this website. Retrieved March 16, 2012, from http://www.cep-dc.org/page.cfm?FloatingPagelD=21

No Child Left Behind Act of 2001, 20 U.S.C. $§ 6319$ (2008). 
Nolan, J. F. \& Hoover, L. A. (2008). Teacher supervision and evaluation: Theory into practice (2nd ed.). Hoboken, NJ: John Wiley \& Sons, Inc.

Nutt, H. W. (1920). The supervision of instruction. Cambridge, MA: The Riverside Press.

Ornstein, A. C., \& Levine, D. U. (2008). Foundations of education, (10 ${ }^{\text {th }}$ ed.). Boston, MA: Houghton Mifflin Company.

O'Shea, J. L. (2009, January 7). 10 things you didn't know about Arne Duncan. U.S. News \& World Reports. Retrieved from http://www.usnews.com/news/obama/articles/2009/01/07/10-things-youdidnt-know-about-arne-duncan.

Patton, M. Q. (2002). Qualitative research and evaluation methods ( $3^{\text {rd }}$ Ed.). Thousand Oaks, CA: Sage Publications.

Philips, R. H. (2012, September 10). No child left behind waiver sought by Alabama, six other states. Retrieved from http://blog.al.com/live/2012/09/no child left behind waiver so.html.

Pilley, J. G. (1941, March). The national teacher examination service. The School Review, 49(3), 177-186. 
Pressman, J., \& Wildavsky, A. (1985). Implementation. Berkley and Los Angeles, CA: University of California Press.

Prestine, N. A. (1991, Summer). Political system theory as an explanatory paradigm for teacher education reform. American Educational Research Journal, 28, 237-274.

Race to the Top (RTTT). (2009, November). Race to the Top Program Executive Summary. Washington, DC: U.S. Department of Education. Retrieved from http://www2.ed.gov/programs/racetothetop/executive-summary.pdf.

Ravitch, D. (2003, August). A brief history of teacher professionalism. Washington, DC: U.S. Government Printing Office.

Reeves, C. (2003). Implementing the No Child Left Behind Act: Implications for Rural Schools and Districts. Naperville, IL: North Central Regional Educational Laboratory. Retrieved from http://www.ncrel.org/policy/pubs/html/implicate/.

Rein, M. (1976). Social science and public policy. New York, NY: Penguin.

Rivkin, S. G., Hanushek, E. A., Kain, J. F. (2005, March). Teachers, schools, and academic achievement. Econometrica, 73(2), 417-458. 
Rogers, B., \& Thacker, T. (2006, November 27). Governor's commission on quality teaching: Initial report. Montgomery, AL: Alabama State Department of Education. Retrieved from http://ti sp.alsde.edu/qt/Shared\%20Documents/GCQT\%20INITIAL\%20RE PORT.pdf.

Rotella, C, (2010, February 1). Profiles: Class warrior: Arne Duncan's bid to shake up schools. The New Yorker, p. 24-29. Retrieved from http://www.vcoe.org/Portals/VcssoPortals/rsdss/Class\%20Warrior\%20Arn e\%20Duncan1.pdf.

Rothstein, J. (2010). Teacher quality in educational production: Tracking, decay, and student achievement. Quarterly Journal of Economics, 125(1), 175214.

S. 1574--110th Congress: Teaching Residency Act. (2007). In www.GovTrack.us. Retrieved March 1, 2012, from http://www.govtrack.us/congress/bills/110/s1574

Sanders, W. L., \& Horn, S. P. (1994). The Tennessee value-added assessment system: Mixed-model methodology in educational assessment. Journal of Personnel Evaluation in Education, 8, 299-311. 
Sanders, W. L. \& Rivers, J. C. (1996). Cumulative and residual effects of teachers on future student academic achievement. Knoxville: University of Tennessee Value-Added Research and Assessment Center.

Sartain, L., Stoelinga, S. R., \& Krone, E. (2010, June). Rethinking teacher evaluation: Findings from the first year of the excellence in teaching project in Chicago Public Schools. (Research Brief). Chicago, IL: The University of Chicago Urban Education Institute, Consortium on Chicago School Research. Retrieved from http://ccsr.uchicago.edu/publications/Teacher\%20Eval\%20Final.pdf.

Sass, T.R. (2008, November). The stability of value-added measures of teacher quality and implications for teacher compensation policy. (Research Brief). Washington, DC: National Center for Analysis of Longitudinal Data in Education Research, The Urban Institute. Retrieved from http://www.urban.org/UploadedPDF/1001266 stabilityofvalue.pdf.

Sabatier, P., \& Mazmanian, D. (1983). Policy implementation. In S. Nagel (Ed.), Encyclopedia of policy studies (pp. 143-169). New York: Marcel Dekker, Inc. 
Schulte, L., Edwards, S., \& Edick, . (2008, Fall). The development and validation of the Diversity Dispositions Index. AASA Journal of Scholarship and Practice, 5(3), 11-19.

Smith, M. L., Miller-Kahn, L., Heinecke, W., \& Jarvis, P. (2004). Political spectacle and the fate of American schools. New York, NY: Rutledge Falmer.

Smith, T. M., Desimone, L. M., \& Ueno, K. (2005, Spring). "Highly qualified" to do what? The relationship between NCLB teacher quality mandates and the use of reform-oriented instruction in middle school mathematics. Educational Evaluation and Policy Analysis, 27(1), 75-109.

Southern Association of Colleges and Schools (SACS) (2012). About the Commission. Retrieved March 18, 2012, from http://www.sacscoc.org/about.asp.

Spears, H. (1953). Improving the supervision of instruction. New York, NY: Prentice-Hall.

Soar, R. S., Medley, D. M., \& Coker, H. (1983). Teacher evaluation: A critique of currently used methods. Phi Delta Kappan, 65(4), 239-246.

Spillane, J. P. (2004). Standards deviation: How schools misunderstood education policy. Cambridge, MA: Harvard University Press. 
Spillane, J. P., Reiser, B. J., \& Gomez, L. M. (2006). Policy implementation and cognition: The role of human, social, and distributed cognition in framing policy implementation. In Honig, M. I. (Ed.), New directions in education policy implementation: Confronting complexity. Albany, NY: State University of New York Press.

Stake, R. (1995). The art of case study research. Thousand Oaks, CA: Sage Publications.

Stigler, J. W., Gonzales, P., Kawanaka, T., Knoll, S., \& Serrano, A. (1999). The TIMSS videotape classroom study: Methods and findings from an exploratory research project on eighth grade mathematics instruction in Germany, Japan, and the United States. Washington, DC: National Center for Education Statistics. Retrieved from http://nces.ed.gov/timss.

Strauss, A. (1978). Negotiations: Varieties, contexts, processes, and social order. San Francisco, CA: Jossey-Bass

Teacher for America (TFA). (2011). Alabama. Retrieved from http://www.teachforamerica.org/where-we-work/alabama.

Teacher Education Accreditation Association (TEAC). (2010). About TEAC. Retrieved December 16, 2011, from http://www.teac.org/about/\#. 
Thomas, J. D., \& Stewart, W. H. (1988). Alabama government and politics. Lincoln, NE: University of Nebraska Press.

United States Department of Education (USDE). (n.d.). ESEA flexibility. Retrieved from http://www.ed.gov/esea/flexibility.

United States Department of Education (USDE). (2002, April). What to know \& where to go: Parents' guide to No Child Left Behind: A new era in education. Washington, DC. Retrieved from http://www.gpo.gov/fdsys/pkg/ERIC-ED465446/pdf/ERIC-ED465446.pdf.

United States Department of Education (USDE). (2010, March). A blueprint for reform: The reauthorization of the Elementary and Secondary Schools Act. Washington, DC: U.S. Department of Education, Office of Planning, Evaluation, and Policy Development. Retrieved from http://www2.ed.gov/policy/elsec/leg/blueprint/blueprint.pdf.

United States Department of Education (USDE). (2011a). Reauthorizing the elementary and secondary education act: Supporting Teachers. Retrieved from http://www2.ed.gov/policy/elsec/leg/blueprint/faq/supportingteachers.pdf. 
United States Department of Education (USDE). (2011b, September). Our future, our teachers: The Obama administration's plan for teacher education reform and improvement. Washington, DC.

United States Department of Education (USDE). (2012, July 13). Arne Duncan, U.S. secretary of education: Biography. Retrieved from http://www2.ed.gov/news/staff/bios/duncan.html.

Van Meter, D., \& Van Horn, C. (1975). The policy implementation process: A conceptual framework. Administration and Society, 6 (4), 445-488.

Virginia Department of Education. (2010). Title II: Part A: Improving teacher quality. Retrieved from http://www.doe.virginia.gov/federal programs/esea/title2/part a/index.sht $\underline{\mathrm{ml}}$.

Webb, Jr., S. L., \& Armbrester, M. E. (Eds.). (2001). Alabama governors: A political history of the state. Tuscaloosa, AL: University of Alabama Press.

Weick, K. (1976, March). Educational organizations as loosely coupled systems. Administrative Science Quarterly, 21(1), 1-19.

Weisberg, D., Sexton, S., Mulhern, J., \& Keeling, D. (2009, June). The widget effect: Our national failure to acknowledge and act on differences in teacher effectiveness. Brooklyn, NY: The New Teacher Project. Retrieved 
from http://www.gatesfoundation.org/learning/Documents/the-widgeteffect.pdf.

Weiss, E. M., \& Weiss, S. G. (1998, December). New directions in teacher evaluations. Washington, DC: ERIC Clearinghouse on Teaching and Teacher Education. (ERIC Document Reproduction Service No. ED429052).

Wenglinsky, H. (2000). How teaching matters: Bringing the classroom back into discussions of teacher quality. Princeton, NJ: Educational Testing Services. Retrieved from http://www.ets.org/media/research/pdf/PICTEAMAT.pdf.

Wenglinsky, H. (2002). How schools matter: The link between teacher classroom practices and student academic performance. Education Policy Analysis Archives, 10(12). Retrieved from http://www.epaa.asu.edu/epaa/v10n12.

Wiley, D, \& Yoon, B, (1995). Teacher reports on opportunity to learn: Analyses of the 1993 California learning assessment system. Educational Evaluation and Policy Analysis, 17, 355-370.

Yanow, D. (1987, Autumn). Toward a policy culture approach to implementation. Policy Studies Review, 7(1), 103-115. 
Yin, R. Y. (1982). Studying the implementation of public programs. In Williams, W., et al., (Eds.), Studying implementation: Methodological and administrative issues (pp. 36-71). Chatham, NJ: Chatham House Publishers.

Yin, R. K. (2009). Case study research: Design and methods (4 ${ }^{\text {th }}$ Ed.). Thousand Oaks, CA: Sage Publications, Inc.

Youngs, P. A., Wiggins, A. Y., Salazar, M. d. C., Diez, M. E., Paliokas, K. (2011, April 10). InTASC model core teaching standards: Empirical research support for a new vision for teacher standards. Paper presented at the annual meeting of the American Educational Research Association. Retrieved from the AERA Online Paper Repository. 


\section{APPENDIX A}

Policy Actors' Positions and Pseudonyms

Pseudonym

Federal Level

M. Smith
Position

Senior Policy Advisor, United States

Department of Education

\section{National Accreditation Level}

E. Jones

\section{State Level}

E. Jones

J. Miller

K. Holmes

T. Johnson
NCATE State Board of Examiners; Member of the Alabama Governor's Commission on Teacher Quality

Alabama State Department of Education Legislative Liaison

Alabama State Department of Education Office of Research and Development, executive

Alabama State Department of Education, Office of Teaching and Leading, executive
March 5, 2012

May 22, 2012 Group

Date of Interview/Focus of Examiners Member

March 5, 2012

March 12, 2012

March 12, 2012

February 28, 2012

Teacher Education Program Level

E. Jones

Teacher Certification

March 5, 2012 
Officer at a public

institution in Alabama

S. Carter

Dean

April 4, 2012

A. Belcher

Director of Teacher

April 24, 2012

Education/de facto

NCATE Coordinator

K. Spacey

Director of Field and

March 26, 2012

Clinical Experiences

M. Wilson

English/language arts

March 15, 2012

methods Professor

G. Rice

mathematics methods

professor

March 13, 2012

Teacher Candidate $1 \quad$ Student teaching

May 3, 2012

Teacher Candidate 2

2 semesters before

student teaching

May 3, 2012

Teacher Candidate 3

3 semesters before

May 3, 2012

student teaching

Teacher Candidate 4

2 semesters before student teaching

May 3, 2012

Teacher Candidate 5

2 semesters before student teaching

May 3, 2012 
The New School

Central Elementary
School of Education

P-12 Partnership School 
Appendix B

\section{Observation Protocol}

The following questions will guide data collection during formal and informal observations. In addition, detailed observation notes will be taken where a detailed record of interactions during each classroom observations and meetings will be obtained. The purpose of such notes will be to garner a deep understanding of what exactly takes place during meetings and courses whether it be related to standards setting and implementation or not.

Observation Location

General

Course Observations

Meetings

\section{Questions}

-What are unexpected or unusual occurrences taking place that would influence how standards are implemented?

-What decisions or actions are actors engaged in related to the standards?

-Who interacts with each other?

-How are actors interacting?

-What tasks are actors engaged in?

- How is power exhibited by what is posted, who engages with who, what is being discussed, who is engaged in the discussions?

-Who appears to have the most influence over what is gets done?

-What is the culture of the institution?

-What is happening during the course that exhibits a relationship to the standards?

-What are course participants discussing that have any relationship to the standards?

-What are the outcomes associated with the course that are linked to the standards?

-What artifacts (assignments student submit or are assigned, class work) show the link between course content and standards?

-How is the meeting agenda linked to standards setting or implementation? 
-How are processes of standards setting and implementation discussed?

-Who is responsible for doing what?

-What are the discussions involving ensuring students meet the standards?

-What general or specific measures of standards are discussed? 


\section{Appendix C \\ Interview and Focus Group Protocol}

Interview and focus groups took place in the following order. The original list of questions is provided. Additional questions were asked to probe or garner further clarification. Some follow-up discussions were conducted. Follow-ups discussions were conducted via email.

\section{INTERVIEWS}

1. State-level policy actors

2. Director of Field \& Clinical Experiences

3. Direct of Teacher Education/de facto NCATE Coordinator and

4. Methods Professors

5. Dean

6. Federal-level policy actor

FOCUS GROUPS

7. Teacher Candidates

Participant(s)

General questions for all interviewees
Interview/Focus Group Questions

-What are some ideas and values that immediately come to mind when you hear the term teacher quality?

-What do standards of teacher quality mean to you?

-Which standards of teacher quality are utilized in SCDTEs in this state? Name them. -Tell me about the standards. How do you use them in your practice? What is your role/responsibility regarding the standards? -How does the language of the standards align with your own ideas and values regarding what teachers should know and be able to do?

-What historical and current political and cultural conditions (nationally, in the state, and at your institution) have led to the 
Federal-level policy actor

State-level policy actors

Dean

Director of Teacher Education/de facto NCATE Coordinator

Director of Field \& Clinical Experiences

Elementary \& Collaborative

Education Program Faculty development of teacher quality definitions and standards?

-What do you think is the intent of Alabama Teacher Quality Standards (and others)? How does the intent of standards align with your ideas and values regarding what teachers should know and be able to do?

-How does the USDE define teacher quality and effectiveness?

-What current policy initiatives guide teacher education?

-Tell me about Race to the Top, ESEA reauthorization, and other current policy initiatives for teacher quality. -What are USDE expectations of states as far as implementing teacher quality policies? What are USDE expectations of teacher education schools as far as implementing teacher quality policies?

-What are your expectations of standards implementers at SCDTEs in this state? -In SCDTEs where you think standards are being implemented to a great extent, what does the program look like? What does the teacher education graduate look like upon graduation?

-What are some qualities you expect the COE to instill in teacher education candidates?

-What is your role in ensuring teacher education graduates are qualified upon graduation?

-Tell me about the internal/external program review and evaluation process.

-What is your role during the internal/external teacher program review and evaluation process? Describe your role in the context of the processes. 
Dean

Director of Teacher Education/de facto NCATE Coordinator Elementary \& Collaborative Education Program Faculty

Director of Field \& Clinical Experiences
-What is the common practice and processes of the implementation of standards by your staff?

-Who is responsible for ensuring teacher education candidates are exposed to and learn the standards?

-How do you know that standards are being implemented in programs and courses and by faculty?

-In what courses are ATQ Standards (and others) most used?

-If standards are being implemented, what do you expect to see in the elementary teacher education program? What does the teacher education graduate look like upon graduation?

-What are the internal/external measures in place that provide evidence that teacher education candidates know and are able to do the things described in the standards?

-In what courses are ATQ Standards (and others) most used?

-How are objectives in your courses aligned with the standards?

-What do you do in your courses to ensure candidates are informed of and use the standards in their practice?

-How are standards linked to course objectives and candidate evaluations? -What are measures you use in your courses as evidence that candidates have been successful in the course and in meeting the standards?

-How are the standards implemented into the curriculum of field and clinical experiences? -Explain how candidates are expected to exhibit what they have learned in courses during their field experiences. 
Director of Teacher Education/de facto NCATE Coordinator

Teacher Candidates
-How do you work with faculty and administrators in determining which measures are used to determine whether candidates meet program requirements? -How do you work with faculty and administrators before, during, and after the program review and evaluation process?

-What do you think of having standards to guide your practice?

-How were the standards used in your courses/teacher preparation program? In what courses?

-What did you learn about what an effective teacher is and does? Provide a reference to the standards, if possible.

-How do standards of teacher quality inform your knowledge, disposition, and practice? -What are the processes by which you implement the standards you learned in your teacher preparation program? 
